\title{
GirlsRead! Girls' Rights: An Empowerment Curriculum
}

\author{
Natalie Jackson Hachonda \\ Population Council \\ Nicole Haberland \\ Population Council \\ Barbara Mensch \\ Population Council \\ Pamela Nyirenda \\ Diana Bulanda-Shalala
}

Follow this and additional works at: https://knowledgecommons.popcouncil.org/departments_sbsr-pgy

Part of the Demography, Population, and Ecology Commons, Family, Life Course, and Society Commons, Gender and Sexuality Commons, and the International Public Health Commons How does access to this work benefit you? Let us know!

\section{Recommended Citation}

Hachonda Jackson, Natalie, Nicole Haberland, Barbara Mensch, Pamela Nyirenda, and Diana BulandaShalala. 2018. "GirlsRead! Girls' Rights: An Empowerment Curriculum." New York: Population Council. 


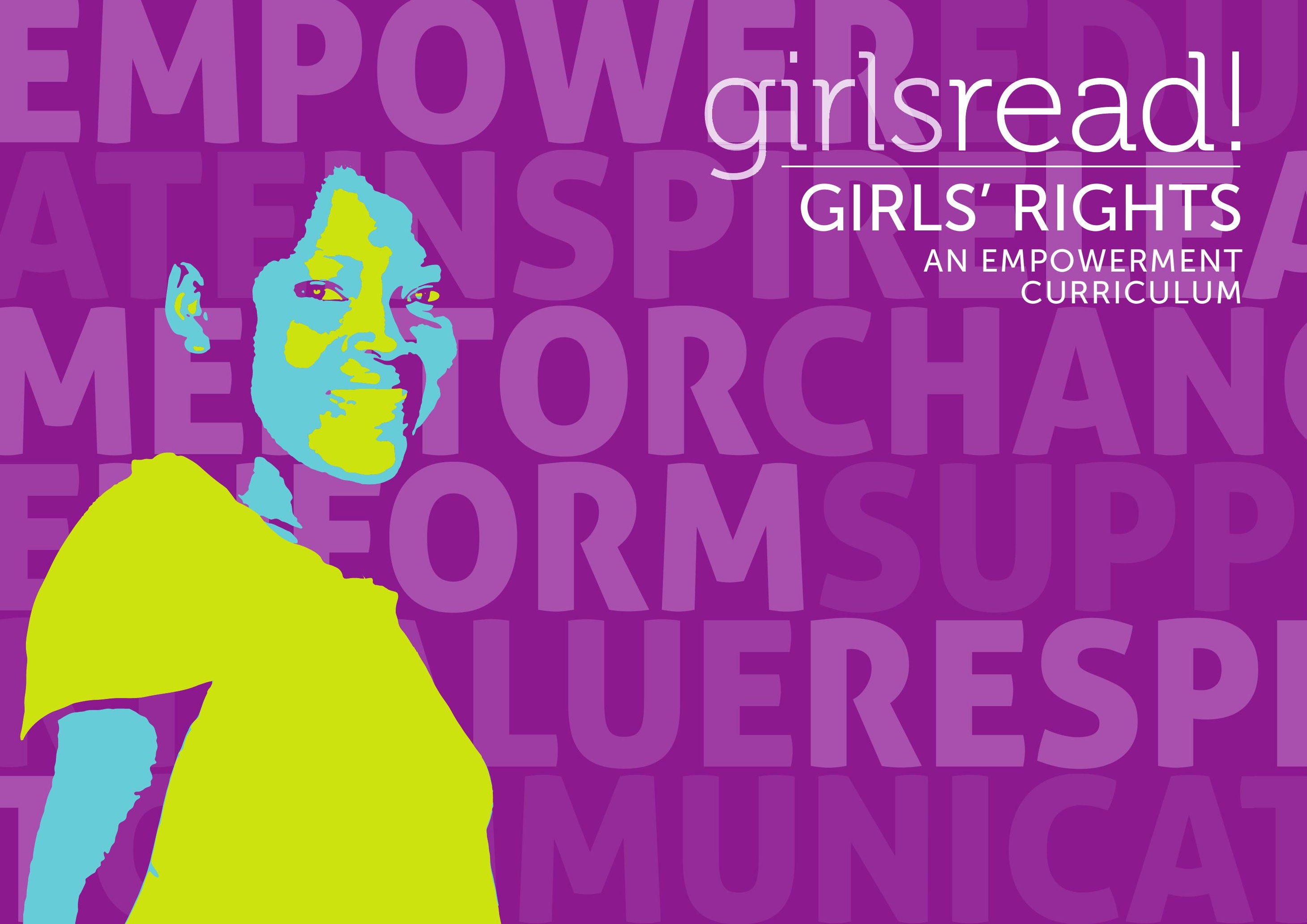




\section{Ponutron \\ Ponconat \\ Ideas. Evidence. Impact.}

The Population Council confronts critical health and development issues-from stopping the spread of HIV to improving reproductive health and ensuring that young people lead full and productive lives. Through biomedical, social science, and public health research in 50 countries, we work with our partners to deliver solutions that lead to more effective policies, programs, and technologies that improve lives around the world. Established in 1952 and headquartered in New York the Council is a nongovernmental, nonprofit organization governed by an international board of trustees.

Population Counci

One Dag Hammarskjold Plaza

New York, NY 10017

Tel: 212-339-0500

Fax: 212-775-6052

www.popcouncil.org

Email: publications@popcouncil.org

Email: info.zambia@popcouncil.org

Population Council - Zambia

Plot 3670 No. 4 Mwaleshi Road

Olympia Park

P/Bag RW 319X

Lusaka, Zambia 10101

Tel: +260211295925
This curriculum has been adapted from several sources which are listed in the References section and footnoted throughout.

This curriculum was funded by a grant from the United States Department of State as part of the DREAMS Innovation Challenge, managed by

JSI Research \& Training Institute, Inc. (JSI). The opinions, findings, and conclusions stated here are those of the authors and do not necessarily reflect those of the United States Department of State or JSI.

Suggested citation: Jackson Hachonda, Natalie, Nicole Haberland, Barbara Mensch, Pamela Nyirenda, Diana Bulanda-Shalala (eds.). 2018. GirlsRead! Girls' Rights: An Empowerment Curriculum. New York:

Population Council.

(c) 2018 The Population Council, Inc

Any part of this volume may be photocopied without permission from the authors or publisher, provided that publication credit is given and copies are distributed free. Any commercial reproduction requires prior written permission from the Population Council. Please also credit any original sources as noted for selected activities. For inquiries regarding rights and permission, including translations, please contact

publications@popcouncil.org.

ISBN: 0-87834-139-0 


\section{acknowledgments}

This curriculum was developed for the GirlsRead! project. We are grateful to the Forum for African Women Educationalists in Zambia (FAWEZA), the key implementing partner for GirlsRead!, for providing technical input on the selection of topics and materials for adaptation of this manual.

We would like to acknowledge several organizations whose materials have been adapted or used in this curriculum including: Centre for Development and Population Activities (CEDPA), ECOS, Global Children's Fund, Innovations for Poverty Action (IPA), International HIV and AIDS Alliance, International Sexuality and HIV Curriculum Working Group, Instituto PAPAI, Johns Hopkins Bloomberg School of Public Health/Center for Communication Programs, Native Youth Sexual Health Network, PACER's National Bullying Prevention Center, Peace Corps, Population Council, Promundo, Raising Voices, Salud y Género, Sonke Gender Justice, and World Education.

Citations for the materials used from these organizations can be found in the footnotes of the respective sessions, and a consolidated list of references, including links to websites, is located in the References section at the end of this document.

We would like to thank the United States Department of State as the funder and JSI Research \& Training Institute, Inc. (JSI) as the grant manager for the grant under the DREAMS Innovation Challenge that has made GirlsRead! possible. 


\section{table of contents}

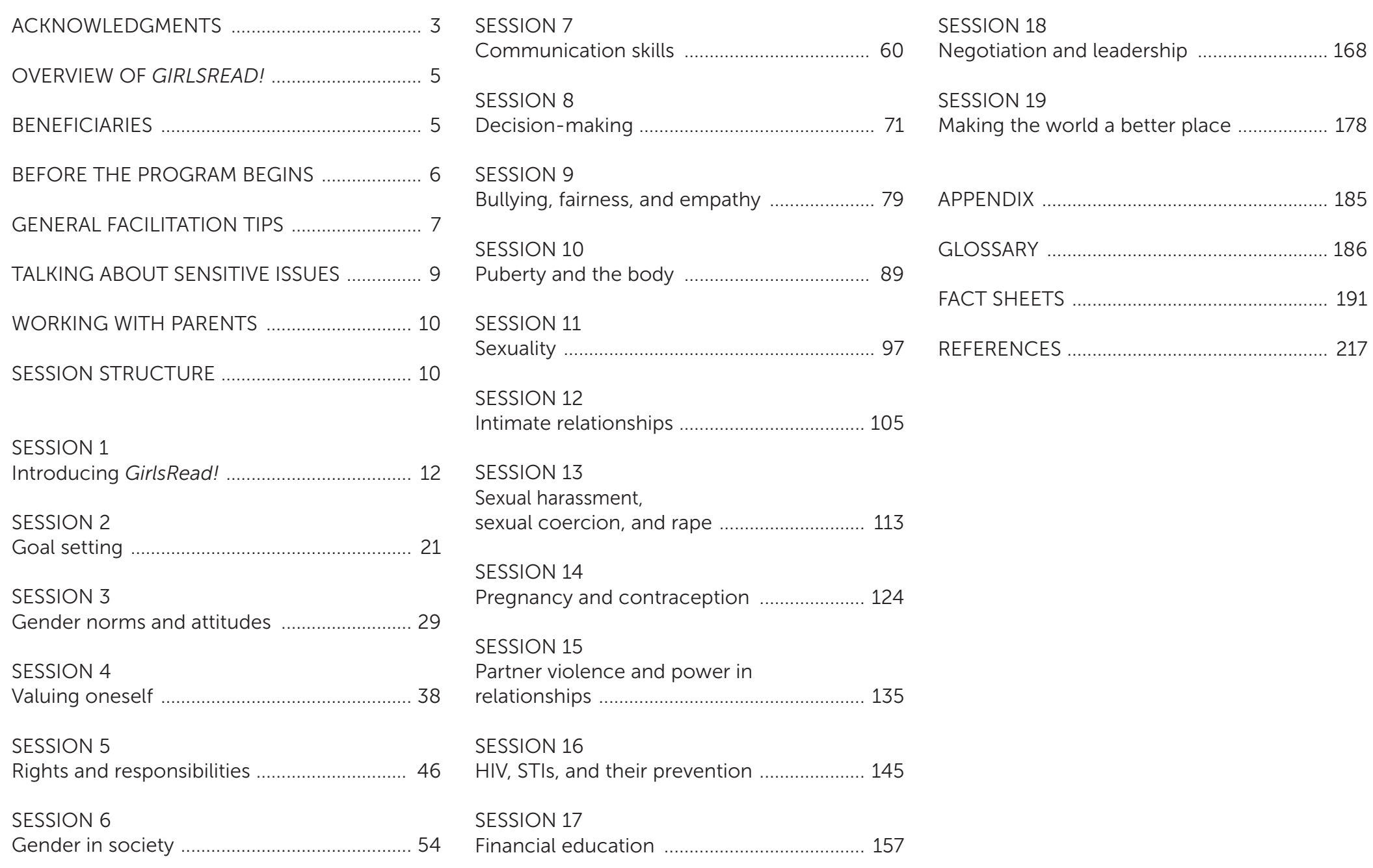




\section{introduction}

\section{OVERVIEW OF GIRLSREAD!}

Zambian adolescent girls are at risk for premature school leaving and HIV infection due to a host of contextual factors including early child marriage, early childbearing, harmful gender norms, and intimate partner violence.

The overall goal of GirlsRead! is to enhance learning and increase progression to secondary school among Zambian adolescent girls in grade 7, the last year of primary school. It works in three districts: Lusaka, Ndola, and Chingola which have been targeted by the Determined Resilient Empowered AIDS-free Mentored Safe (DREAMS) Core intervention funded by the US President's Emergency Plan for AIDS Relief (PEPFAR) to prevent HIV in adolescent girls and young women ages 10-24 in 10 countries in sub-Saharan Africa. GirlsRead! is part of the DREAMS Innovation Challenge, a US State Department funded initiative working in conjunction with DREAMS Core to test innovative initiatives in six challenge focal areas. GirlsRead! is part of the "Keeping Girls in Secondary School" focal area.

Through GirlsRead!, Population Council, together with FAWEZA and Worldreader are aiming to improve school retention by bolstering girls learning outcomes, furthering social connections, improving critical thinking skills, increasing agency, and fostering community norms supportive of girls' schooling. GirlsRead! participants meet in groups of 15-20 girls in weekly group meetings called safe spaces under the guidance of a female mentor to directly engage girls in critical thinking about gender inequalities and discrimination, and help girls build

the assets and confidence needed to act on their own behalf and as progressive voices in their communities.

The safe spaces are broken up into two parts with two different curricula. During the first part of the safe space, mentors use this curriculum, GirlsRead! Girls' Rights: An Empowerment Curriculum, to facilitate sessions that aim to:
1. Increase adolescent girls' understanding of gender equality, rights, sexual and reproductive health, and HIV.

2. Reinforce and promote attitudes and behaviors that will lead to a better quality of life for adolescent girls, including reducing bullying, harassment, and sexual coercion.

3. Instill skills among adolescents to enable them to overcome the challenges of growing up and becoming responsible adults including communication skills, decision-making and negotiation, goal setting and developing healthy relationships.

During the second part of the safe space, mentors use the curriculum GirlsRead! E-reader Curriculum, to facilitate sessions that aim to:

1. Introduce the basic steps of how to use an e-reader and access the approximately 100 e-books loaded onto the e-reader.

2. Build participants' reading skills.

3. Foster participants' joy of reading.

\section{BENEFICIARIES}

GirlsRead! participants are girls in grade 7 -the last year of primary school-when they are at high risk of leaving school.

\section{Group structure}

Each group meets once a week in the afternoon after their morning classes. The sessions will last 2 hours, with the first hour focused on the empowerment curriculum and the second hour focused on the e-reader curriculum.

\section{Meeting functions}

The meetings serve two functions. The first is for the mentor to facilitate a short training session. There are 19 sessions that cover a range of topics from gender equality to sexuality to rights. These sessions should be engaging, interactive, and learner-centered.

Continued on next page 


\section{introduction (cont.)}

The second function is for the meetings to provide a space and opportunity for girls to regularly interact with each other. During meeting times, they can share updates about their weeks, address any concerns they may have, laugh, sing, dance, express themselves, and in general, have fun. As cultivating this sort of environment is a primary aim of weekly girls' group meetings, it is important that these groups not be run like a classroom. Mentors will have to ensure that during each meeting, girls have ample time for conversation and interaction, and should encourage an informal learning environment.

\section{BEFORE THE PROGRAM BEGINS*}

Mentors should peruse the curriculum and thoroughly read as much of the background information as possible (i.e. facilitator notes at the beginning of each session and extra information provided in the Fact Sheets in the Appendix at the end of the document). This will help mentors gain a strong general sense of the topics that will be covered throughout the program, and an idea of where to find answers to any questions that participants may ask. This information for each session should be re-read just before conducting the corresponding session. Mentors should prepare any necessary materials before each session ahead of time, as well as think about their own values regarding young people, and the topics to be discussed.

\section{Collect and have referral information on hand for:}

1. Sexual/reproductive health services (including contraceptives)

2. HIV testing and counseling

3. How/where to report sexual or domestic violence

4. Psychosocial counseling referral for any girls who have been abused or raped

5. Legal services

\section{Know your audience}

Depending on the group, it may be necessary to change the approach to leading the sessions. For example, some groups may have lower literacy skills than others. For lower literacy groups, facilitators may want to draw more pictures and use more symbols when writing on the chalkboard. Facilitators should also use simple language and be sure that the instructions are clear before starting any activity.

It is important that mentors work with participants according to their education/competency level. Mentors should also check sessions for cultural acceptability. Be familiar with local cultural norms and adjust sessions accordingly.

\section{Be prepared}

Every training experience has the potential to raise challenges. The most effective way to minimize challenges is to be prepared. Mentors should know the material they will present and practice facilitating the activities on their own or with a friend.

\section{Continued on next page}




\section{introduction (cont.)}

\section{GENERAL FACILITATION TIPS}

Below are some tips and methods to help build your capacity as a facilitator.

\section{Establish a learning environment based on equality, respect, and} human rights.

1. Create a supportive learning environment. All participants should feel involved, listened to, comfortable, and safe from ridicule especially when they take risks with new ideas. Encourage participation, particularly among those who feel alone or intimidated. (Various conditions and situations can trigger such feelings. For example, differences in social power associated with gender, social class, or age can be a factor. Participants with limited fluency in the language spoken at school may avoid joining discussions. Those living with a physical disability or other special needs may feel shy.) You can boost class involvement by using activities that promote respect and team building and by spreading leadership opportunities. Of course, it is also important to ensure the safety and privacy of the physical space.

2. During an early session, ask participants to work together to devise a list of guidelines for their own respectful classroom.

3. Ask participants to respect other people's privacy, and remind them not to disclose information to others that they feel should be kept private. Consider how some participants might intimidate or even abuse others after leaving a classroom in which sensitive topics have been discussed. Assure them that you, as their mentor, will keep all discussions confidential. In this way, you serve as a role model for respecting others' privacy.

4. Make certain that they understand that they have the right not to participate or share if doing so makes them uncomfortable.

5. Encourage all participants to share their thoughts. Do not judge their ideas.
Foster a process that draws on participants' experiences, integrating new information and ideas into what they already know and think about a topic.

1. Remember that all participants have knowledge and experience. Listen and ask questions to draw them out.

2. Listen to their concerns and pose hypothetical problems that reflect their real lives. Engage them in solving these problems, making their own choices and developing their ideas along the way.

3. Encourage them to explore the significance of an issue in their own lives.

4. Think of your role as facilitating discussion of participants' ideas rather than as a lecturer or transmitter of information. Sometimes you may need to correct factual errors or help them recognize when a comment is disrespectful.

5. Occasionally, you may wish to share an example from your own experience that is relevant to the lesson. However, be extremely careful to maintain appropriate boundaries with the participants.

\section{Build on their power to reflect, study, and think critically about their}

own lives and the world around them, and to solve problems.

1. Encourage participants to question conventional wisdom. Ask them to think about their beliefs and their community's standards and norms. Invite them to explore opinions different from their own in a respectful manner.

2. Encourage creativity

3. Encourage them to take risks in their thinking and to be unafraid of making mistakes. Be willing to demonstrate such behavior yourself.

4. Organize small groups to explore issues and engage in collective activities.

5. Encourage various perspectives in analyzing problems and suggesting possible solutions.

Continued on next page 


\section{introduction (cont.)}

Foster participants' ability to apply what they learn to their lives and communities, that is, help them to become active citizens and forces for positive change.

1. Repeatedly ask participants to relate the content to their own lives and world. Encourage them to consider the material in light of principles of fairness and social justice.

2. Be aware of the environment in which you work so that you can avoid putting participants in harm's way.

3. Keep in mind that young people often draw inspiration from their teachers and community leaders.

\section{A good facilitator}

1. Sees the participants as experts with information and skills to share, rather than seeing themselves as the only experts in the room.

2. Encourages participants to learn from each other, and guides this process rather than providing direct instructions and lecture-style learning.

3. Believes we learn by doing, experiencing, practicing, and feeling, rather than by memorizing, repeating, and recording information.

4. Is organized, but flexible in changing methods based on participant needs.

5. Is enthusiastic about the topic and participants.

6. Keeps promises to the group - to let participants speak, take a break, etc.

7. Is patient and a good listener

8. Is prepared to handle strong emotions that may arise during discussions.

\section{Before each session}

1. Carefully read through all of the session's background notes and activities. Think about how you will perform each step and what you will add to every session.

2. Try to anticipate questions that may be asked, and know where to look for answers in the materials provided. If participants ask questions that you cannot answer right away, write them down and follow-up on them before the next session, so that you can discuss them then

3. Adapt the activities and group discussions to make them more appropriate to the age and education level of your participants.

4. Think about and plan for any issues that may arise during more "difficult" sessions with complex material or sensitive topics.

5. Think of local examples and ways to make the activities more relevant to the participants' daily lives and concerns.

6. Have materials prepared beforehand.

\section{Additional facilitation tips}

1. Have a "parking lot" for issues that arise during a session, but that are not relevant to the session objectives. You can come back to them at another time or simply explain at the end of the training that it was important, but outside of the scope of the curriculum

2. Capture important points on the chalkboard during discussions for use during the summary activities. It can be very challenging to both lead the discussion and write down all important points, so consider having someone assist you in writing down key points.

3. Whenever appropriate, identify next steps or possible solutions to problems.

4. Relate the information to what has been learned in previous sessions whenever possible.

5. Check to make sure you are not speaking more than the participants. If you find that you are doing most of the talking, encourage participants to answer each other's questions. For instance, if someone asks a question, open discussion to the participants with the inquiry: "Does anyone have an answer to that question?"

6. The way you hold your body will help effectively facilitate the group. Being attentive and nodding will make them feel their contribution is important. Looking away can effectively tell the person not to talk or participate. Always face the person to whom you are speaking.

7. Have fun!

Continued on next page 


\section{introduction (cont.)}

\section{TALKING ABOUT SENSITIVE ISSUES}

Many of the issues raised in this manual are linked to sex, relationships, violence, and HIV, which are often seen as sensitive topics to both participants and facilitators. Some facilitators may feel that talking about sex and contraception with young people encourages young people to have sex. On the contrary, research shows that sexuality and HIV education does not lead to earlier sexual initiation nor does it lead to riskier sex. However, facilitators should not assume the participants are abstaining from sex.

Young people will often giggle with embarrassment when discussing topics related to sex or reproduction. Mentors should not let this discourage them or make them uncomfortable. Girls need accurate information on these subjects to make healthy choices and feel more comfortable with the changes they are experiencing. Let the embarrassment pass, wait for girls to settle down, and then focus on the information and skills they need. You might consider having all the girls say "vagina" or "penis" together to help them get their giggles out.

\section{Tips for mentors to let participants know you are comfortable talking} about these issues

1. Think about your own values and clarify how you feel about an issue before you discuss it with participants.

2. Be prepared and plan ahead. Find out as much as you can beforehand, so that you feel confident facilitating the session.

3. You do not have to know everything. Be honest with participants when you are not sure how to answer their questions. Turn the question into an investigative project and ask participants to help you find the answer. Tell them that you will also ask a health care provider or another expert and try to have answers for them at the next session.

4. Accept participants' slang terms. Don't be afraid to ask what they mean if you don't know.

5. Do not dismiss or look down on what participants know.
Participants have been exposed to a variety of information and experiences. Their experiences have value and are important.

6. Set your own limits. Participants will be excited because you are prepared to talk about topics that interest them. Few adults guide them or give them this knowledge, so they may ask questions that make you feel embarrassed. Be as open and honest as you can, but tell them when it is enough or when their behavior is disrespectful. Explain when you feel uncomfortable answering a particular question.

7. Do not answer personal questions about your own sexual experience. If these questions come up, let participants know that your role as a facilitator is not to discuss your own experience.

8. Stick to the facts. You might have personal opinions about the topic, or how you personally would act in a certain situation, but it is important to remain neutral and open so that the participants will feel free to ask any question and share their thoughts, fears, and opinions.

9. Get advice and help if you need it. Teaching life skills and reproductive health is not easy. If you had a difficult session, find someone you trust to talk with afterwards. However, respect the participants' privacy and do not share personal information that they shared with you during the session, unless you feel they may be in danger. Information from participants may be shared in meetings between mentors, as long as the identity of the participant involved is not disclosed.

\section{Handling emotion}

Participants may get emotional during group meetings. Mentors should react sensitively and effectively when a participant becomes visibly upset during a session. Mentors should strive to ensure that participants feel safe and are not embarrassed so that the group can move past any awkwardness or discomfort. Ways for a mentor to deal with an emotional situation include: moving the discussion away from an upsetting topic, relating an anecdote, moving on to a new topic, or taking a break.

Continued on next page 


\section{introduction (cont.)}

Participants may also get upset by some of the topics in the group meetings. They may have doubts about themselves or may feel uncomfortable talking about issues related to sex with other adolescents. The discussion activities may remind them of their own uncomfortable situations, or their own experience of abuse, at home or at school.

If a participant is upset by an activity, the mentor should try to talk to the participant privately in order to find out how and why the participant is uncomfortable. The mentor may suggest that the participant step out of the meeting space. The mentor should not force the participant to talk about what is upsetting, but should be available to listen if the participant would like to talk. Listen to what the participant says. A mentor's role is to provide the participant with understanding, support, and assistance. The mentor should not tell the participant how she feels or how the mentor thinks the participant should feel; instead, assure the participant that it is normal to feel upset.

Please note: As a mentor, you should be prepared to provide a participant who has been abused with contact information for psychosocial counseling. The GirlsRead! project will provide you with this information and you should have it on hand before the first session.

\section{WORKING WITH PARENTS}

Parents are co-educators in teaching life skills and reproduction to their children. If teachers, community members, religious leaders, and parents can work together, then young people are more likely to emerge as well-rounded, healthy individuals. Unfortunately, it is not always easy to collaborate with parents. Parents often have concerns when reproduction is taught and they may not feel comfortable or equipped to deal with these issues themselves.

\section{Tips for working with parents}

1. Keep parents informed about what you are doing and why.

2. Get the opinions of parents.

3. Talk with parents about their concerns and fears around reproductive health and HIV and AIDS. Do this through GirlsRead! parent meetings and home visits.

4. Invite parents to meetings to discuss their concerns.

5. Know your community. Find out about its needs and concerns, as well as the skills and expertise of the parents. For example, a parent may be a nurse at a local clinic who could talk to the participants and give you advice and support.

6. Involve parents. Assign activities that require participants to talk to their parents. For example, ask participants to interview their parents or family members about when they were young.

\section{SESSION STRUCTURE}

The GirlsRead! Girls' Rights: An Empowerment Curriculum has 19 sessions. Each session is outlined as follows:

\section{Session description}

Objectives

Session time

Required materials

Pre-session preparation

Facilitator notes \& terms

Warm-up \& action item debrief

Activities

Wrap-up

Action item

\section{Session title}

The session title names the main topic covered in the session.

\section{Session description}

The session description summarizes the activities undertaken in each session.

Continued on next page 


\section{introduction (cont.)}

\section{Objectives}

The objectives provide an overview of the learning aims and purpose of each session.

\section{Session time}

A breakdown of the estimated time to be spent on each activity is provided at the beginning of each session and underneath each activity title. These general time frames have been assigned to aid in determining the division of time between each activity in a session so that all the material can be covered. However, participants may want to explore some issues in more depth, or at other times they may work through the material more quickly. Allow participants flexibility with the space and time allocated to each part of a session. This will help them grasp key messages associated with each session and develop an understanding of how to apply the information to their lives.

\section{Required materials}

Materials needed to prepare for each session are listed. Participants will be provided with notebooks to use for note-taking and working on various activities throughout the program. They should be reminded to bring these with them to each session. Chalk and a chalkboard are needed for most sessions. When these materials are not available, adapt the session accordingly.

\section{Pre-session preparation}

Preparation activities for each session are noted. It is important for the facilitator to complete these preparations before each session. Being prepared for the learning session will make the facilitator's job much easier and help the session to run smoothly. Review this information carefully.

\section{Facilitator notes}

These notes provide details about relevant session background

information for the facilitator, additional session-specific tips that may

be helpful, and reminders about how to facilitate each session.
Terms

Terms relevant to each session are listed and defined. These definitions can be referred to throughout the session as terms are discussed or if clarification of terms is needed. A consolidated list of all terms in the curriculum is located in the Glossary of Terms.

\section{Warm-up/action item debrief}

A warm-up and action item debrief are included at the beginning of a session. Ideally the warm-up is related to the session topic. The action item debrief is a time to discuss the results of the action item assigned at the end of the previous session.

\section{Activities}

Step-by-step instructions for the learning activities are provided to guide the facilitator in helping participants learn and work with the concepts of the session. The steps are listed in the order in which they should be implemented and it is intended that the steps be followed as outlined. While a general script for each session is provided, facilitators should feel free to use their own words to explain each point.

\section{Wrap-up}

A suggested outline to wrap-up each session normally includes instructions to ask participants to summarize what they have learned during the session while the facilitator fills in any key points they miss, addresses any questions or comments, and ends the session on a positive note, with a clear key message.

\section{Action item}

Action items are to help reinforce the skills and knowledge that were gained during the session. Participants work on these simple, short assignments between sessions, and their experience undertaking them are discussed at the beginning of the following session. 


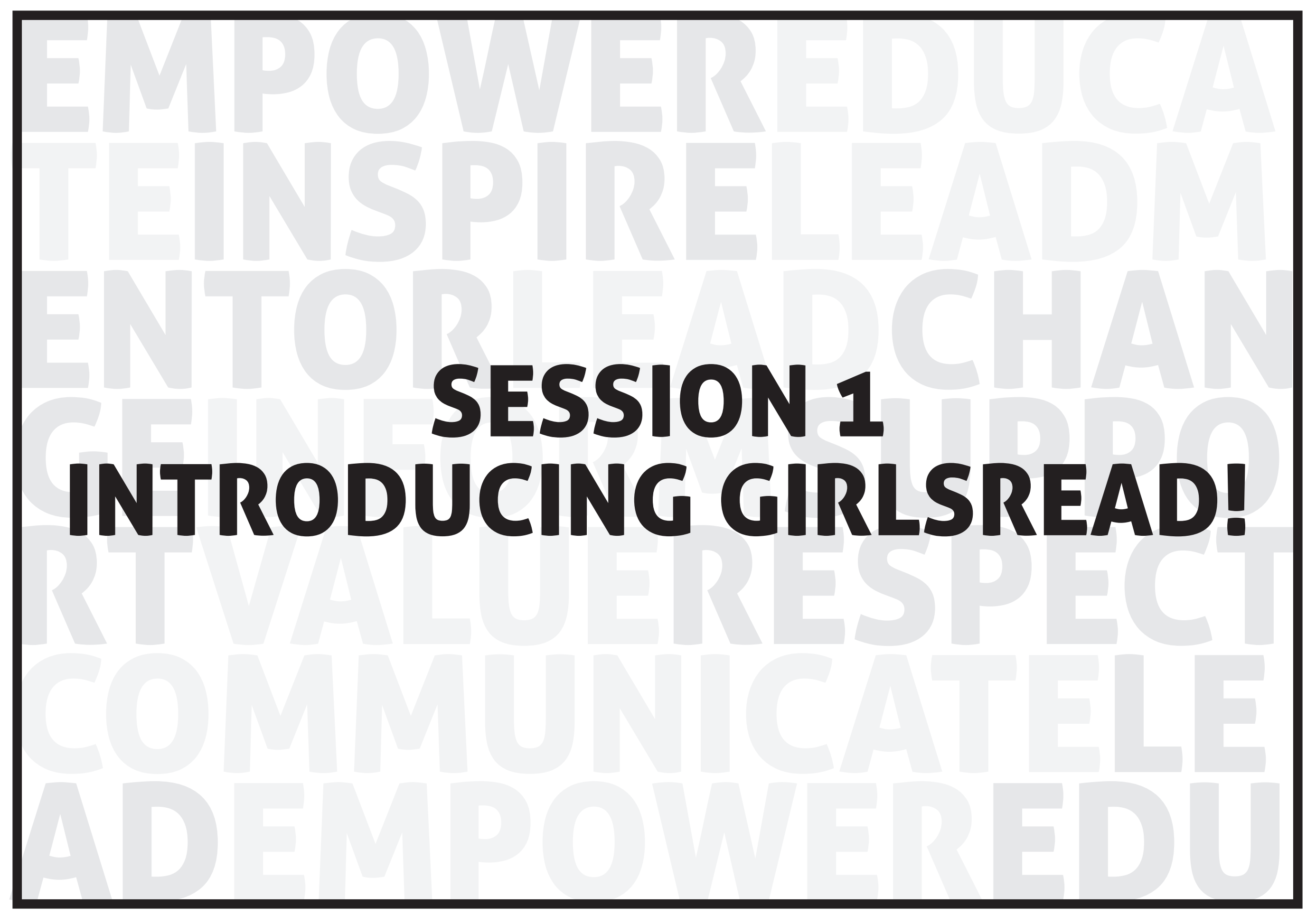




\section{session 1 / introducing girlsread!}

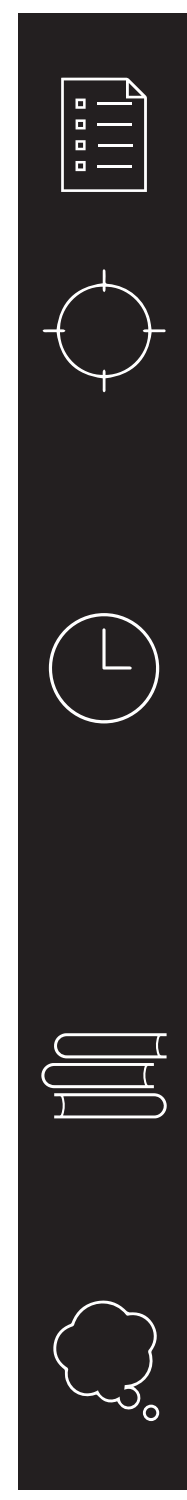

SESSION DESCRIPTION

An introduction to the program and explanation of the purpose of

GirlsRead! safe spaces.

\section{OBJECTIVES}

By the end of the session, participants will:

Know each other better

Develop confidence in representing themselves in front of others

- Understand the program goals

- Establish ground rules for safe space meetings

- Think about education benefits, barriers, and solutions

\section{SESSION TIME}

1 hour

Warm-up: Knowing each other, 10 minutes

Activity 1: Introducing GirlsRead! safe spaces and ground rules, 12 minutes

Activity 2: Blindfold walk: team building, 10 minutes

Activity 3: Let's have a ball: education benefits, barriers, and solutions,

20 minutes

Wrap-up: 5 minutes

Action item: 3 minutes

\section{REQUIRED MATERIALS}

Chalkboard and chalk

- Small ball or paper crumpled into ball

- Blindfold

- Items for the obstacle course (desks, chairs, boxes, etc.)

\section{PRE-SESSION PREPARATION}

- Read through the entire session and, if necessary, practice presenting the activities. Prepare all materials needed.

- Write three questions on the board for Activity 3. 


\section{session 1 / introducing girlsread! (cont.)}

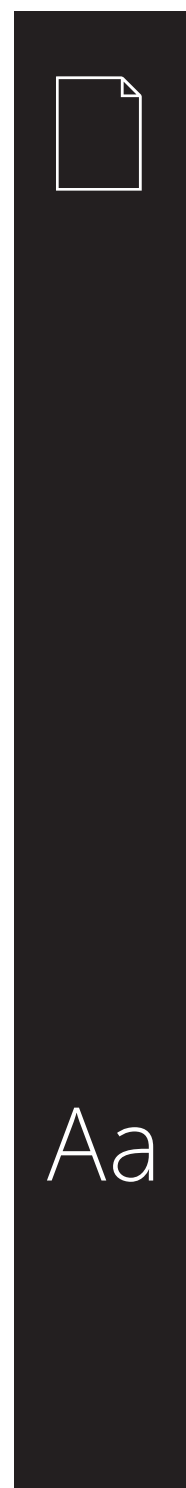

\section{FACILITATOR NOTES*}

Remember, your aim from the start is to foster a learning environment based on equality, respect, and human rights. Here is how:

Create a supportive learning environment. All participants should feel involved, listened to, comfortable, and safe from ridicule, especially when they take risks with new ideas.

Encourage participation, particularly among those who feel alone or intimidated. Various conditions and situations can trigger such feelings. For example, differences in social power associated with gender, social class, or age can be a factor. Those with limited fluency in the language spoken at school may avoid joining discussions. Participants living with a physical disability and those with other special needs may feel shy.

You can boost participation by using activities that promote respect and team building and by spreading leadership opportunities.
Of course, it is also important to ensure the safety and privacy of the physical space.

During this first session you will ask

participants to work together to devise a list of guidelines for their own respectful safe space group.

Ask participants to respect other people's privacy, and remind them not to disclose information to others that they feel should be kept private. Consider how some participants might intimidate or even abuse others after leaving a session in which sensitive topics

have been discussed. Assure your participants that you, as their mentor, will keep all discussions confidential. In this way, you serve as a role model for respecting others' privacy.

Make certain that learners understand that they have the right not to participate or share if doing so makes them uncomfortable.
Encourage all participants to share their thoughts. Do not judge their ideas.

*Source: International Sexuality and HIV Curriculum Working Group. 2009, updated 2011. It's All One Curriculum: Guidelines and Activities for a Unified Approach to Sexuality, Gender, HIV and Human Rights Education. New York: Population Council. Activities: Page 4. 


\section{warm-up}

\section{KNOWING EACH OTHER* [10 MINUTES]}

1. Ask everyone to please stand in a circle.

2. Explain: Think about something that defines who you are. It could be that you love football, or eating, or that you are shy, or good at school. Don't tell anyone yet just keep it to yourself. We know that there are many things that define each one of us, but for this game we are going to pick just one characteristic.

We are all going to take turns and act out the quality that defines us using a gesture or two - no words! The rest of the group has to try and guess the person's quality. After we guess, everyone in the circle repeats the action and the participant's name.

Now we will go around the circle until we have all had a turn.

Ask: Who would like to volunteer to come to the middle of the circle and act out the quality that defines them?
3. Allow everyone to take a turn. Participants can call out their guesses - no need to raise hands. Keep the action moving - the pace should be energizing and fun

[Note: If no girls volunteer to go first, then be the first one to go - do something short - for example, mime laughing uncontrollably if you are funny, do a

quick dance move if you love to dance, or pretend to read a book if you read a lot.]

4. Wrap up by saying: That was GREAT! You are an amazing and talented group. We are going to learn so much from each other. 


\section{activity 1}

\section{INTRODUCING GIRLSREAD! SAFE SPACES AND GROUND RULES \\ [12 MINUTES]}

1. Ask: Could someone tell me the goal of GirlsRead! safe spaces?

[Wait for a few responses.]

2. Explain the goal of GirlsRead! safe spaces:

The goal of GirlsRead! safe spaces

is to provide a safe and fun learning

environment where you will build life skills and knowledge. The knowledge and skills that you gain in these groups, together with the friends that you will make, will help you maintain a happy and healthy life, and feel confident and empowered to assert your rights and protect yourselves from harm and threats to your health.

[Allow time for the group to ask questions.

3. Tell the participants where and when the group will meet, explaining that there are two GirlsRead! groups per school with one to two mentors who will manage both groups. Explain that the meetings will run from March to July.

4. Explain: The first half of each meeting will include interactive activities that address a different topic (such as gender equality, communication, relationships, sexuality, and rights) each week. We will work together to make the meetings a safe place for us to discuss topics and questions that you may not otherwise get to talk about with adults. You should not feel embarrassed about anything that is discussed, any questions you may have, or any experiences you want to share. You are expected to attend each session. If you miss two sessions in a row, the mentor will follow up to find out if you are alright. The activities are participatory. You are asked and encouraged to talk, share discuss, have fun, and play at each meeting.

5. The second half of each meeting will focus on the e-reader curriculum for another hour, making the full session 2 hours.

6. Explain: We would like to establish some ground rules to make sure that everyone feels safe and comfortable participating.

7. Ask: What are some of the ground rules you think we should all follow during these meetings? [Record the suggested ground rules on the board. If the following are not mentioned, add them.]
- Respect one another

Keep things confidential: Sometimes we

will be talking about private things - do

not talk about other people's private lives outside of the group

Be non-judgmental: We all have different reasons for what we do and how we do it. We all have faults

Arrive on time

- Participate actively

- Help one another 


\section{activity 2}

\section{BLINDFOLD WALK: TEAM BUILDING* \\ [10 MINUTES]}

1. Begin by arranging the room as an obstacle course. Place desks, chairs, boxes, or other items in various parts of the room

2. Ask for a volunteer

3. Explain to the volunteer: I am going to blindfold you and you have to try to cross to the other side of the room.

Explain to the group: No one is allowed to say anything or do anything to help the volunteer.

4. Blindfold the volunteer. Then spin the volunteer around in circles so they feel disoriented. Have the volunteer try to find their way to the other side of the room

After 1 minute, stop the exercise.

5. Now ask for another volunteer. Blindfold them and spin them around.

6. Explain to the group: Now you are allowed to help the volunteer only with words. You can tell the volunteer to turn in a certain direction or to go backwards, etc.
7. Let the volunteer try to find their way to the other side of the room. After 1 minute, stop the exercise.

8. Now ask for the last volunteer. Blindfold them and spin them around.

9. Explain to the group: Now you are allowed to help the volunteer any way you want. You can use words and actions. You can gently touch the volunteer and guide them in the right direction.

10. Let the volunteer try to find their way to the other side of the room. After 1 minute, stop the exercise.

11. After the exercise, have a discussion with the class.

12. Ask: What did you learn? [Possible responses include: It is difficult to do things alone; when you have support from your friends it is easier to accomplish a task.]

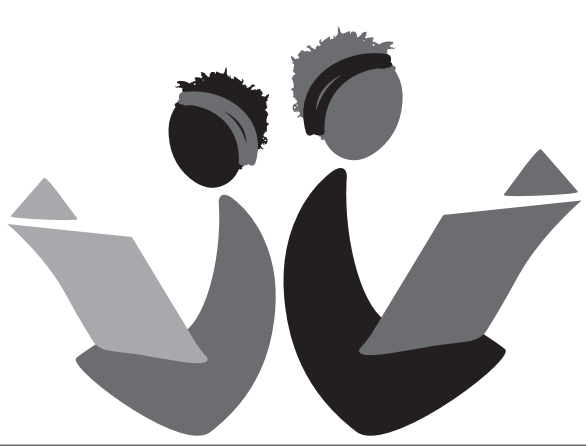




\section{activity 3}

\section{LET'S HAVE A BALL: EDUCATION BENEFITS, BARRIERS, AND SOLUTIONS* [20 MINUTES]}

1. Before the session, write these three questions on different parts of the board:

1. What are the benefits of girls going to school?

2. What are the barriers that keep girls from going to school? Or cause girls to drop out of school?

3. What are the solutions to keep girls in school to complete grade 12 ?

2. Ask participants to stand in two parallel lines facing each other. Crumple up a piece of paper or use a small ball and toss it to a participant.

3. Explain: You are going to toss the ball back and forth while I play music [or sing, or drum on the desk]. When the music stops, whoever is holding the paper or ball must tell the group their thoughts about the first question. They just need to give one example. Once they have answered, they have to sit down.
4. Repeat until about a third of the participants have had a turn answering question 1. Then switch to the second question, and repeat until an additional third of the participants have answered question 2. When two-thirds of the

participants are sitting down, switch from question 2 to 3 .

5. Ask the remaining participants to sit down. Have a discussion about the questions. Ask: Can you think of other answers?

\section{Continued on next page}

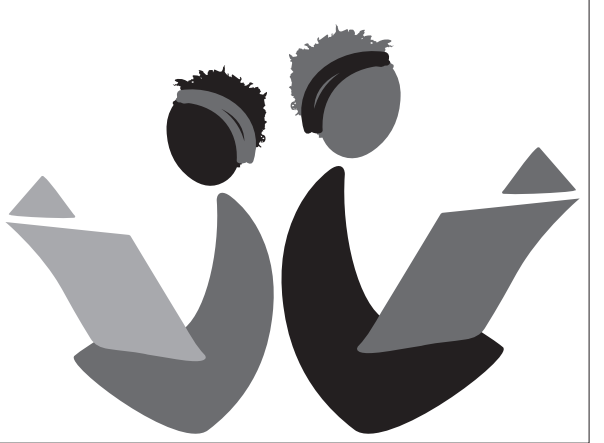




\section{activity 3 (cont.)}

In case these did not come out, explain the following:

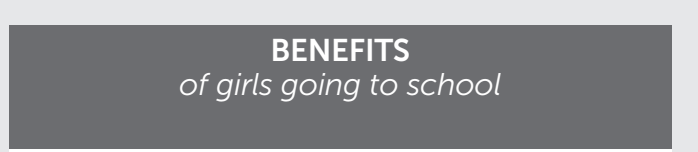

Increases literacy

Increases understanding of math

Increases options for work/livelihoods

after school

Builds self-esteem and self-awareness

Increases ability to obtain and understand

health care information on your own

- Enhances ability to make decisions about

and negotiate fair prices of purchases

Enhances ability to understand local and

national political discussions and how

policies can affect you

\section{BARRIERS}

that keep girls from going to schoo or cause girls to drop out of school

- Lack of family/community encouragement Lack of financial support for school fees and supplies

Loss of a parent, leading to increased responsibility at home

No schools available in the area where the girl lives, particularly for secondary school Early marriage

- Pregnancy/motherhood [although

it is illegal to stop girls from going to school when pregnant, many girls feel

uncomfortable or ashamed going to school while pregnant; after the child is born, there is a school re-entry policy

where girls are encouraged to return to

school but many do not feel comfortable or do not have someone to take care of

their child while they are at school]

Discouraged by low grades

Discouraged by teachers or peers teasing mocking, or bullying

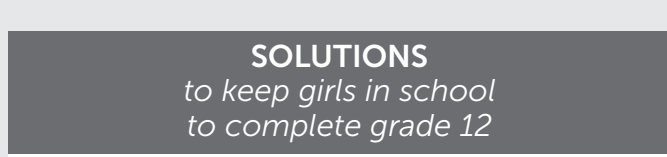

Family and community support

Encouragement from teachers and peers

Financial support for school fees

Prevention of pregnancy

Prevention of early marriage

Learning support

Studying and reading

Safe and welcoming schools 


\title{
wrap-up
}

\author{
WRAP-UP \\ [5 MINUTES]
}

Ask participants to summarize what they have

learned. Fill in any key points they miss.

Key Message: You will be participating in

GirlsRead! over the course of the next few

months. GirlsRead! sessions are a safe space

where you will learn about gender equality,

discrimination, communication, relationships,

and reproductive health as well as make

friends and have fun.

\section{Action item: 3 minutes}

Explain: Before we meet again, I want each of you to tell your parent or guardian about GirlsRead! and bring any questions that they have to the next session so that we can answer them.

Ask for any final questions or comments.

Remind participants where and when the next meeting will take place, and what topics will be discussed.

Thank them for their participation.

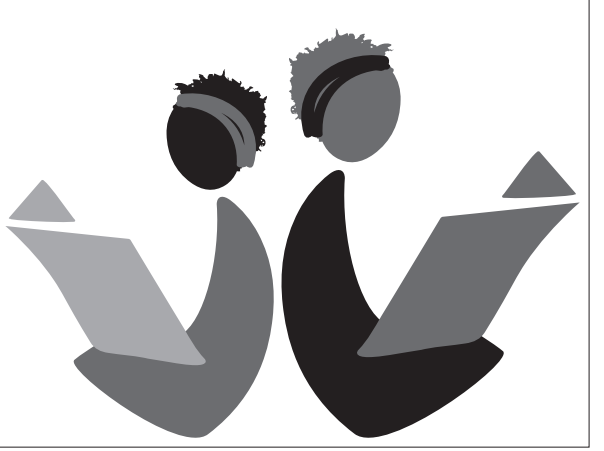




\section{SESSION 2 GOAL SETTING}




\section{session 2 / goal setting}

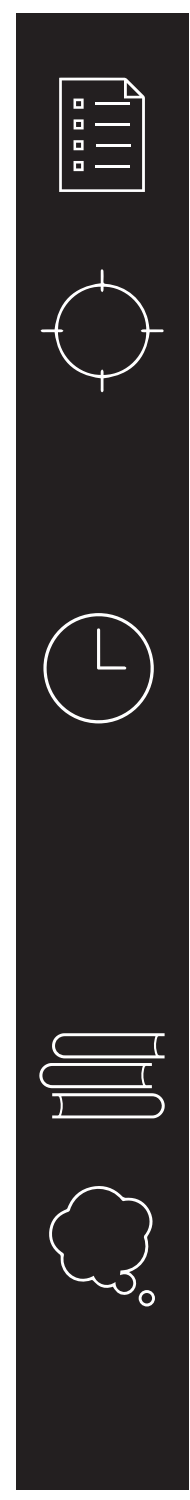

SESSION DESCRIPTION

Participants will think about their future, learn what goals are, and practice developing goals.

\section{OBJECTIVES}

By the end of the session, participants will:

- Discuss their dreams for the future

Define what a goal is

- Work on short-term goal setting

- Understand the importance of having someone help them achieve their goals

\section{SESSION TIME}

1 hour

Action item debrief: 10 minutes

Warm-up: What are your dreams? 10 minutes

Activity 1: Goal setting, 10 minutes

Activity 2: Helping hands, 17 minutes

Activity 3: Goodbye I can't, 5 minutes

Wrap-up: 5 minutes

Action item: 3 minutes

\section{REQUIRED MATERIALS}

Chalkboard and chalk

\section{PRE-SESSION PREPARATION}

Read through the entire session and practice presenting the activities.

Prepare all materials needed. 


\section{session 2 / goal setting (cont.)}

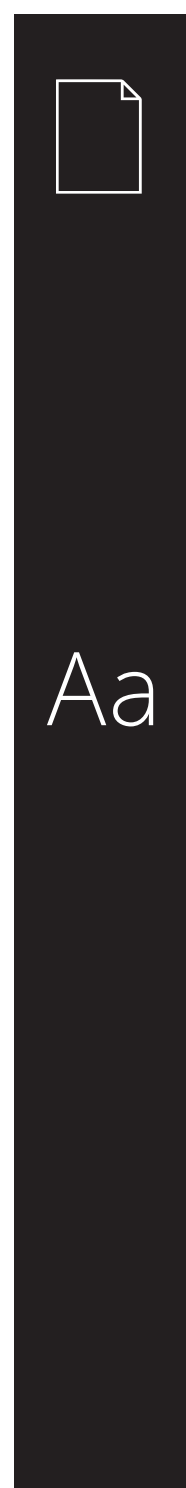

\section{FACILITATOR NOTES*}

A goal is something that you want to achieve or accomplish. It can be something to do, someplace to go or something to have. Goals give us something to look forward to and can motivate us and give us energy. To set a goal, we must gather information and make decisions and choices. We must learn about what we want to achieve. Goals should be specific, practical, and have a deadline. Something realistic and easy to manage makes achieving it easier and creates confidence to make other, greater goals. Thinking about the expected benefits can be motivating. In order to reach a goal, it is helpful to have a plan with steps to achieve it, and also to think about possible difficulties and how to overcome them.

\section{TERMS}

Goal: Something that you hope to achieve, especially when much time and effort will be needed 


\section{warm-up}

\section{ACTION ITEM DEBRIEF [10 MINUTES]}

1. Explain: Last week we asked you to tell your parents or guardian about the program. What did your parents say? Did any of them have questions about the program?

\section{WHAT ARE YOUR DREAMS?*}

\section{[10 MINUTES]}

1. Explain: We are meeting together in our safe spaces group to support each other and to learn about how to make good decisions about our lives. I want you to think about your dreams. Close your eyes for just a moment, and think about how old you are now.

\section{Ask:}

How old will you be in five years? Think about yourself five years from now.

Where are you living?

What are you doing?

-What goals or plans have you achieved?
2. Answer all questions, or, if you do not know the answer, tell participants you do not know, but will find out by the next session If that is the case, write down the question and ask the GirlsRead! program team.

Now, I want you to think about one specific dream you want to achieve in five years.

[Pause for a minute to give participants time to identify a dream.] Got it? Now open your eyes.

3. Make sure that all girls have thought of at least one dream. Then, ask two or three volunteers to share their dreams.

4. Make the connection between the girls dreams and education.

Say: Now that we have all thought about some of our dreams, I want everyone to stand up and clap if reaching your dream will involve having an education.
3. Offer: If any of your parents would like, we are happy to speak with them.

As we can see many of our dreams require an education to be reached. So we need to find ways to stay in school and study hard to do well so that our dreams can come true.

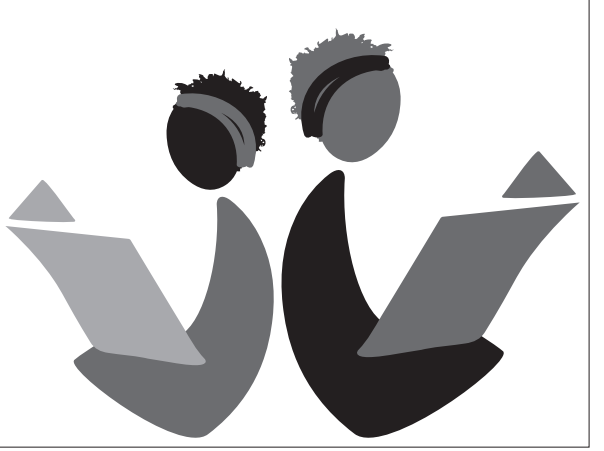




\section{activity 1}

\section{GOAL SETTING* \\ [10 MINUTES]}

1. Get a few volunteers to play an imaginary football game in the classroom for 1

minute. When they have finished explain:

In football, a goal is when you score to

benefit your team. It is something you strive to do throughout the entire game - you and your team try to score as many goals as you can in one game. Imagine a game of footbal with no goals. Without goals, the game does not have a purpose. It is the same in life: if you have no goals, you are just on the field aimlessly kicking the ball around.

2. Tell participants that in order to develop goals, one should use this simple outline (write the key words - in bold - on the chalkboard as you describe each one):

MISSION STATEMENT: A brief phrase explaining what you want to accomplish [for example: to go to teacher college]

WHAT: Be specific; explain the mission statement more here [for example: to study to be a teacher]

WHO: The people who will help you toward your goals [for example: parents, teachers, and school administrators]
WHERE: A place, anywhere in the world [for example: local and national colleges or schools]

WHEN: Set up a timeline and a specific date [for example: study to take tests next year, to be in a teacher's college within three years]

HOW: Make lists of ideas to achieve your goal-explain "to do" lists [for example: research what teacher colleges exist in the area; talk to teachers back home; contact friends and relatives who could help; look in the newspaper and on the internet for information and, possibly, groups for emotional and financial support]

WHY: Should refer back to the mission statement [for example: because I have a lot to offer my community as a teacher]

Goals are very important in life, just as in football. Also like in football, when setting a goal you will miss a few shots. Famous Zambian soccer player, Christopher Katongo, did not walk off the field when he missed a shot. He is not considered a failure. Expect to have failures and challenges as you work towards your goals.

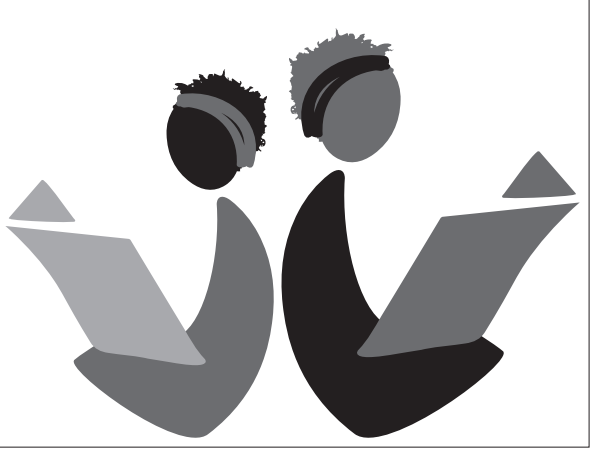




\section{activity 2}

\section{HELPING HANDS* \\ [17 MINUTES]}

1. Divide the group into pairs. Ask each person to share with their partner a goal they want to achieve this school term. It might be getting a good mark in science, learning to play football, or coming to school on time.

2. Ask everyone to draw the outline of their hand in their notebooks and to write their goal on the paper in the middle of the palm of the hand.

3. In turns, have them work with their partner to think of five things they can do to achieve that goal. For example, if they want to get a good mark in science, what are five things they can do to help them achieve this? Perhaps study science for 30 minutes every day; ask the teacher for extra help; work with a student who is very smart in science; read extra books in the library; ask their parents to encourage them. Have them write one strategy in each of the fingers of the hand drawn on the paper.

4. Give participants a few minutes to complete the task, then switch and have the other partner in the pair do the same.
5. After both partners have drawn their hands and filled in the fingers, have them talk about the ways in which they can help their partner reach their goals. Have them switch papers and write on their partner's paper three things they will do to help their partner keep on track to achieve their goal.

Explain that the partners will provide a helping hand to each other to support them in realizing their goals.

6. Throughout the activity, check in on "helping hand partners" to see how they are progressing. Be encouraging and supportive - compliment their ideas and plans, offer help if they seem to be struggling. 


\section{activity 3}

\section{GOODBYE I CAN'T* \\ [5 MINUTES]}

1. Explain: Now I want you to think of things you think you cannot do. Maybe you feel you cannot travel to the other side of the country to visit your aunt, or be assertive with your big brother if you disagree with him, or go to university to be a doctor. Try to think of at least two things you cannot do, imagine writing them on a piece of paper. When the participants have thought of at least two things, ask them to all stand up.

2. Say: We are gathered here today to say goodbye to something that has been around for a long time. We are going to say goodbye to the things that we think we cannot do. It is important to believe in yourself. With strong self-esteem and well-planned goals, you can achieve anything you want. This is a goodbye to " can't" because you CAN do these things you think you can't do. Don't allow others to tell you that you can't do something.

3. Instruct the girls to pretend that they are tearing their "I can't" papers into small pieces and throwing them in the air while shouting, "Goodbye 'I can't'!"

4. Say: You can do anything you set your mind to!

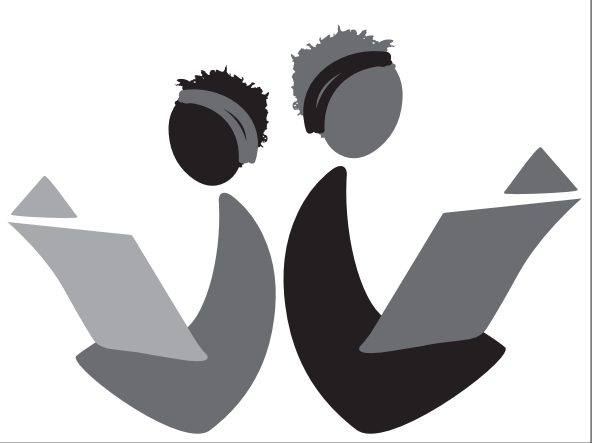




\title{
wrap-up
}

\author{
WRAP-UP \\ [5 MINUTES]
}

Ask participants to summarize what they have

learned. Fill in any key points they miss.

Key Message: Dreams rarely just happen. They happen because we make them happen. By

focusing on what our goals are; being specific about the who, what, when, where, and how; following our plan; and getting support, we can achieve our goals.

\section{Action item: 3 minutes}

Explain: Take a look again at your helping hands. Pick one of the things you plan to do - one of the fingers. Before the next session, complete that action. If you can, complete two. You will be on your way to achieving your dream!

Ask for any final questions or comments.

Remind participants where and when the next meeting will take place, and what topics will be discussed.

Congratulate them on their terrific work and thank them for their participation.

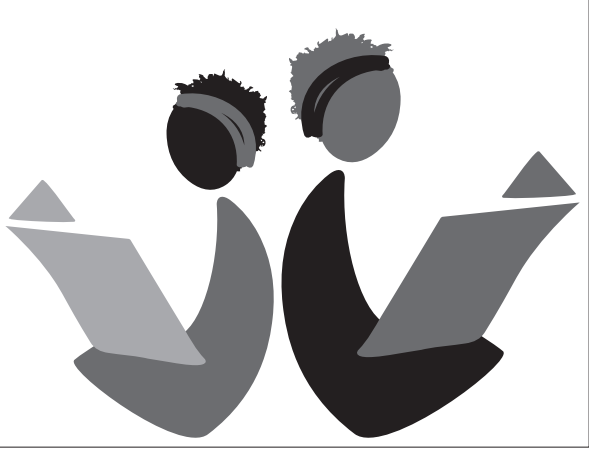




\section{SESSION 3}

GENDER NORMS

AND ATTITUDES 


\section{session 3 / gender norms and attitudes}

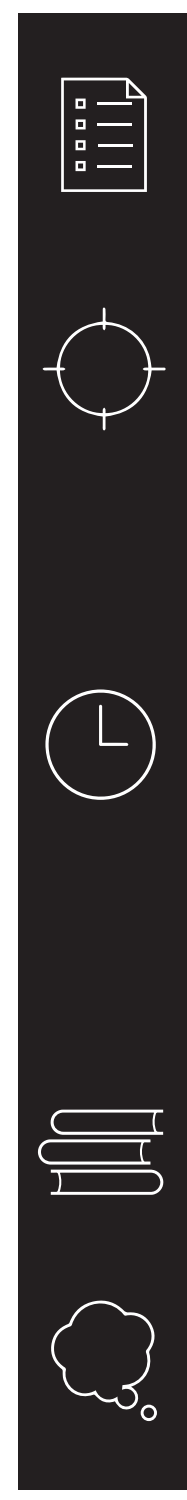

\section{SESSION DESCRIPTION}

Participants identify what society expects of boys and girls, identify what society discourages boys and girls from doing, and consider norms and behaviors that are more equitable and fair.

\section{OBJECTIVES}

By the end of the session, participants will be able to:

Understand that we each have our own stereotypes of what we believe about boys and girls

Give examples of how we absorb messages about gender roles Explore and clarify gender values

- Mention one girl or woman who has stepped outside her gender role to succeed

\section{SESSION TIME}

1 hour

Action item debrief: 5 minutes

Warm-up: Slap, clap, snap, 5 minutes

Activity 1: Memory journey, 15 minutes

Activity 2: Clarifying gender values, 20 minutes

Activity 3: She did something different, 10 minutes

Wrap-up: 2 minutes

Action item: 3 minutes

\section{REQUIRED MATERIALS}

Chalkboard and chalk

Two signs: Agree and Disagree

\section{PRE-SESSION PREPARATION}

Read through the entire session and practice presenting the activities. Prepare all materials needed. 
session 3 / gender norms and attitudes (cont.)

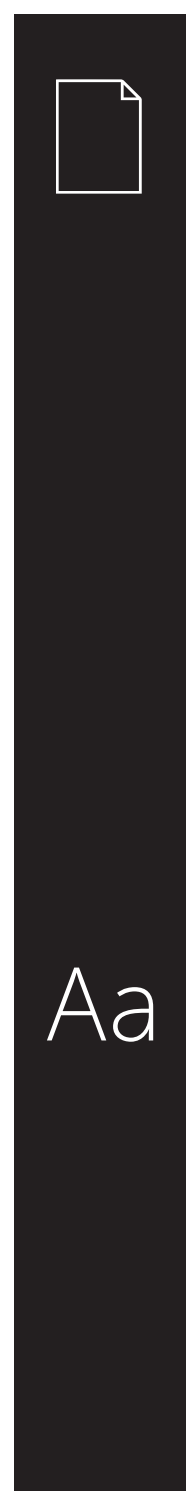

\section{FACILITATOR NOTES*}

Every culture has expectations of how men and women should act and what their roles are in society. These expected roles are known as gender roles. Fulfilling the roles expected by the community can give women or girls a sense of belonging. But these roles can also limit the activities and choices of women and girls, and make them feel less valued than men. When this happens, everyone (women, their family, and their community) suffers.

In most communities, women are expected to be wives and mothers. Many women like this role because it can be very satisfying and it gives them status in the community. Some women would prefer to follow other interests, or want to have only a few children, but their families and communities do not give them this choice. If a woman or girl is expected to have many children, she may have less chance to learn new skills or to go to school.

\section{TERMS}

Gender: The way society defines the roles, behaviors, activities, and attributes of males and females. These definitions are not fixed, but change over time and from society to society.

Gender equality: Men and women are equal. They have the same rights, opportunities, and responsibilities. They should be treated with equal concern and respect, and should be entitled to develop to their full human potential.
Most of her time and energy will be spent taking care of others' needs. Or, if a woman is unable to have children, her community may value her less than other women.

Most communities value men's work more than women's work. For example, if a woman cooks, cleans, and cares for the children all day, it is often still her responsibility to continue to work to ensure her husband's comfort when he returns home from his job. This is because his work is considered to be more important than her own. When the woman's children see this, they will grow up thinking men's work is more important, and value the work and contributions of women less. Women are often considered more emotional than men, and are free to express these emotions with others. Men, however, are often taught that showing emotions like sadness or tenderness is unmanly, so they hide their feelings. Or they

Gender norms: Gender norms are the standards and expectations to which women and men generally conform. Gender norms are ideas about how women and men should be and act. Internalized early in life, gender norms can establish a life cycle of gender socialization and stereotyping.

Gender stereotype: An oversimplified or biased description of the abilities of men and women or how men and women think, feel, or act. express their feelings in angry or violent ways that are considered more acceptable for men. When men are unable to show their feelings, children may feel more distant from their fathers, and men are less able to get support from others for their problems.

Gender stereotypes are generally used to describe the abilities of men versus those of women in the community in an oversimplified way. A stereotype is an oversimplified or biased description of a group. Stereotypes are often negative and harmful. Stereotypes are often recognized as being illogical even though many people still believe them.

It is important to remember that gender norms and roles change over time and differ from place to place. They are not innate. We can all work for a world with greater equality, and greater opportunity for everyone.

Sex: The biological and physiological characteristics of males and females. For example, only females can become pregnant. Sex is not the same as gender.

Values: The beliefs that govern what people view as right and wrong. The things that are important to us (that we value), which we use to guide and direct our lives, and which are seen in the way we live and in our actions and behavior 


\section{warm-up}

\section{ACTION ITEM DEBRIEF [5 MINUTES]}

Last week we made our "helping hands." Who was able to complete ONE item on their todo list (the fingers on your drawings)? Was anyone able to complete TWO? Who wants to share what they did? How did it go?

\section{SLAP, CLAP, SNAP*}

\section{[5 MINUTES]}

1. Explain: We are going to play a quick game to help understand the genderbased roles that boys and girls are expected to live by. The game is called "Slap, Clap, Snap!" Everyone will perform these three actions in a row. First, slap you lap, then clap your hands, then snap your ingers. IDemonstrate and practice a few times with the group to develop a rhythm.

2. Ask participants to stand in a circle in the middle of the room

3. Explain: We're all going to do the slapclap-snap rhythm, and at some point in the slap-clap-snap rhythm, I will point to a person and either say "boy" or "girl." The person I point to must name a job a boy/girl may grow up to do, a characteristic that is acceptable for a boy/girl in your school and
What is next on your list toward achieving your goal? We also identified ways to help each other - don't forget that part. We are stronger together! community, or work that is assigned in your school for a boy/girl. You must be quick and say the first thing that comes to your mind before we get back to "slap." For example:

- If I say "boy," you (the participant) might say "aggressive"

If I say "girl," you might say "quiet" - If I say "boy," you might say "doctor"

If I say "girl," you might say "nurse"

4. Ask a volunteer to take notes on the blackboard under two headings - "boy" and "girl." At the end of the exercise, you should have a list of careers, chores and characteristics the group considers acceptable for boys and for girls.
5. Once everyone has had a turn, compare the two lists. Ask the group what this means for opportunities open to girls.

6. Erase the titles and reverse them, writing "girl" on top of the "boy" list, and "boy" on top of the "girl" list. Ask the group whether girls could do or be these things that you have said boys can do or be. Could boys do or be the things that you said girls can do or be?

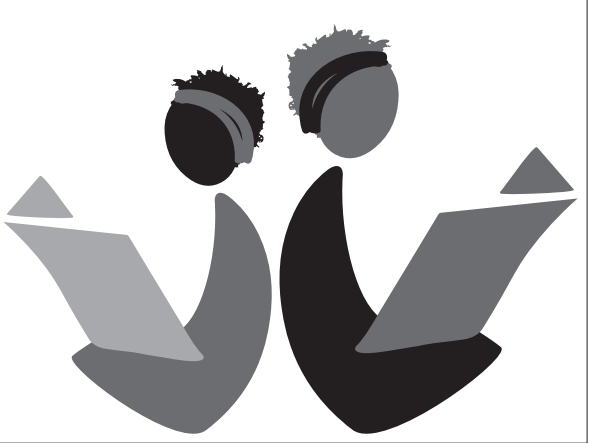




\section{activity 1}

\section{MEMORY JOURNEY* \\ [15 MINUTES]}

1. Explain: Today we will explore what it means to grow up as a boy or as a girl.

First, we will take a short journey into our memories, so get comfortable, close your eyes, and relax. Think back to a time when you realized that you were being treated a certain way because of your sex - because you were a girl. [Pause to let them think.] What feelings come up for you as you recall that experience?

2. After a few minutes, say: Open your eyes. Is anyone willing to share their experiences or feelings?

3. After a few participants share, ask:

What do these experiences tell us about the way people think girls and women should behave or the roles they should play in society? And what about the same question for boys and men?

- Does this seem fair to you - to have set expectations for girls/women and boys/ men? Why or why not?

What are some changes that would need to be made to achieve equality between males and females?

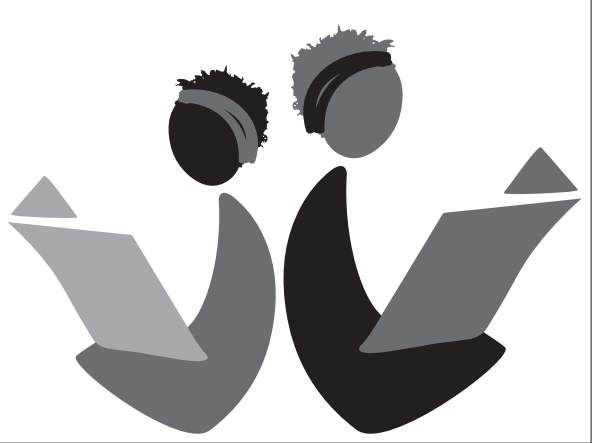

*Source: International Sexuality and HIV Curriculum Working Group. 2009, updated 2011. It's All One Curriculum: Guidelines and Activities for a Unified Approach to Sexuality, Gender, HIV and Human Rights Education. New York: Population Council. Activities: Page 34. 


\section{activity 2}

\section{CLARIFYING GENDER VALUES* [20 MINUTES]}

1. Before you begin the activity, clarify the following terms with participants: sex, gender, gender equality, gender norms and gender stereotype.

\section{Explain:}

Sex: The biological and physiological characteristics that define males and females. For example, only females can become pregnant. Sex is not the same as gender.

Gender: The way society defines the roles, behaviors, activities, and attributes of males and females. These definitions are not fixed, but change over time and from society to society.

Gender equality: Men and women are equal. They have the same rights, opportunities, and responsibilities. They should be treated with equal concern and respect, and should be entitled to develop to their full human potential.

Gender norms: Gender norms are the standards and expectations to which women and men generally conform. Gender norms are ideas about how women and men should be and act. Internalized early in life, gender norms can establish a life cycle of gender socialization and stereotyping.

Gender stereotype: An oversimplified or biased description of the abilities of men and women or how men and women think feel, or act.

[Make sure the participants are absolutely clear about these terms before proceeding.

2. Put up the two signs, Agree and Disagree, on opposite sides of the room.

3. Explain: This activity will help us explore our values and attitudes about gender.

4. Clarify that everyone understands the word, "values." [Give and ask for examples.]

Values: The beliefs that govern what people view as right and wrong. The things that are important to us (that we value), which we use to guide and direct our lives, and which are seen in the way we live and in our actions and behavior.

5. Remind participants that everyone has a right to their own opinion, and that in this activity no response is right or wrong.
6. Ask participants to stand in the center of the room. Explain that you want them to think about whether they agree or disagree with each statement you will read out to them.

Continued on next page 


\section{activity 2 (cont.)}

7. Read Statement A (only) from the box on the right out loud. Ask participants to go stand next to the sign that shows what they think about this statement.

8. Once everyone is at a sign, ask one or two participants next to each sign to briefly explain why they are standing there and why they feel this way about the statement.

9. When the participants are all finished explaining their reasoning, ask if anyone wants to change their mind and move to the other sign. Let them do this. If they want to, they can explain why they changed their mind.

10. Bring everyone back together into the center of the room and read Statement B. Repeat the steps followed above. Continue in this way for the other statements.
11. After completing these steps for all the statements, ask everyone to sit down and lead a discussion about values and attitudes about gender by asking these questions:

- Which statements did you feel most strongly about? Why?

How do you think men's and boy's feelings about these statements affect how they behave towards girls and women?

What other examples can you think of to show how attitudes and values affect the way people treat girls and women?

How can you be involved in helping to change these attitudes and values, and the actions they lead to?

What do you think you'll do differently as a result of this exercise?
A. "Real" girls should obey boys because boys are stronger and better in decision-making than girls.

B. Boys should spend as much time on household chores as girls.

C. Girls who wear short skirts are partly to blame if boys sexually harass them

D. Girls who wear short skirts are partly to blame if they are raped.

E. All violence against women and girls is wrong and must be stopped. This includes dating violence, sexual violence, and violence in the home (or domestic violence).

F. A woman is more of a woman when she has had children.

G. Relationships based on equality and respect are far more satisfying than relationships based on fear and domination. 


\section{activity 3}

\section{SHE DID SOMETHING DIFFERENT* \\ [10 MINUTES]}

1. Tell the story of a local woman who challenged gender roles or read the story of Mayamiko below.

\section{Mayamiko the Pilot}

Mayamiko had four brothers and no sisters. Her brothers were all performing well at school; however, Mayamiko was performing better than all of her brothers at school. Her brothers felt very uncomfortable about her success at school. They told her that she was only a girl and that the best that could happen to her was to get married and become a housewife. Mayamiko had a goal and dream of becoming an airplane pilot. When she told people in her village what she wanted to do they laughed and said "Women can't fly airplanes!" After years of studying and hard work she went to university. At the university she chose a subject that women usually don't study: aviation. She turned out to be the first woman pilot in the country. Everyone is proud of her success. She is now a very good pilot and serves as a role model for both boys and girls.
2. Ask participants to identify how this role model accomplished her goal despite the obstacles she faced along the way. 


\section{wrap-up}

\section{WRAP-UP \\ [2 MINUTES]}

Ask participants to summarize what they have learned. Fill in any key points they miss.

Key Message: Some gender norms and attitudes are harmful and lead to unfair or unequal treatment of girls and women, but gender roles can be challenged and changed!

\section{Action item: 3 minutes*}

Explain: Before the next session, I want each of you to interview a grandmother - or another female from that generation - to learn about how gender roles and norms may have changed (or not changed). Ask the person what male and female roles were like during their adolescence and youth. Find out what things like schooling, household chores, being a parent, having fun with friends, and/ or employment were like for them. Listen carefully and politely! You don't have to cover all those topics - though you can - just a couple is enough. Then think about how that experience - school, chores, work, friends, parenting - is for you and other girls and young women today. Pick one of the topics and be prepared to share how things used to be compared to how things are now. How have gender roles changed, if at all?

Ask for any final questions or comments.

Remind participants where and when the next meeting will take place, and what topics will be discussed.

Thank them for their wonderful participation!

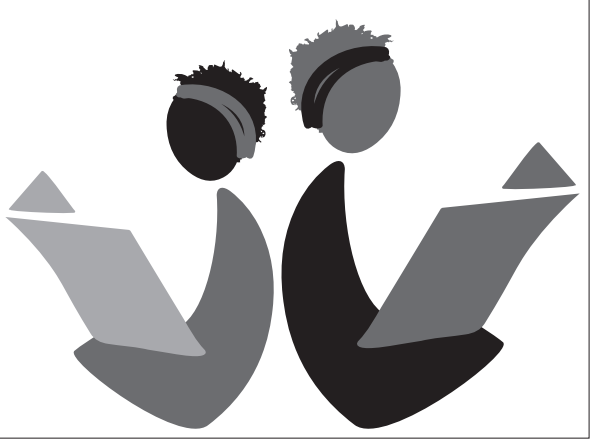

Source: International Sexuality and HIV Curriculum Working Group. 2009, updated 2011. It's All One Curriculum: Guidelines and Activities for a Unified Approach to Sexuality, Gender, HIV and Human Rights Education. New York: Population Council. Activities: Page 50. 


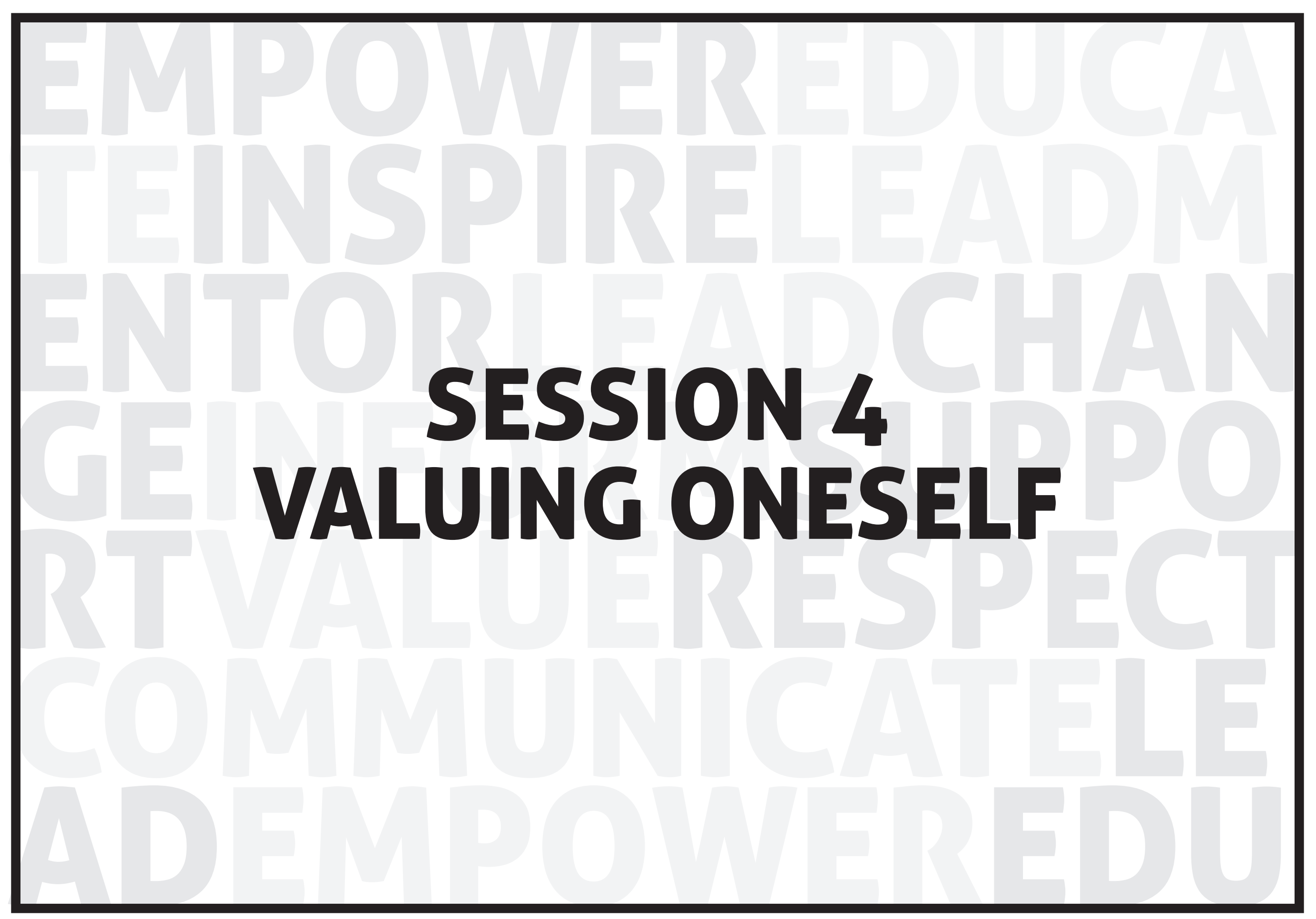




\section{session 4 / valuing oneself}

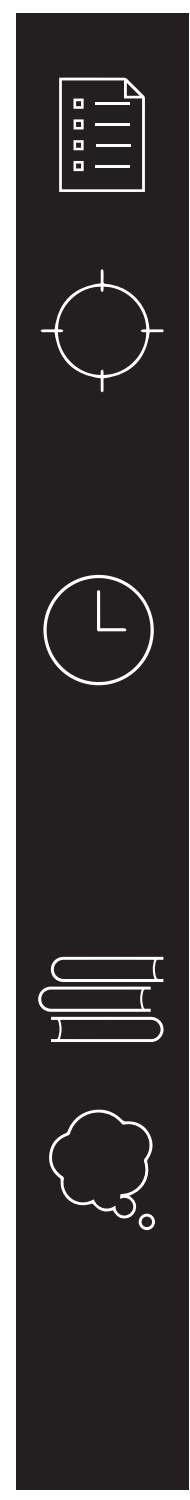

SESSION DESCRIPTION

Participants think about their positive qualities, what they value, and build self-esteem.

\section{OBJECTIVES}

By the end of the session, participants will:

Remember what inspires them or makes them happy

- Reflect on how they construct their identities and life plans and the importance of having a positive sense of self

Reflect on what is most important to them

\section{SESSION TIME}

1 hour

Action item debrief: 5 minutes

Warm-up: What we value, 5 minutes

Activity 1: Poetry reading, 20 minutes

Activity 2: Who am I? 20 minutes

Wrap-up: 5 minutes

Action item: 5 minutes

REQUIRED MATERIALS

Chalkboard and chalk

\section{PRE-SESSION PREPARATION}

Read through the entire session and practice presenting the activities Prepare all materials needed.

Write the values and priorities listed in Activity 2 on the board before Session 4 begins

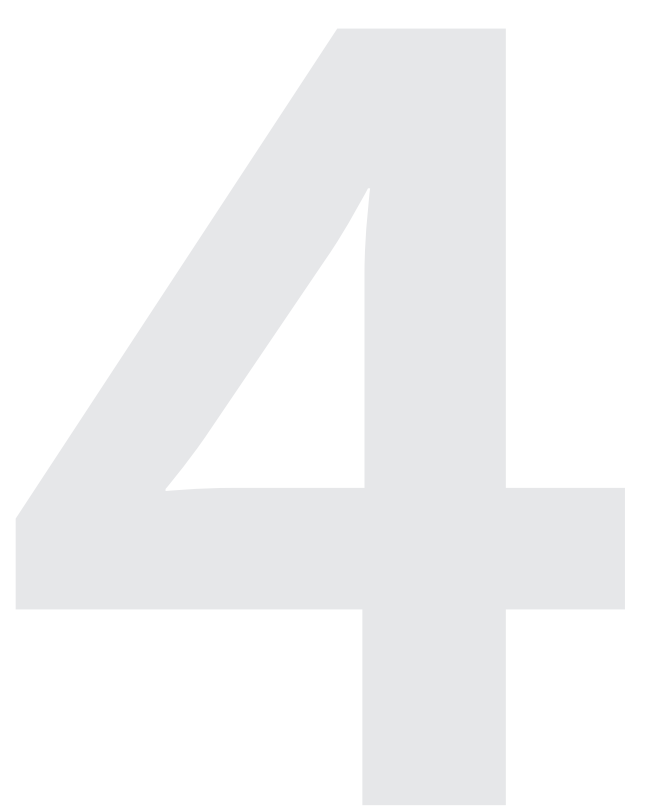




\section{session 4 / valuing oneself (cont.)}

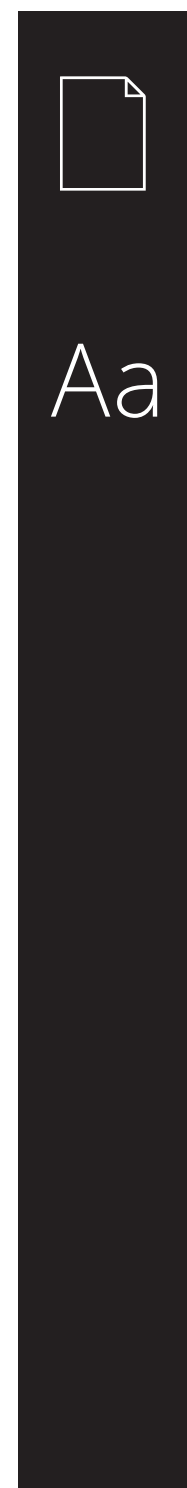

FACILITATOR NOTES

The lessons you impart in this session are easy to reinforce throughout the curriculum. Remember to compliment the participants, encourage them, never denigrate or embarrass them. You are their mentor and

champion.

\section{TERMS}

Phenomenal: remarkable, extraordinary, amazing. 


\section{warm-up}

\section{ACTION ITEM DEBRIEF [5 MINUTES]}

1. Tell participants: I want to hear how your interviews went from your action item at the end of Session 3! Who wants to share what they learned about girls and schooling in our grandparents generation? Have things changed? How? [Get a few responses.]

\section{WHAT WE VALUE}

[5 MINUTES]

1. Explain: We are going to do a short reflection to start today. I want you to close your eyes and relax, and to think about your home, your family, or your community. Think about a memory or an experience that makes you happy. Perhaps it is a holiday you love to celebrate, a favorite photograph, a meal you cook together, or a favorite relative who comes to visit. What makes you smile? Give participants a minute to think.
2. How about having fun with friends? Who can tell me what it used to be like compared to now? [Get a few responses.]

3. If there is time, ask about work or parental roles.

2. Ask participants to open their eyes. Ask if anyone wants to share what they were thinking of. Do not pressure them to respond, if no one wants to share, that is okay.

3. Ask participants why it is important to remember what inspires us and makes us happy.

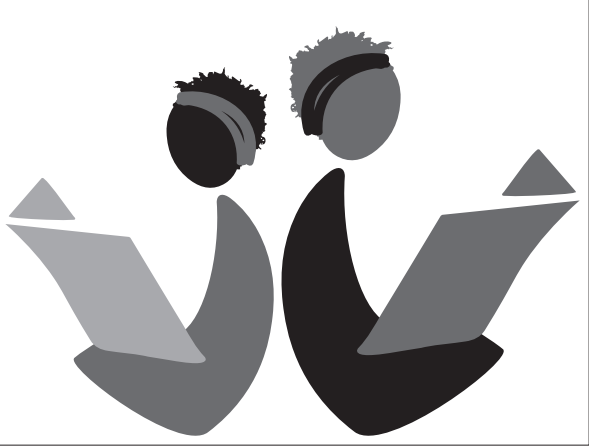




\section{activity 1}

\section{POETRY READING* [20 MINUTES]}

1. Tell participants that you are going to read an empowering poem together. The poem is by Maya Angelou and is called "Phenomenal Woman."

2. Ask if anyone knows what "phenomenal" means. Take a couple of responses and if no one answers correctly, share the definition. (Phenomenal means remarkable, extraordinary, amazing.)

3. Explain: We are all phenomenal girls and women, and it's important to remind you of how phenomenal you are. I'm going to read the poem to you once, and then we'll read it together.

4. Write the repeating verse: "I'm a woman, phenomenally. Phenomenal woman, that's me." on the board.

5. Read the poem aloud - be dramatic and put your energy into it. Each time you get to the repeating verse, point to what you wrote on the board.

Poem on following page

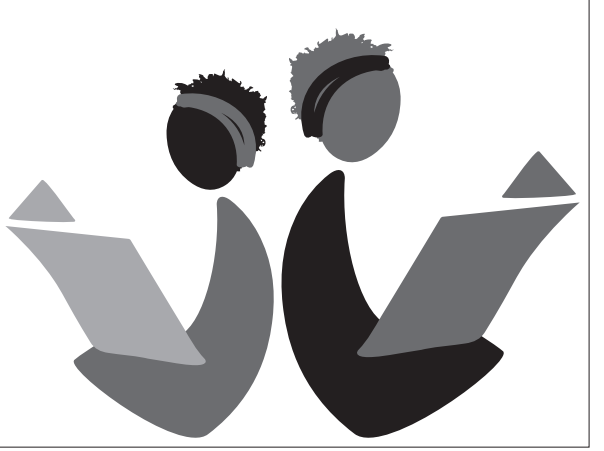




\section{activity 1 (cont.)}

Phenomenal Woman

by Maya Angelou

Pretty women wonder where my secret lies. I'm not cute or built to suit a fashion model's size

But when I start to tell them,

They think I'm telling lies.

I say.

It's in the reach of my arms,

The span of my hips,

The stride of my step,

The curl of my lips.

I'm a woman

Phenomenally.

Phenomenal woman

That's me.

walk into a room

Just as cool as you please,

And to a man,

The fellows stand or

Fall down on their knees.

Then they swarm around me,

A hive of honey bees.

I say,

It's the fire in my eyes,

And the flash of my teeth

The swing in my waist,

And the joy in my feet.

I'm a woman

Phenomenally.

Phenomenal woman

That's me.
Men themselves have wondered What they see in me.

They try so much

But they can't touch

My inner mystery.

When I try to show them,

They say they still can't see.

I say,

It's in the arch of my back

The sun of my smile,

The ride of my breasts,

The grace of my style.

I'm a woman

Phenomenally.

Phenomenal woman

\section{That's me.}

Now you understand

Just why my head's not bowed.

I don't shout or jump about

Or have to talk real loud.

When you see me passing,

It ought to make you proud.

I say,

It's in the click of my heels,

The bend of my hair,

the palm of my hand,

The need for my care.

'Cause I'm a woman

Phenomenally.

Phenomenal woman,

That's me.
6. Explain: Now I'm going to read the poem again. If anyone wants to come up here and read with me, you are welcome to. When I point to the verse on the board everyone say it out loud together

7. Read the poem again, pointing to the board each time you get to the repeating verse. The group recites those lines all together.

8. Lead a discussion using the following prompts:

What does the poem mean to you?

How does the poet talk about what makes us phenomenal?

9. Building on the participants' responses, point out that the qualities that make us phenomenal come from inside and how we feel about ourselves. Remind participants that they are strong and beautiful and deserve to be treated with respect. They are phenomenal. 


\section{activity 2}

\section{WHO AM I?* \\ [20 MINUTES]}

1. Before the beginning of the session, write the following values and priorities on

the chalk board. You may change or add

values, based on your situation.

- Making friends

- Being popular

- Studying hard

Making my family proud

- Having fun

- Getting good marks

- Being smart

- Having good discipline

- Being good at sports

- Being good at music and drama

- Being good at reading

Being honest

- Being responsible

- Being a good friend

Helping others

- Making money

- Taking care of my family

- Being healthy

- Being kind

- Being creative

- Having a boyfriend

- Being respected

- Feeling loved

- Learning about my country

- Culture
- Religion

Sleeping and resting

- Learning new things

- Making my country a better place

Caring for my siblings

2. Read the values and priorities aloud with the participants.

3. Ask participants to choose the ten values that they feel are the most important to them. Have them write those ten in their notebooks.

4. Next, ask them to read those ten and narrow it down to five values. Have them cross out the five they eliminated.

5. Then, ask them to read those five and narrow it down to three values. Have them cross out the two they eliminated.

6. Ask: Was it difficult to narrow down the choices? Are you surprised about the three you ended up with? Is it a true reflection of who you are?

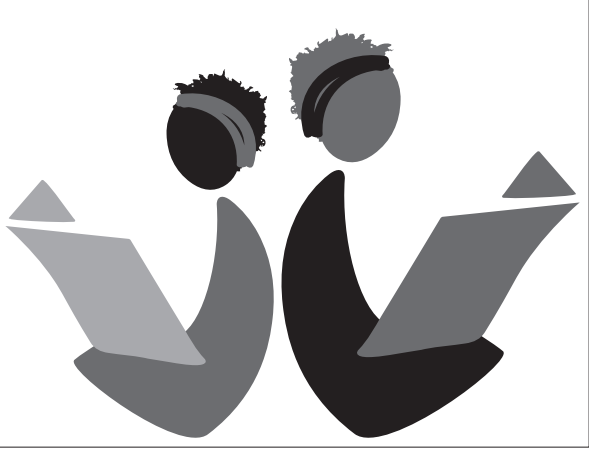




\section{wrap-up}

\section{WRAP-UP* \\ [5 MINUTES]}

Ask participants to summarize what they have learned. Fill in any key points they miss.

Key Message: We should recognize and value our dreams and hopes throughout our life, and at the same time form bonds with other women who support our growth. We should try to recognize both our strengths and weaknesses and always try to learn from them. Knowing who you are and what you want can be a lifelong process. There is no set course, and there is no prescribed path, for who you will be in the future.

\section{Action item: 5 minutes}

After reviewing what the group covered remind participants that they also read poem about the importance of inner strength and confidence. Ask participants to write their own poem that tells their story and reflects on some of the topics discussed today. It can be a poem about who they are, about what makes them feel strong or what makes them happy, or about bonds and support they share with other girls or women. Tell them that the poem does not have to rhyme, it does not have to be long, and that they will have a chance at the next meeting to read their poem to the group or perform their poem as spoken word.

\section{Ask for any final questions or comments.}

Thank them for their phenomenal

participation. Remind participants where and when the next meeting will take place, and what topics will be discussed.

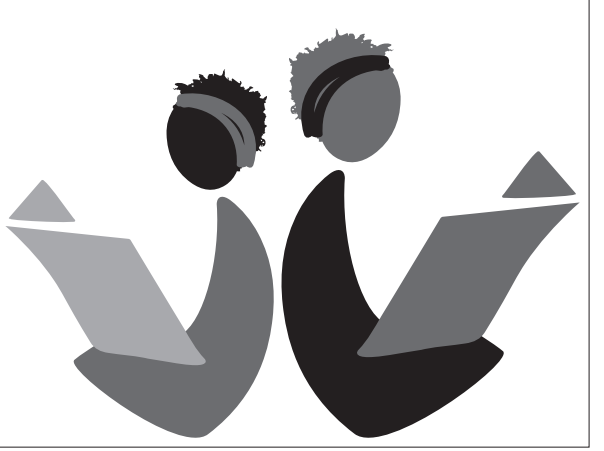

* Source: Promundo, Salud y Género, ECOS, Instituto PAPAI and World Education 2006.

Program M: Working with Young Women: Empowerment, Rights and Health. Pages 27-38. 


\section{SESSION 5 RIGHTS AND RESPONSIBILITIES}




\section{session 5 / rights and responsibilities}

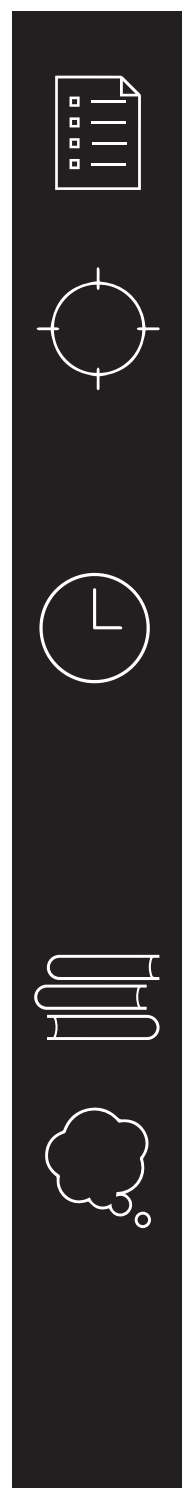

SESSION DESCRIPTION

Introduce the concept of human rights and the strong link between

rights and personal responsibility.

\section{OBJECTIVES}

By the end of the session, participants will:

Describe the concept of human rights and be able to name several

basic human rights

- Appreciate the relationship between rights and responsibilities

- Analyze who is responsible for upholding human rights

\section{SESSION TIME}

1 hour

Action item debrief: 5 minutes

Warm-up: The voice in your head, 5 minutes

Activity 1: Introduction to human rights, 25 minutes

Activity 2: Rights and responsibilities, 15 minutes

Wrap-up: 5 minutes

Action item: 5 minutes

REQUIRED MATERIALS

Chalkboard and chalk

\section{PRE-SESSION PREPARATION}

Read through the entire session and practice presenting the activities.

Prepare all materials needed.

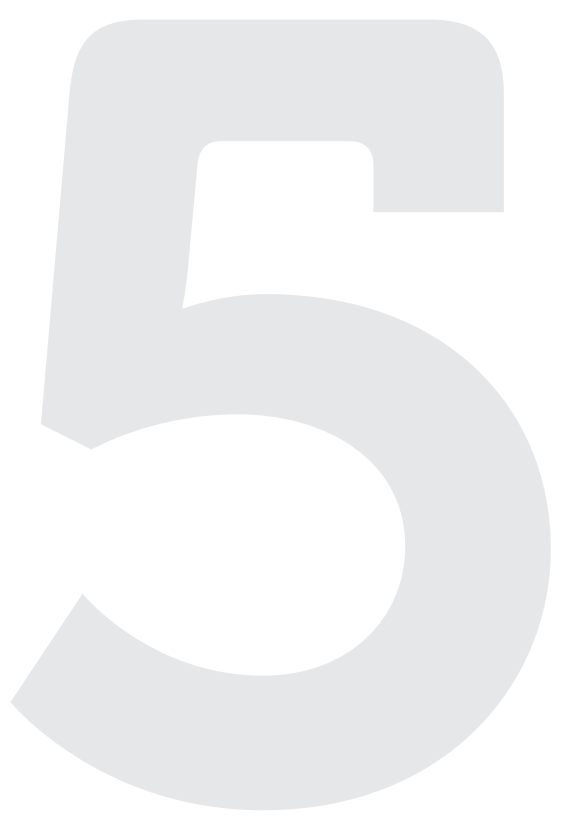




\section{session 5 / rights and responsibilities (cont.)}

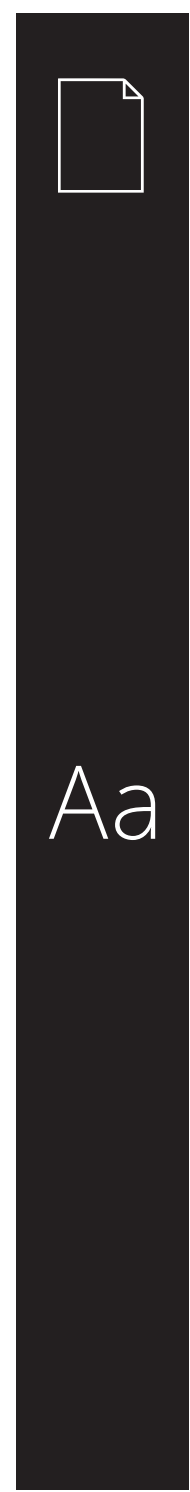

\section{FACILITATOR NOTES*}

To enjoy safe and healthy lives, young people must be able to exercise their basic human rights. For example, everyone has a right to dignity, bodily safety, and access to health information and services. Only when people can exercise these rights can they really choose whether or not to have sex, negotiate condom and contraceptive use, and seek the services they need. Promoting human rights also encourages young people to take responsibility for protecting the well-being and rights of others. Unfortunately, hundreds of millions of people, especially young people, still remain vulnerable to such abuses as forced sex (often increasing their risk of acquiring HIV or becoming pregnant), violence, child marriage, and stigma related to their sexual behavior. When

people's rights are violated, their capacity for safe and satisfying sexuality is undermined for their whole lifetime. Knowing about human rights allows young people to gain a sense that they matter in the world.

\section{TERMS}

Discrimination: When a person is treated less favorably than another person in a similar situation because of a particular personal characteristic such as their age, sex, race nationality, or beliefs.

Equality: The quality of being equal. Equality is an important value in human rights and is the central idea behind universal human rights - i.e. every single person has these rights.

Freedom: The power or right to act, speak, or think as one wants. Or, the state of being free rather than in confinement or under physical restraint.
Human rights: The fundamental freedoms that every person in the world is entitled to just because they are human. Nobody can take away these rights, and you have them forever

Right: A right is a moral or legal entitlement to have or do something.

United Nations: An international organization that was founded in 1945 by the governments of the world with the aim of promoting global peace, security, and human rights.

Universal Declaration of Human Rights: The key United Nations document establishing the standards of basic human rights for everyone.
The Universal Declaration of Human Rights was adopted by the United Nations General Assembly on December 10, 1948

*Source: International Sexuality and HIV Curriculum Working Group. 2009, updated 2011. It's All One Curriculum: Guidelines and Activities for a Unified Approach to Sexuality, Gender, HIV and Human Rights Education. New York: Population Council. Guidelines: Page 18. 


\section{warm-up}

\section{ACTION ITEM DEBRIEF [5 MINUTES]}

1. Ask: How did the poems come out from your action item at the end of Session 4? I can't wait to hear what you wrote! Who would like to read their poem or perform their poem as spoken word?

\section{THE VOICE IN YOUR HEAD*}

\section{[5 MINUTES]}

1. Explain: All of us have a voice inside that tells us things about ourselves. Sometimes that voice tells us that we are not good enough, pretty enough, smart enough, that our parents don't believe in us, or our friends don't accept us. That voice can be our greatest friend or our greatest enemy.

2. Ask: How many of you have this voice inside your head?

3. Explain: You can all make this voice your friend through recognizing it and thinking positively. For example, if your voice is telling you "I am not clever," change the statement around and add an affirmation "I am not stupid. I am good at xyz.
[If more than a few girls want to read their poems, offer to stay a little later today to

listen.]

4. Ask: Close your eyes and think of a negative thought you often have about yourself (such as I am stupid, I am ugly, I am slow, I am not liked by my classmates, etc.).

5. After 1 minute, ask participants to open their eyes. Have them pretend to write down the negative thought on an imaginary piece of paper. Then have everyone stand up in a circle with their imaginary piece of paper and destroy it, rip it up into a bunch of pieces, crumple it in a ball, stomp on it - do whatever they want to get rid of it
6. Ask participants to think of a positive thought that they will remember if the negative one returns. Remind them that next time they catch themselves having negative thoughts, remember and repeat the positive one instead. 


\section{activity 1}

\section{INTRODUCTION TO HUMAN RIGHTS* [25 MINUTES]}

1. Explain: I am going to read out a few statements, and I want you to decide if they are true or false. Please all stand in a straigh line facing me with your arms at your side. After I read a statement, if you think it is

true I want you to jump up with your hands to the sky. If you think it is false (not true), I want you to crouch down with your hands on the floor. Try to decide your answer on your own without worrying about what others in the group have decided. After we discuss each statement, I want you to stand up with your arms by your sides as you wait for the next statement. Okay, let's start.

2. Say:

- "A right is a moral or legal entitlement to have or do something." [TRUE.]

"Human rights are universal, meaning they apply to everyone."

ITRUE. Human rights apply to all of us, regardless of our sex, age, marital status, race, ethnicity, political beliefs, religious beliefs, social or economic status, physical and mental ability, or health status. Human rights are not conditional.]
- "A person can have their human rights taken away if they don't deserve them." [FALSE. Your human rights cannot be taken away from you. Everyone has the right to be treated fairly and equally. However, unfortunately abuses and violations of human rights do occur.]

"There are responsibilities that go with every right."

[TRUE. Human rights involve responsibility toward other people and the wider community. Individuals have a responsibility to be sure that they use their rights, while also thinking about the rights of others.]

3. Explain: There is a list of 30 basic rights and protections for every single human being in the world called the Universal Declaration of Human Rights, agreed upon by the global community of states through the United Nations. They are things we need in order to thrive and participate fully in society; they can be rights to have something positive, as well as rights to be free from something negative. These rights include, but are not limited to:
Equal treatment under the law

Food, water, shelter, and clothing

Being treated with respect and dignity

- Freedom from torture

- Freedom of expression

Freedom of thought, conscience, and religion

The right to assemble and to participate in society

The right to education

The right to health, including access to health information and services

Continued on next page

*Sources: Australian Human Rights Commission. 2016. Introduction to Human Rights and Responsibilities; International Sexuality and HIV Curriculum Working Group. 2009, updated 2011. It's All One Curriculum: Guidelines and Activities for a Unified Approach to Sexuality, Gender, HIV and Human Rights Education. New York: Population Council. Activities: Pages 22-25; Guidelines: Pages 23-26. 


\section{activity 1 (cont.)}

[The Universal Declaration of Human Rights in simple language is listed in the appendix at the back of this training manual on pages 214-215. If any participants would like to see the full list of rights, you can invite them to look at it after the session concludes.]

Explain: Although all of us should be able to enjoy our human rights, we cannot always do so. Sometimes countries do not fulfill or protect our rights. For example, they might outlaw political protest, or punish people for speaking their views. Or a government may not protect all individuals' ability to enjoy

their rights. For example, they may not ensure that all people - regardless of class, sex, ethnicity, or sexual identity - have the same opportunity to obtain an education or job, or to take part in a country's political affairs. Or they may treat lightly the murder of a woman or girl by her male partner. 


\section{activity 2}

\section{RIGHTS AND RESPONSIBILITIES* [15 MINUTES]}

1. Explain: As we discussed in activity 1 , individuals have a responsibility to be sure that they use their rights as well as thinking about the rights of others. We are going to explore this idea further by looking at some essential rights and considering the responsibilities that come with those rights. I will read out a right, then I want volunteers to make suggestions of responsibilities that could go with that right. Let's get started:

Right: I have a right to feel safe. [Possible answer: I have a responsibility to behave in a way that will keep myself and others safe.]

Right: I have a right to speak freely and express my ideas and opinions.

[Possible answer: I have a responsibility to be respectful of other people's ideas and opinions even if they are different than mine. Another way to phrase it: I have a responsibility not to say things that deliberately hurt the feelings of others, for example talking about someone else's secrets or private business or calling someone hurtful names.]
Right: I have the right to be treated the same as everyone else, no matter my age, sex, race, nationality, beliefs, or other personal characteristics.

IPossible answer: I have a responsibility

to treat others equally, without

discrimination. Discrimination is when a person is treated less favorably than another person in a similar situation

because of a particular personal

characteristic such as their age, sex, race nationality, or beliefs.]

Right: I have the right to believe in a particular religion or belief, or in no religion at all.

[Possible answer: I have the responsibility to respect the different religions and beliefs of other people and the ways they choose to practice their beliefs.]

2. Ask: What might happen to your rights if no one acted on the responsibilities we have just discussed?

[Probe for: Your rights would not be upheld or recognized. Your rights would be more likely to be violated.]
3. Ask:

- Is it fair that not everyone can enjoy the same rights and opportunities?

Should everyone be safe? Is everyone safe? Who is not always safe?

What are some things that need to be changed to make sure that everyone in our community is safe?

4. Explain: Every single person has a responsibility to respect the rights of every other person.

*Sources: Australian Human Rights Commission. 2016. Introduction to Human Rights and Responsibilities; International Sexuality and HIV Curriculum Working Group. 2009, updated 2011. It's All One Curriculum: Guidelines and Activities for a Unified Approach to Sexuality, Gender, HIV and Human Rights Education. New York: Population Council. Guidelines: Page 26 


\section{wrap-up}

\section{WRAP-UP \\ [5 MINUTES]}

Ask participants to summarize what they have learned. Fill in any key points they miss.

Key Message: Every person is entitled to basic human rights. Every person has the responsibility

to respect the rights of every other person.

\section{Action item: 5 minutes}

Ask: Remember in Session 3, we talked about gender norms and stereotypes? Can someone give me a stereotype about girls or an example of what people think that girls should say, feel, or do?

Explain: Over the coming week, keep your eyes open for the gender norm messages that surround us. Try to critically observe what you hear and see: everyday examples of media ( $T V$, radio, newspaper), advertising, music, etc. that depict women in stereotypical ways, or show men dominating women. For example the Boom washing powder commercials that always show women doing the laundry, such as "Boom. Mum knows best." Or the songs "Dorika" and "Mwanakazi Nikumbuyo" that portray women as sex objects.
Pick one or two examples to bring in and share next week. You can bring a newspaper clipping, write down a song lyric or something said on the radio, take a picture or make a quick sketch of a billboard (or some other media). Bring it in so we can discuss it at the next session.

Ask for any final questions or comments.

Remind participants where and when the next meeting will take place, and what topics will be discussed.

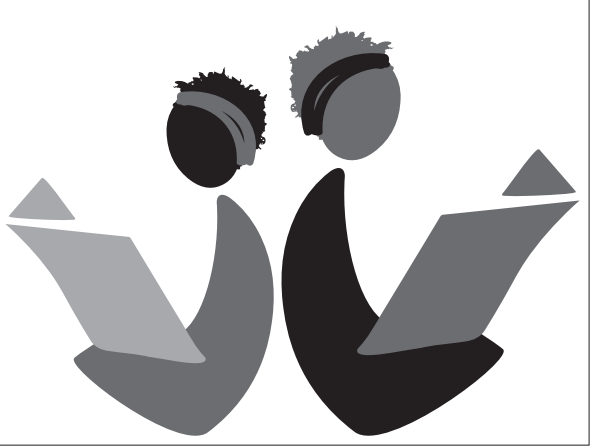




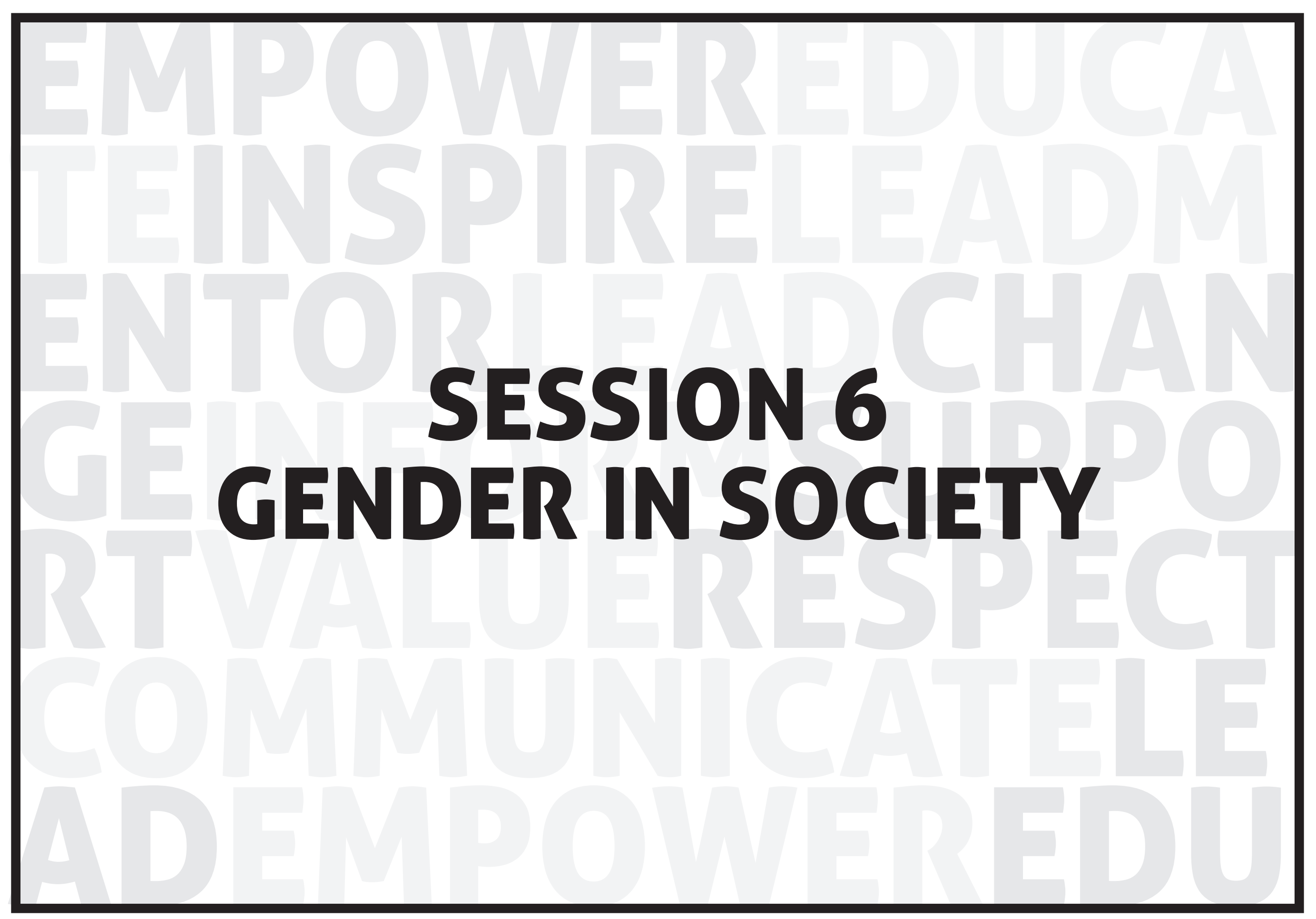




\section{session 6 / gender in society}

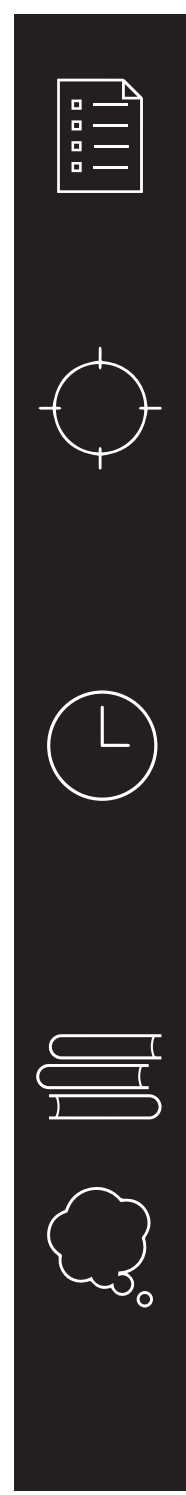

\section{SESSION DESCRIPTION}

Participants explore cultural perceptions of the "ideal" woman and "ideal" man, and they consider how these stereotyped images may put pressure on people to live up to unrealistic or unwanted roles and expectations.

\section{OBJECTIVES}

By the end of the session, participants will:

- Learn that sharing power is an effective way to accomplish a task

- List the "ideal images" the society has for those of their own age and gender

- Identify the ways in which those stereotypes can be limiting or used

to pressure a person into behaving a certain way

\section{SESSION TIME}

1 hour

Warm-up: I've got your back, 10 minutes

Action item debrief: 5 minutes

Activity 1: Gender and culture: ideal images in society, 35 minutes

Wrap-up: 5 minutes

Action item: 5 minutes

\section{REQUIRED MATERIALS}

Chalkboard and chalk

\section{PRE-SESSION PREPARATION}

Read through the entire session and practice presenting the activities. Prepare all materials needed.

In the preceding session, ask participants to bring some examples of advertisements, songs, media images, short stories, or proverbs that pertain to the issue of gender roles (the action item from Session 5). 


\section{session 6 / gender in society (cont.)}

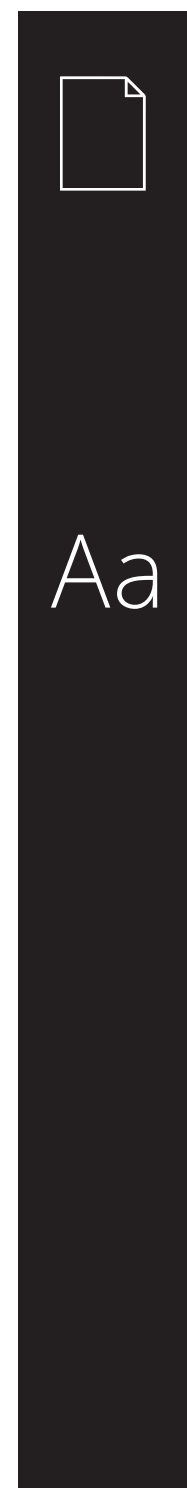

\section{FACILITATOR NOTES*}

Gender norms affect everyone's well-being, including sexual health and risk of HIV. Most countries have identified the achievement of gender equality as a moral imperative and as key to fighting AIDS and to strengthening families and societies. Around the world, gender

norms and roles are changing rapidly.

Emphasize that boys, as well as girls, can benefit from less rigid gender norms and arrangements.

\section{TERMS}

Stereotype: Widely held generalizations and assumptions about a particular type of person or thing. For example, the stereotype of the woman as caregiver, or the stereotype of the city as polluted. 


\section{warm-up}

\section{I'VE GOT YOUR BACK* [10 MINUTES]}

1. Divide participants into pairs and have them decide who is person $A$ and who is person B. Ask each pair to sit down on the ground back-to-back (so they are leaning against each other's backs).

2. Have them try to stand up without using their hands, always maintaining contact between their backs. Is everyone able to stand up? (It should be somewhat easy.)

\section{ACTION ITEM DEBRIEF \\ [5 MINUTES]}

1. Say: Last week your action item was to bring in an advertisement or a song or some other media message from TV, radio, or the newspaper that reinforces gender stereotypes. Let's see the gender norm messages you found!

2. Have everyone share their example and say a sentence or two about how and why their image or lyrics reinforce(s) gender stereotypes.
3. Now, have the pairs try again. This time, instruct person A to stop using pressure at any time without warning. What happens? For the last try, have person A put too much pressure. What happens?

4. Compare this exercise to our daily lives by asking the following questions:

3. After everyone has shared their example, ask:

What are these messages telling girls? - What are they telling boys?
What happens when we put too much pressure on a situation?

- What happens when we don't use any pressure?

What happens when two people share power and create balance?

[Answer: When two people share power and create balance, it is easier to get things accomplished!] 


\section{activity 1}

\section{GENDER AND CULTURE: IDEAL IMAGES IN SOCIETY AND MEDIA* [35 MINUTES]}

1. Explain: Today we are going to explore the topic of gender norms some more.

2. Ask: Could someone remind me what gender norms mean? [Gender norms are ideas about how women and men should be and act.]

3. Explain: Think about the examples of media, advertising, and music that you shared earlier in the action item debrief. Do you see any links between these images and what men and women are expected to be in this culture?

4. After a short discussion, ask participants to break into small groups and to focus on the ideal image in our society and in media for their own age and gender - so adolescent girls. In small groups, ask them to discuss this question:

- Describe what a young woman is expected to say and do, or not say and not do in our culture.
5. After about 10 minutes of small group discussion, ask the participants to come together and share with the whole group their ideas about what stereotypes and expectations society has for young women.

6. Ask:

How easy do you find it to live up to the expectations that our society has for you? Are there contradictions? That is, do some expectations of young women conflict

with other expectations of young women?

What are your real experiences as you try

to live up to society's expectations for you?

- How does that make you feel?

What do you think we can do to challenge gender stereotypes in our society? 


\section{wrap-up}

\section{WRAP-UP \\ [5 MINUTES]}

Ask participants to summarize what they have learned. Fill in any key points they miss.

Key Message: Gender norms and stereotypes are all around us. They can be harmful, they can reduce girls' and women's opportunities, and they can undermine girls' and women's rights. We can help create new norms by challenging these stereotypes and biases in

ways big and small.

\section{Action item: 5 minutes}

Explain: This week I want each of you to find a small way to do something that challenges gender stereotypes. Play football with your brother or cousins, or when talking with a friend at school who isn't in GirlsRead!, and you hear lyrics, or see an advertisement or show that reflects stereotypes, point out some of the things we discussed today. Every time we do this, we make the inequality visible and we take a leadership role in challenging harmful stereotypes.
Ask for any final questions or comments.

Remind participants where and when the next meeting will take place, and what topics will

be discussed. 


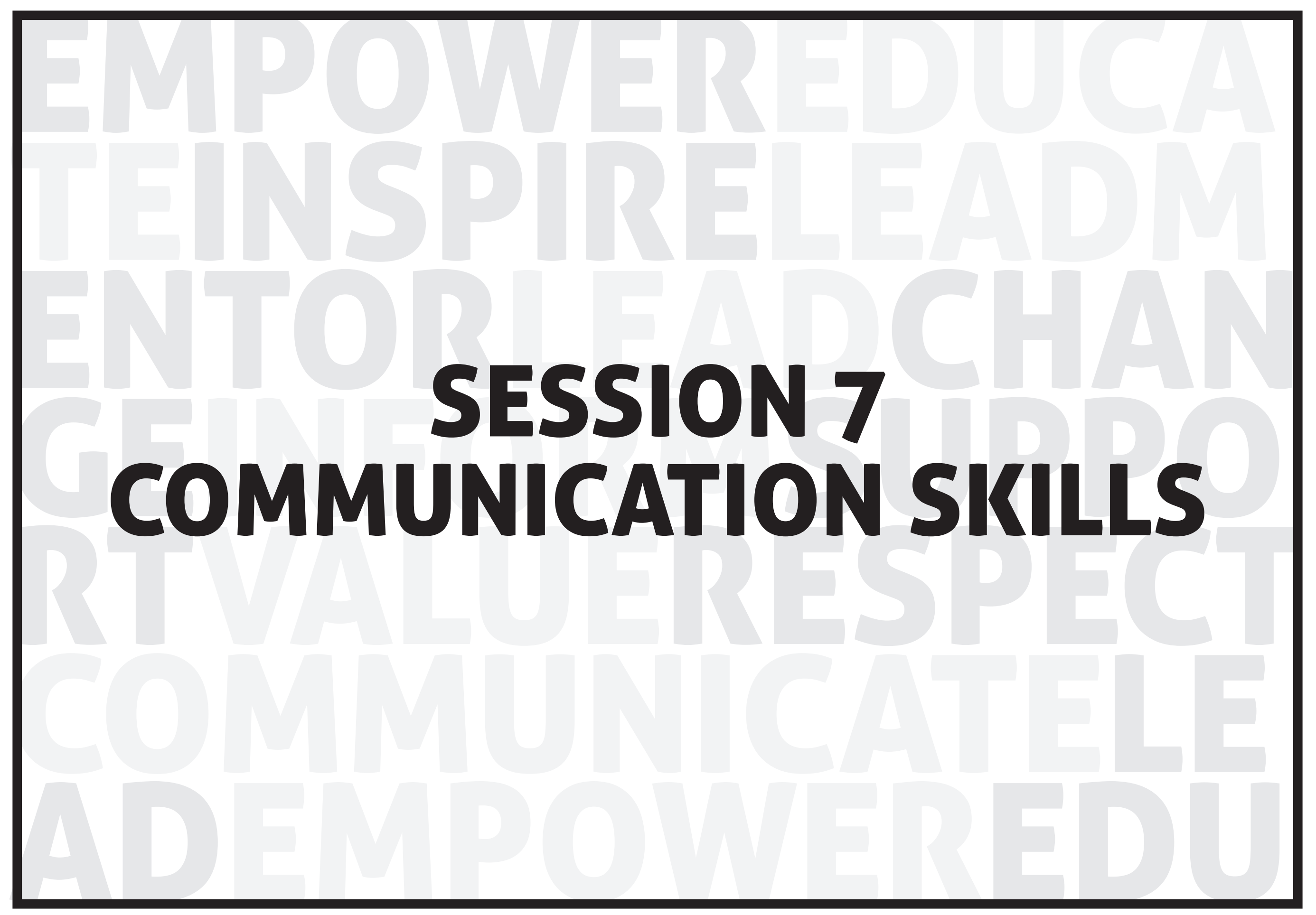




\section{session 7 / communication skills}

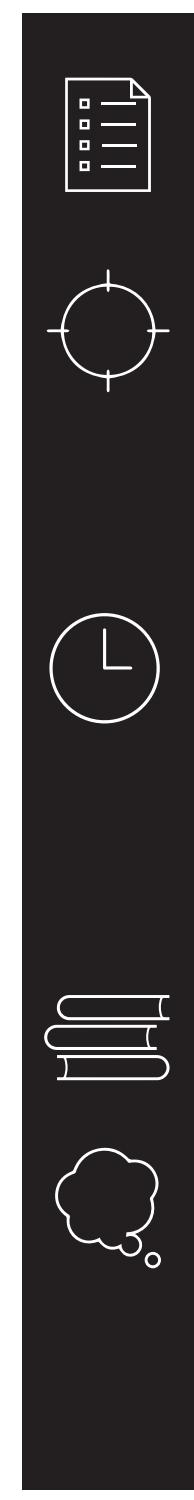

SESSION DESCRIPTION

Learn about and practice behaviors that enhance communication.

OBJECTIVES

By the end of the session, participants will:

Learn that what one person says and the other person hears are

sometimes different

- Understand the need to be very clear in what one says

- Increase their ability to formulate assertive responses

Be able to adopt behaviors that enhance communication

\section{SESSION TIME}

1 hour

Action item debrief: 10 minutes

Warm-up: The listening line, 5 minutes

Activity 1: Practicing assertive communication, 15 minutes

Activity 2: Active listening, 22 minutes

Wrap-up: 5 minutes

Action item: 3 minutes

\section{REQUIRED MATERIALS}

Chalkboard and chalk

\section{PRE-SESSION PREPARATION}

Read through the entire session and practice presenting the activities.

Prepare all materials needed. 


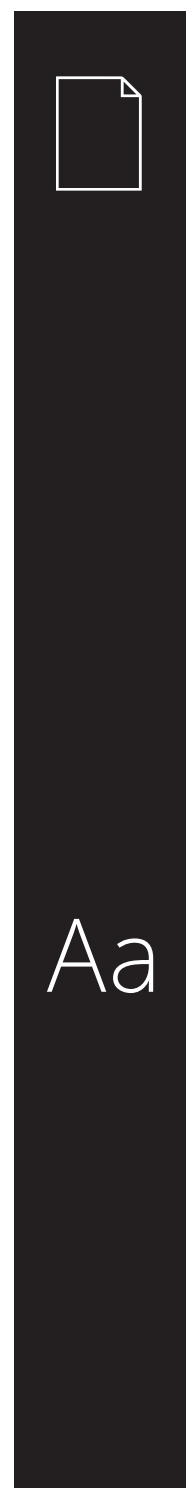

\section{FACILITATOR NOTES*}

Communication is the process of sending and receiving information or thoughts through words, actions, or signs.

Assertive communication is direct and firm. It delivers a clear message by honestly expressing one's thoughts and feelings without being aggressive or putting down others. Using "I statements" that express one's feelings or thoughts is one way to communicate assertively.

Communicating passively is when a person goes along with what is happening without taking initiative to make a change. It means not expressing one's own needs and feelings, or expressing them so weakly that they will not be heard.
Aggressive communication is when a person asks for what they want or say how they feel in a threatening, sarcastic, or humiliating way that may offend the other person(s). It is disrespectful of other people's feelings and thoughts.

Non-verbal communication or body language gives meaning to what is said and includes tone of voice, facial expressions (smiling, frowning, etc.), eye contact, body position (sitting, standing, pacing, leaning forward or backward), touch, and actions. Body language - just like verbal communication - can convey assertiveness (e.g. making eye contact), passiveness (e.g. avoid finishing sentences or making eye contact), or aggressiveness.
Listening well and with respect is essential for good communication. Active and nonjudgmental listening includes making eye contact, validating the other person's ideas or feelings, showing interest in hearing more, as well as non-verbal cues such as a smile or pat on the back. Unfortunately, many times the listener is busy thinking about what they are going to say and does not pay close attention to what the speaker is saying. This can cause misunderstanding and confusion. It is important to listen closely to everything that is said without interrupting the person who is speaking.

As a mentor, modeling good communication skills such as active listening and non-

judgmental responses is critical. With practice everyone can communicate more effectively.

\section{TERMS}

Communication: Process of sending and receiving information or thoughts, or expressing ideas, desires, or feelings, through

Verbal communication: The use of language words, actions, or signs.

\section{Effective communication: Communication}

that is clear and direct, avoids

misunderstandings and improves

relationships.

Non-verbal communication: Facial expressions,

eye movements and contact, body position,

touch, and actions that transmit meaning.

*Source: International Sexuality and HIV Curriculum Working Group. 2009, updated 2011. It's All One Curriculum: Guidelines and Activities for a Unified Approach to Sexuality, Gender, HIV and Human Rights Education. New York: Population Council. Activities: Pages 144-148; Population Council. 2013. Life Skills and Health Curriculum for the Adolescent Girls Empowerment Program (AGEP). Page 131. 


\section{warm-up}

\section{ACTION ITEM DEBRIEF [10 MINUTES]}

Remind participants: Last week your action item was to do a small thing that challenges gender stereotypes. Tell me how it went - I am excited to hear!

\section{THE LISTENING LINE* [5 MINUTES]}

1. Think of a message to whisper. It should be something fairly easy to misinterpret. For example, "Tuesday's maths test will be postponed until the province provides proper pencils." Or "A bunch of bananas bounced off the bus and was swiftly seized by several monkeys."

2. Divide participants into two teams and have them stand in two lines on different sides of the room

3. Explain: I am going to whisper the same message to the first person in each line. That person has to listen carefully and then repeat the sentence - only once - to the next person in a whisper without letting anyone else hear it. Then the second person whispers what they heard to the third person, and so on until you get to the end of the line. Remember, the message can be given to the next person only once. When the message gets to the end of the line, the last person tells the group what message she heard. Whoever gets closest to the original statement, wins.

4. Have a discussion about how people hear things differently. Ask:

What does this mean? What does this game show us?

[lf no one mentions rumors, ask

participants what they think this shows about rumors.]
How can we be sure people understand what we are trying to say?

How can we help prevent

misunderstandings?

[Possible answers include: Not repeating information that we are not sure is true or that was passed along by multiple sources: Keeping our comments and discussions

about others positive.]

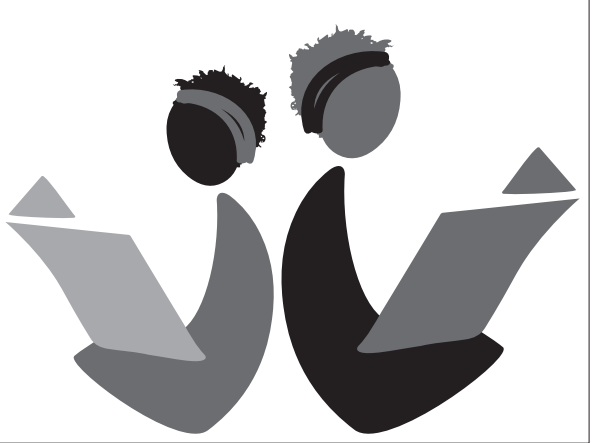




\section{activity 1}

\section{PRACTICING ASSERTIVE COMMUNICATION* [15 MINUTES]}

1. Explain: Today we are going to practice good communication skills. Sometimes it is difficult to say clearly what you want (for example that you want to be considered for a leadership position at school). It may also be difficult to say what you do not want (for example that you do not want to eat what someone prepared for you).

2. Ask: Who can remember a time when you were unsure how to express your desires or wishes clearly?

3. Note: Speaking up can be difficult even when the situation really matters to us, or when real physical or emotional consequences might be an issue. Practicing respectful, but assertive, communication is helpful. The more we practice, the more natural it becomes, even under pressure.

4. Ask: What do we mean by "assertive" communication?

[Probe for: being honest; being direct; speaking about your feelings and needs; using assertive body language; speaking for yourself; communicating clearly but without aggressiveness.]
5. Explain: I will read a series of questions or statements that are "prompts." For each one, think of a response that is assertive but not aggressive. I will ask for volunteers to share their responses.

We'll do the first prompt together. The prompt is: "Tell me why I should vote for you for class prefect."

6. Who can share an assertive way to say this?

[Help participants arrive at an appropriate response, such as: "I believe I am the most qualified candidate for class prefect. I hope I can count on your support." Be sure that the responses are complete sentences.]

7. Repeat the process for each prompt, providing the sample response only after the girls share their answers verbally (unless they are having trouble and ask for clarification or an example).

Prompt: "Will you let me copy your test? The teacher won't know."

Sample Response: "Sorry. I do not believe in sharing test answers."
Prompt: "Tell your father you wish to continue in school next year, despite his wishes."

Sample Response: "Father, I respect your views, but it is extremely important to me to continue my schooling. I want to discuss my reasons with you."

\section{Continued on next page}

*Source: International Sexuality and HIV Curriculum Working Group. 2009, updated 2011. It's All One Curriculum: Guidelines and Activities for a Unified Approach to Sexuality, Gender, HIV and Human Rights Education. New York: Population Council. Activities: Pages 113-114. 


\section{activity 1 (cont.)}

Prompt: "Why don't you like sports like everyone else does? What's wrong with you?"

Sample Response: "Everyone is different. I enjoy reading and music."

Prompt: "Come hang out with us behind the old abandoned building; the police never go there."

Sample Response: "No, thanks. I'm not interested."

Prompt: "That new girl from the other class is walking this way. Let's trip her."

Sample Response: "Leave her alone. She has done nothing to us."

8. Explain: Now think of the situation you remembered at the start of this activity, when you were asked about a time that you wish you had expressed your wishes more directly. Think about what you might have said in that situation. You will not be asked to share this response.
9. Wrap up by discussing the following questions:

Some people may think that being assertive goes against their culture or is rude. What is a situation in which a person should be assertive even if such a response is considered rude? [Probe for: when you feel your rights are being violated.]

Are girls who are assertive treated in the same way as boys who are assertive? Is someone who is assertive viewed differently if that person is from an ethnic or racial minority group? How can such biases limit people's ability to stand up for themselves? 


\section{activity 2}

\section{ACTIVE LISTENING* [22 MINUTES]}

1. Before the session begins, pull two volunteers aside and explain "the poor listener" skit \#1 and the two roles found on page 68 in Box 1. Then pull aside two more volunteers and explain "the good listener" skit \#2 and the two roles found on page 69 in Box 2. Allow them to take a few minutes to prepare or rehearse outside while you introduce the session.

2. Introduce the topic to the rest of the class by explaining:

- We say that communication is a two-way process. When one person is speaking, what is the other person doing? [Answer: Listening.]

So is listening part of communication? [Answer: Yes.]

- Today we will explore what we communicate when we are listening. We will learn about what a big difference "active listening" makes in communication between people.

- We will start with a demonstration. Take out your notebooks. Observe the listener in each of the following skits, and write down each behavior you observe that you think gets in the way of effective communication.
3. Have the volunteers enact the "negative" communication skit (see skit \#1 in Box 1 on page 68).

4. After skit \#1, ask:

How would you evaluate this conversation? Was it satisfying and effective?

- What verbal and non-verbal behaviors did the listener display? [On the board, write each negative behavior that participants mention. Probe for the following.]

\section{Non-verbal behaviors:}

Frowning

Looking dismissive, rolling your eyes toward the sky

Shaking your head as if to say "no"

- Looking or moving away, looking bored or uninterested, yawning

Verbal behaviors:

Interrupting the speaker, showing

impatience, indicating that the speaker is taking too long

Expressing negative judgments of the

speaker, such as "you are wrong" or "that is a dumb idea"
5. Ask the speaker in the pair how it felt not to be listened to.

Continued on next page

Source: International Sexuality and HIV Curriculum Working Group. 2009, updated 2011. It's All One Curriculum: Guidelines and Activities 


\section{activity 2 (cont.)}

6. Now have the second two volunteers enact the "positive" communication skit (see skit \#2 in Box 2 on page 69).

\section{After the skit, ask:}

How would you evaluate this conversation? Was it more satisfying?

What verbal and non-verbal behaviors made this conversation more successfu than the last one? [On the board, write each positive behavior that participants mention. Probe for the following.]

Non-verbal behaviors:

- Maintaining eye contact

- Nodding your head (as if to say "yes")

- Leaning in a bit toward the speaker to

show that you are listening

- Offering a smile or a pat on the back

Verbal behaviors:

- Asking for clarification to make sure that you understand the speaker

- Showing interest in hearing more (for example, "Tell me more about that ... ")

Validating the speaker's feelings (for example, "I can understand how you feel.")

Validating the speaker's ideas (for example "Good point.")

Avoiding making any statements that make the speaker feel judged or inadequate

- Thanking the speaker for trusting you to

share what is on his or her mind
8. Ask:

How does it feel when you are the speaker and the person is not listening well?

What happens when the two people have

a real conflict and they are both upset? Is it

harder or easier to communicate well?

Some researchers have observed that

males and females have different styles

of communication. What are girls and

women taught about how to express

themselves when they are upset?

What are men and boys taught about

how to express themselves when they are

upset? Can people learn to communicate

in a way that is not violent or aggressive?

Continued on next page 


\section{activity 2 (cont.)}

Box 1

\section{INSTRUCTIONS FOR "THE POOR LISTENER" (SKIT \#1)}

One of you will be the "speaker" and one of you will be the "listener."

SPEAKER: Develop a script based on an imaginary situation. Select either: (1) something that (you are pretending) happened to you that you think was unfair; or (2) a wild plan or idea you (are pretending to) have that you are excited about. For the skit, you want to express your experience or ideas and the feelings you have very clearly. You will spend several minutes trying to talk with your partner about this, trying to be heard. Plan to speak for one to two minutes.

Respond according to the way your partner is listening to you. If you feel that he/she is not listening to you, show your frustration, raise your voice, or respond in whatever way might feel natural in such a situation. If the other person is listening carefully and respectfully, behave accordingly.

LISTENER: You are a POOR LISTENER.

When the speaker is trying to talk to you,

demonstrate poor listening skills. Your job is to

use as many of the negative verbal and non-

verbal behaviors as you can from the list here:
Non-verbal behaviors:

Frowning

Looking dismissive, rolling your eyes

toward the sky

Shaking your head as if to say "no"

Showing impatience - looking or moving away, looking bored or uninterested, yawning

\section{Verbal behaviors:}

Interrupting the speaker, starting to talk about yourself or changing the subject Expressing negative judgments of the speaker (such as "Wrong!" or "That is a dumb idea.")

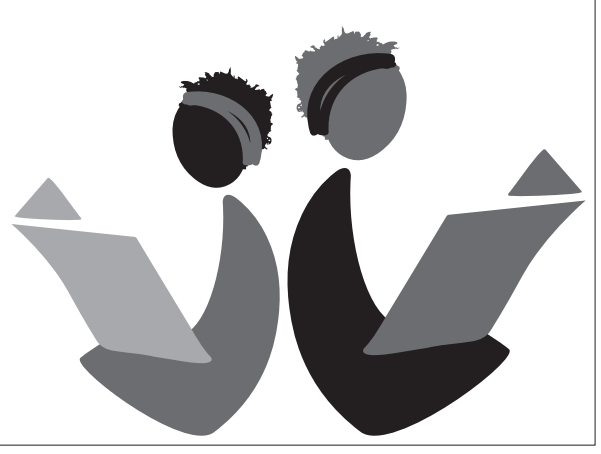




\section{activity 2 (cont.)}

Box 2

\section{INSTRUCTIONS FOR “THE GOOD LISTENER” (SKIT \#2)}

One of you will be the "speaker" and one of you will be the "listener."

SPEAKER: (Instructions are the same as for skit \#1): Develop a script based on an imaginary situation. Select either: (1) something that (you are pretending) happened to you that you think was unfair; or (2) a wild plan or idea you (are pretending to) have that you are excited about. For the skit, you want to express your experience or ideas and the feelings you have very clearly. You will spend several minutes trying to talk to your partner about this, trying to be heard. Plan to speak for one to two minutes.

Respond according to the way your partner is listening to you. If you feel that he/she is not listening to you, show your frustration, raise your voice, or respond in whatever way might feel natural in such a situation. If the other person is listening carefully and respectfully, behave accordingly.

LISTENER: You are an ACTIVE LISTENER. When the speaker is trying to talk to you, demonstrate active listening skills. Your job is to use as many of the positive verbal and non-verbal behaviors as you can from the list below:
Non-verbal behaviors:

Maintaining eye contact

Nodding your head (as if to say "yes") Leaning in a bit toward the speaker to show that you are listening

Offering a smile or a pat on the back

\section{Verbal behaviors:}

Asking for clarification to make sure you understand the speaker

- Showing interest in hearing more (for example, "Tell me more about that...")

Validating the speaker's feelings (for

example, "I can understand how you feel.") - Validating the speaker's ideas (for example, "Good point.")

Avoiding making any statements that make the speaker feel judged or inadequate

Thanking the speaker for trusting you to share what is on his/her mind 


\title{
wrap-up
}

\author{
WRAP-UP \\ [5 MINUTES]
}

Ask participants to summarize what they have

learned. Fill in any key points they miss.

Key Message: Being able to listen well and to express yourself so that you are understood are important life skills. They can help you

solve conflicts without violence, develop

relationships based on mutual understanding, and help you succeed at school and at

work. It is not always easy for everyone to

communicate well, but everyone can learn to communicate more effectively.

\section{Action item: 3 minutes}

Practice your assertive communication

skills three times between now and when

we meet again. For example, say no (using

assertive communication techniques) to a

friend or family member who wants you to do

something you don't feel comfortable doing:

or ask for what you want or need.

Ask for any final questions or comments.

Remind participants where and when the next

meeting will take place, and what topics will

be discussed.

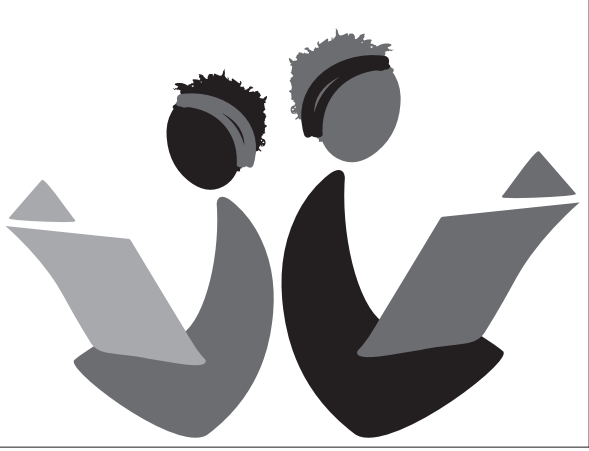




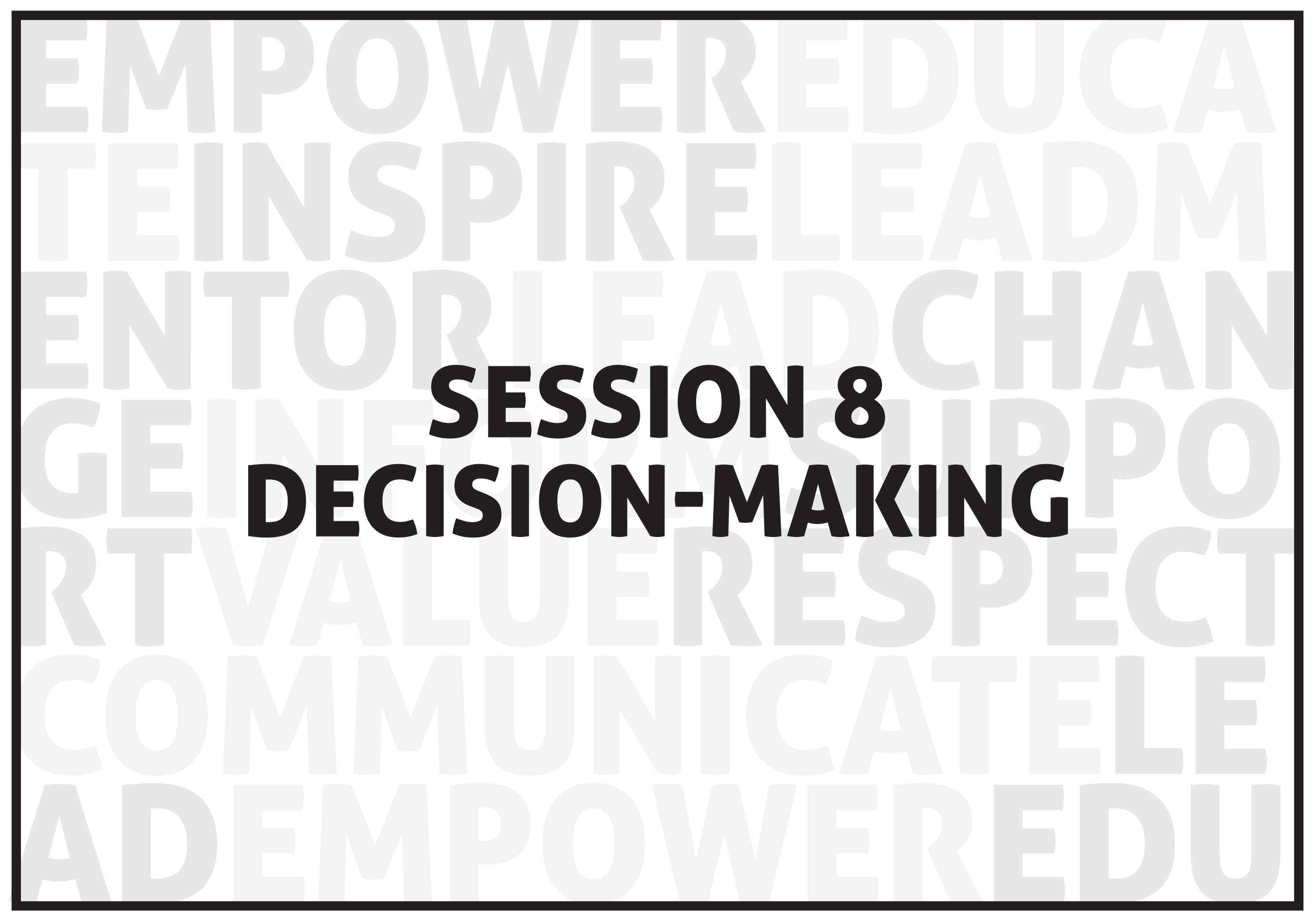




\section{session 8 / decision-making}

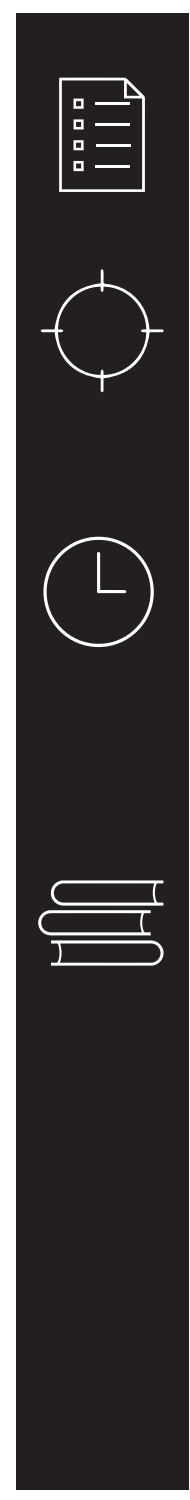

SESSION DESCRIPTION

Participants learn basic steps for, and practice, making decisions.

OBJECTIVES

By the end of the session, participants will:

Use the steps in BE A STAR model to make responsible choices and

decisions

- Reflect on decisions, actions, and personal accountability

SESSION TIME

1 hour

Action item debrief: 5 minutes

Warm-up: My decision chart, 10 minutes

Activity 1: Which road will you take? 35 minutes

Wrap-up: 5 minutes

Action item: 5 minutes

REQUIRED MATERIALS

Chalkboard and chalk 


\section{session 8 / decision-making (cont.)}

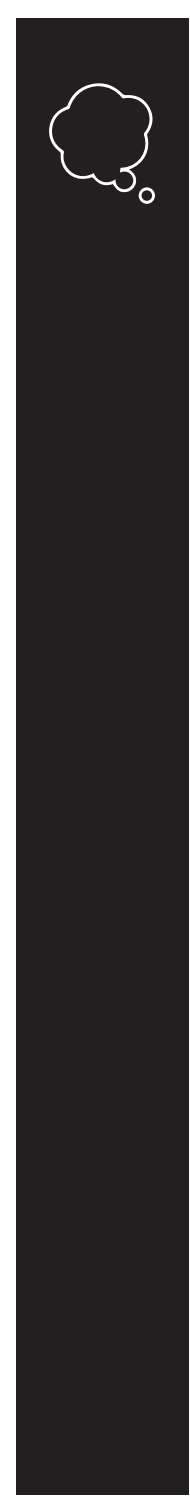

PRE-SESSION PREPARATION*

Read through the entire session and practice presenting the activities. Prepare all materials needed.

Prepare a BE A STAR diagram on the black board.

Write out the four cases for Activity 2 on four small pieces of paper:
1. Urged on by his friends, a young man grabs a female classmate inappropriately despite her efforts to push him away. Others around them are uncomfortable but don't know what to do. What will you do?

2. A cousin just turned 16 and her parents are pressuring her to marry. She wants to continue her schooling and does not want to marry yet. What will you do?
3. An older boy your friend likes has been giving her gifts and they are seeing more and more of each other. Now he is starting to pressure her to have sex with him. What will you do?

4. A student in your grade struggles with maths. The teacher regularly makes fun of him in front of the whole class. Other participants laugh at him and he is clearly embarrassed. What will you do?

\section{REFLECT}

Evaluate the outcome of your decision and action.

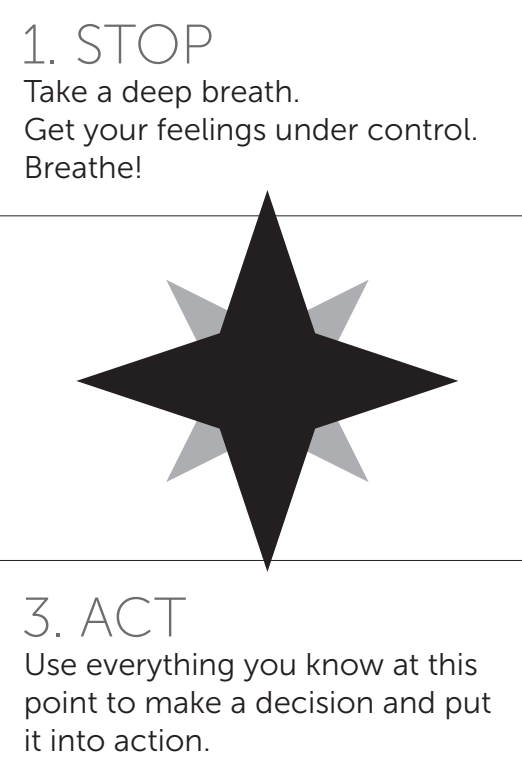

\section{STOP}

Take a deep breath.

Breathe!

it into action.

\section{THINK}

Think about the situation, the actions you can take, and the outcomes. 


\section{session 8 / decision-making (cont.)}

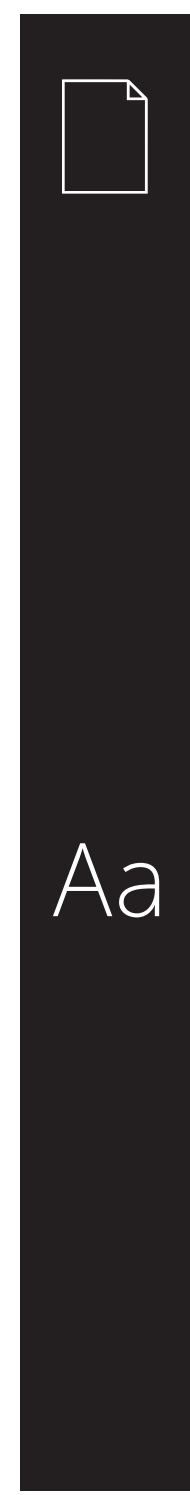

\section{FACILITATOR NOTES*}

A decision is a choice that we make between two or more possible options. We all make decisions every day. We will need to make more and more decisions as we go through life and some of these decisions will affect us the rest of our lives.

One of the most important parts of decisionmaking is looking ahead to see what might happen if you do something. This is called predicting outcomes or understanding

consequences. The better you are at

predicting outcomes, the better you will be at making decisions that result in the outcomes or consequences you want

\section{TERMS}

Accountability: The ability to account for the decisions and actions we take; the ability to accept the results of our decisions and not blame others for the consequences they lead to.

Decisions: A conclusion or resolution reached after consideration.

Fairness: To ensure that everyone is treated with the same importance, and has the same rights and opportunities.

Responsibility: The ability to respond to the demands of a situation that one finds oneself in.
Key steps for good decision-making include: Describe the problem, situation, or issue that needs a decision.

Get more information if you have

questions about the situation.

- Think about the possible consequences or outcomes of each course of action.

Think about your personal and family values, and which courses of action are consistent with these values.

Think about the ways in which your decision may affect other people.

Choose the decision that seems most appropriate based on your knowledge, values, morals, religious upbringing, and present and future goals.
Reflect on the decision and how you feel about it.

Be sure you carefully considered all the alternatives and feel comfortable with the choice you made. 


\section{warm-up}

\section{ACTION ITEM DEBRIEF [5 MINUTES]}

Tell participants: Before we do anything else, I want to hear how using assertive communication went! Who wants to share what they communicated and how? I would love one volunteer to share. [Get a response.]

\section{MY DECISION CHART*}

\section{[10 MINUTES]}

1. Ask: When you have to make a decision, how do you decide what is best to do? [Listen to one or two responses.]

2. Tell the group that today we are going to learn some skills that will help us make better decisions. Explain that you will start with an easy example that has probably happened in one form or another to most everyone. Read this example of a decision:

Chipo was invited to a football match. But she has a very important maths test in the morning and she has to study. Should Chipo go to the game or not?

3. Write two columns on the board entitled "positive" and "negative."
Praise the participant - even if she did not do a terrific job at phrasing her statement or question, this is new and she gets lots of credit for trying! Ask if anyone has suggestions for how the communication could have been better. If needed, you should suggest ways that the communication could have been less passive or less aggressive or clearer, etc.
4. Ask: What are all of the positive things that might happen if Chipo goes to the football match?

Then ask: What are all of the negative things that might happen if Chipo goes to the football match?

5. Explain: Whenever you are faced with a decision, you should take the time to go through the process of thinking carefully about the positive and negative results of your actions. What other steps can you take to make sure your decision is a good one? [Some other things a person can do is: ask for advice, sleep on it, etc.]

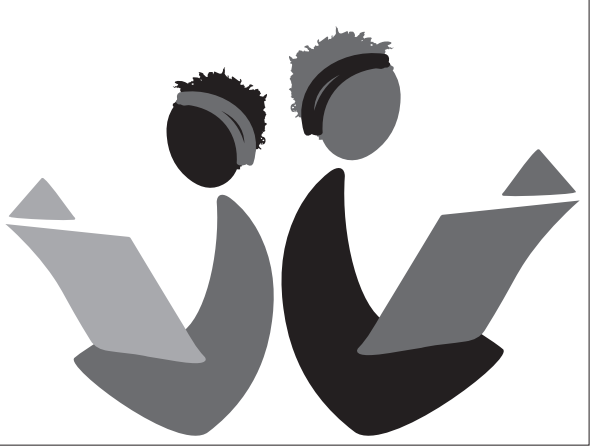




\section{activity 1}

\section{WHICH ROAD WILL YOU TAKE?* [35 MINUTES]}

1. As a group, define these three words: responsibility, accountability, and decisions.

Get two or three answers from the group for each word. Then read these definitions to the group:

Responsibility: The ability to respond to the demands of a situation that one finds oneself in.

Accountability: The ability to account for the decisions and actions we take; the ability to accept the results of our decisions and not blame others for the consequences (unwanted outcomes) they lead to.

Decisions: A conclusion or resolution reached after consideration.

2. Explain the following

- Every day we have choices and decisions to make.

Every decision we make has results and consequences - even if we decide not to do anything about a situation (not doing anything is still a decision!); and even if we did not intend for the result to happen.
Personal accountability means that we accept the results of our decisions and do not blame others for the results or consequences they lead to.

- We therefore need to make responsible decisions that we are prepared to be accountable for.

3. Turn to the BE A STAR diagram prepared on the chalkboard. Explain that these four steps are one way of making responsible decisions. Go through each step:

STOP. Take a deep breath. Get your feelings under control. Breathe in deeply and breathe out slowly and fully!

- THINK. Think about the situation: What is happening? Why? Who is involved? What can I do about it? Consider all the options.

Think about what all the possible outcomes of my actions would be. Consider the positives and negatives for each action. Is it safe? Is it legal? Is it non-violent? Are the risks reasonable? Are these actions in keeping with my values?

Think about whether it would be helpful and appropriate to seek advice or information from someone you trust. If so, seek and consider their input as you make your decision.

ACT. Use everything you know at this point to make a decision and then put it into action. You may want to discuss the decision and plan your response with someone you trust. Remember you are not alone.

REFLECT. What was the outcome of your decision and action? Did it differ from what was expected? Would you make a different decision next time? Should you re-evaluate your decision or change your mind?

\section{Continued on next page}




\section{activity 1 (cont.)}

4. Break up into four small groups. Assign each group one case example to work on (see below). These case examples should

be written out on four small pieces of paper before the session starts.

5. Explain that they should use the steps in BE A STAR to decide what action to take (including choosing to do nothing). Remind participants about making responsible decisions and being held personally accountable for the decisions we make.

- Urged on by his friends, a young man grabs a female classmate inappropriately despite her efforts to push him away. Others around them are uncomfortable but don't know what to do. What will you do?

- A cousin just turned 16 and her parent are pressuring her to marry. She wants to continue her schooling and does not want to marry yet. What will you do?

- An older boy your friend likes has been giving her gifts and they are seeing more and more of each other. Now he is starting to pressure her to have sex with him. What will you do?

A student in your grade struggles with maths. The teacher regularly makes fun of him in front of the whole class. Other participants laugh at him and he is clearly embarrassed. What will you do?
6. After 5 minutes, bring the group back together. Ask each group to report back on the following:

What decisions and actions did you take? - What do you think the positive and

negative consequences of these decision and actions will be?

Are you prepared to be personally accountable for these decisions and actions?

\section{Then ask:}

How did you use the steps in BE A STAR to make a decision and take action? Could you use these steps in your life to help you make decisions? Please give some examples. 


\section{wrap-up}

\section{WRAP-UP \\ [5 MINUTES]}

Ask participants to summarize what they have learned. Fill in any key points they miss.

Key Message: To make sound decisions, remember to follow these simple steps: Stop.

Think, Act, and Reflect.

\section{Action item: 5 minutes}

Ask: Who can give me a definition of fairness?

[Wait for a response. Fairness means ensuring that everyone is treated with the same

importance, and has the same rights and opportunities.]

Ask: Before our next meeting I want you to talk with a parent, guardian, or other trusted adult and ask them what fairness means to them. Discuss the meaning with them and whether they think all people are treated fairly. Come to our next meeting prepared to share what you think about their definition, and what it reflects, at the next meeting.
Ask for any final questions or comments.

Remind participants where and when the next meeting will take place, and what topics will be discussed

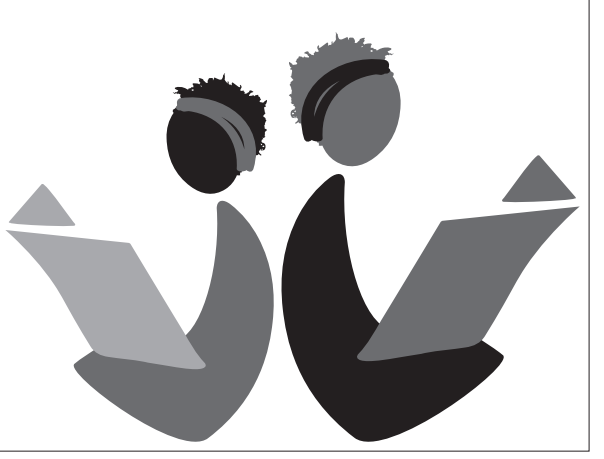




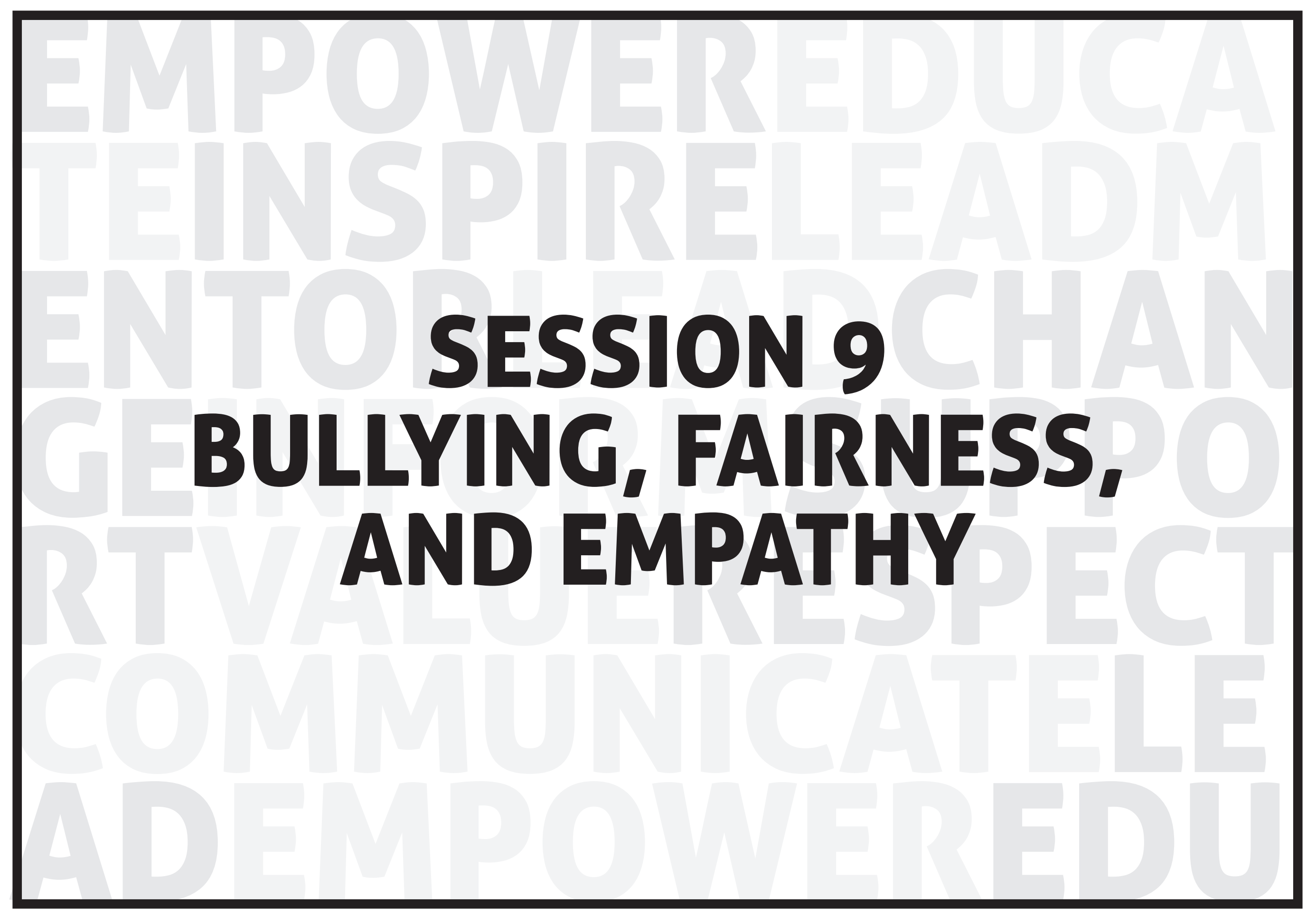




\section{session 9 / bullying, fairness, and empathy}

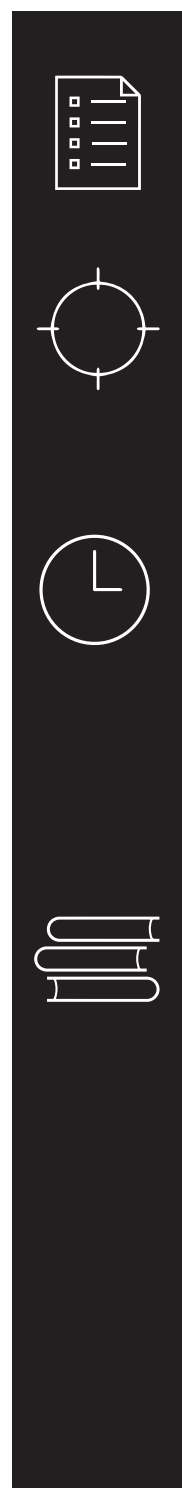

SESSION DESCRIPTION

Participants discuss the importance of treating people fairly and learn

about bullying and what to do to prevent it.

OBJECTIVES

By the end of the session, participants will:

Understand the importance of fairness

- Know what to do when they see bullying or are bullied

- Expand their capacity for empathy

\section{SESSION TIME}

1 hour

Action item debrief: 5 minutes

Warm-up: Emotions, 13 minutes

Activity 1: Why fairness matters, 20 minutes

Activity 2: Bullying, 15 minutes

Wrap-up: 2 minutes

Action item: 5 minutes

REQUIRED MATERIALS

Chalkboard and chalk 


\section{session 9 / bullying, fairness, and empathy}

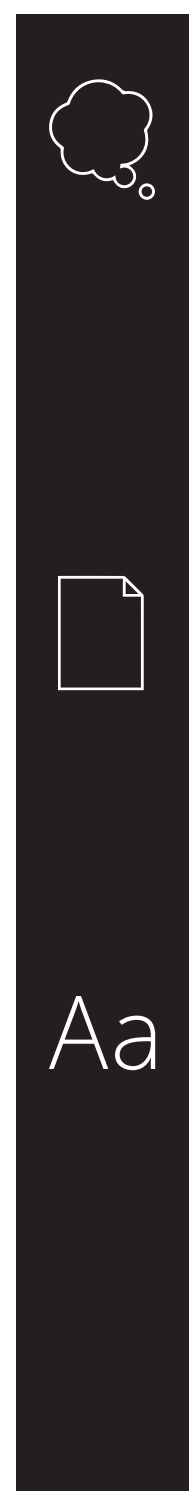

PRE-SESSION PREPARATION

1. Read through the entire session and

practice presenting the activities. Prepare all

materials needed.

Write the following four quotes on the black board

"The future will be shaped by our fairness

to other people's children."

\section{FACILITATOR NOTES}

The quotes in Activity 1 (Why fairness matters) are attributed to the following individuals, following the order in which they appear: rights advocate Marian Wright Edelman; writer H. Jackson Brown, Jr.; education activist Malala Yousafzai; and business educator Everett W. Lord.

\section{TERMS}

Bullying: Unwanted, aggressive behaviour that involves a real or perceived power

imbalance. The behaviour is repeated, or has the potential to be repeated, over time. Both people who are bullied and people who bully others may have serious, lasting problems.

Empathy: Understanding and sharing the

feelings of another person; putting ourselves in their place.
- "Live so that when other people think of fairness and respect, they think of you."

"We cannot succeed when half of us are held back."

"Be fair. Treat others as you would like to be treated."

Teasing and bullying are not the same thing Teasing usually involves two or more friends who act together in a way that seems fun to all the people involved. Often they tease each other equally, but it never involves physical or emotional harassment or abuse.

Fairness: Impartial and just treatment or behavior without favouritism or discrimination.
2. Before the session begins, prepare six small pieces of paper with one of these emotions written on each; fold up each paper:

- Happy

Scared

Angry

Sad

Worried

Embarrassed 


\section{warm-up}

ACTION ITEM DEBRIEF

[5 MINUTES]

1. Ask: Remember that in the last session,

Session 8, we asked you to ask a parent or

adult about fairness. How did it go? What

did your adults tell you about what fairness

means to them? 


\section{warm-up}

\section{EMOTIONS* \\ [13 MINUTES]}

1. Before the session begins, prepare six smal pieces of paper with one of these emotions

written on each: fold up each paper:

Happy

- Scared

Angry

Sad

- Worried

- Embarrassed

2. Explain: I need six volunteers to act out six different emotions. I am going to give the volunteers small pieces of paper; each paper has an emotion written on it. If you don't understand what is written on your paper, let me know and I will whisper the meaning in your ear. Don't tell us what the emotion is right away. We're going to guess. We may not get it right, but that's okay. That's why we practice thinking about other people's feelings whenever we can

After we have guessed each emotion, would like each volunteer to explain what could have made them feel the emotion they acted out. What could have led to that emotion?
3. Ask: Who can tell me what empathy means?

[Wait for a response. Clarify if necessary: Empathy is understanding and sharing the feelings of another person - putting ourselves in their place. For example, when you feel sad or happy because of sadness or happiness someone else is experiencing, that is empathy. Someone who is empathetic can also anticipate what might make a person feel better.]

4. Ask: What are some ways we can show empathy? [Answers: Listen, get a deeper understanding of someone's perspective offer help, offer a hug, be kind, be compassionate.]

5. Ask: Could I have two volunteers different than those who modeled emotions - to describe a time when they have felt empathy toward someone else, meaning that you felt sad or happy because you could sense what the other person was feeling? [Allow two volunteers to share brief examples.
6. Explain: If we empathize with someone, we are more likely to recognize when someone is feeling sad or hurt. It makes us less likely to engage in hurtful behaviors and more likely to do something if we witness people trying to hurt others. It can also help us treat others more fairly in general.

*Source: The Inclusion Lab: Tips and Takeaways for Teaching All Kids, Brookes Publishing, http://blog.brookespublishing.com/5-activities-for-building-empathyin-your-students/; Carrizales-Engelmann, Dianna, Laura L. Feuerborn, Barbara A. Gueldner, and Oanh K. Tran. 2016. Merrell's Strong Kids-Grades 3-5: A Social and Emotional Learning Curriculum. Brookes Publishing; Global Children's Fund, Child Safety and Abuse Prevention Programs, www.keepyourchildsafe.org. 


\section{activity 1}

\section{WHY FAIRNESS MATTERS* [20 MINUTES]}

1. Before the session begins, write the following four quotes on the black board:

- "The future will be shaped by our fairness to other people's children."

- "Live so that when other people think of fairness and respect, they think of you."

- "We cannot succeed when half of us are held back."

- "Be fair. Treat others as you would like to be treated."

2. Ask: What does fairness mean to you?

[Possible answers: Fairness is:

- Sharing and taking turns

- Playing fair and by the rules

- Being honest

Compromising

- Caring and including others

- Not blaming others

Admitting when you are wrong

- Making decisions in a fair way

- Keeping an open mind about different

opinions.]
3. Say: Overall, fairness is about making sure all are treated with the kindness and respect they deserve.

4. Explain: Now let's look at the quotes written on the board. Who would like to read the quotes aloud? [Allow different volunteers to read the quotes. Do not discuss the quotes at this time.

- Pick a quote that inspires you

- Think about what it means and why it speaks to you or inspires you.

- Think of an example from your own life, or from something that happened in your community or elsewhere where this message would have been helpful. It might be an example from a time when you were mistreated or a time when you did not

treat someone else fairly or witnessed an interaction between other people.

- How could the message from this quote have been helpful?

- There is no need to write anything down. but if you would like to write your answers please go ahead.
- Does anyone have a question about the assignment?

- You have three minutes.

Continued on next page

*Source: International Sexuality and HIV Curriculum Working Group. 2009, updated 2011. It's All One Curriculum: Guidelines and Activities 


\section{activity 1 (cont.)}

5. Ask for a few volunteers to share their response to the chosen quote.

6. Thank the volunteers then ask the group

- Is being fair always easy?

Why do you think fairness is so important in the world?

- In our hearts, do we treat all people with fairness and respect, regardless of our differences? Do our laws treat all people with fairness and respect? Can anyone give an example? [lf possible, encourage participants to think of examples from their own society and also examples from what they have heard about events in another country.]

\section{Explain:}

- People do not always agree about what it means to behave with fairness and respect toward each other or about how people have a right to be treated. For more than 50 years, however, the global community has agreed that every person deserves to be treated with respect and dignity.

As a matter of fairness, every single person deserves certain basic protections and rights. These rights are called "human

rights." They refer to how we treat each

other as individuals and as members of a society, just because we are human beings.
8. If they want participants can share the quotes with the adult with whom they discussed fairness. 


\section{activity 2}

\section{BULLYING* \\ [15 MINUTES]}

1. Ask: What is bullying? How would you define it?

[If the group is having trouble, read out this definition: Bullying is when someone is being hurt either by words or actions on purpose, repeatedly and over time, feels bad because of it, and has a hard time stopping what is happening to them.]

2. Explain: No one deserves to be treated cruelly.

3. Explain: Bullying can be:

PHYSICAL:

- Hitting

Pushing and shoving

- Fighting

- Tripping

- Yelling at someone

- Making rude gestures

- Taking or breaking another person's things
EMOTIONAL:

Name calling

- Making fun of someone

- Laughing at someone

- Leaving someone out on purpose

Starting rumors or telling lies about

someone

- Sending mean messages on a computer or cellphone

- Trying to make someone feel bad about who they are

4. Ask: Where does bullying happen?

Listen to answers from the group,

then summarize: Bullying can happen

anywhere. It can occur in your

neighborhood, while going to school, at

school, and while on the internet.
Continued on next page 


\section{activity 2 (cont.)}

5. Ask: Who is bullied and why do people bully?

Listen to answers from the group, highlight any points below that were not raised:

- Bullying can happen to ANYONE.

- People bully because they want to feel powerful and get positive attention. They probably don't feel good about themselves or may be envious of others.

- People who bully may find satisfaction in causing injury and suffering to others.

- Bullying can be directed at the shy, quiet student, or the class tough guy.

- Girls bully, boys bully, preschool kids bully, and adults bully-there is no one kind of person that bullies.

- The one sure thing is that no one EVER deserves to be bullied.

6. Remember two things:

- If you are being bullied, it is NOT your fault!

Putting someone down will never help you reach the top.

7. Ask participants how they think they can prevent bullying.

Listen to answers from the group. Provide the ideas below if they don't come up in the discussion:
Ask the person who is bullying to stop. Sometimes a person doesn't realize that what they are doing is hurting someone else. Speaking out against bullying helps everyone.

Do not join in and do not give positive attention to the person doing the bullying. Someone who bullies often likes an audience, it makes it more fun for them. If you ignore the bullying, it shows them it's not cool. Be a person against bullying.

Help the person being bullied get away from the situation. It is easy for someone to be bullied when no one sticks up for them. Be a friend. Walk with them to class, play or talk with them, and let them know they're not alone.

- Tell an adult. Adults really do care. They are the ones that can enforce the rules. It can be done while the bullying is happening or after. Remember: telling an adult is NOT "telling on someone," it is done to help someone.

- Let the person know that no one deserves to be bullied. Children and young people who are bullied often feel alone, like no one cares, like it might even be their fault. Let them know that someone cares.
Ask others to stand against bullying. When people stick together and don't accept bullying, they can put an end to cruelty and harassment. Together we can make a difference.

- Ask your school to start a bullying prevention program. Everyone at your school needs to know what to do to prevent bullying. The end of bullying begins with each one of us. 


\section{wrap-up}

\section{WRAP-UP \\ [2 MINUTES]}

Ask participants to summarize what they have learned. Fill in any key points they miss.

Key Message: Bullying is cruel. Each one of us can help prevent bullying. Be fair. Treat others

as you would like to be treated.

\section{Action item: 5 minutes}

Explain: All of us have witnessed bullying some of you may have experienced bullying and others may have bullied someone. We talked about some things we can all do to prevent bullying. Another way to help prevent bullying is to build our empathy skills.

Explain: Every day between now and when we meet again, try to understand one other person's feelings. Ask yourself:

- How is the person feeling?

How do I know that this is how they are feeling?

- Why are they feeling this way?

How can I show empathy for their

feelings?
Remember: Try to "stand in their shoes." That is, try to understand how a situation might be experienced by another person.

Ask for any final questions or comments.

Remind participants where and when the next meeting will take place, and what topics will be discussed.

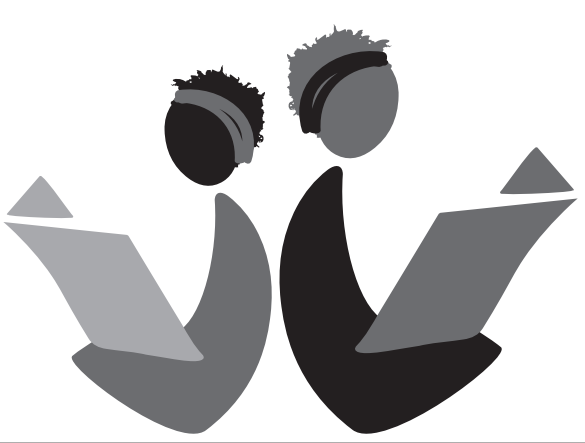




\section{SESSION 10 PUBERTY AND THE BODY}




\section{session 10 / puberty and the body}

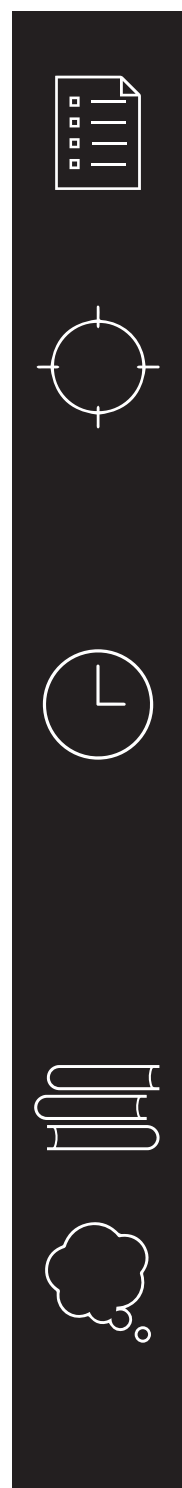

SESSION DESCRIPTION

Discuss pressures related to physical appearance, the changes that occur during puberty, and how peers can help each other through puberty.

\section{OBJECTIVES}

By the end of the session, participants will:

Describe how cultural pressures related to appearance affect their selfesteem

Describe the physical and emotional changes that occur during puberty

- Understand that these changes that occur during puberty are normal

\section{SESSION TIME}

1 hour

Action item debrief: 3 minutes

Warm-up: Head and shoulders, 2 minutes

Activity 1: What you see in me, 15 minutes

Activity 2: Physical and emotional changes in boys and girls, 15 minutes

Activity 3: Making puberty easier, 12 minutes

Wrap-up: 10 minutes

Action item: 3 minutes

\section{REQUIRED MATERIALS}

Chalkboard and chalk

\section{PRE-SESSION PREPARATION}

Read through the entire session and practice presenting the activities. Prepare all materials needed.

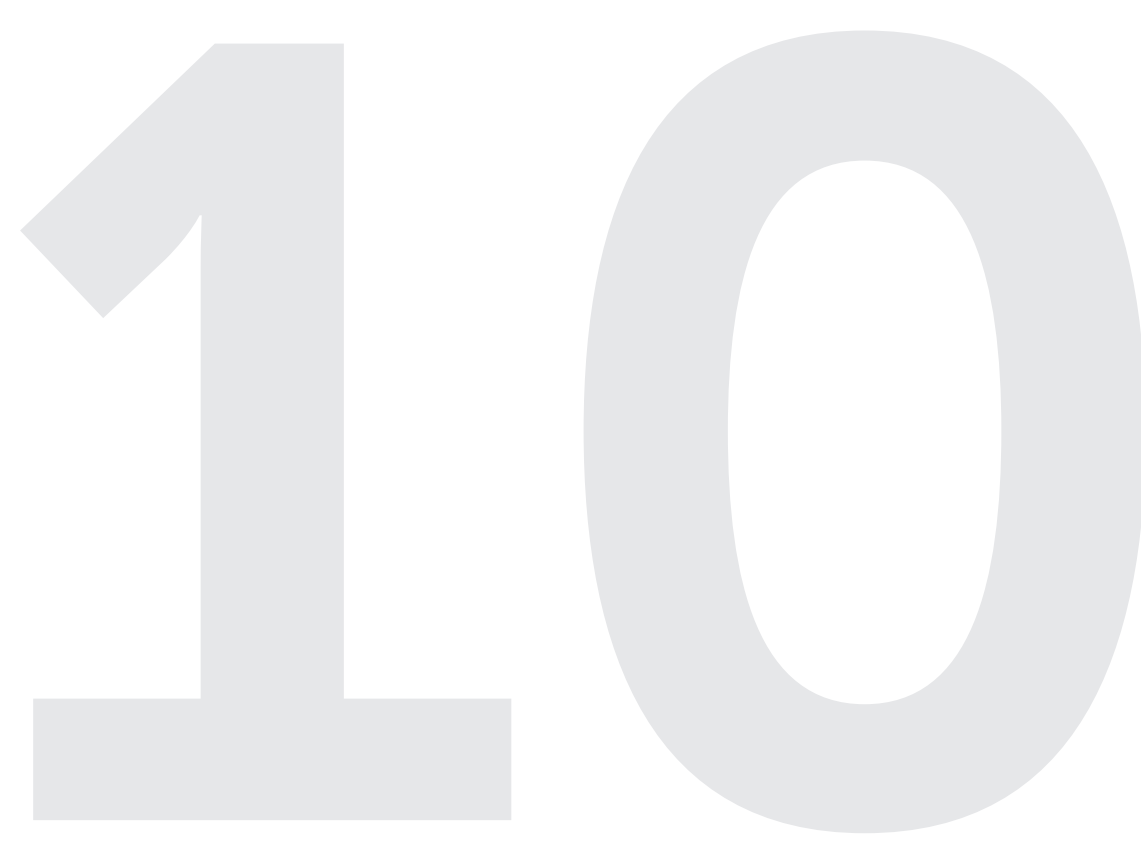




\section{session 10 / puberty and the body (cont.)}

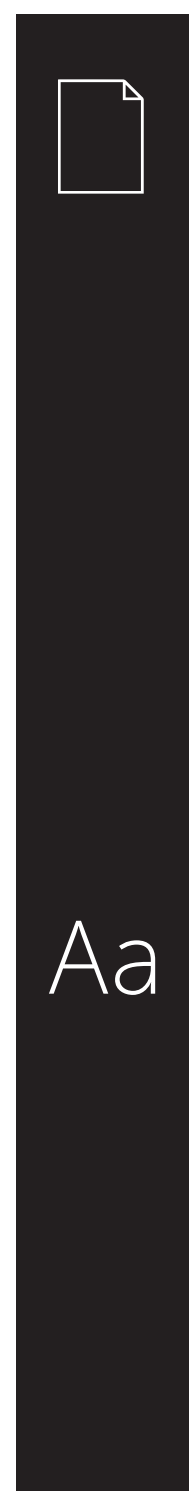

\section{FACILITATOR NOTES*}

Puberty is a time when the bodies of boys and girls physically change - bodies grow bigger and taller, genitals mature, and hair often starts growing in new places on the body. During puberty, a girl becomes physically able to become pregnant and a boy becomes physically able to father a child. New chemicals produced by the body, called hormones, create changes in the body and turn young people into adults. Puberty typically starts between ages 8 to 13 in girls, and ages 10 to 15 in boys, although some young people start puberty a bit earlier or later. For girls, puberty is typically completed by the ages of 16 or 17 or around the time that their skeletal growth is complete. Boys typically finish puberty later - in their late teens or early twenties. People are different, so everyone starts and goes through puberty at their own pace.

During puberty, young people also experience

\section{TERMS}

Adolescence: The period of time when people transition from childhood to adulthood, usually between ages 10 and 19 .

Hormones: A chemical substance produced in the body that controls and regulates the activity of certain cells or organs.

Puberty: The physical and emotional changes that people go through during adolescence; results in sexual maturity and capability for reproduction. a major growth spurt. Some people grow ten or more centimeters in one year

When discussing the physical changes

experienced during puberty, be sure to relate

them to the emotional changes that go along with them.

Moreover, as young people go through puberty and begin to develop, the way people treat them changes. For example, new opportunities for leadership at school, new pressures related to sexuality, and more domestic responsibilities. 


\section{warm-up}

\section{ACTION ITEM DEBRIEF [3 MINUTES]}

Since our last session, you all practiced your empathy skills. How did it go? How did it feel? What did you learn?

[As you facilitate the debrief, be sure to encourage participants to share insights, lessons, and tips with each other.]

Keep practicing and using your empathy skills!

It is one simple, concrete way we can help

make our world a better place every day.

\section{HEAD AND SHOULDERS* \\ [2 MINUTES]}

\section{Explain:}

Touch the following body parts as they sing the following lyrics:

Head, shoulders, knees and toes, knees and toes,

Head, shoulders, knees and toes, knees and toes,

And eyes and ears and mouth and nose, Head, shoulders, knees and toes, knees and toes!
Then modify the song to include body parts that change during puberty, touching the

body parts while singing. For example:

Hips, shoulders, breasts and toes, breasts and toes,

Hips, shoulders, breasts and toes, breasts and toes,

And pimples and armpit hair and mouth and nose,

Hips, shoulders, breasts and toes, breasts and toes!

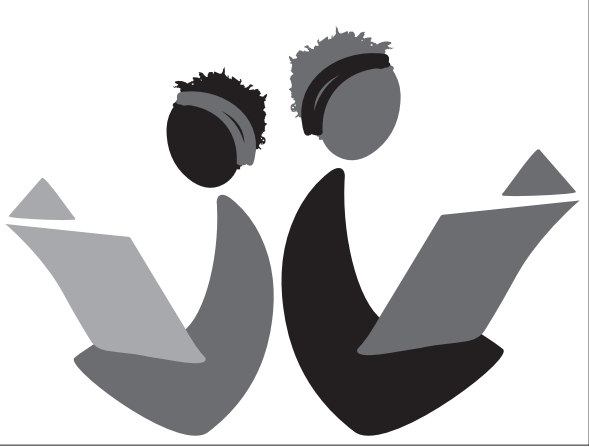




\section{activity 1}

\section{WHAT YOU SEE IN ME* [15 MINUTES]}

1. Open discussion with the following guiding questions:

- Many factors influence how we feel about our bodies. We will explore some of these questions today.

- Think about when you were nine years old How do most nine-year-olds feel about their bodies and how they look? Do most children worry a lot about their looks?

What happens during adolescence, which ranges from 10-19 years old? Do most adolescents feel carefree and comfortable about their appearance, or do they worry about how they look?

What kinds of messages and images do adolescents receive from movies and

advertisements about how they should look and what their bodies should be like? Is this pressure more intense for girls or for boys?

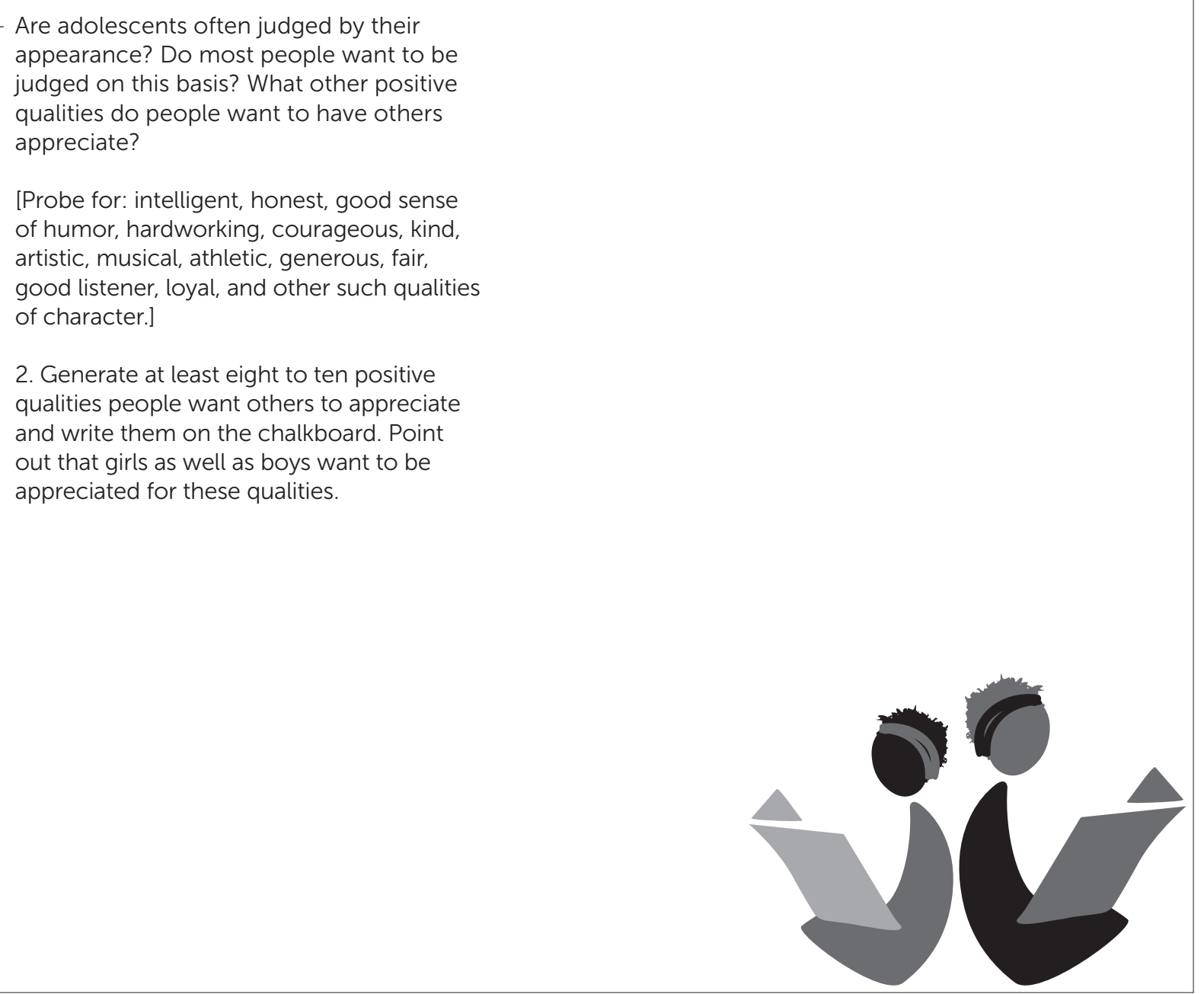

*Source: International Sexuality and HIV Curriculum Working Group. 2009, updated 2011. It's All One Curriculum: Guidelines and Activities for a Unified Approach to Sexuality, Gender, HIV and Human Rights Education. New York: Population Council. Activities: Page 127. 


\section{activity 2}

\section{PHYSICAL AND EMOTIONAL CHANGES IN BOYS AND GIRLS* \\ [15 MINUTES]}

1. Explain: Adolescence is the time in everyone's life when they change from a child to an adult. Adolescence is the age between 10 and 19. The period during which adolescents reach sexual maturity and become capable of reproduction is called 'puberty.' Today we are going to learn about the physical and emotional changes that occur during adolescence.

2. Divide participants into three groups Assign one of the following types of changes to each group: 1) boy's physical changes, 2) girl's physical changes, 3) emotional changes for both girls and boys.

3. Explain: Now in one of your notebooks you will write (or draw) the changes that occur during adolescence in the category assigned to your group.

4. When all three groups have finished writing down changes, ask two participants from each group to share their group's list. Write the responses on the chalkboard.

\section{Box 3}

Physical and Emotional Changes in Both

\section{- Grow in size}

Weight gain

Pubic and underarm hair

Genitals enlarge

Acne

Sexual feelings

Changes in mood

Feel embarrassed easily

Feel closer to friends than family

Feel shy

Better able to reason and solve problems

Rebel against parents, want to be

independent

Concerns about being normal

Experimentation

Physical Changes during Adolescence

\section{... in Boys}

\section{... in Girls}

Shoulders

broaden

Facial hair

- Hips widen

Voice deepens

Breasts develop

Sperm production

Ovulation and

and ejaculation

Wet dreams
5. Ask if the other groups have any changes to add to the list. Help distinguish

between physical and emotional changes.

Point out any other changes that were

not mentioned, referring to Box 3 .

6. Explain: One of the biggest changes a girl experiences during adolescence is the start of menstruation.

7. Ask: What happens to girls in your community once they start menstruating?

[They are seen as a woman, they stay inside during menstruation, they get married, etc.]

How do you feel about what happens to girls in your community once they start menstruating - is it good or bad do you wish something different happened?

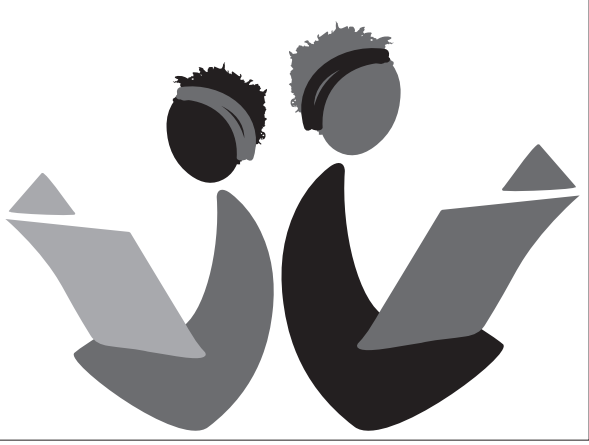




\section{activity 3}

\section{MAKING PUBERTY EASIER* [12 MINUTES]}

1. Remind participants that while puberty is an exciting time of change, it can also be challenging.

2. Ask: What are some things that could help one get through these changes?

[Examples: Social support from peers; talking to a mother, sister, aunt, or friend; get knowledge and information about bodily changes from health providers or books; keep busy to distract your mind, etc.]

What is one of the most embarrassing or challenging aspects of puberty for girls?

[Examples: Soiling their pants/dress during menstruation, unwanted attention due to growing breasts, etc.]

What can your peers do to help minimize the embarrassment and make you feel more comfortable? [Examples: Always carry extra menstrual hygiene items, bring extra clothes in case pants/dress is soiled, go shopping for bras or facial cleaners together, etc.]

What can you do to help each other get through the ups and downs of menstruation, and puberty overall?

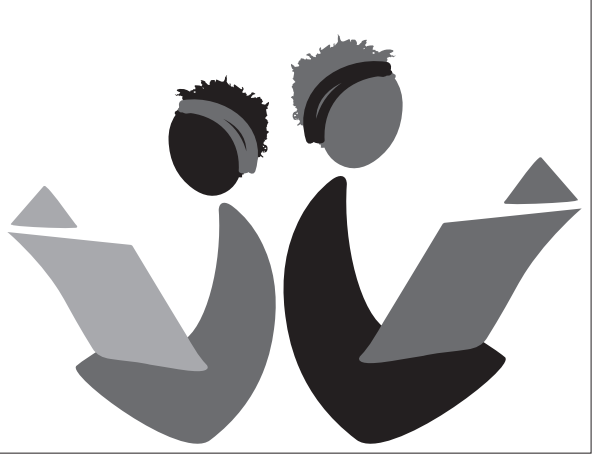




\title{
wrap-up
}

\author{
WRAP-UP \\ [10 MINUTES]
}

Ask participants to summarize what they have learned. Fill in any key points they miss.

Key Message: Boys and girls go through many physical and emotional changes during puberty - all of these changes are normal and represent a healthy body! They also experience new and different social pressures, and people relate differently to them.

\section{Action item: 3 minutes}

Explain: This week, the action item will be our responsibility. Tear out a small piece of paper from your notebook. Think about a question you have about puberty - something you are curious or confused about or simply don't know. Write your question down on your slip of paper. Don't put your name on the paper - just your question. When you are done, fold your paper so no one can see your question. and give it to me. At the next session we'll pick a few questions to answer. No one will know who asked the question, including me.

Ask for any final questions or comments. Remind participants where and when the next meeting

will take place, and what topics will be discussed.

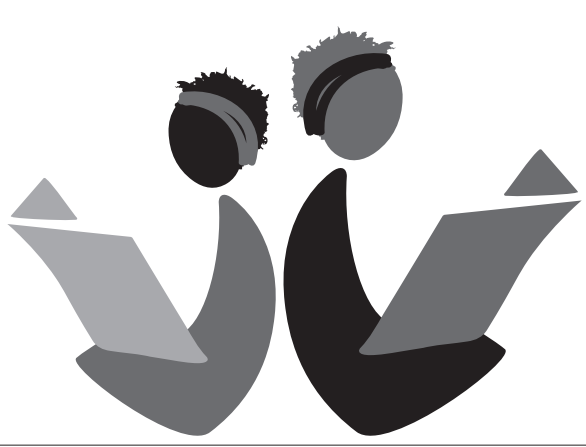




\section{SESSION 11 SEXUALITY}




\section{session 11 / sexuality}

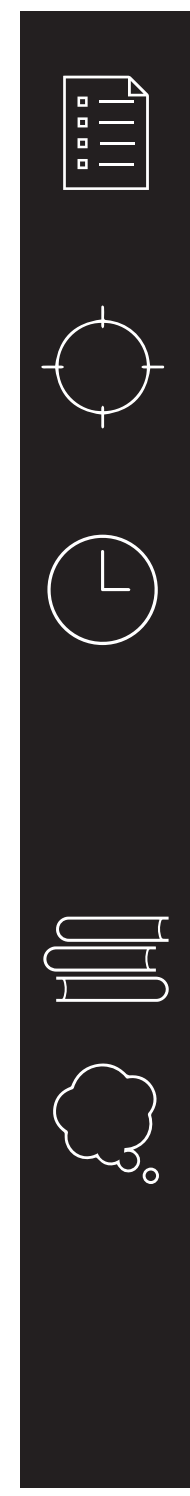

\section{SESSION DESCRIPTION}

Participants consider whether statements about sexual behavior are true or false, correcting misconceptions, and choose whether they agree or disagree with statements about why people choose to have sex or not have sex.

\section{OBJECTIVES}

By the end of the session, participants will:

- Identify correct information about sexual behavior

- Reflect critically about their own and others' decision-making related to sex

\section{SESSION TIME}

1 hour

Warm-up: Step into the circle, 5 minutes

Action item debrief: 10 minutes

Activity 1: Sexual behavior - myths and facts, 20 minutes

Activity 2: Sexual decision-making, 20 minutes

Wrap-up: 2 minutes

Action item: 3 minutes

\section{REQUIRED MATERIALS}

Chalkboard and chalk

\section{PRE-SESSION PREPARATION}

Review the anonymous questions that girls submitted to you at the end of Session 10. If you are uncertain of the answers to any of the questions, contact GirlsRead! staff and they will assist you. Consolidate questions that are essentially the same as it is likely that some participants will ask about similar concerns. Write down the questions and answers on a sheet of paper so you are prepared to discuss them with the group.

Read through the entire session and, if necessary, practice presenting the activities. Prepare all materials needed.

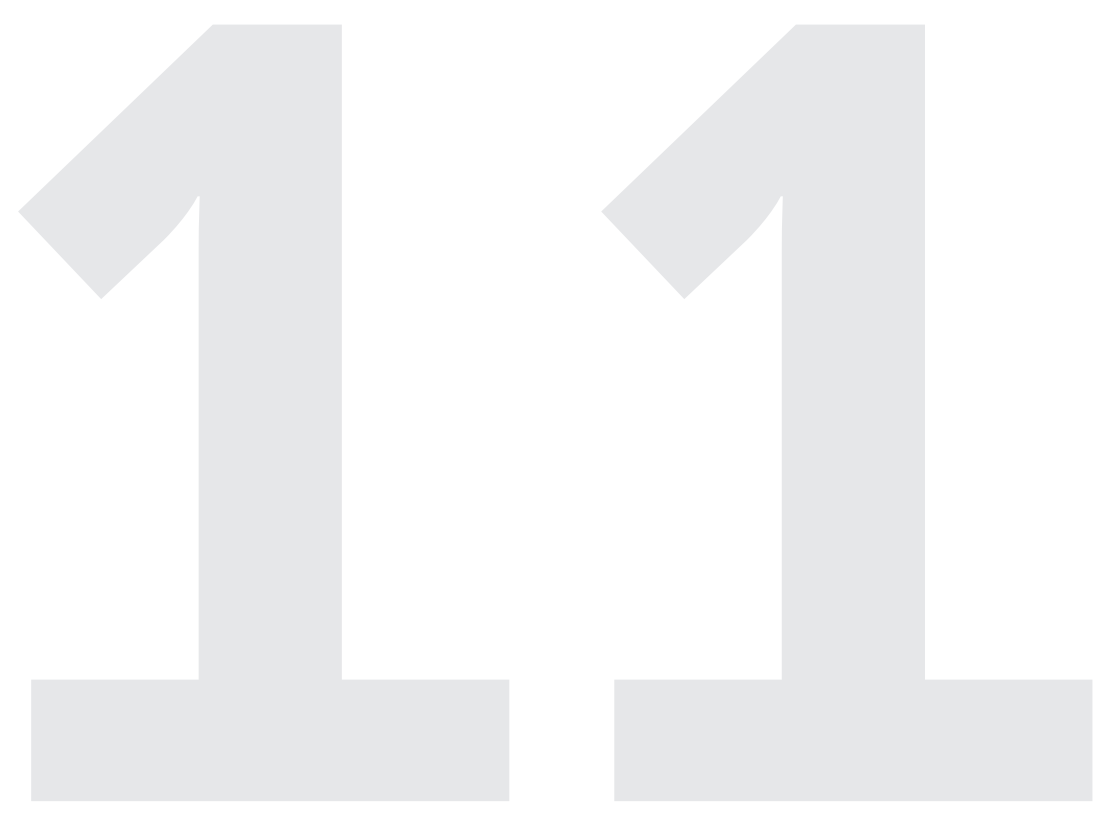




\section{session 11 / sexuality (cont.)}

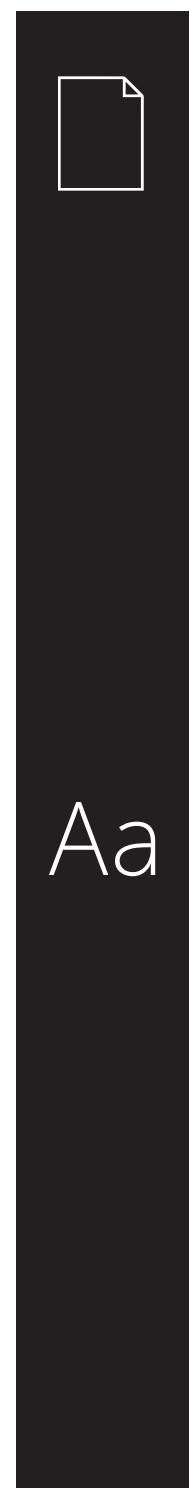

\section{FACILITATOR NOTES*}

Sexuality is an important aspect of life. It can enhance happiness, well-being, health, and the quality of life. It can also foster intimacy and trust between partners. Developing comfort and confidence about sexuality is part of growing up. Such comfort is also influenced by individual, family, and social

factors and experiences.

It is important to discuss this topic now with girls so they know the facts about sex and sexuality before they become sexually active and before they are flooded with misinformation. Teaching about sex does not mean that you think girls should be having sex already. Some of your participants may be sexually active - some are older, some have been coerced, etc. - and they should never be made to feel badly about the fact that they have had sex. They need to know how to be

\section{TERMS}

Masturbation: Touching or stroking oneself (especially one's own genitals) for sexual pleasure.

Sexual norms: Social standards that shape our understanding, attitudes, and experiences related to sexuality.

Sexuality: How people experience and express themselves as sexual beings.

Many factors contribute to people's sexual behaviors, relationships, feelings, identity, safe, have correct information, and how to get help. Some of your participants are still young and not sexually active - they also have a right to this knowledge but waiting to have sex until they are older and more mature is best.

A critical aspect of sexual experience is that it be voluntary and wanted by both partners.

Sexual consent involves deciding freely and voluntarily to engage in sexual activity with another person. Because people may have conflicting or confusing feelings about whether they want to have sex, or about whether they can comfortably refuse unwanted sex, ensuring consent can be a complicated matter. As young people mature, their capacity to give meaningful consent evolves.

Sexual norms and scripts vary according to

desires, and attitudes. One of these factors is biology, especially sex hormones. Another factor is individual personality and experience. Yet another factor is culture, which influences people's attitudes, expectations, and experiences related to sexuality. Cultural norms also affect laws and policies about sexuality. All of these factors interact throughout life. gender roles, leading, in many settings, to a "double standard" for sexual behavior. Boys are often permitted, or even pressured, to be sexually active. They may feel significant pressures to "prove their manhood" through early, repeated, and sometimes even aggressive, heterosexual experience.

Girls often receive negative or contradictory messages about sex. Many girls are taught that they should not be sexually active prior to marriage. They may even be punished for being sexually active. At the same time, girls are expected to be sexually appealing. Media images may 'sexualize' girls at a young age. Girls are often socialized to be submissive to their boyfriends and husbands and to men in general, making assertiveness difficult. Some girls experience pressure to have sex in order to prove they are capable of having children.

*Source: International Sexuality and HIV Curriculum Working Group. 2009, updated 2011. It's All One Curriculum: Guidelines and Activities

for a Unified Approach to Sexuality, Gender, HIV and Human Rights Education. New York: Population Council. Guidelines: Pages 84-90; 112-13. 


\section{warm-up}

\section{STEP INTO THE CIRCLE* [5 MINUTES]}

The point of this game is to show how much we do and do not have in common. Please all stand up and come together and stand in a circle.

Explain: I will instruct "Step into the circle if..." and if what I say applies to you, then you step into the circle. Then you will all step back outside the circle, and I will ask the next statement
Step into the circle if:

You are proud to be Zambian

- You have a younger sister

- You like the color red

- You don't like mathematics

- You like to read

- You don't like papaya

- You have lived in a different neighborhood than where you live now

You have had to make a difficult decision

- You have been told confusing information about sex

Your grade 6 class received sexuality education in school

\section{ACTION ITEM DEBRIEF [10 MINUTES]}

Before the session, sort through the anonymous questions and select several of the most frequently occurring questions and/ or those that most urgently need clarification. If there is a lot of discussion around some of the questions, you may not be able to get through all of them. them we will do the rest another time.
Explain: Last week you all wrote anonymous questions for me. There are some really great questions! We'll go through as many as we can today, but if we don't get through all of

Read out each question and your answer. Give participants the opportunity to ask follow-on questions or ask for further clarification.
Ask:

Are there things that you have in common with others in the group that surprised you?

Are there things that you thought more people would have in common with you? 


\section{activity 1}

\section{SEXUAL BEHAVIOR - MYTHS AND FACTS* [20 MINUTES]}

1. Tell participants they will be discussing common myths about sexual behavior and separating myth from fact.

2. Divide the group into two teams. On the board, make a scoresheet with a column for each team.

\section{Explain:}

In teams, you will discuss each statement that read out and decide whether it is true or false. - In one of your notebooks, write the numbers 1 through 10 in a column. This is where you will mark your answers. - At the end, we will go over all of the questions, and each team will give its response. I will record a point every time a team gives a correct answer.

3. Read out each statement below, one by one, allowing the teams time to consult and record an answer quickly before moving on to the next statement.

4. To review and score, read the first statement aloud. Then ask each team whether it decided if the statement was True or False. Clarify the correct answer (see text below each statement), mark a point for whichever team(s) answered correctly, and address any confusion or questions. Repeat for each statement. Allow one minute for each.

Masturbation, which is touching or stroking oneself (especially one's own genitals) for sexual pleasure, is harmful.

[False: Masturbation is not harmful; rather it is safe and a good way to learn about one's own body. However, it is a personal choice. Most people masturbate, but some people choose not to, and some are not comfortable with the idea.]

- If a girl does not bleed the first time she has sex, it means she is not a virgin.

[False: Some bleeding is caused by the tearing of the hymen. However, the hymen can easily stretch or tear during normal physical activity or sports and can be stretched open by fingers or a tampon which is a plug of soft material produced to be inserted into the vagina to absorb menstrual blood. The absence of a hymen or bleeding does not mean a girl has had sex.

It is important to keep the vagina clean by douching (cleaning out the vagina usually with a water/vinegar solution).
[False: The vagina is naturally self-cleansing. Never put sprays, washes, soap, perfumes, or herbs inside the vagina. These can harm the natural balance of the genital tract and can lead to infections. Gently washing the vulva - the outside part of a woman's genitals -

with water or with mild soap and water when bathing is all that is recommended. Do not put soap inside the vagina.

Many women do not have orgasms, meaning the climax of sexual excitement from vaginal intercourse alone.

[True: Most women do not reach orgasm from vaginal intercourse alone. Rather, they reach orgasm through stimulation of the clitoris. Women are more likely to have an orgasm if they (or their partner) stimulate the clitoris directly before, during, or after vaginal intercourse.]

Continued on next page

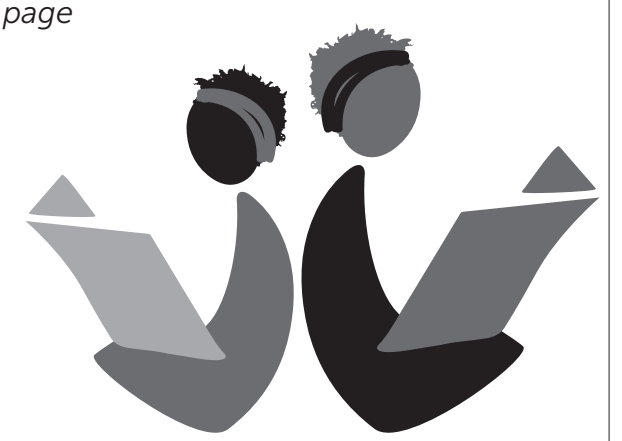

*Source: International Sexuality and HIV Curriculum Working Group. 2009, updated 2011. It's All One Curriculum: Guidelines and Activities 


\section{activity 1 (cont.)}

\section{The first time a woman has sex it will hurt.}

[False: The first time a woman has sex it may or may not hurt. To minimize discomfort or pain, partners should take time to explore each other's bodies and become fully aroused before penetration, so that the woman's vagina is well

lubricated. If either partner feels nervous or afraid, the couple may want to wait.

Once a man becomes sexually excited, he cannot control himself and must ejaculate.

[False: Some men believe that if they are really sexually excited, they have to have an orgasm, but this is not true. Stopping may cause some discomfort, but the discomfort will diminish on its own. Anyone - male or female - can stop at any point in a sexual experience.]

The easiest way to know how to please your partner is to talk about what he or she likes and what feels good.

[True: Every person has his or her own preferences concerning what is sexually arousing. Rather than guessing what one's partner likes or finds pleasurable, it is quicker and more reliable just to ask her or him. Communication is one key to having a positive sexual relationship that is pleasurable to both partners.]
You can acquire a sexually transmitted infection (STI) from oral sex.

[True: Oral sex can result in the transmission of various STIs. This list of STIs includes herpes, gonorrhea, human papilloma virus (which leads to warts or cancer), syphilis, chlamydia, hepatitis B, and chancroid, as well as HIV.]

A woman who likes sex a lot can't be trusted to be faithful to her partner.

[False: Enjoying sex is natural for men and for women. A person's enjoyment of sex has nothing to do with his or her trustworthiness. The idea behind this statement, that women should not like sex, reflects the common misconception that men but not women, like sex. This idea is unfair, inaccurate, and a stereotype.]

After going over all the statements, announce which team won. Ask why there are so many myths about sex and sexual behavior. Possible answers:

Sex is often considered a taboo or improper subject that should not be discussed, and when people don't talk about something, they don't learn the correct information. Without facts, myths about sex and sexual behavior flourish.
Another issue is that gender norms - how women and men are expected to behave and act - have a powerful influence

on people's views about sex and sexual behavior. For example, when people think that women are less important or have less authority than men (which is not true!) they may also believe myths about women not having a say in whether, when, and how to have sex. This is wrong.

Similarly, gender norms about men being dominant and strong are replicated in myths about men having a powerful need to release themselves sexually or to have many partners. This is also not true.

Often people repeat myths because it serves their interests and maintains their power over others - remind the girls to be critical thinkers and not to be manipulated.

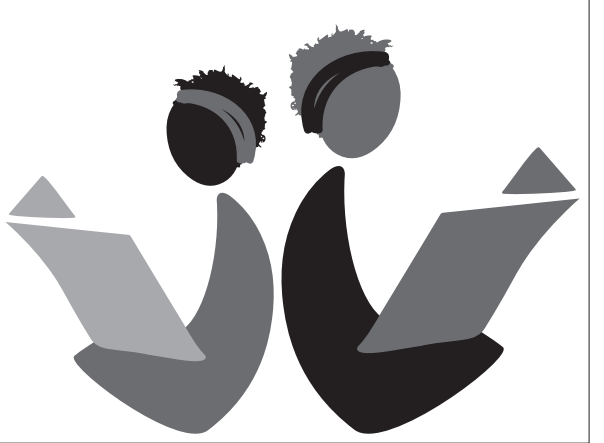




\section{activity 2}

\section{SEXUAL DECISION-MAKING* [20 MINUTES]}

1. Place an "agree" and a "disagree" sign on opposite ends of the room, or write "agree" and "disagree" on opposite ends of the chalkboard.

2. Introduce the activity:

Today we will discuss some of the reasons people decide to have sex or not to have sex. Many different circumstances and

feelings influence people's decisions about whether to have sex. Sometimes people can have mixed feelings.

To explore this topic, I will read a few statements. These are values statements, and there is no right or wrong response to any of them. For each statement, if you agree, go stand by that corner/side of the room (indicate where the agree section is located). If you disagree, go to that corner/side of the room (indicate where the disagree section is located). "Force" yourself to choose one side or the other, even if your view is somewhere in between the two sides. Then, a couple of people can share their views. [Make sure everyone understands the rules.]

3. Read each statement, below. After each statement, allow time for participants to move to their "side." Allow two comments from each side. Then go on to the next statement even if the conversation has not come to an end.

If a girl loves her boyfriend, she should show it by having sex with him.

I think it's okay to accept money for having sex, if you need the money.

- I think that a real man takes risks and is sexually aggressive.

Images on television and in magazines make young people feel that they should be having sex.

Pressuring someone to have sex against his or her will, even if you don't use physical force, is more or less the same as rape.

A lot of girls I know have sex because they feel they have to.

A lot of people who decide to have sex regret it later.

Before they have sex, most adolescents talk thoroughly with their partner about whether they both feel comfortable and want to have sex, as well as about how to protect against infection and pregnancy.

Reserve a couple of minutes to sum up, asking:

Why is it important for a young person to think clearly about the reasons for his or her choice to have or not have sex? [Probe for: sense of comfort, safety, voluntariness, and pleasure, as well as protecting one's health.] Young people have many different reasons when they choose to have or not to have sex. What kinds of misunderstandings or problems can result from these differences in reasons? We see that people often are not aware of all their motivations and feelings, or have not analyzed their circumstances. What are some ways that we can become more aware of what is going on, how we feel, and what we want and do not want? [Probe for: writing in a journal talking to someone trusted, thinking honestly and critically.]

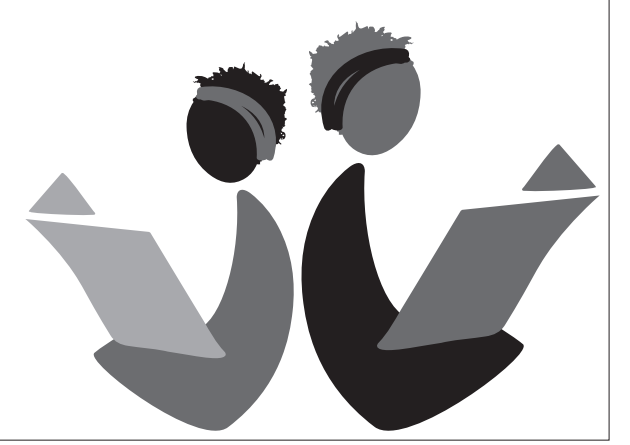

*Source: International Sexuality and HIV Curriculum Working Group. 2009, updated 2011. It's All One Curriculum: Guidelines and Activities for a Unified Approach to Sexuality, Gender, HIV and Human Rights Education. New York: Population Council. Activities: Pages 70-71. 


\section{wrap-up}

\section{WRAP-UP \\ [2 MINUTES]}

Ask participants to summarize what they have learned. Fill in any key points they miss.

Key Message: Developing comfort and confidence about sexuality is part of growing up. Having accurate information can help, but it is also critical to be aware of societal norms and pressures regarding sex. People may have conflicting or confusing feelings about whether they want to have sex, or about whether they can comfortably refuse unwanted sex. Thinking critically and honestly about a situation can help a person make better decisions, including decisions about sex.

\section{Action item: 3 minutes}

Mutuality, the sharing of a feeling or action, and respect are important for all relationships, including sexual relationships. Prepare a short spoken word poem about what mutuality and respect in relationships means to you.
Ask for any final questions or comments.

Remind participants where and when the next meeting will take place, and what topics will be discussed.

Thank them for their participation.

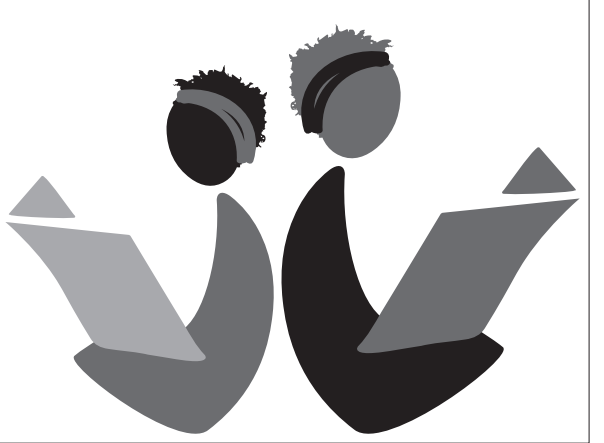




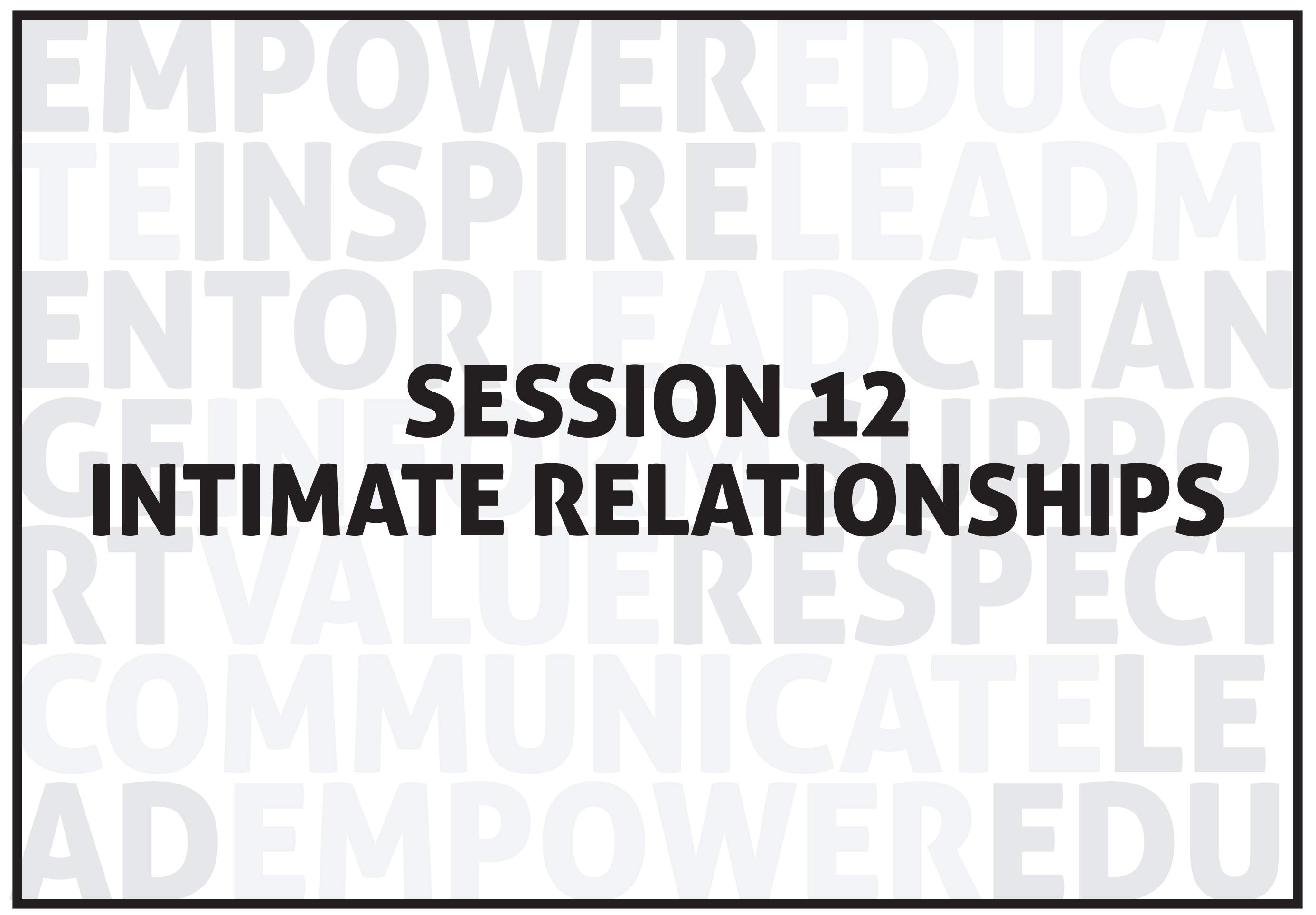




\section{session 12 / intimate relationships}

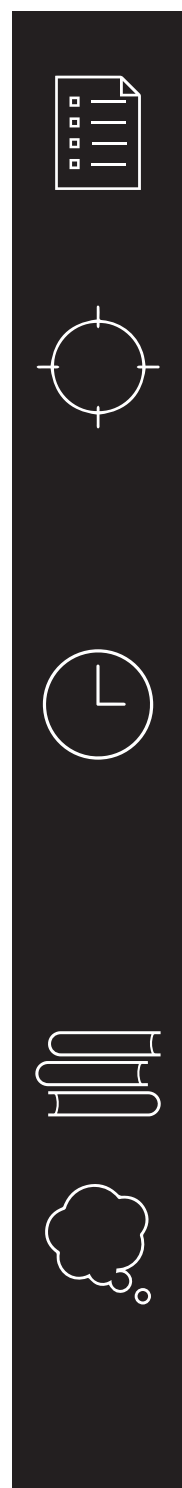

SESSION DESCRIPTION

Participants learn to distinguish unwanted sexual attention, discuss friendships between girls and boys, and, through case studies, identify inequality in relationships.

\section{OBJECTIVES}

By the end of the session, participants will:

Understand that not all attention is good attention and develop

strategies for stopping unwanted attention

Be able to identify how societal inequality can affect intimate relationships, particularly between younger girls and older male partners

\section{SESSION TIME}

1 hour

Action item debrief: 5 minutes

Warm-up: Unwanted attention, 10 minutes

Activity 1: Can girls and boys be friends? 20 minutes

Activity 2: What's going on between these two? 20 minutes

Wrap-up: 3 minutes

Action item: 2 minutes

\section{REQUIRED MATERIALS}

Chalkboard and chalk

PRE-SESSION PREPARATION

Read through the entire session and practice presenting the activities.

Prepare all materials needed.

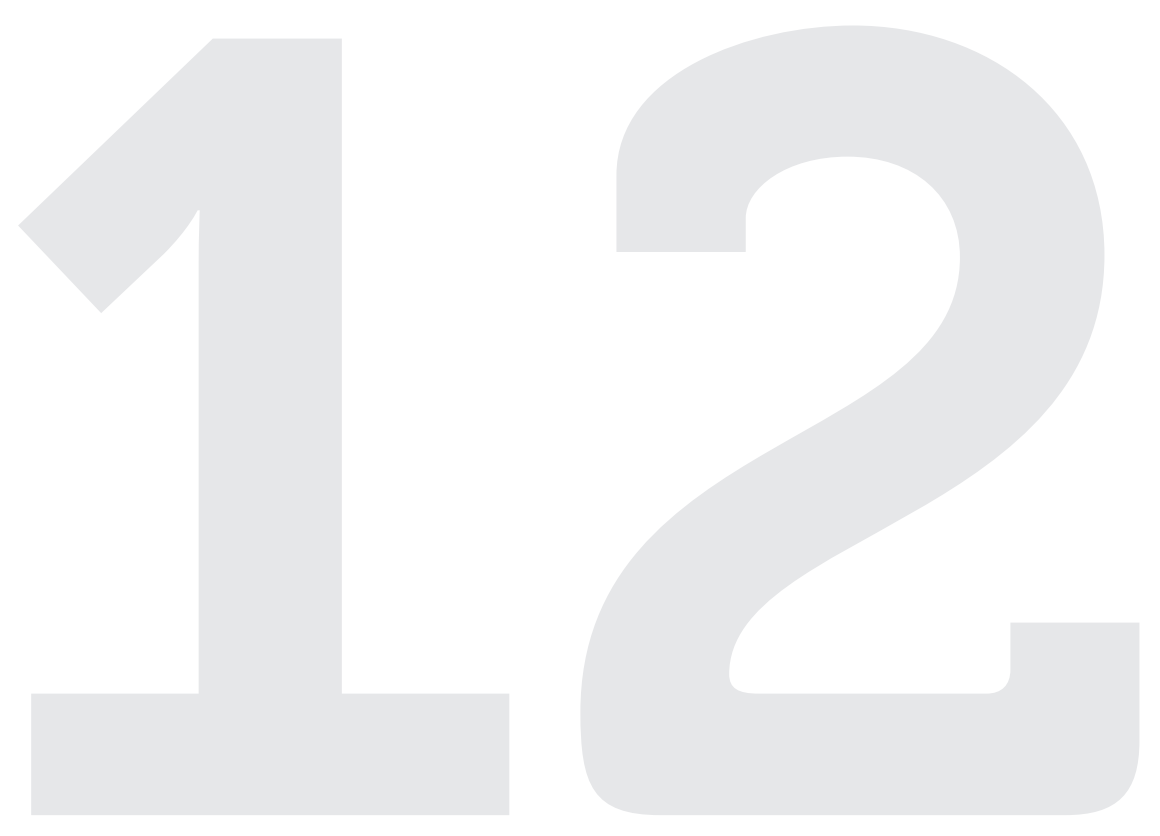




\section{session 12 / intimate relationships (cont.)}

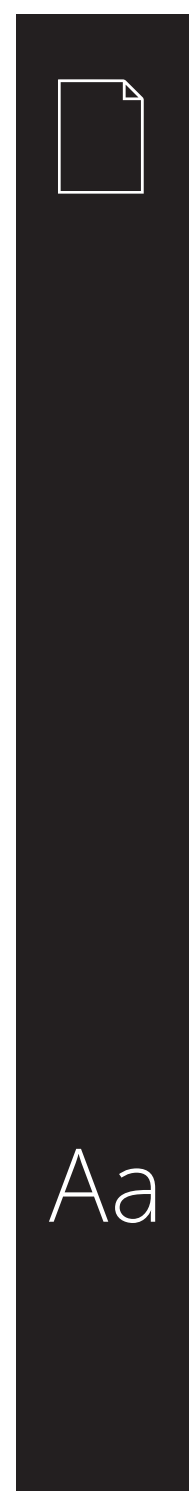

\section{FACILITATOR NOTES*}

A friendship can be a particularly fulfilling relationship involving intimacy, trust, and honesty. In early adolescence, friendships are often established between boys and girls based on trust, shared feelings, and thoughts. Sometimes there is a deep attraction that is not necessarily sexual, but just a preference for that friend over everyone else. The relationship provides love, closeness, affection, tenderness, and care.

Love is a complex emotion, and every person may define love differently based on his or her own experience with loving relationships. Generally, love refers to a deep feeling of fondness, attraction, respect, caring, and understanding for another person, despite their weaknesses or faults. It is important to remember that sexual intercourse is not the only way of showing love to someone. Also, having sex does not mean that two people will fall in love. Remember, love is about respect and caring for each other. Love is never a good reason to do anything that puts your health and future at risk.

\section{TERMS}

Friendship: A particularly fulfilling relationship involving intimacy, trust, and honesty.

Love: A strong feeling of affection towards something or someone.
Becoming a couple means that a person will start on a new, undiscovered path of experience and will live through many profound changes. Falling in love means loving in a new way and learning to care for our health and our life's goals. If we have the proper skills, we can establish a healthy relationship that promotes our well-being and the proper care of our physical, emotional, and sexual health. During this stage in their development, teens can practice having healthy, loving, and constructive relationships, in which both members can learn to become better individuals, a better couple, and better members of society.

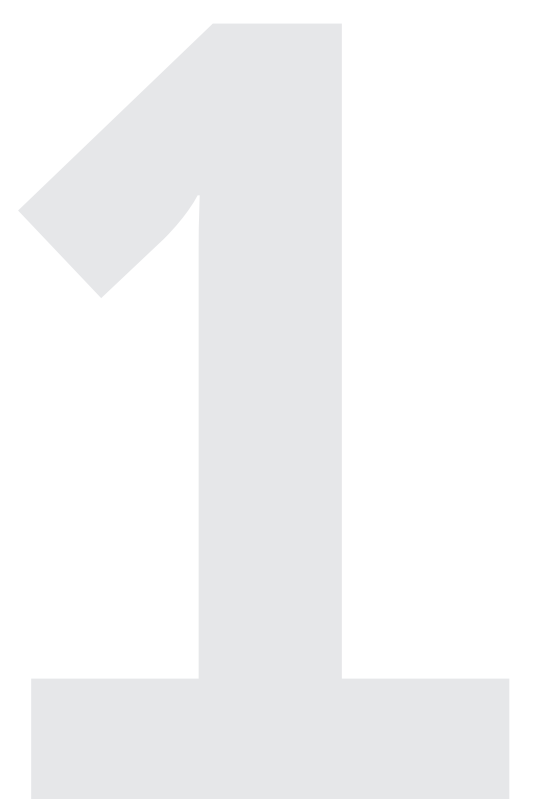




\section{warm-up}

\section{ACTION ITEM DEBRIEF [5 MINUTES]}

Ask: How did your spoken word poems about mutuality and respect turn out? Who would like to present? I can't wait to hear!

\section{UNWANTED ATTENTION*}

\section{[10 MINUTES]}

1. Explain: We are going to talk about a sensitive issue and everyone should be kind and respectful to each other. First, we are going to talk about positive attention.

2. Ask: What are some things that happen between two people that are 'feel good' behaviors?

[Examples might include hugs

handshakes, a pat on the back, holding

hands, getting a compliment.]

3. Explain: Sometimes children and adolescents experience unwanted attention from adults or from peers.

4. Ask: What are some kinds of attention that "feel bad?"

[Examples might include men shouting

things at girls in the streets, someone saying rude things to you, someone touching your private parts, someone forcing you to do things you don't want to do.]

- How do you know if a behavior represents positive attention or negative attention?

[Emphasize that if the attention makes them feel bad, then it is unwanted attention.]

Who are some of the people who give us positive attention?

[Make a list on the board of their answers.]

Who are some of the people who give us unwanted or negative attention?

[Make a list on the board.]

5. Explain: Sometimes the same people give both positive and negative attention. Talk about what this means - that sometimes the people you are supposed to be able to trust can do things that hurt you. You need

to believe in yourselves and know that unwanted attention is not good, no matter who is giving it to you. Emphasize that when someone is giving you unwanted attention, it is important to tell that person to stop. If it continues, it is important to find someone you trust and tell them what is happening. If you do not get help from the person you have told, find someone else to help you until it stops

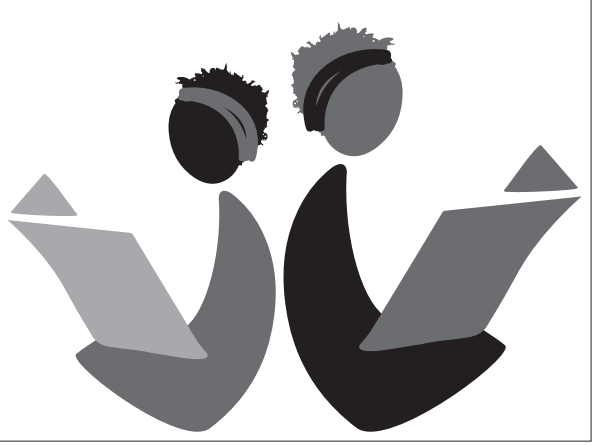




\section{activity 1}

\section{CAN GIRLS AND BOYS BE FRIENDS?* \\ [20 MINUTES]}

1. Explain that this session looks at relationships between girls and boys.

2. Read the statement: "Some people think that girls and boys can't be friends."

Ask participants how they feel about that statement? What are their opinions about that?

Give some time for comments to get the session started.

3. Ask: What are your own experiences with friendships with the opposite sex? Is it easier to have friendships with boys now or when you were younger?

[Participants will probably recall that they were able to move freely with boys when they were younger, but restrictions have been put on them as they have grown older, as well as on boys, and now they are not allowed to interact any more. Ask the girls if they think it's similar for the boys, that more restrictions are put on them as they get older.]

\section{Dear Susan}

How are things with you? I am very confused about so many things these days. I feel like I know less about life now that I am 14 years old. I am confused and frustrated.

Do you remember I told you about Andy who is now 16 years old? Andy is a strong. good-looking boy, and I like him. He began writing letters to me and I answered his letters. We became friends.

Last week, he said he really loved me and wanted to be alone with me to show his love. I said that I liked him also but did not feel ready to love him. I said my parents would be very angry if I had a boyfriend while I was still young. Andy got very angry and upset He said if I really cared I would show it. He said I was acting like a child and that I should grow up!
Now Andy won't even talk to me anymore. I am really hurt by the things he has said. I feel foolish to have even thought that he could be my friend. Do boys only have one thing on their minds? Maybe he was right and I need to grow up.

What do you think? When I was younger I used to play with boys and girls in the neighborhood. We all used to play together and no one said anything. Now my parents tell me that I have grown up and should not play with boys. I should play only with girls. If they see me talking to a boy, they scold me. They say people will spread rumors about me if I mix around with boys. Tell me, is it bad? Can't girls and boys be friends? Please write to me or come visit, as I am very confused and want your advice.

\section{Lots of love}

Idah

\section{Continued on next page}

4. Say: Now, I am going to read a letter from a girl named Idah to her friend Susan:

*Source: Centre for Development and Population Activities (CEDPA). 2009 


\section{activity 1 (cont.)}

After reading the letter, ask:

Do you think it's possible for girls and boys

to be just friends? Why or why not?

How do you think girls and boys can start and maintain a friendship?

What discourages girls from meeting or spending time with boys, either as friends or having a romantic relationship?

- What makes you enjoy talking or being with boys?

What qualities would you hope to find in a friend of the opposite sex?

How do your parents/teachers/other friends/relatives react when you are friendly with boys or girls? What can you

do about their reactions? 


\section{activity 2}

\section{WHAT'S GOING ON BETWEEN THESE TWO?* \\ [20 MINUTES]}

1. Explain: Next we will explore how inequality and power differences between people can affect our relationships, particularly between younger girls and older men.

To explore this, I will read a story and then we will discuss some questions:

I was attracted to my boyfriend because he was older and no one knew him. He seemed mysterious and exciting. We fell in love and now we spend most of our time together. You know how it is. I really like listening to his stories about all his experiences. When we go out, he mostly decides where we go because he pays and knows all of these great places. He has influenced me a lot. I was never that interested in sports, but he loves football, so I spend a lot of my free time now with him at games or watching sports on TV.

After we'd known each other for a few months, he said that he wanted to make love to me. I hesitated, but I thought that he might leave me if I didn't. He's 23, after all, and experienced. These days, I hardly see my friends. They complain and say that I've changed. I miss them and sometimes I think about how I used to study more and how much I liked reading. But, you know, I just think that's what happens when you are in love.

\section{Ask}

Different kinds of inequality exist among groups in society. [For example, people may have greater or lesser status based on their ethnic or racial groups, economic class, sex age, or other characteristics.] Which forms of inequality are present in this relationship?

Which person has the more powerful position in this relationship as a result of his or her status in society? What is the basis for this inequality? How is this more powerful position demonstrated?

- Which person has the inferior position in this relationship because of his or her social status? How is this inferior position demonstrated?

What effect, if any, does this inequality have on each person? How does it affect the relationship?

Do you think these kinds of issues exist in our community? Please comment on them.

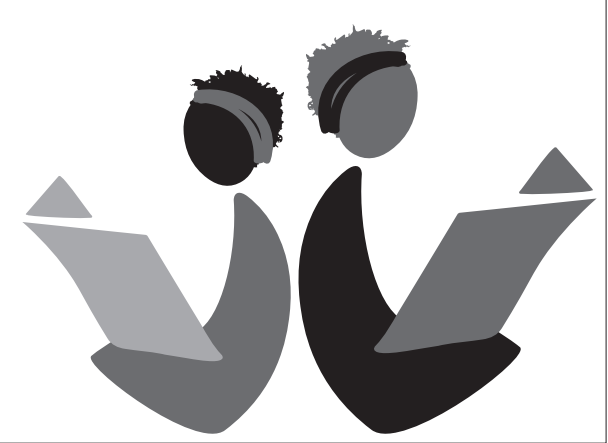

*Source: International Sexuality and HIV Curriculum Working Group. 2009 updated 2011. It's All One Curriculum: Guidelines and Activities for a Unified Approach to Sexuality, Gender, HIV and Human Rights Education. New York: Population Council. Pages 86-87. 


\section{wrap-up}

\section{WRAP-UP \\ [3 MINUTE]}

Ask participants to summarize what they have learned. Fill in any key points they miss.

Key Message: Every person has many differen kinds of relationships, including family, friends, neighbors, teachers, boyfriends and girlfriends, coworkers and others. Inequality can undermine mutual respect and comfort in people's

relationships. Unwanted sexual attention is not

good, no matter who is giving it to you and it is

important to tell that person to stop.

\section{Action item: 2 minutes}

Think about the qualities you value in the people you feel closest to - whether they are family members or friends. You have two action items:

1. Come prepared for the next session with at least 3 adjectives that describe those qualities. For example, honest, caring, and so on.

2. Tell the person how you feel - too often we don't stop and tell the people we are closest to that we care about them and why.
3. Ask for any final questions or comments. Remind participants where and when the next meeting will take place, and what

topics will be discussed.

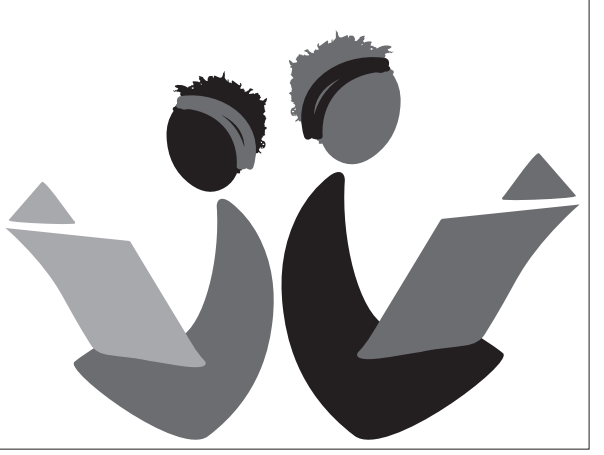




\section{SESSION 13 \\ SEXUAL HARASSMENT, SEXUAL COERCION, AND RAPE}




\section{session 13 / sexual harassment, sexual coercion, and rape}

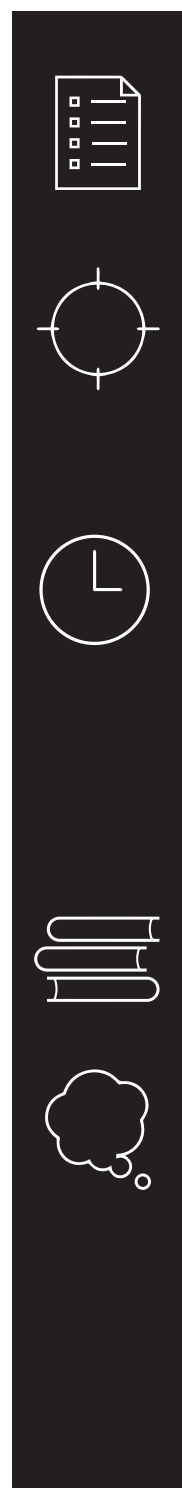

SESSION DESCRIPTION

Participants learn the meaning of sexual harassment, sexual coercion,

and rape, and what to do when confronted with them.

\section{OBJECTIVES}

By the end of the session, participants will:

Increase awareness about sexual harassment

- Increase awareness about sexual coercion

- Increase knowledge of the dynamics of rape

\section{SESSION TIME}

Session Time: 1 hour

Action item debrief: 5 minutes

Activity 1: Identifying sexual harassment, 15 minutes

Activity 2: Is it coercion? 15 minutes

Activity 3: "Mythinformation" game: rape, 20 minutes

Wrap-up: 2 minutes

Action item: 3 minutes

\section{REQUIRED MATERIALS}

Chalkboard and chalk (at least two pieces)

PRE-SESSION PREPARATION

Read through the entire session and practice presenting the activities.

Prepare all materials needed.

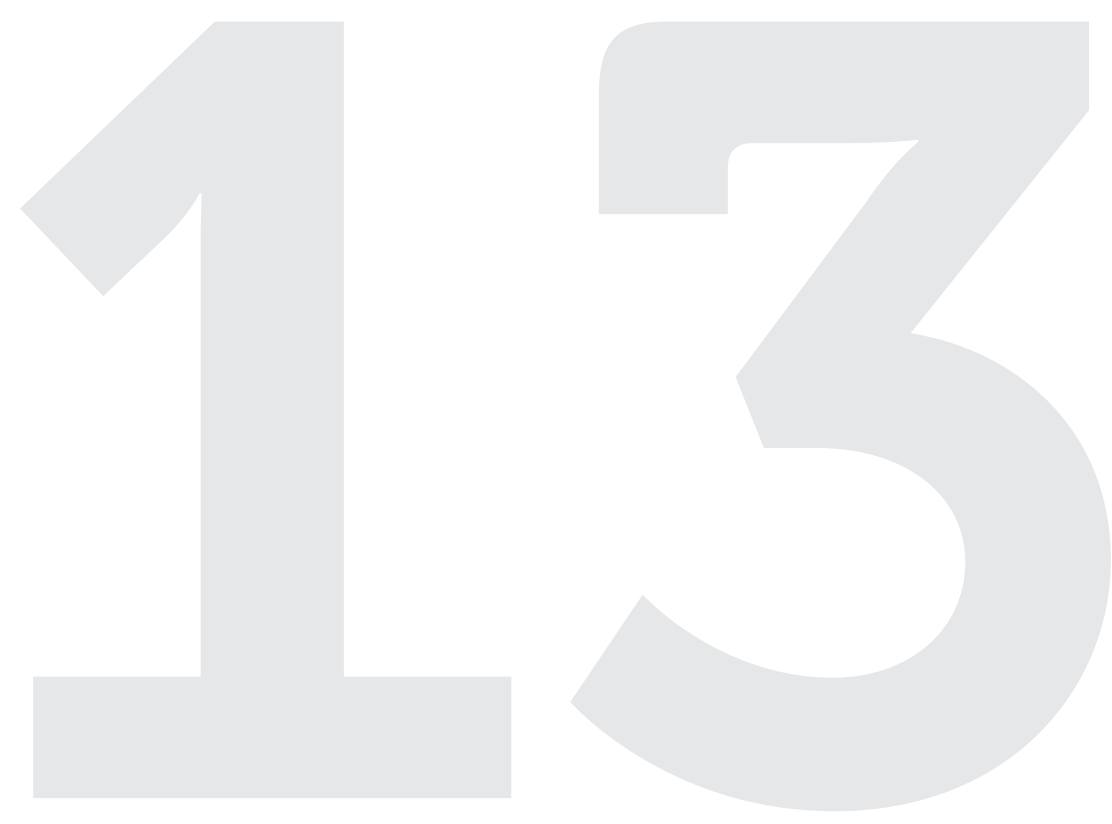




\section{session 13 / sexual harassment, sexual coercion, and rape (cont.)}

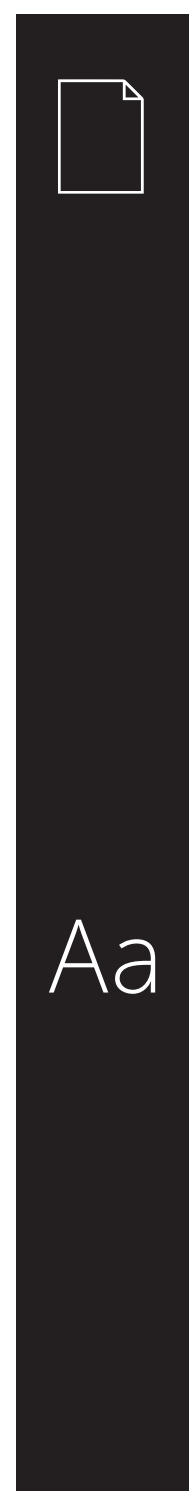

\section{FACILITATOR NOTES*}

For many young people, especially women and girls, sex is not a choice. Some adolescents are forced to have sexual relations; feel pressured to have sex in exchange for good grades or pocket money; are assaulted if they refuse to have sex; or sell sex in order to survive.

Every adolescent should know that his or her sexual organs are private and personal property. Nobody should touch them without permission. Some victims of sexual abuse are assaulted by family members or acquaintances. Because of the older person's position in the family, he or she may be able to pressure the child into doing sexual things without actually having to use force. These crimes, including rape, are the fault of the perpetrator or older person and not the fault of the victim or child.
The short-and long-term consequences of sexual violence can be physically and emotionally damaging. People who have experienced sexual violence often suffer from serious mental health issues. If someone tells you they have been raped encourage them to go to a hospital or health center that provides services for people who have been raped. The hospital should be able to give them a medical evaluation and attention to any injuries, counseling support for the survivor and her family, and treatment to prevent infection with HIV, pregnancy, and other sexually transmitted infections. If the rape was

perpetrated by an intimate partner, referrals to safe homes, legal assistance, or other services may be required.
[Note to facilitator: Be aware that one or more of your participants may have been sexually coerced, raped, or molested. If a participant becomes upset during this discussion, you may want to speak quietly to that person and make plans to talk privately at a later time. You should have local resources on-hand (police, spiritual leaders, etc.) for rape victims (address and phone numbers) prior to presenting this topic. If the rape occurred recently, a girl can use emergency contraceptives to prevent pregnancy within 120 hours or 5 days.

\section{TERMS}

Consent: Permission for something to happen or agreement to do something.

Date rape: Rape between individuals who are dating or know each other; also called Acquaintance Rape.

Gender-Based Violence (GBV): Any act that results in, or is likely to result in, physical, sexual or psychological harm or suffering that targets individuals or groups on the basis of their gender.

Incest: An act of two members of the same family having sexual intercourse, for example a father and daughter, or a brother and sister.

Rape: Forced sexual activity, usually involving sexual intercourse, which is initiated by one or more people without the other person's consent.

Sexual coercion: The use of status and/or powe to coerce (meaning to persuade an unwilling person) or attempt to coerce a person into having sex. A person might use emotional manipulation, deception, physical force or threats, verbal

\section{insistence, or economic inducements.}

Sexual harassment: Sexual harassment is unwanted attention of a sexual nature from someone in school or the workplace; it includes unwelcome sexual jokes, glances, or comments.

Statutory rape: Sex with a person who the law defines as too young to legally consent, regardless of whether or not they consented. 


\section{warm-up}

\section{ACTION ITEM DEBRIEF \\ [5 MINUTES]}

Last week your action item was to think about

the qualities you value in the people you feel

closest to. What qualities did you identify?

[Write the adjectives that the girls call out on

the board.]

How did it feel to share your feelings with the people directly? How did your closest friends or family react when you told them? 


\section{activity 1}

\section{IDENTIFYING SEXUAL HARASSMENT \\ [15 MINUTES]}

1. Ask: What is sexual harassment?

[After listening to some answers, provide this definition: Sexual harassment is unwanted attention of a sexual nature

from someone in school, the community, or the workplace. It includes unwelcome sexual jokes, glances, or comments. Note that both girls and boys can be sexually harassed. In schools, sexual harassment is wrong regardless of whether it is perpetrated by students, teachers, or school administrators.]

2. Split participants up into five small groups.

3. Explain: This is a quick activity to discover what you know and think about sexual harassment in your daily lives. I will read you a couple of scenarios that end with a question. You will have 1-2 minutes to discuss with your small group and decide what you think. People might have different opinions, but see if you can come up with an agreed upon answer from your group.
4. Read the following scenario:

Patience and Paul are in the same class. Most days, at the end of the day, when the class lines up for dismissal, Paul stands near Patience and makes comments about her breasts. It makes Patience uncomfortable and she has asked him to stop, but he continues to do so. Is this sexual harassment?

[Allow 1-2 minutes for the small groups to decide what their answer is.]

5. Ask one of the groups what they decided. After they respond, ask if the other groups agree. If any of the groups think it is not sexual harassment, ask a group that does think it is sexual harassment to explain their answer. [Note: This is sexual harassment.]
6. Read this next scenario:

Musonda, Brenda, Felistus and Tamba walk home from school together every day. Some days, as they leave the school yard, a group of older male students is hanging out. As the girls pass, the boys whistle, and some of them reach out to touch the girls. The boys' behavior is intimidating to the girls and sometimes the girls stay at school longer to avoid dealing with the boys. Musonda wants to tell someone at the school about it, but Brenda says it is not such a big deal, "boys will be boys." What do you think? Should the girls report the harassment or just tolerate it?

[Allow 1-2 minutes for the small groups to decide what their answer is.]

\section{Continued on next page}

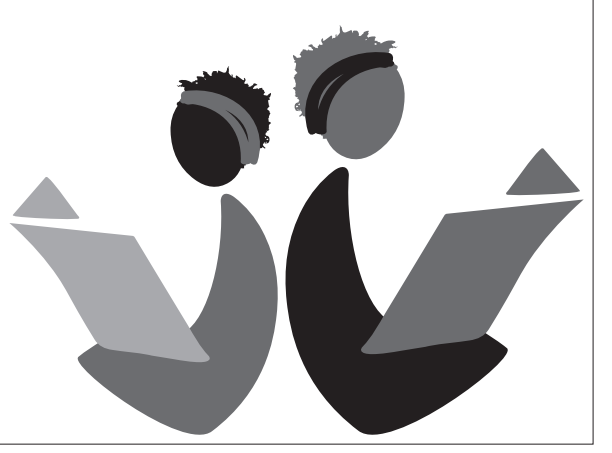




\section{activity 1 (cont.)}

7. Ask the groups whether they think the girls should report the harassment. If any of the groups respond yes, ask them to explain why. Elaborate with the following if the girls don't mention it themselves:

- This type of behavior creates an unsafe environment that can interfere with the girls' ability to learn and participate in activities.

- The boys' behavior is unwanted. The girls have a right to be treated with respect and dignity. This behavior is the opposite of that

8. Ask participants: How common is sexual harassment in your school? What are some things we can do to end sexual harassment at our school?

Listen to girls suggestions and add the following if they don't mention them:

- Organize an awareness-raising day - Make posters that criticize sexual harassment

- Ask the head teacher what the school's sexual harassment policy is

Publicize the school's sexual harassment policy

Report incidents and ask teachers/

administrators what they will do about the incident

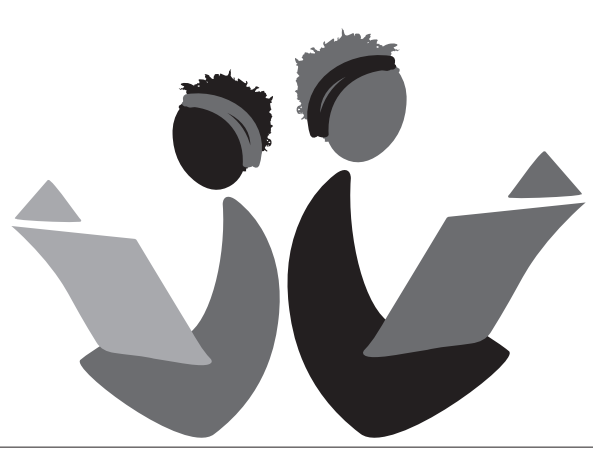




\section{activity 2}

\section{IS IT COERCION?* [15 MINUTES]}

1. Ask: What is sexual coercion?

[After listening to some answers, provide this definition: Sexual Coercion is the use of status and/or power to coerce (meaning to persuade an unwilling person) or attempt to coerce a person into having sex. A person might use emotional manipulation, deception, physical force or threats, verbal

insistence, or economic inducements.]

2. Explain: I'm going to read you a few scenarios, and I want you to tell me whether you think it is voluntary and wanted, coerced, or rape.

3. Read the following case studies and let the group tell you whether they believe it is voluntary and wanted, coerced, or rape. Repeat for each case study.

Chota and Daliso: The last time Chota refused her husband Daliso, he threatened her and beat her badly, giving her a black eye. She doesn't want to have sex with Daliso today but he might beat her again, so she doesn't refuse.

Is this voluntary and wanted, coerced, or rape? [Answer: Sexual coercion.]
Chansa and Mutinta: Chansa and Mutinta are classmates at university. They have been dating for a few months and are very attracted to each other. They are not deeply in love but they agree that they

want to have sex. After agreeing to use a condom, they have sexual intercourse.

Is this voluntary and wanted, coerced, or rape? [Answer: Voluntary and wanted.]

Bwalya and Chipampe: Bwalya comes from a poor family. She works in a shop for Chipampe and her salary is her family's main income. One day Chipampe starts touching her and after the shop closes, he pulls her into the storeroom in the back and lifts up her dress. Bwalya is confused and frightened about losing her job. She starts to resist but when Chipampe says, "What? You don't like working here?" she gives in.

Is this voluntary and wanted, coerced, or rape? [Answer: while Chipampe does not physically force her, this is absolutely sexual coercion and could be considered rape.]

Continued on next page

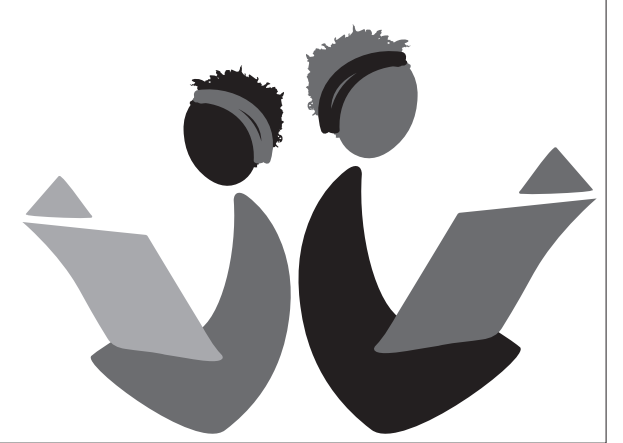

*Source: International Sexuality and HIV Curriculum Working Group. 2009, updated 2011. It's All One Curriculum: Guidelines and Activities for a Unified Approach to Sexuality, Gender, HIV and Human Rights Education. New York: Population Council. Activities: Page 72. 


\section{activity 2 (cont.)}

Mulenga and Dorcas: Mulenga often buys Dorcas gifts and other things she needs. Tonight they went out for dinner and he paid. Even though Dorcas doesn't feel

ready to have sex, she feels that she owes it to Mulenga. She doesn't refuse him.

Is this voluntary and wanted, coerced, or rape? [Answer: Sexual coercion.]

Discuss the following questions with the group:

- Forcing someone to have unwanted

sex is a violation of that person's human rights. By a show of hands, who believes that forced sex is common among young people? Who thinks it is rare?

- We discussed that a person who does not want to have sex and is not forced into it may still voluntarily engage in sex. Who believes this is a fairly common experience among young people? Who thinks it is rare?

- Are girls and boys equally likely to have sex in a situation that is not forced but also not wanted? [Probe: Do you think girls and boys usually share equal power in sexual relationships? What about adult men and women?]

[Note: Emphasize that even if a situation does not fall under the extreme "forced" end of the spectrum it may, nonetheless, be unacceptable.
4. Remind the group: Remember you ALWAYS have the right to say no to sex. Your body is your own. 


\section{activity 3}

\section{"MYTHINFORMATION" GAME: RAPE* [20 MINUTES]}

1. Ask: What is the definition of rape? [Definition: Rape is a type of sexual assault usually involving sexual intercourse, which is initiated by one or more people without the other person's consent.

What is date or acquaintance rape? [Definition: Rape between individuals who are dating or know each other.

2. Explain: We are going to play a 'mythinformation' game. A myth is a widely held but false belief or idea. The topic of the game will be rape and other forms of sexual abuse. Teams will compete to see which team knows the most correct information about rape and other forms of sexual abuse.

3. Divide the group into two or more teams and have them move to different sides of the room. Ask each team to choose a name for itself, then write the team names on the chalkboard.

[Explain that you will read a statement to each team in turn, and the team members must decide together whether the statement is a fact or a myth.]
4. Begin by reading a statement to one of the teams. Encourage team members to talk briefly among themselves to decide whether the statement is a myth or a fact. Give them 30 seconds to a minute.

If they answer correctly, record a point for that team on the blackboard. Ask the team to explain why they answered the way they did. If they do not mention the correct information from the Myth/ Fact Statements and Answers, share that information.

If the response is incorrect, offer correct information from the Myth/Fact Statements and Answers, and allow a few minutes for discussion.

5. Continue reading statements to alternate teams until all statements have been read or you are out of time.

Myth/Fact Statements and Answers:

Read the statement to participants. After you receive an answer, use the comments below each statement to clarify whether the answer is correct and to provide additional information.
1. Most rapes are committed by strangers [MYTH. The vast majority of rape victims are assaulted by someone they know.]

2. Date rape is defined as using force or the threat of physical force to coerce a date into having sex or having sex with a date who is not capable of saying no. [FACT.]

Continued on next page 


\section{activity 3 (cont.)}

3. It is considered rape if a guy has sex with a girl when they are at a party together and she has fallen asleep in one of the back

rooms after drinking a lot of beer.

[FACT. A girl who is drunk, high or asleep is not capable of making her own decisions. A male who takes advantage of the fact that a female is not physically or mentally able to say no to him is committing rape. Thus, if the girl is too young to know

what is happening, has a mental disability, or is incapable of making a decision for some other reason, having sex with her is considered rape.]

4. Most rapes take place at night in unfamiliar territory.

[MYTH. The majority of rapes occur in the victim's daily surroundings - home, school, parking lot, parks, etc. A significant percentage of rapes occur in broad daylight.]

5. Rapists are typically sexually unfulfilled men who can't get sex.

[MYTH. Most rapists have an available sexual partner in their lives.]

6. If a husband forces his wife to have sex it is not rape because they are married. [MYTH. Forced sex in the context of marriage is still rape.]
Ask:

What pressures might influence a boy to force a girl to have sex?

- What can teenagers do to avoid date rape situations?

What advice would you give to a friend who was just raped?

[Probe for: Tell a parent or trusted adult, see a health practitioner for an exam and testing for sexually transmitted infections, seek counselling, visit the police victim support unit.] 


\section{wrap-up}

\section{WRAP-UP \\ [2 MINUTES]}

Ask participants to summarize what they have learned. Fill in any key points they miss.

Key Message: Report anyone who makes advances that may be suspicious or who touches parts of the body in inappropriate ways. Sexual harassment and rape can occur with anyone and anywhere, even teachers at school or relatives at home. It should not be tolerated. Please seek out help and support from a parent or trusted adult.

\section{Action item: 3 minutes}

Have the participants sit in a circle. Explain that one thing that can help a person have equal power in their relationship is to value themselves and be confident.

Instruct: To help all of us feel more confident, sometime before the group meets again we are going to remind each other of our positive qualities. Everyone has to give a compliment to the person on their right before the next

session. The compliment must be genuine - it can be about how well they handled a difficult social situation, how well they answered question in class, how beautifully they sing, how well they did in a football game, or something else.

Tell everyone to look again to the person on their right and remember who they are assigned to.

Ask for any final questions or comments. Remind participants where and when the next meeting will take place, and what topics will be discussed. 


\section{SESSION 14 PREGNANCY AND CONTRACEPTION}




\section{session 14 / pregnancy and contraception}

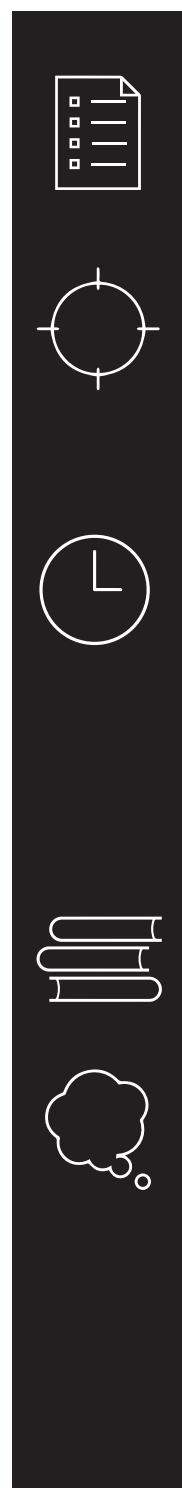

SESSION DESCRIPTION

Participants learn the parts of the reproductive system, how menstruation and pregnancy happen, and myths about pregnancy prevention.

\section{OBJECTIVES}

By the end of the session, participants will:

Learn how women's and men's reproductive systems function

Explain how a baby is created

- Identify common myths related to teenage pregnancy

\section{SESSION TIME}

1 hour

Action item debrief: 5 minutes

Warm-up: Birthday graph, 5 minutes

Activity 1: How pregnancy happens, 20 minutes

Activity 2: You can't get pregnant if..., 25 minutes

Wrap-up: 2 minutes

Action item: 3 minutes

\section{REQUIRED MATERIALS}

Chalkboard and chalk

\section{PRE-SESSION PREPARATION}

Read through the entire session and practice presenting the activities. Prepare all materials needed.

Be familiar with the illustrations for this session ("The Male

Reproductive System," "The Female Reproductive System,"

"The Process of Menstruation," and "How Pregnancy Happens".) 


\section{session 14 / pregnancy and contraception (cont.)}

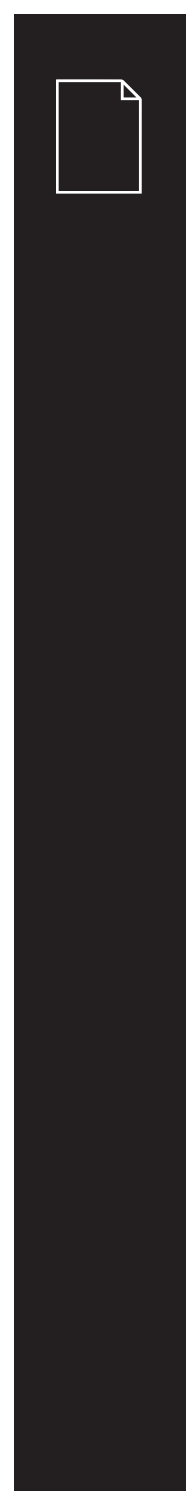

\section{FACILITATOR NOTES*}

Male Reproductive System

Under the penis there is a small bag of skin containing the testes. There are two of them and they produce sperm and testosterone. Testosterone is the male sex hormone and it makes pubic hair grow and boys' voices become deeper. Semen is the fluid that carries the sperm. Sperm makes babies when it joins up with women's eggs. Most of the time sperm is inside the body. There is only one exit for the sperm, which is through the hole at the end of the penis, called the urethra. When the penis is soft, that hole is used to urinate; when it is erect, it is used to release semen.

An erection occurs when the penis fills with blood and becomes hard and straight because a boy or man is sexually excited. Boys do not have any control over when this will happen, and it is normal for it to occur while a boy is sleeping. Having erections is not a sign that a boy needs to have sex. Ejaculation is when semen comes out of an erect penis due to sexual excitement. A man does not have to ejaculate every time he has an erection. If he waits, the erection will go down without causing any harm. Boys are not born with sperm; they begin to produce them during puberty and continue to produce them throughout their entire life. If the sperm is ejaculated into the woman's vagina, she may become pregnant. The semen can also carry diseases that could infect another person.

\section{Female Reproductive System}

The female external genital organs are called the vulva. It includes the clitoris, the vagina, and two folds of skin called the labia. The labia have two sets of rounded folds of skin called the outer and inner lips. Near the top of the lips, inside the folds, is a small cylindrical body called the clitoris. The clitoris has no other function than to help a woman have sexual pleasure. The vagina is where a man puts his penis during sexual intercourse. Also, menstrual blood and babies come out of the vagina. The vagina is an incredibly elastic muscle that can stretch wide enough to allow a baby to pass through.

Every female is born with thousands of eggs in her ovaries. Once a girl reaches puberty, a tiny egg matures in one of her ovaries and then travels down a fallopian tube on its way to the uterus. This release of the egg from the ovary is called ovulation. The uterus prepares for the egg's arrival by developing a thick and soft lining like a pillow. If the girl has had sex in the last few days before or the day after ovulation, by the time the egg arrives in the fallopian tube, there might be some sperm waiting to unite with the egg. If the arriving egg is united with the sperm (called fertilization) the fertilized egg travels to the uterus and attaches to the lining of the uterus (called implantation) and a pregnancy begins. If the egg is not fertilized, there is no pregnancy and the uterus does not need the thick lining it has made to protect the egg. It discards the lining, along with some blood, body fluids, and the unfertilized egg. All of this flows through the cervix and then out of the vagina. This flow of blood is called the "period" or menstruation. The blood and tissue usually leave the body slowly over

three to seven days. 


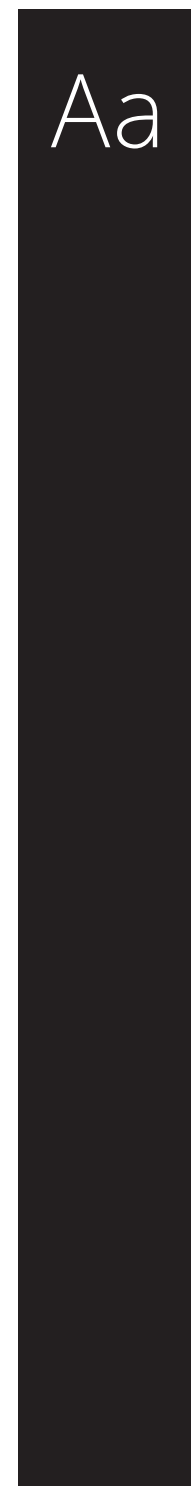

TERMS

Bladder: The sac where urine is collected before excretion.

Cervix: The neck-like passage from the uterus to the vagina.

Clitoris: A sensitive area near the top of the opening of the vagina that helps a woman have sexual pleasure.

Ejaculation: Release of semen from the penis during orgasm.

Erection: The stiffened and swollen state of erectile tissue, especially that of the penis, usually as a result of sexual arousal.

Fallopian tubes: Tubes that connect a woman's ovaries to her uterus.

Fertilization: The fusion of a male sperm cell and a female egg; necessary before an egg can begin to grow into an embryo.

Implantation: An event that occurs early in human pregnancy when a fertilized egg adheres to the uterus wall.

Labia: The two folds of skin, or lips, at the opening of the vagina.

Menstrual cycle: The period of time beginning on the first day of a woman's period until the day before she begins her next period.
Menstrual hygiene: Taking care of oneself in a clean, safe, and healthy way during menstruation.

Menstruation: When blood leaves a woman's body through the vagina, because the egg that was released into her uterus was not fertilized. Menstruation signifies that a woman or girl can become pregnant if she has sexual intercourse. It occurs around once a month for most women, and is commonly called "menses" or "p's" in Zambia. It usually lasts between three and seven days.

Ovulation: The periodic release of a mature egg from the ovary, which happens around the middle of a woman's menstrual cycle.

Ovaries: A pair of organs that contain a female's eggs or ova.

Ovum: The mature female reproductive cell, which can produce an embryo after fertilization by sperm.

Penis: The male sex organ. It provides passage for both urine and semen; it places sperm in the woman's vagina during sexual intercourse.

Scrotum: The pouch of skin containing the testicles.

Sperm: Male reproductive cells, which fuse with eggs during fertilization.
Testicles: These are two egg-shaped organs in front of and between a man's thighs; each testicle produces and stores sperm, which can fertilize a woman's egg during sexual intercourse.

Urethra: The duct which conveys urine (in males and females) and sperm (in males) outside the body.

Uterus: Where a fertilized egg grows and develops when a woman becomes pregnant also called the womb.

Vagina: An elastic canal, leading from the vulva to the cervix and uterus. Menstrual blood leaves the body through the vagina, as does the baby when it is born. In vaginal intercourse, the penis penetrates the vagina.

Vas deferens: The duct that conveys sperm from the testicles to the urethra.

Vulva: External female genital organs.

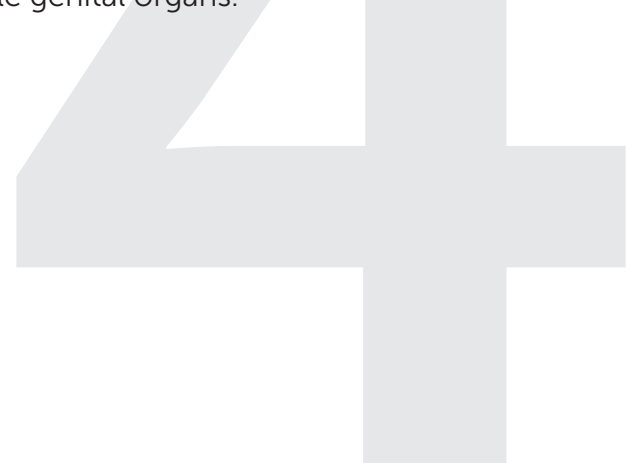




\section{warm-up}

\section{ACTION ITEM DEBRIEF \\ [5 MINUTES]}

Our action item was to give a compliment to one of the other participants in our group.

How did it go? How did it feel to get the

compliment? How did it feel to give the compliment?

\section{BIRTHDAY GRAPH* \\ [5 MINUTES]}

Ask everyone to line up according to their birthday month.

Once everyone is in line, discuss which month

or season has the largest number and what

reasons there might be for this. 


\section{activity 1}

\section{HOW PREGNANCY HAPPENS* [20 MINUTES]}

\section{Explain:}

It is important to know and understand how female and male reproductive organs work.

Show the illustration of the female reproductive system. Talk about the internal organs and briefly explain the purpose of each organ.

Show the illustration of male organs and briefly explain how they work.

Show the illustration of how pregnancy occurs and talk about sexual intercourse and fertilization of the egg. Explain that it is the male sperm that determines whether the egg will become a male or female.

2. Tell the group that sometimes girls will see a whitish or clear fluid on their underpants or experience a feeling of wetness around their vagina. This fluid or wetness is called mucus or a "secretion."

Explain that secretions happen every day but are more noticeable on some days of the menstrual cycle.

- Having secretions does not mean that a woman's vagina is dirty.

-Women are most aware of their secretions during ovulation - when women are most fertile - because the secretions have more water in them at this time.

- Women may have thicker secretions during the rest of their cycle with less water.

- Some women have more secretions than others.

Tell the participants that if they pay attention to their vaginal secretions, they can recognize the days when they are fertile and what is normal for them. If they see anything different from the normal, they should consult a doctor/health provider. For example, yellow or strong smelling discharges from the vagina can be a sign of infection.

3. Ask the group when a woman is most fertile. [For most women this is around the midpoint of the menstrual cycle. For women who have cycles between 26 and 32 days this means that if we consider the first day of the period day number 1 , sometime starting about day number 8 through day 19 are the fertile days.

However, everyone's cycle is different so this is an estimate only.]

Illustrations on next page

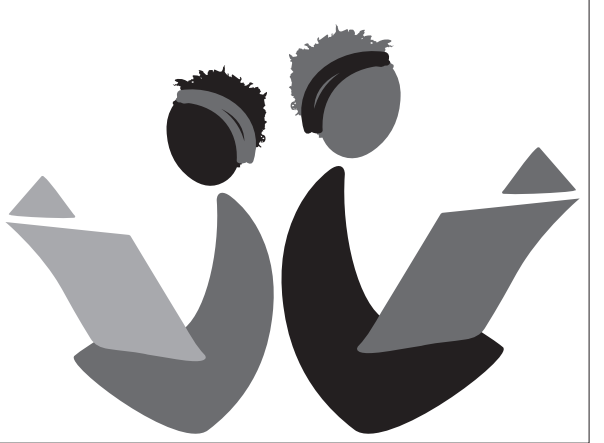

Source: Centre for Development and Population Activities (CEDPA). 2009.

Choose a Future! Issues and Options for Adolescent Girls in Southern Africa. Pages 192-193. 


\section{activity 1 (cont.)}

\section{THE FEMALE REPRODUCTIVE SYSTEM}

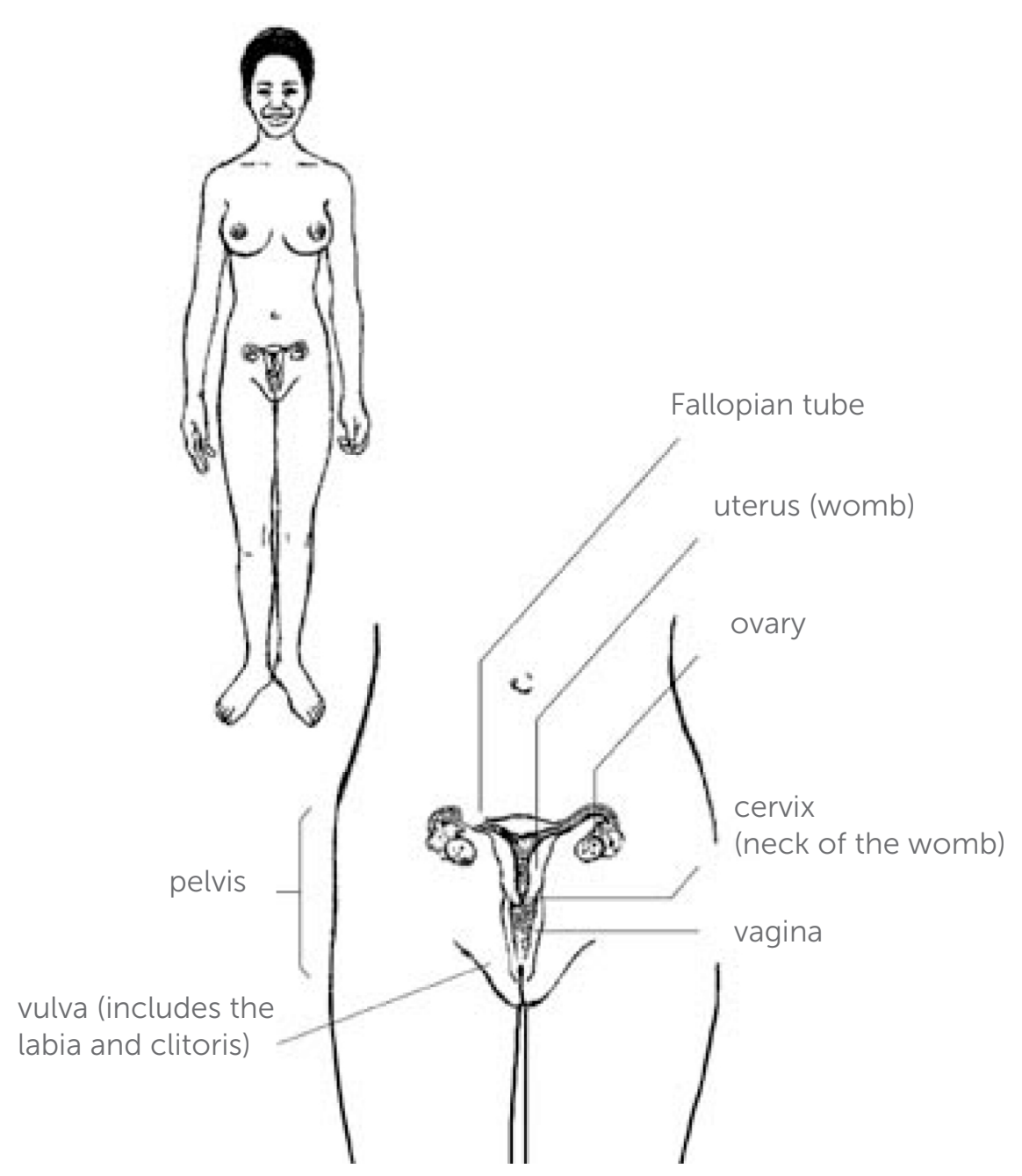

\section{THE MALE REPRODUCTIVE SYSTEM}

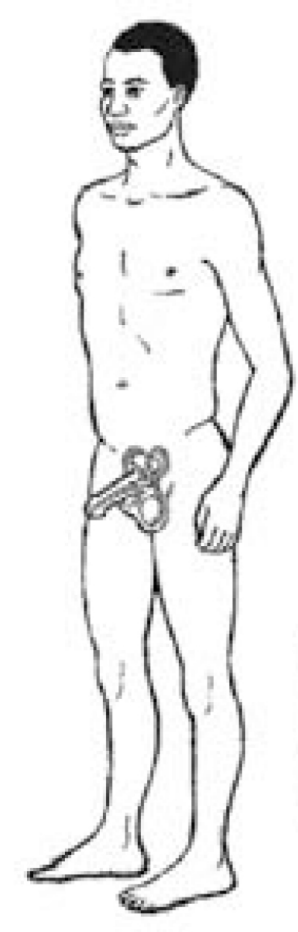

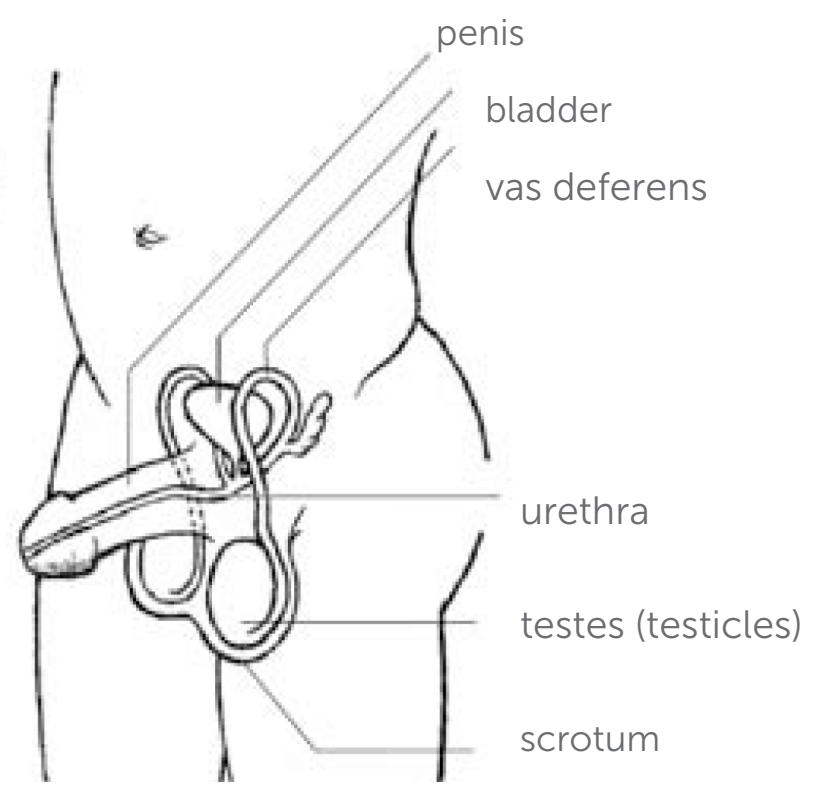




\section{activity 1 (cont.)}

THE PROCESS OF MENSTRUATION

egg

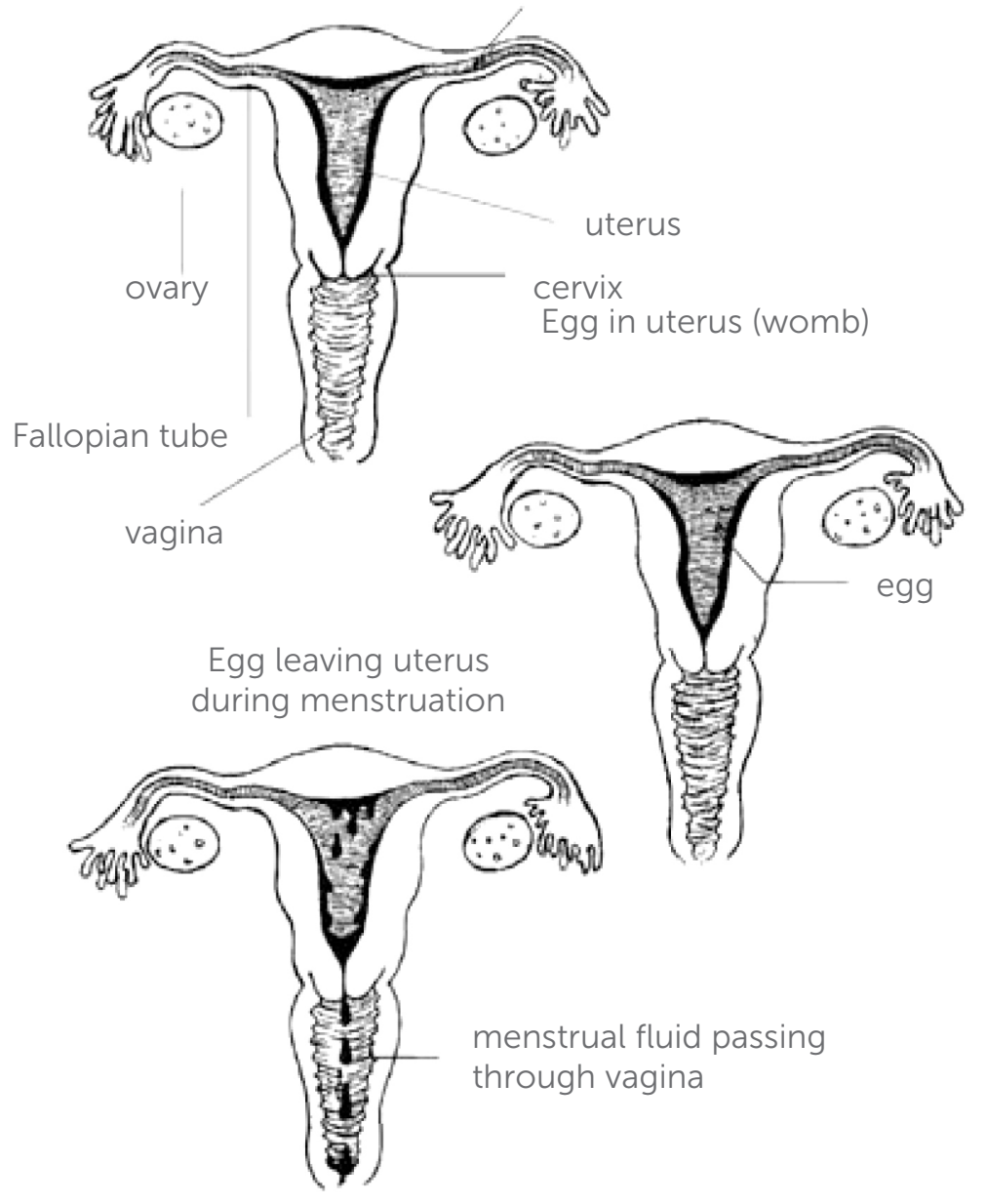

HOW PREGNANCY HAPPENS

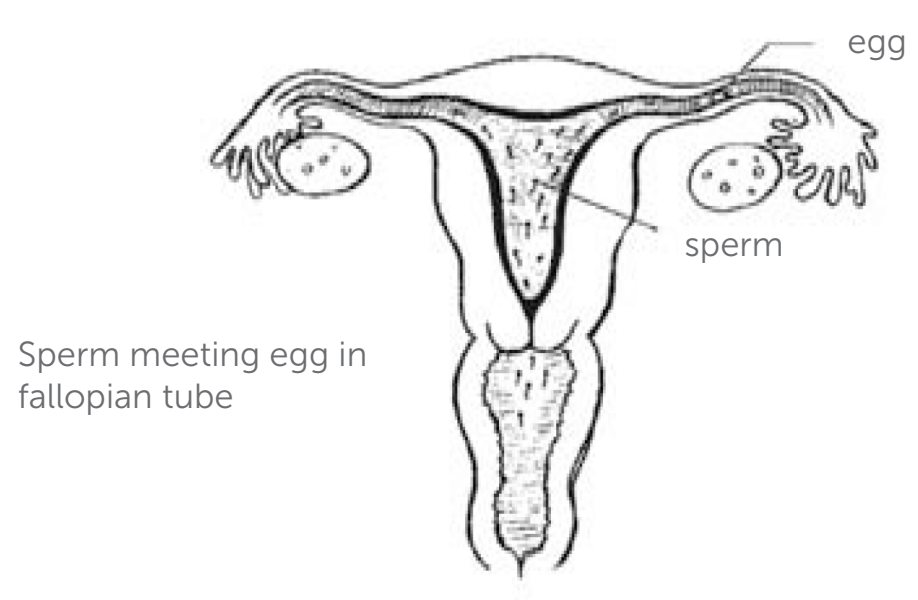

Fertilized egg implanted

in the uterus

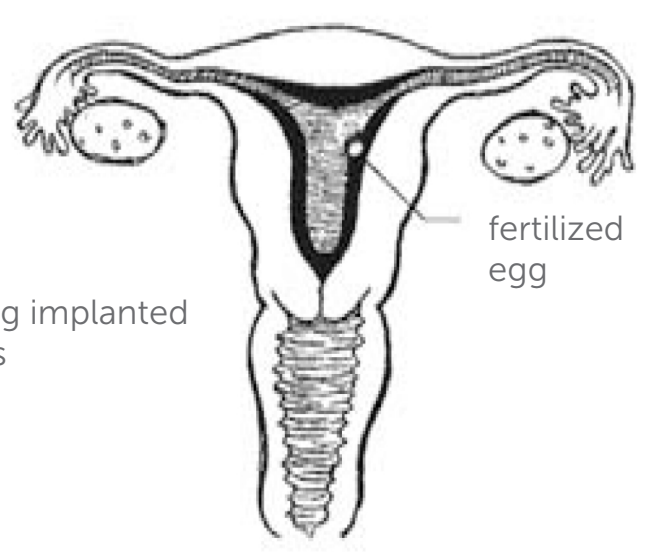




\section{activity 2}

\section{YOU CAN'T GET PREGNANT IF...* [25 MINUTES]}

1. Explain: We are going to play a quick game about avoiding pregnancy. This corner of the room is the 'True' corner (point to designated corner) and this corner of the room is the 'False' corner (point to the other designated corner).

Each time I read a statement, you will need to decide if you think the statement is true or false and move to the corresponding corner. If you are not sure, you can stand in the middle. After you choose your answer, we will pause and briefly discuss each statement.

[Provide the correct answer if it does not come out from the group.]

2. Read the first statement from the "You can't get pregnant if..." list below.

"You can't get pregnant if..."

You have not started menstruating [FALSE. Eggs may be released into the uterus before menstruation begins.]

You have menstrual bleeding. [FALSE. When girls start menstruating, their cycles are irregular, and eggs can be released into the uterus at different times.]

- You have sexual intercourse standing up. [FALSE. You can get pregnant by having sexual intercourse in any position.]

You urinate right after sexual intercourse. [FALSE. Urine passes through the urethra, so it does not remove the sperm in the vagina.]

- You cleanse your vagina after sexual intercourse.

[FALSE. Sperm reach the uterus very quickly and will not be removed by vaginal cleansing.]

- You are under 12 years old, because you are too young to get pregnant.

[FALSE. Eggs can be released in girls as young as nine years of age.]

A male pulls his penis out of your vagina before ejaculating.

[FALSE. Some sperm can be released even before the primary ejaculation.]

You are having sexual intercourse for the first time.
[FALSE. Any time you have intercourse, you can become pregnant.]

You don't have sexual intercourse.

[TRUE. No one can get pregnant if they

do not have sexual intercourse. However sperm ejaculated on or near the vagina may enter the vaginal canal and possibly result in pregnancy.]

You use modern contraceptive methods to regulate your fertility.

[TRUE. In most cases, if a modern method of contraception is used properly, it can prevent pregnancy.]

Continued on next page 


\section{activity 2 (cont.)}

3. Explain: The only ways to prevent pregnancy are to abstain from sexual intercourse or to use a method of contraception.

There are many different kinds of contraceptive methods. Some of the most commonly used reversible methods in Zambia are:

Condom: A thin latex sheath that is rolled onto the erect penis before intercourse. A condom prevents sperm from entering the vagina. Condoms also protect against some sexually transmitted infections and HIV.

Oral contraceptives ("the pill"): Oral contraceptives contain hormones that prevent ovulation and thicken the cervical mucus. A woman takes them every day for 21 or 28 days. They do not protect against HIV or sexually transmitted infections.

- Injectables: An injection containing hormones is given to a woman at regular intervals, usually every 3 months. They do not protect against HIV or sexually transmitted infections.

- Implants: Small, soft rods implanted in a woman's upper arm that release hormones. They last around 4 years. They do not protect against HIV or sexually transmitted infections.
4. Ask: Where are some places a person can obtain contraceptives? [Condoms, pills, injectables, and implants are available at the local government clinic in your area, as well as private and NGO clinics in the area.] At these clinics, counselors can explain more about these contraceptive methods, other available methods, and answer any questions you may have.

As a group, discuss where one can go to get these services in their community and make sure the girls know where the clinic(s) are located. 


\section{wrap-up}

\section{WRAP-UP \\ [2 MINUTES]}

Ask participants to summarize what they have learned. Fill in any key points they miss.

Key Message: After going through puberty, women and girls begin menstruating and become capable of pregnancy - even before their first period starts. Pregnancy can be prevented by abstaining from sex or using contraception.

\section{Action item: 3 minutes}

Explain: We covered a LOT of information today so we'll have another anonymous question activity. Tear out a small piece of paper from your notebook. If you have a question about anything we discussed today, write your question down on your slip of paper. Don't put your name on the paper just your question. When you are done, fold your paper so no one can see your question and give it to me. At the next session we'll pick a few questions to answer. No one will know who asked the question, including me.
Ask for any final questions or comments.

Remind participants where and when the next meeting will take place, and what topics will be discussed. 


\section{SESSION 15 PARTNER VIOLENCE AND POWER IN RELATIONSHIPS}




\section{session 15 / partner violence and power in relationships}

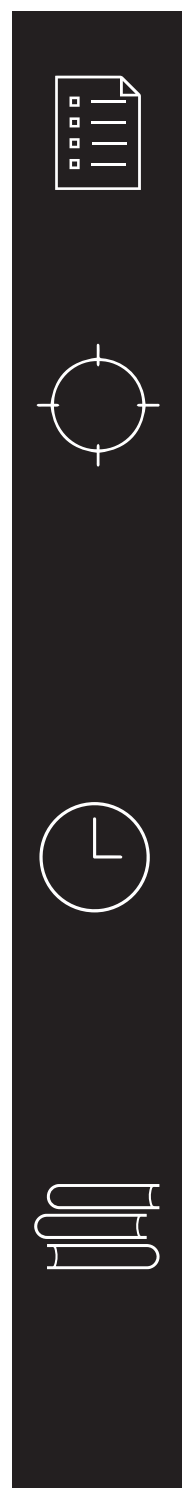

SESSION DESCRIPTION

Participants explore power in relationships and how power inequalities affect a person's ability to protect their health; they explore intimate partner violence and the factors that underlie it; and they learn where a person experiencing violence can go for help.

OBJECTIVES

By the end of the session, participants will:

- Understand the power that different individuals and groups have in society and how this power can determine their ability to access their rights

To identify different types of violence and discuss the particular types of violence that most commonly occur in intimate relationships

Identify who to go to and where to go to for help in addressing cases of domestic or intimate partner violence

\section{SESSION TIME}

1 hour

Action item debrief: 5 minutes

Activity 1: Power, status and health, 20 minutes

Activity 2: What is violence? 20 minutes

Activity 3: Getting help, 10 minutes

Wrap-up: 2 minutes

Action item: 3 minutes

REQUIRED MATERIALS

Chalkboard and chalk
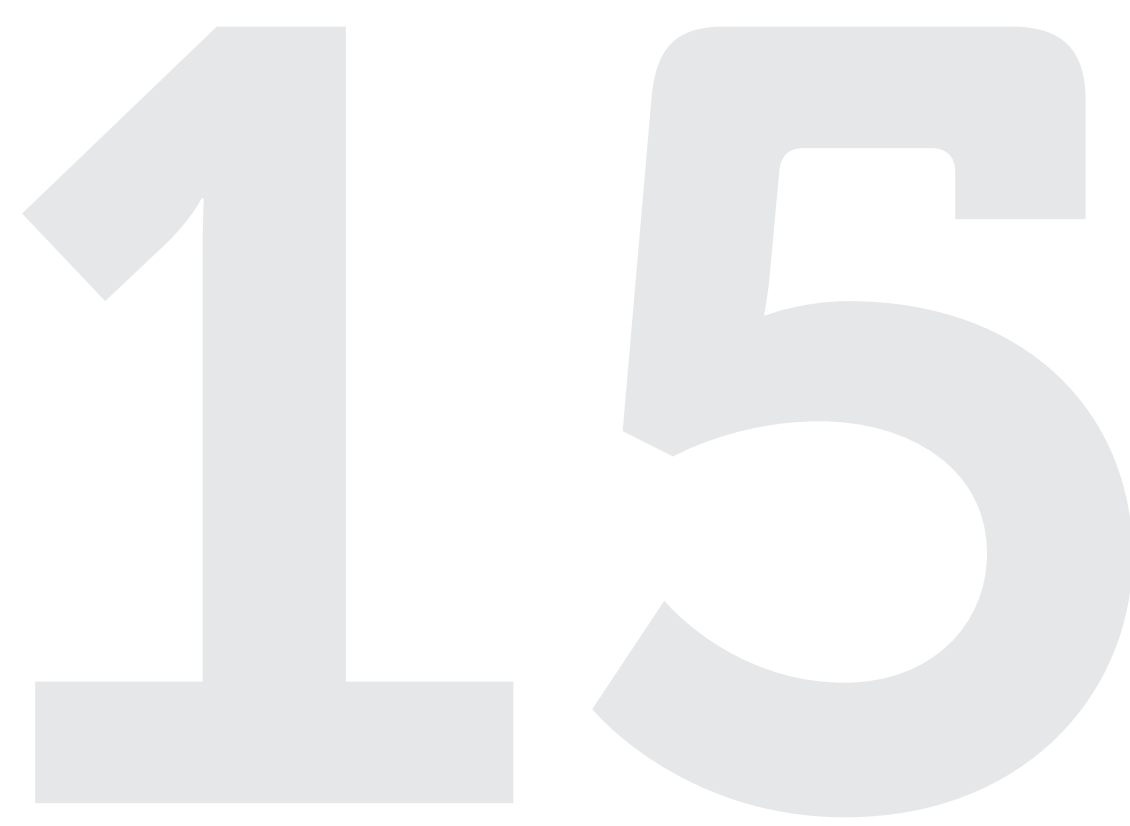


\section{session 15 / partner violence and power in relationships (cont.)}

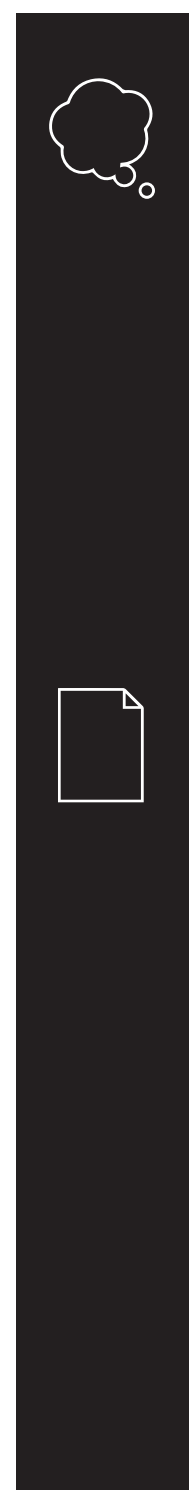

PRE-SESSION PREPARATION

- Read through the entire session and if necessary, practice presenting the activities. Prepare all materials needed. On individual pieces of paper, write the following descriptions of different types of people in society:

1. Advertising Executive, Female

2. Refugee from DRC, Female, 35 years old

3. Female migrant farmworker

4. Taxi Driver, Male

5. Unemployed Woman, 25 years old

\section{FACILITATOR NOTES}

Participants may speak to you about experiences of violence at home, school, or in a relationship. Think about how to support them. If possible, visit the local resources so that you are familiar with them. Remember: no one deserves to be beaten.

\section{TERMS}

Economic abuse: When a person tries to use their money to control their partner. For example, not allowing access to the family finances, preventing the person from having or keeping a job, taking the person's money, demanding an account of everything that the person buys. In this way, the exertion of power through the control of money can also be a form of violence.
6. Grandmother taking care of seven orphaned grandchildren with her pension

7. Commercial Sex Worker, Female

8. Young Girl, 12 years old, living in informal settlement

9. Male corporate executive

10. Young Boy, 14 years old, living in security complex in the suburbs

11. Married Mother of 3, employed in town as domestic worker

12. Female Nurse

13. Male Doctor
14. Street Kid, 10 years old, male

15. Unemployed AIDS Activist living openly and positively

16. Male teacher, 30 years old

17. Widow with 2 children, living with late stage AIDS

18. Farm supervisor

Prepare a list of local contacts relevant to gender-based violence

Write poem "Stand Tall" on the board
Emotional or psychological violence: Often the most difficult form of violence to identify. It may include humiliating, threatening, insulting, pressuring, and expressions of jealousy or possessiveness such as controlling decisions and activities.

Physical violence: Using physical force such as hitting, slapping, or pushing.
Sexual violence: Pressuring or forcing someone to perform sexual acts (from kissing to sex) against their will or making sexual comments that make someone feel humiliated or uncomfortable. It does not matter if there has been prior consenting sexual behavior. 


\section{warm-up}

\section{ACTION ITEM DEBRIEF \\ [5 MINUTES]}

Before the session, sort through the

anonymous questions collected at the end

of the last session and select several of the

most frequently occurring questions and/or

those that most urgently need clarification. If

there is a lot of discussion around some of the questions, you may not be able to get through all of them

Explain: Last week you all wrote anonymous questions for me. There are some really great questions! We'll go through as many as we can today, but if we don't get through all of them we will do the rest another time.

Read out each question and your answer. Give participants the opportunity to ask follow-on questions or ask for further clarification. 


\section{activity 1}

\section{POWER, STATUS AND HEALTH* [20 MINUTES]}

1. Explain to the participants that this exercise will help them to understand how gender and people's access to resources can contribute to positive or negative health outcomes.

2. Ask the participants to stand in one straight line, shoulder to shoulder at the back of the room. Make sure there is plenty of space to walk forward. If space is an issue, do the exercise outside.

Give each of the participants one of the pieces of paper that you prepared earlier that provide descriptions of different people in society (refer to Pre-session preparation). Make sure to prepare enough pieces of paper to match the number of participants. You can have more than one of each identity if need be.

3. Introduce the activity by asking all the participants to read out the role that has been given to them. Ask if everyone understands their role. If someone is unable to read their role or doesn't understand it, read it out and explain the role to the group.

4. Explain: For this activity you will assume the role that has been written on the piece of paper given to you.
I will read a series of statements. For each statement, I would like you to consider whether that statement applies to the role you have been given. If it does, you should move forward one step. If it doesn't, you should stay where you are.

For example, one of the participants has been asked to assume the role of a member of parliament. Then if I were to read the statement - I can protect myself from HIV - the person playing this role would move forward one step as it is likely that the member of parliament can protect himself or herself from HIV.

5. Read each of the following statements, pausing after each one for people to move one step forward or to stay where they are. Allow one or two people to comment briefly on why they did or did not step forward.

- I can get a loan when I need extra money. - I can negotiate safer sex with my partner.

- I can read and write.

- I can refuse a proposition of sex for money, housing, or other resources.

- I don't have to worry about where my next meal will come from.

- I can leave my partner if s/he threatens my safety.
I have had or will have opportunities to complete my education.

- I can determine when and how many children I will have.

- I can walk down a street at night and not worry about being raped.

- I am respected by most members of my community

Continued on next page

*Source: Sonke Gender Justice. 2008). One Man Can: Workshop Activities:

Talking to men about gender, domestic and sexual violence and HIV/AIDS. Pages 13-14. 


\section{activity 1 (cont.)}

6. After finishing all the statements, ask the following questions:

- Do the participants agree with the steps that different people took? Why or why not?

- Why did the participants get distributed in this way even though they had started at the same place in the game?

- How do the participants feel about where they have ended up?

7. Explain that individuals are discriminated against on the basis of their class, age, sex educational levels, physical abilities, and so on. Power structures operate to keep discrimination in place and very often use violence to achieve this.

Our position, or status, in society, plays a big role in determining how vulnerable we are to poverty, violence, HIV, and other health problems.

Those who are involved in community structures and know their rights are more likely to have greater control of their lives and be able to access rights and services. 


\section{activity 2}

\section{WHAT IS VIOLENCE?* [20 MINUTES]}

1. Explain to the participants that the objective of this activity is to talk about different types of violence that exist.

2. Ask: How do you define violence? What does it mean to you?

Write the ideas on the board, then together agree on a definition.

3. Explain: Acts of violence can be divided into categories:

Physical violence uses physical force such as hitting, slapping, or pushing.

Emotional or psychological violence is often the most difficult form of violence to identify. It may include humiliating, threatening, insulting, pressuring, and expressions of jealousy or possessiveness such as controlling decisions and activities.

Economic abuse is when a person tries to use their money to control their partner. For example, not allowing access to the family finances, preventing the person from having or keeping a job, taking the person's money, demanding an account of everything that the person buys. In this way, the exertion of power through the control of money can also be a form of violence.

Sexual violence is pressuring or forcing someone to perform sexual acts (from kissing to sex) against their will or making sexual comments that make someone feel humiliated or uncomfortable. It does not matter if there has been prior consenting sexual behavior.

4. Now read the following two stories to the group:

Story 1: Clement asks Susan to go out with him one afternoon. They chat a little, get some food, and Clement invites her to a motel, saying he has some money to spend a few hours there. Susan agrees. They get to the motel and start kissing and caressing. Clement begins to take off her clothes. Susan stops him and says that she doesn't want to have sex. Clement is furious. He tells her that he has spent a lot of money on the room and says, "What are my friends going to say?" He pressures her to change her mind. First he tries to be sweet and seductive, then he begins yelling at her in frustration. Finally, he pulls at her forcefully, pushing her down on the bed.
Story 2: Violet has been dating Moses for a few months. Recently, Moses has started asking her questions all the time: who she talks to in class, why she isn't home when he phones, why she spends so much time with her girlfriends when she could be seeing him, and so on. Violet has tried not to pay much attention to these questions, but lately Moses has started to get pushier and angrier. He has been yelling at her in the hallways at school and calling her names. Afterwards, he usually apologizes but once he even hit her. He says he is upset because he loves her so much and she is "driving him crazy" with jealousy.

Continued on next page

*Source: Promundo, Salud y Género, ECOS, Instituto PAPAI and World Education. 2006.

Program M: Working with Young Women: Empowerment, Rights and Health. Pages 38-41. 


\section{activity 2 (cont.)}

\section{Ask:}

Are these situations realistic? Do they happen in your community?

Does a person, man or woman, ever 'deserve' to be hit or suffer some type of violence? Why or why not? [Note:

Allow participants to discuss but be very clear that the answer is 'no, no one EVER deserves to be beaten or abused.']

- How do gender norms contribute to intimate partner violence? [Listen to responses. Add the following if participants do not mention: Belief that men should be strong and dominant; that men are entitled to sex; that there are times that a wife deserves to be beaten; that men are aggressive and women are submissive.]

\section{Ask:}

- How might unequal power in a

relationship make violence more likely? For example, what if a young man has more money than his partner or he controls the money? [Listen to responses. Answers include: If she is financially dependent on him, it can make it more difficult for her to leave the relationship or she may feel she "owes" him.]

What other inequalities might lead to one person having more power over another in a relationship? [Listen for responses. Answers include: Political, employer/ employee, teacher/student.
7. Ask:

What are the consequences of violence on individuals? On relationships? On communities?

What have you learned in this activity? Have you learned anything that can be applied in your own life and relationships? 


\section{activity 3}

\section{GETTING HELP* \\ [10 MINUTES]}

1. Write the poem "Stand Tall" on the board.

2. Ask: Where - or to whom - could girls who are experiencing abuse, including coerced sex, go to for help? [Reference list of local contacts relevant to support services for gender-based violence, prepared in advance.]

What can she do if the people she goes to for help don't believe her or don't take any action?

[If the first person you tell does not believe you, you should keep on trying until someone does.

Remember that it is important to find and identify trusted adults in and outside the family who you can talk to.

Explain: Could I have a volunteer to recite the poem on the board?

\section{Stand Tall}

By Eunique Jones

\section{Our self-esteem}

has been knocked down before

But we're survivors and we won't allow it

to happen anymore

We've struggled to make it this far

And in our struggle sometimes we did fall

But in the end we've always stood tall

After reading the poem, ask: What do you

think the poem means? [Wait for responses.]

Remind participants of the assets and strengths they possess which can help protect them and see them through a bad experience.

Remind them that no one ever deserves to be beaten or abused and that if they experience abuse they must get help.

*Source: Johns Hopkins Bloomberg School of Public Health/Center for Communication Programs. 2011. Go Girls! Community-based Life Skills for Girls: 


\section{wrap-up}

\section{WRAP-UP \\ [2 MINUTES]}

Ask participants to summarize what they have learned. Fill in any key points they miss.

Key Message: At its most basic level, violence is a way to control or have power over another person. When people talk about violence, they think mainly of physical aggression. It is important, however, to also think of other forms of violence as well as the different settings and circumstances in which violence happens. Violence is always a violation of human rights and is rooted in power imbalances. It is important to know where you, your family, and your friends can get help in your community when dealing with cases of violence.

\section{Action item: 3 minutes}

Ask: Who knows what a "slogan" is? [It is a short, memorable phrase.]

Explain: For next week, write a "slogan" for a poster or billboard for a campaign about ending violence against women.

Ask for any final questions or comments.
Remind participants where and when the next meeting will take place, and what topics will be discussed.

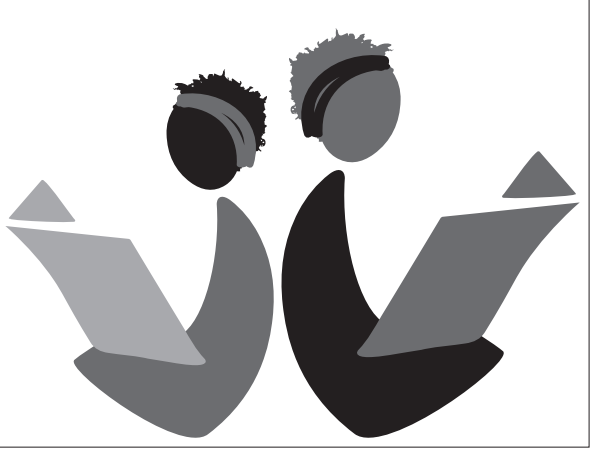




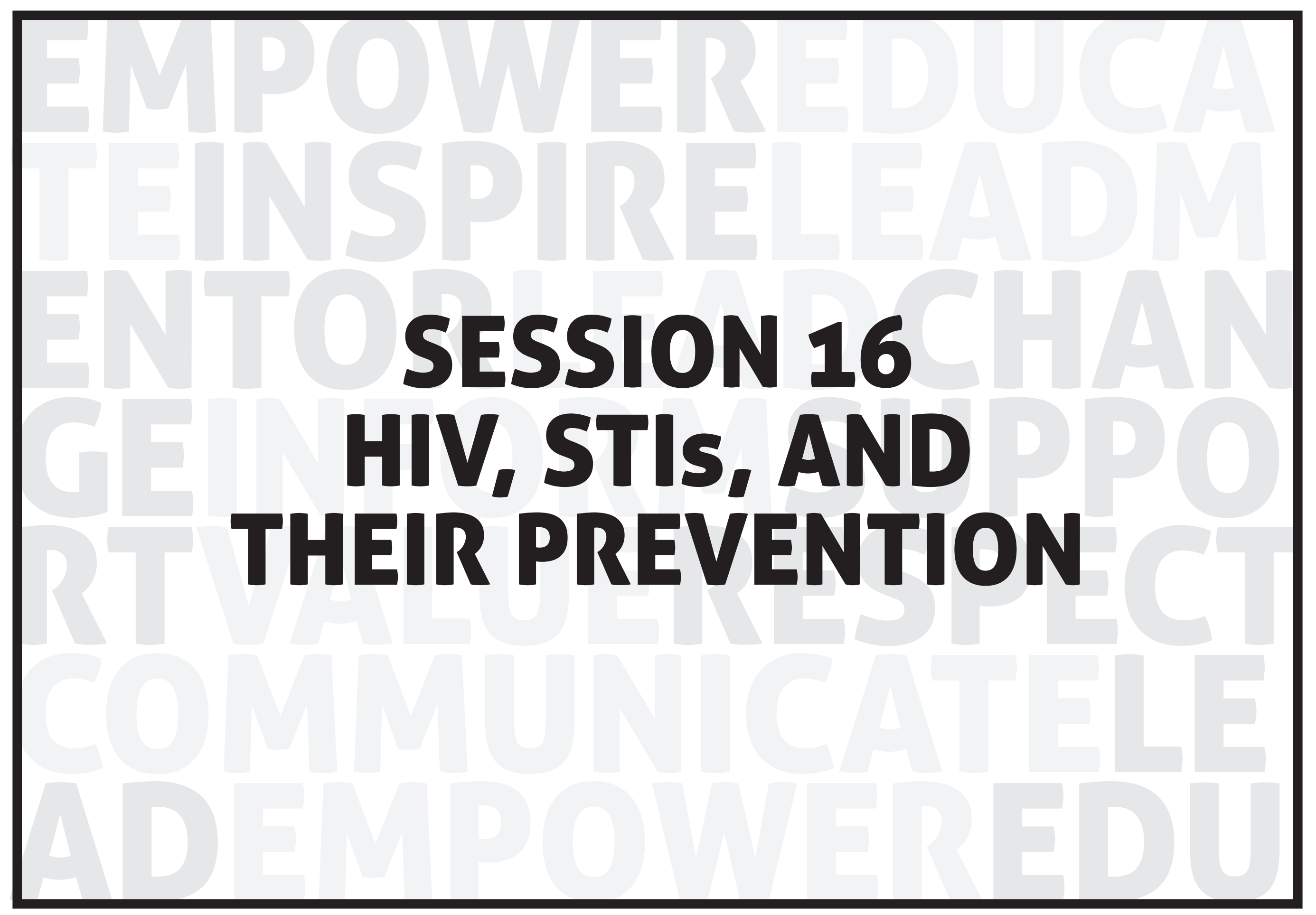




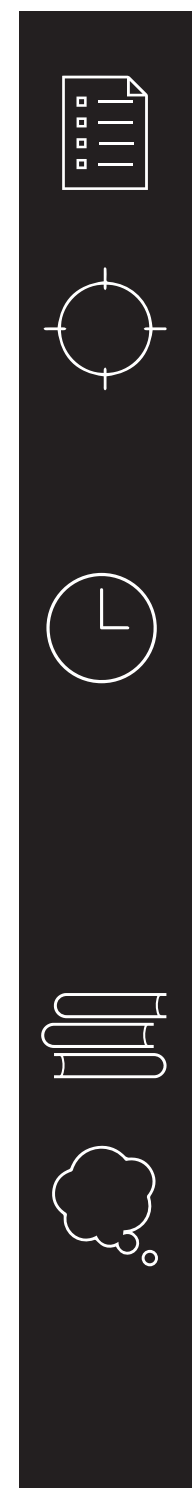

SESSION DESCRIPTION

Participants learn about HIV/AIDS and STIs, and what behaviors do and do not put one at risk of being infected with HIV.

\section{OBJECTIVES}

By the end of the session, participants will:

- Define HIV/AIDS and STIS

- Explain modes of transmission of HIV and STIs

- Understand how to protect oneself from STIs and HIV

- Identify risky and non-risky behaviors

\section{SESSION TIME}

1 hour

Warm-up: People to people, 3 minutes

Action item debrief: 5 minutes

Activity 1: STIs, HIV\&AIDS, 12 minutes

Activity 2: Shaking hands, 20 minutes

Activity 3: Risky and non-risky behaviors and practices, 15 minutes

Wrap-up: 2 minutes

Action item: 3 minutes

\section{REQUIRED MATERIALS}

Chalkboard and chalk

\section{PRE-SESSION PREPARATION}

Read through the entire session and, if necessary, practice presenting the activities. Prepare all materials needed.

Prepare small pieces of paper for Activity 2: Shaking hands; each person should have one piece of paper - but be sure to follow the quantities of each type listed here:

1. One piece with a small ' $x$ ' in the corner

2. One piece with a small ' $z$ ' in the corner

3. Three pieces with a small ' $c$ ' in the corner

4. Three pieces with the instructions 'Don't follow any of my directions, stay seated

5. On the rest of the pieces write 'Follow all of my directions' 


\section{session 16 / HIV, STIs, and their prevention (cont.)}

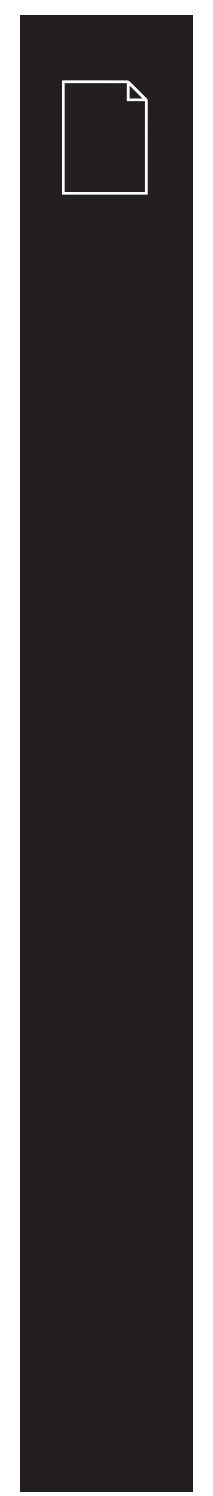

\section{FACILITATOR NOTES*}

There are over 34 million people living with HIV and AIDS worldwide. Over half of them live in sub-Saharan Africa. AIDS is spreading among young people in Africa faster than in any other age group. Of all adults in Zambia, 13\% are HIV positive (adult women - 15\%, adult men - 11\%). Young females are much more likely to be infected than their male counterparts. Among those aged $15-19$, rates are $5 \%$ among females and $4 \%$ among males. Among those aged $20-24,11 \%$ of females are infected, versus only $7 \%$ of males. The number of people dying in Zambia as a result of AIDS is estimated at 31,000 per year, leaving behind a growing number of AIDS orphans, currently estimated at 680,000

How Is HIV transmitted?

HIV is passed between people in three ways:

1. Sex: Penetrative sex with a person who has HIV where the penis enters the vagina, anus, or mouth of another person. Vaginal and anal sex is considered much higher risk for HIV transmission than oral sex.

2. Blood to blood: From the blood of a person who has HIV to another person's blood through an opening in the body such as a cut, from a transfusion, or by sharing something that cuts or pierces the skin (knife, razor, needle). This includes sharing circumcision knives, needles, tattooing, or ear piercing, with someone who has HIV.
3. Mother to child: HIV can be passed from a mother who is HIV infected to her baby during pregnancy, at the time of birth, or through breastfeeding

The majority of people in Zambia are infected with HIV by having sex with someone who is HIV infected. It is important to note that a person suffering from other STIs is eight to ten times more likely to contract HIV. HIV cannot survive in air, water, or on things people touch.

\section{Protecting against HIV}

In this session, help young people understand that there are many ways to express sexual feelings that do not risk unplanned pregnancy or sexually transmitted infections. Touching, fantasizing, caressing, massaging, masturbating, talking, kissing, whispering, hugging, singing, dancing, and holding hands are ways of showing and receiving affection from a partner. Abstinence from all types of sexual intercourse is the best and only certain way to prevent HIV infection.

Latex condoms have been proven to be an effective barrier of HIV. They can, however break or leak especially when used incorrectly. It is important for adolescents to understand how to use a condom correctly and that they must be used for every act of sexual intercourse to protect against HIV infection. Condoms offer the best protection against the spread of HIV during sexual intercourse with a partner whose HIV status is unknown. Some behaviors present more of a risk for HIV than others. These Risky and Non-Risky Behaviors are summarized on page 148.

Male circumcision reduces a male's chances of acquiring HIV. It does not give complete protection, but it reduces a man's chances of becoming infected with HIV by about $60 \%$. If a man is circumcised it does not mean that he does not have HIV. If a man who has HIV is circumcised it does not mean his female partner is protected. Male circumcision does not provide direct protection from HIV for women

If a person has HIV, but regularly takes their ART medicines to suppress the virus, they are far less likely to transmit the virus. It's thus very important to adhere to ART.

[Note to facilitator: Because the number of people infected with HIV changes frequently, facilitators should undertake a quick internet search to amend the statistics mentioned in these notes.] 


\section{session 16 / HIV, STIs, and their prevention (cont.)}

\section{Risky and Non-Risky Behaviors}

\section{Definitely a Risk}

- Sharing contaminated needles for drug use

Sharing contaminated needles for ear piercing

- Having sexual intercourse without condoms

\section{Probably a Risk}

- Being born to a mother who is HIV positive Getting a blood transfusion

\section{Probably Not a Risk}

- Sharing a toothbrush

- Having sexual intercourse with a person

using a condom

- Deep or (open mouth) kissing

\section{Definitely Not a Risk}

Abstaining from sexual intercourse

- Kissing

- Being close to a person with HIV who is

coughing

Donating blood

- Using a public telephone

- Shaking hands with a person with HIV or

AIDS

- Hugging or talking to a person with HIV or AIDS

-Going to school with a person who has

HIV or AIDS

- Sharing plates, utensils, glasses, or towels used by someone with HIV or AIDS

- Using swimming pools, toilet seats,

doorknobs, gym equipment, or telephones used by people with HIV or AIDS
Having someone with HIV or AIDS spit, sweat, or cry on you

Being sneezed at or coughed on by a person with HIV or AIDS

Being bitten by a mosquito (no risk of HIV, but risk of malaria!)

- Having sexual intercourse with a person

who has been tested for HIV, found

negative, and engaging in a mutually monogamous and faithful relationship with that person

For more information, see Fact Sheet: HIV (Human Immunodeficiency Virus) and AIDS (Acquired Immune Deficiency Syndrome) in the Appendix at the end of this curriculum. 


\section{session 16 / HIV, STIs, and their prevention (cont.)}

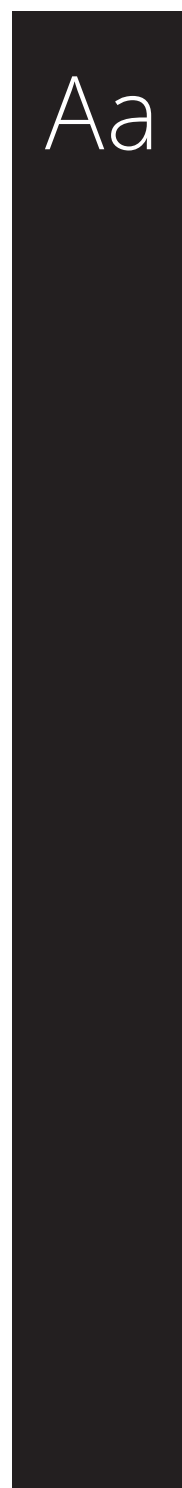

\section{TERMS}

AIDS: Acquired Immune Deficiency

Syndrome; the final stage of HIV disease,

which causes severe damage to the immune

system.

ART: Antiretroviral therapy; medication that treats HIV. The drugs do not kill or cure the virus. However, they can suppress (meaning restrain or keep down) replication of the virus. ART keeps the level of HIV in your blood low and reduces the likelihood of transmitting the virus to uninfected sexual partners. However, this is only true if a person can get and stay virally suppressed. One thing that can increase viral load is not taking HIV medicines the right way, every day.

HIV: Human Immunodeficiency Virus; the virus that causes AIDS and is transmitted through blood, semen, vaginal fluid, and breast milk.

Immune system: The body's natural defense system for fighting off disease.

STIs: Sexually Transmitted Infections:

infections passed from person to person

through sexual intercourse or genital contact.

These serious diseases infect the sexual and

reproductive organs and can cause infertility,

miscarriages, and stillbirths. 


\section{warm-up}

\section{PEOPLE TO PEOPLE* [3 MINUTES]}

Divide the group into pairs.

Explain: I am going to call out an action then in your pairs, follow the instructions. So for example: "nose to nose!" I want to see you all nose to nose with your partner. If I say, "people to people!" you have to change partners. Remember to have fun with this! Okay get ready.

\section{ACTION ITEM DEBRIEF [5 MINUTES]}

Last week your action item was to write a slogan for a poster or billboard about ending violence against women. Let's hear what you wrote! Who wants to go first? [Listen to all, compliment each girl on her work.
Call out:

"Back to back"

- "Hand to hand"

- "People to people!" [make sure everyone switches partners]

"Elbow to elbow"

- "Knee to knee"

- "People to people!" [make sure everyone switches partners]

- "Hip to hip"

- "Bum to bum"
Hopefully everyone will be laughing and

having fun. Thank them for their participation

and ask them to take their seats.

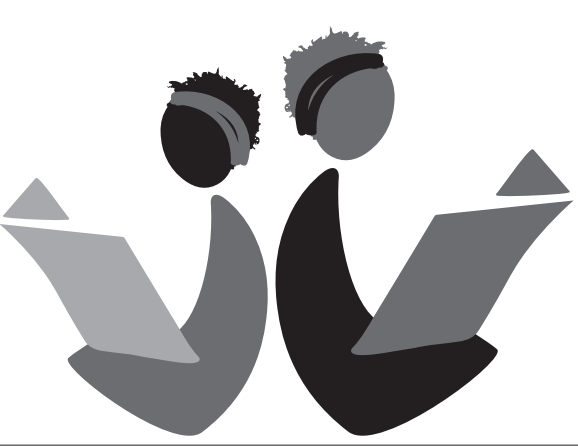




\section{activity 1}

\section{STIS, HIV \& AIDS* [12 MINUTES]}

1. Ask participants if they have any information about sexually transmitted infections. Ask them to name as many STIs as they can think of. Write them on the chalkboard. Ask about slang terms.

2. Explain: Sexually Transmitted Infections (STIs) are infections passed from person to person through sexual intercourse or genital contact. These serious diseases infect the sexual and reproductive organs and can cause infertility, miscarriage, and stillbirths. [Pause and check if participants know what these are, if not, explain.] They greatly increase the chance of getting HIV which causes AIDS.

The most common STIs are HIV/AIDS gonorrhea, syphilis, genital herpes, genital warts, trichomonas vaginalis, and chlamydia.

Most STIs can be cured with treatment. But there is no cure for HIV at this time. There is also no cure for genital herpes or HPV. Many times, especially for women - this is important to know! - you can have an ST with no signs or symptoms. Other times, the symptoms go away on their own Whether you have symptoms or not, you still have the STI until you get treated.
If you notice any unusual discharge, sores, redness, or growths on the genitals, or if you suspect that you have been exposed to an STI, go to a health professional.

Government health clinics and private doctors treat STIs. Your sexual partner(s) must also be treated, even if he has no symptoms. He may re-infect you or develop serious complications. So when you go to get treated, you should try to go with your partner so that he gets treated as well.

Even if a person has HIV or an STI that can't be cured, it is still important to get treatment. Treatment can help reduce symptoms and/or dramatically slow the progress of those infections. In the case of HIV, if a person regularly takes their medication, they can also reduce the chance that they will infect another person with HIV.

3. Ask the participants if they know what sexually transmitted infections look like. What are the signs and symptoms?

After hearing their responses, go over this list of signs and symptoms of Sexually Transmitted Infections:
- Unusual white, yellowish, and/or smelly discharge from the penis or vagina

Blisters or sores on the genital area

- Warts on the penis, or in the vaginal, genital, or anal area

Itching in the genitals or pubic area

Burning urine

Swelling on or near the genitals

- Lower abdominal pain

Swollen glands in the groin

Rash in the genital area

Frequent passing of urine

Remind participants that, however, many times an STI won't show any symptoms, and that for women and girls, it is perfectly normal to have some vaginal discharge.

Continued on next page

*Source: Centre for Development and Population Activities (CEDPA). 2009

Choose a Future! Issues and Options for Adolescent Girls in Southern Africa. Pages 152-154. 


\section{activity 1 (cont.)}

4. Say: One of the most common sexually transmitted infections is HIV.

5. Ask: Could someone tell me the meaning of HIV?

Wait for answers, then on the board, write the following:

HIV means Human Immunodeficiency

Virus. This is a virus that attacks and

eventually destroys the immune system

which leads to Acquired Immune

Deficiency Syndrome or AIDS.

\section{Ask: How can you get HIV?}

[Answers include: Sexual intercourse, blood transfusion (donated blood is now screened), pregnancy, childbirth, breastfeeding, or sharing contaminated

knives, needles, or syringes - for circumcision or drug use.]

7. Ask: Can transmission of HIV be prevented? If so, how?

[Yes, HIV can be prevented through abstinence, being faithful to one partner - but only if both are faithful, or use of a male or female condom.]

Be sure to dispel any myths and remind them that there is NO cure for HIV or AIDS.

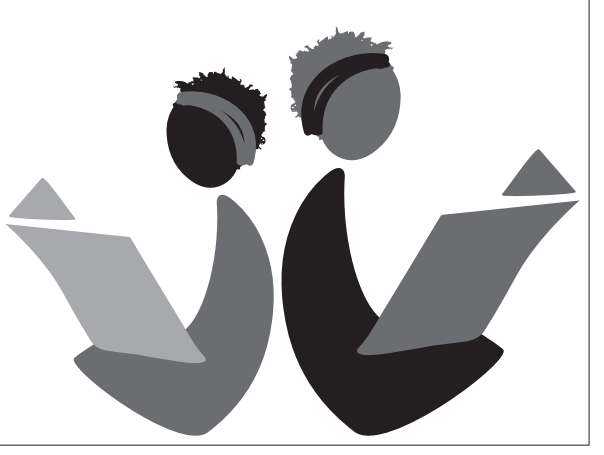




\section{activity 2}

\section{SHAKING HANDS* [20 MINUTES]}

1. Advance preparation: Cut small pieces of paper - enough so that each participant has one. Mark the papers as follows:

- One piece with a small ' $x$ ' in the corner - One piece with a small ' $z$ ' in the corner - Three pieces with a small ' $c$ ' in the corner - Three pieces with the instructions 'Don't follow any of my directions; stay seated'

- On the rest of the pieces write 'Follow all of my directions'

2. Distribute one piece of paper to each participant as they enter the learning space. Tell them that each paper has special instructions on it. Inform them to keep the special instructions secret and to follow the instructions. Let them know that they will each need a pen or pencil.

3. Explain: Now stand and move around the room to shake hands with three people. When you shake hands with someone, that person must sign your paper - and you must sign their paper. Make sure you move around the room while you do this!

4. Once the participants have collected three signatures, have them take their seats. Ask participants with the ' $z$ ' and the ' $x$ ' on their papers to stand up.
Then ask everyone who shook hands with a standing person to stand up. When these people have stood up, ask everyone who shook hands with a standing person to stand up. Continue this until everyone is standing. [Except for those with 'Don't follow any of my directions; stay seated' on their paper who should still be seated.]

5. Explain: Now pretend the person with the paper marked with an ' $x$ ' was infected with HIV and instead of shaking hands, that person had unprotected sex with the three people whose signatures she collected.

Also pretend that the person with the paper marked ' $z$ ' was infected with genital herpes and instead of shaking hands, that person had unprotected sexual intercourse with three people whose signatures she collected.

6. Ask: Those that are still seated, why haven't you been standing? [We were told not to follow any instructions and stay seated.]

Explain: These people chose to abstain from sexual intercourse, and were therefore protected from HIV and STIs.
7. Ask participants to check if they had a ' $c$ ' marked on their paper. If so, tell them they can sit down.

8. Explain: Fortunately those with papers marked ' $c$ ' had used condoms and were not at significant risk for infection.

Continued on next page 


\section{activity 2 (cont.)}

9. Tell all participants to sit and remind them that this was only a game. Lead a group discussion about the game by asking the following questions:

- How did person ' $x$ ' representing someone with HIV feel?

How did person ' $z$ ' representing someone with genital herpes feel?

- How did you feel towards others when you found out they were infected?

- How did people who were instructed not to participate in the exercise feel at the beginning?

And then later?

Who had a 'do not follow my instructions; stay seated' paper but got signatures anyway?

- Why did you get signatures anyway?

What does this tell us about people's behavior?

How did the people who discovered they had used condoms feel?

How did the people feel to find out they might have been infected?
Is it possible to know who is infected and who is not by looking at them?

10. Explain that you cannot tell someone's HIV status by looking at them. The only way to prevent infection is from abstaining from sex, only sleeping with one person

(who is also only sleeping with you and you have both been tested and found you do not have HIV or STIs), or using a male or female condom.

\section{Explain the concept of Multiple}

Concurrent Partnerships (MCP) where a

sexual network of people with multiple

partners can quickly connect many

different people and spread disease. 


\section{activity 3}

\section{RISKY AND NON-RISKY BEHAVIORS AND PRACTICES*}

\section{[15 MINUTES]}

1. Explain: We are now going to consider whether a person is at risk of being infected with HIV if she or he does certain things. I am drawing an imaginary line here in this open space of the room (show them where you are drawing the imaginary line; if you have a piece of rope, string, tape, or chalk to mark the line, even better).

I want you to all stand up and get on the same side of this line.

I am going to read a list of items, and if you think the statement puts a person at risk for HIV - cross the line to the other side. If you don't think it puts a person at risk for HIV, remain where you are; do not cross the line.

2. Before reading each statement below, ask: 'Cross the line if someone is at risk of being infected with HIV...' then ask participants to share their opinions and discuss with the group for each of the statements:

Cross the line if someone is at risk of being infected with HIV:

- If someone hugs, kisses, or massages your friend.
[Not a risk]

If someone gets bitten by a mosquito. [Not a risk]

If someone doesn't protect himself/herself when handling blood.

[Risk]

If you share food with a person who has AIDS

[Not a risk]

If someone drinks beer or other kinds of alcohol.

[Risk - can lead to other risky behavior]

If someone masturbates.

[Not a risk]

If someone has sex with more than one person.

[Risk]

If someone or someone's partner has had an STI in the past.

[Risk]

If someone has sex with one partner only. [Less risky if BOTH are faithful, use protection, and have both been tested for HIV and STIs.
If someone lives, works or plays with a person with HIV or AIDS.

[Not a risk]

If someone uses witchcraft against you. [Not a risk]

- If someone doesn't know if his/her sexual partner is HIV positive or has an STI. [Risk]

3. Facilitate a discussion with the following questions:

Does knowing that some things are definitely or probably a risk worry you? Did you learn any new information? Do you have any questions about any behaviors we did not list today?

- If you were explaining information on risky or non-risky behaviors to a friend, what would you say first?

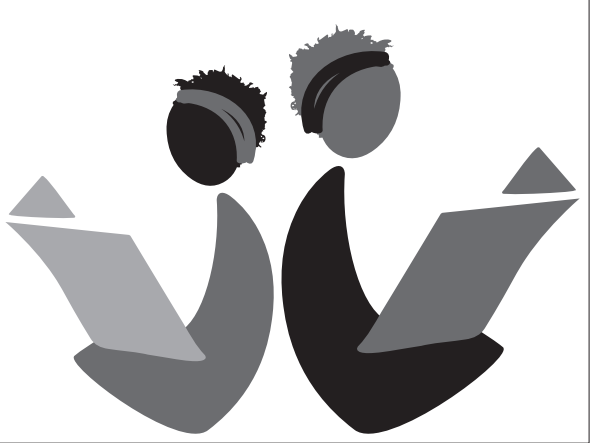




\title{
wrap-up
}

\author{
WRAP-UP \\ [2 MINUTES]
}

Ask participants to summarize what they have

learned. Fill in any key points they miss.

Key Message: HIV and STIs affect millions of people worldwide. Practicing non-risky behaviors protects you from STIs and HIV.

\section{Action item: 3 minutes}

One of the things that can help with some risky situations is communicating clearly and assertively. Everyone team up with a friend either from your group or in your community to practice assertive communication before we meet again. Think of sexual situations where it is important to communicate assertively. With your friend, practice communicating clearly with your words and with your body language. Remember that your words and body language should be communicating the same message.

Ask for any final questions or comments. Remind participants where and when the next meeting will take place, and what topics will be discussed.

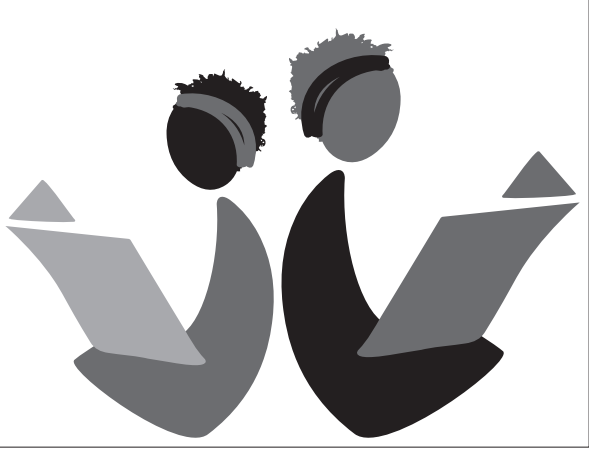




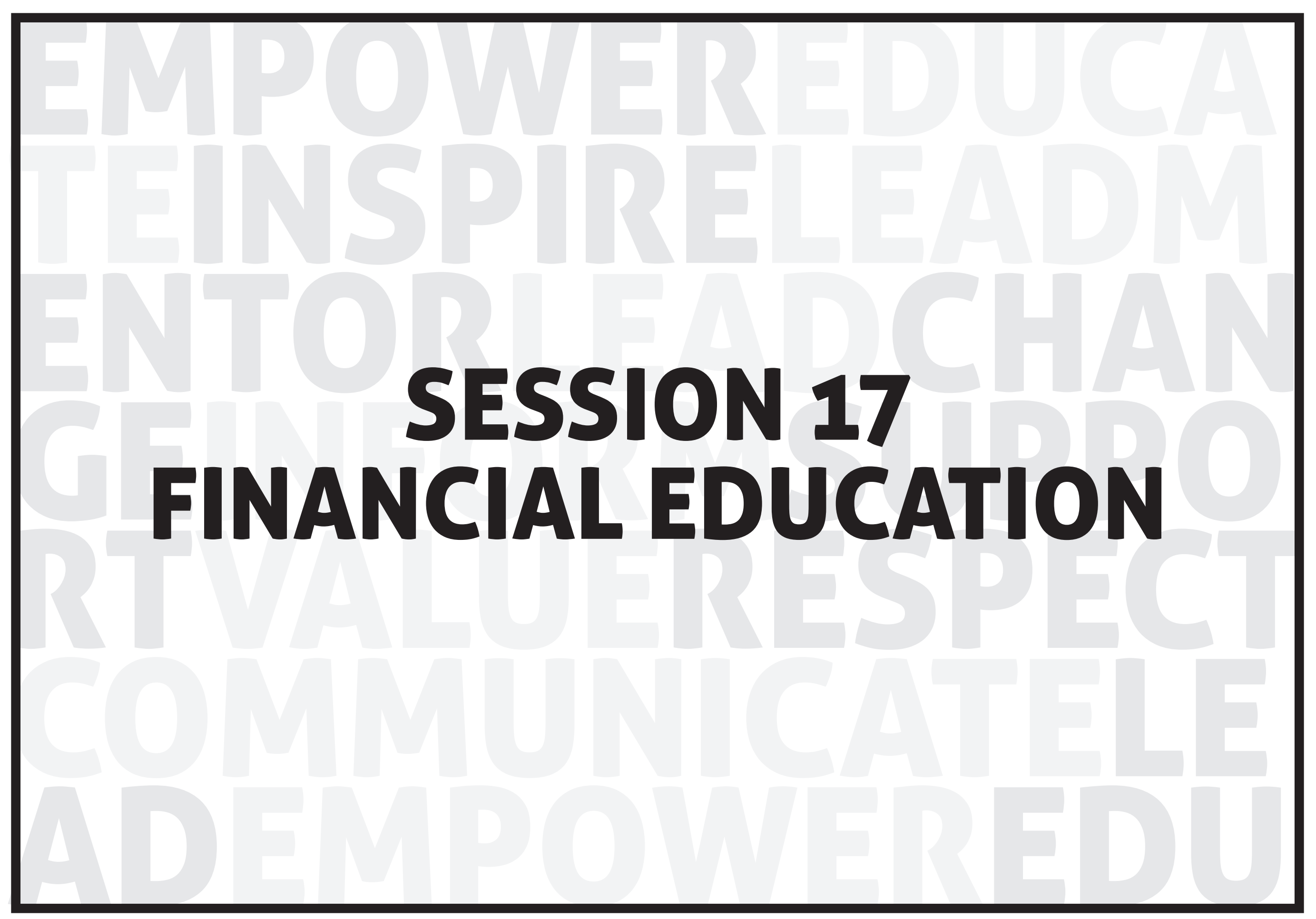




\section{session 17 / financial education}

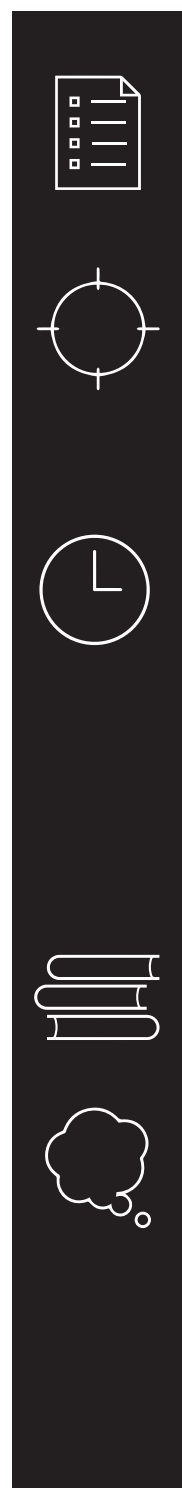

SESSION DESCRIPTION

Participants learn some basic savings principles and consider ways to reduce risky income.

\section{OBJECTIVES}

By the end of the session, participants will:

- Learn the "Eight steps for savings"

- Determine their own savings priorities

- Discuss the risks and risk-reduction strategies of girls' income cycles

\section{SESSION TIME}

1 hour

Action item debrief: 2 minutes

Warm-up: Last week recall, 3 minutes

Activity 1: The eight steps for savings, 20 minutes

Activity 2: Many reasons to save: What are your priorities? 20 minutes

Activity 3: What is risky income? 10 minutes

Wrap-up: 2 minutes

Action item: 3 minutes

REQUIRED MATERIALS

Chalkboard and chalk

\section{PRE-SESSION PREPARATION}

Read through the entire session and, if necessary, practice presenting the activities. Prepare all materials needed.
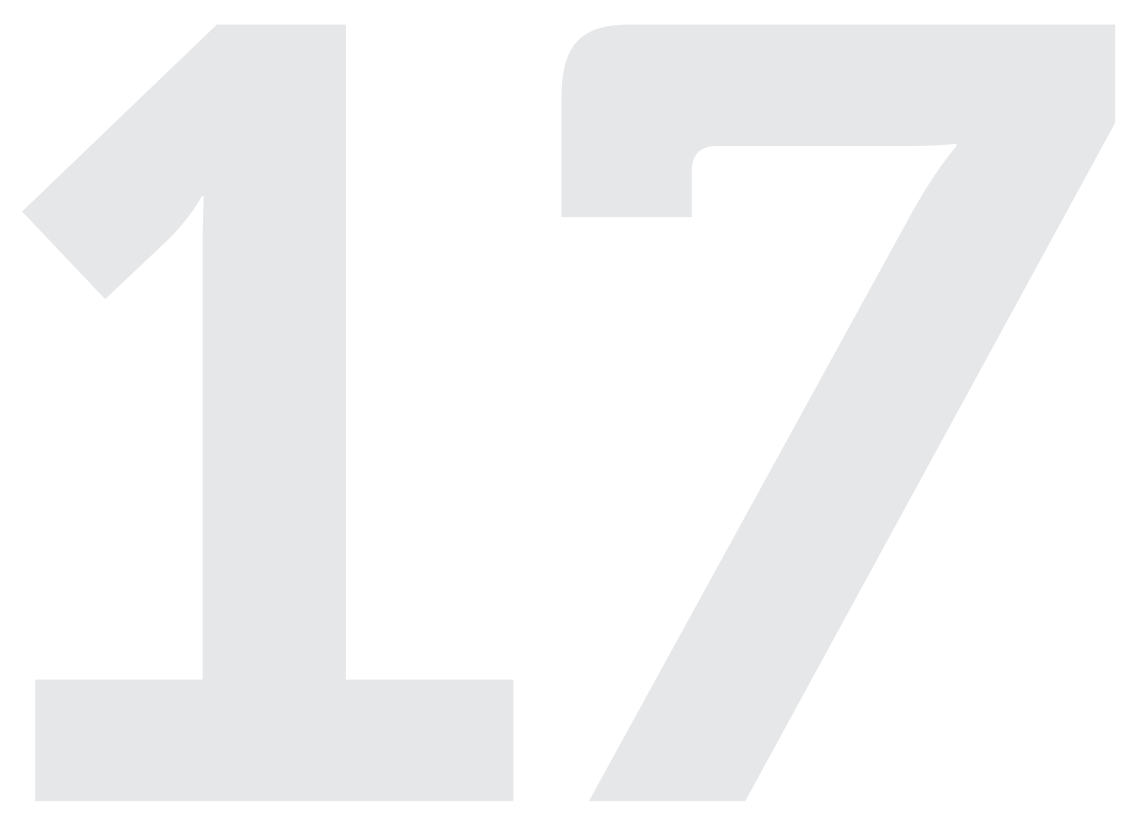


\section{session 17 / financial education (cont.)}

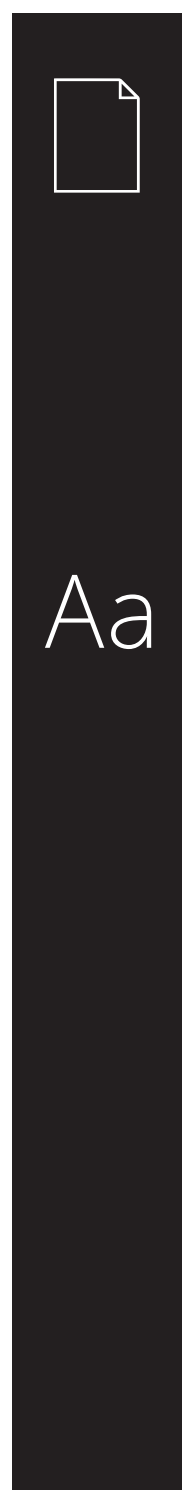

\section{FACILITATOR NOTES*}

At a basic level, financial education focuses on concepts of money and ways to manage it well. It promotes regular saving, wise spending, and ways to make the most of our resources. These skills serve as a foundation for girls and young women who are transitioning from dependent to independent roles in their financial responsibilities. They are shifting from depending on their families for support to earning their own money and making independent financial decisions. At a very basic level, they must know how to handle themselves, pursue income opportunities, pay for their expenses, and plan for the future. However, in a few years' time, they will have more responsibilities for marriage, households, children, as well as additional responsibilities related to employment, shelter, and relationships.

\section{TERMS}

Budget: A written plan that estimates future income, expenses, and savings.

Deficit: When there is not enough money to cover all costs at the end of a budget period.

Expenses: Money out-this can be money spent for any purpose.

Income: Money in-this could be regular or irregular, from a job, or even a gift.

Loan: A sum of money that is borrowed and that must be paid back.

Needs: A basic necessity that you cannot live without-like food, water, and a place to live.

Risky income: When getting money that is not in exchange for work, especially if it comes from boyfriends or other men, there may be an expectation that eventually you will have sex, or some kind of sexual activity, with them.

Saving: Putting money aside for future needs, wants, emergencies, education, or larger investments such as school or a house.

Savings plan: A written guide for how to manage and save money to achieve a savings goal.

Self-employment: A self-employed person operates his or her own business or job, and makes all of the necessary decisions related to the business-such as working hours, investment, products and services, etc.

Surplus: Money remaining or left over (at the end of a budget period-like a week or month).

Wants: Something that is desired, but not necessary for daily survival - such as sweets, makeup, hair extensions, etc.
Financial education will help girls manage their day to day expenses now, but also in the future. Good money management can minimize some of the risks girls face in their lives, and build financial support for the future. 


\section{warm-up}

\section{ACTION ITEM DEBRIEF \\ [2 MINUTES]}

Last week your action item was to practice with a friend communicating assertively, pretending you were in a sexual situation. How did it go? Let's see a couple of demonstrations. [Have two people role

play one of their assertive communication situations.]

\section{LAST WEEK RECALL*}

[3 MINUTES]

1. Ask participants to take out their notebooks and a pen/pencil.

2. Say: Think back to the last week. What have you done during that time? More importantly, how much money did you spend? Take a moment and write down EVERY NGWEE you spent during that week.

[Give participants about a minute or less to write.]
3. Ask: Was it easy to recall what you spent? Do you think you remembered everything? How difficult is it to remember a week ago? How does this relate to developing a spending plan or budget? 


\section{activity 1}

\section{EIGHT STEPS FOR SAVINGS* [20 MINUTES]}

1. For the game below, make sure to keep the group moving. If you stop to discuss each statement, the time needed for the activity will increase greatly. Keep the group moving to keep the energy of the game!

2. Explain: Today our goal is to learn one important way of managing our money. We will start by talking about putting money aside because it is the key to being wise about money. We call "putting money aside" saving.

So let's start with a short activity to find out a little more about what managing money really means.

3. Explain: I am going to say a series of statements and ask you to stand up for each one that is true for you. After each one, you will sit back down.

Stand up if you:

- Walked here today

- Are wearing green

- Never saved money before

Like to spend money

- Know how much you spent on food last week
- Wish you had more money

- Are saving for something specific you want

- Think saving is important

Think saving money is difficult

4. Ask: For those of you who think that saving is important, why do you think so?

[If these answers don't come up, share: Helps you use your money better, helps you depend less on other people, makes you feel secure when you have a problem and need money, helps you to plan for the future and achieve those plans.]

Why is saving money difficult?

[If these answers don't come up, share: Do not have regular income, do not have any extra money, give any leftover money to parents for household expenses, spend extra money on things like sweets or make-up, do not have a safe place to keep money aside.]

What would make you want to save money?

[If these answers don't come up, share: Take care of personal needs/wants, avoid depending on other people, be able to make own decisions, help out family with household needs.

What would make you not want to save money?

[If these answers don't come up, share: It is not safe to save, you can lose your money, money is too little to save, don't know how to save.]

Continued on next page 
activity 1 (cont.)

5. Explain: Managing money involves all of these things:

\section{- Saving money}

- Spending money

Planning how you will spend your money

- Keeping track of how you spend your money

Since most of us do not have enough money to pay for everything we need and want, we have to make choices about what we will buy and what we won't. We try to save for things we will want in the future. We figure out how to stretch our money to cover the necessary expenses we face. It can be hard.

6. Show the "Eight steps for savings" in Box 4. Explain that the group will do some activities today that will help us with these steps.

\section{EIGHT STEPS FOR SAVINGS}

1. CHOOSE A SAVINGS GOAL

2. MAKE A SAVINGS PLAN

3. KNOW THE DIFFERENCE BETWEEN NEEDS AND WANTS

4. CONTROL SPENDING

5. THINK ABOUT THE FUTURE: MONEY IN AND MONEY OUT

6. SAVE REGULARLY

7. SAVE IN A SAFE PLACE

8. DEAL WITH SETBACKS IN SAVING 


\section{activity 2}

\section{MANY REASONS TO SAVE: WHAT ARE YOUR PRIORITIES?* \\ [20 MINUTES]}

1. Explain: You have named many different reasons to save. Most will relate to one of the following main reasons (or categories) for saving.

- The first main reason is: personal or family use, which can include food, clothes, rent, or snacks.

What are other examples of "personal or family use"?

[Answers include: Hair maintenance, sanitary towels, lotion, Zesco units for lights, etc.]

- The second main reason is: emergencies, those unexpected events that we need to deal with right away. Some examples are illness, accidents, or natural disasters.

What other emergencies can we save for? [Answers include: Theft, fire, parent losing a job, poor harvest, health issues, etc.]

- The third main reason is: future opportunities, like those ideas some of you have for the future. We can save to meet these goals. We might save money for school fees, to get training in a skil or trade, for the next planting season, to move into our own house/room, or to start a business.

What other future opportunities can we save for?

[Answers include: Education, wedding, training or skills school, children's education, a house or land, a lump sum of money to start a business, etc.]

2. Assign a place for each of these three main reasons: 1) Personal or family use; 2) Emergencies; 3) Future opportunities (if you are inside, you can use a corner, the door, a window; if you are outside, select or mark three distinct spots - for example near a tree, bush, or rock - close by).

3. When you have pointed out the three places, say: I would like you all to stand up. Your job is to decide which of these main reasons, or categories of reasons to save is the highest priority for you, so either 1) Personal or family use; 2) Emergencies; or 3) Future opportunities. Choose one and go stand in the location assigned the category you have selected as your most important reason to save You have 15 seconds to make your choice and move!
4. Once everyone has moved to the place that marks the savings category of their choice ask them to spend one minute sharing with the others who have chosen the same priority why they think this reason to save is the most important.

[Note: If all the girls move to one or two of the categories, you will have to ask for volunteers to "choose" the one that has not been selected and ask them to move to the spot that does not have enough people.]

Continued on next page 


\section{activity 2 (cont.)}

5. Select a volunteer from each group to explain to everyone why they chose the category they did.

\section{Ask the other two groups:}

Do you agree? Why or why not?

Start a brief discussion - but don't let it become a shouting match or fight and keep it brief. Make sure that each group has an opportunity to explain why their selected category is a high priority. When the discussion is over, ask participants to sit down.

6. Explain: You might have guessed by now that there is no wrong answer for which of these categories is the most important. They are all good reasons to save, and the importance depends on the individual's or family's needs and wants. The level of importance might also change over time. But, in reality, it can be difficult to save for all three. Sometimes you have to decide what is most important to you.

7. Ask: What happens when a girl needs money for these things, like personal needs or to deal with an emergency, but she does not have money of her own?

8. Listen to girls' answers to the question.
[The answers can vary widely including not buying items, going hungry, working earning money, or getting money from other people.]

9. When they are done, explain:

Sometimes when girls need money to buy personal items, help their family with food or rent, or manage an emergency that might come up, if they do not have their own money saved up that they can use, they find other ways to get that money. A lot of times, that means going to men to ask for money. Relying on men for money can lead to situations where the men expect sex in return, whether right then and there, or at a later time. This can be a risky situation for your health and your safety since it might be hard to say no when you feel like you owe the person something. So, one important reason to save is that when these needs come up personal items, future use, or emergencies - you have your own money to use instead of putting yourself in a potentially risky situation to get money. 


\section{activity 3}

\section{WHAT IS RISKY INCOME?* [10 MINUTES]}

1. Note to mentor: It is common for adolescent girls to get money from sources that may put them at risk of unsafe sexual behavior. This can be from boyfriends or other older men who give them money and gifts in exchange for sex. When girls depend on these men for money and other resources, it can make it harder for them to be in a position to say no to sex or to negotiate for safer sex, i.e., condom use. It is often the case that girls who have their own money, or have a little bit of economic independence, are less dependent on men for money.

2. Ask: In our previous discussions, we talked about different ways that a girl might get her money. Do you think it matters where this money comes from?

From the different ways that a girl gets money, which are some that might have some risks to them?

For each of the risky sources of income mentioned:

Ask: What makes this way of getting money risky? What can a girl do to avoid some of these risks?
If "from men" or "from boyfriends" does not come up, ask: What are the risks in girls getting money or other gifts from boyfriends or other men that they know?

If a girl had her own money that she kept aside as savings, either at her home or in a bank account, how would that change the way she gets money from boyfriends or other men?

Encourage discussion and then explain:

Often, when people other than your parents give you money, there is an expectation that they will get something back. In many cases, what you give back is work. You wash clothes, plait hair, work in the field, and in exchange you get paid an amount of money.

However, when you are getting money that is not in exchange for work, especially if it comes from boyfriends or other men that you know, there may be an expectation that eventually you will give something back. Often times that expectation is some kind of sexual activity. When you are in this situation, or feeling like you "owe" someone something for the money or gift that they gave you, it may be hard to say no to sex or to ask your partner to use a condom. Even in situations where a girl really likes the boy or man, she might still feel more obligated to do things she is not comfortable with if he gives her money or presents.

Continued on next page

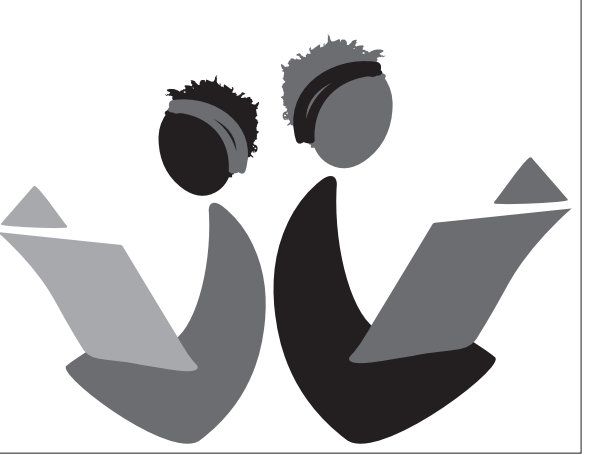




\section{activity 3 (cont.)}

Let's be aware of these kind of

expectations before we accept money or gifts from boyfriends or other men. Some of the risks associated with getting money through such ways include the possibility of contracting HIV \& AIDS and other

sexually transmitted infections, unwanted pregnancies, involvement in drugs, in

sexual violence and sexual exploitation,

forced marriages, and exposure to other social and health risks.

Let's try to think about our savings as a way that we can use our own money so that we do not have to depend on these gifts or money from men for our daily

needs. It helps us be empowered girls and women!

3. Ask: Does anyone here have an example of when something like this happened to someone they know?

Let a few girls share examples. 


\section{wrap-up}

\section{WRAP-UP \\ [2 MINUTES]}

Ask participants to summarize what they have learned. Fill in any key points they miss.

Key Message: There are many steps to savings and we have to make choices about what to buy or use our money on and what not to. There are different reasons to save, and sometimes we have to prioritize one over the other which can be difficult. It is important to be aware of risky income, particularly when getting money from boyfriends or other men as they may expect some kind of sexual activity in return.

\section{Action item: 3 minutes}

Our action item this week is to figure out how much we think we can save on a weekly basis. In your notebooks, keep a diary of what you spend on yourself each day. Enter what you bought - a snack, lunch, candy, soap - and how much each item cost at the end of each day.

The day before we meet for our next session, take a look at what you spent. What could you have saved instead? Could you have skipped the candy and saved that amount? Are there other savings? Come up with a realistic amount to save each week.
And, a bonus question: If you save that money each week, for two months, how much money will you have saved?

Ask for any final questions or comments.

Remind participants where and when the next meeting will take place, and what topics will be discussed.

Thank them for their participation.

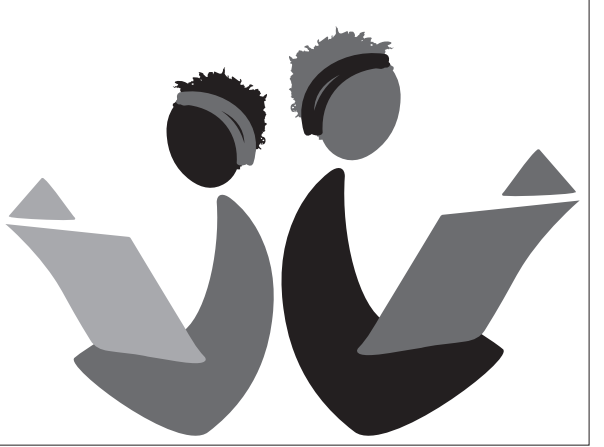




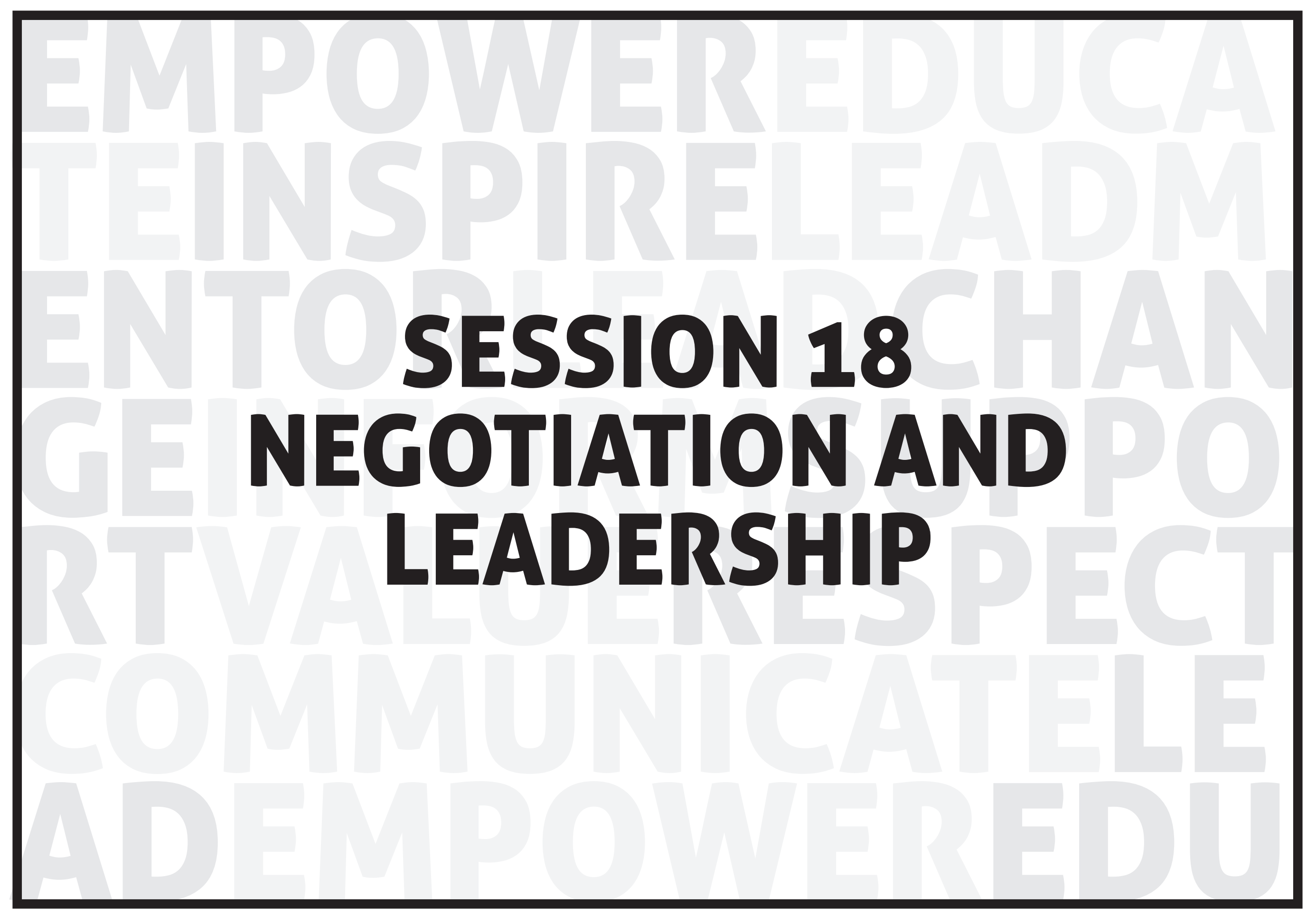




\section{session 18 / negotiation and leadership}

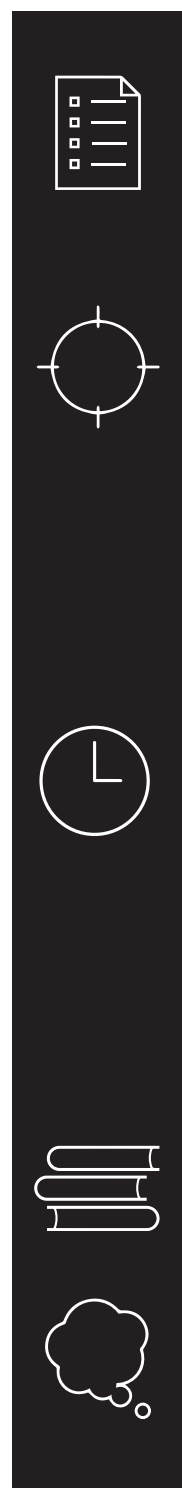

\section{SESSION DESCRIPTION}

Participants learn that negotiation is a way of talking and working together with others to solve problems. Also, participants consider what makes an effective leader and how to avoid using negative leadership behaviors

\section{OBJECTIVES}

By the end of the session, participants will:

Learn that by cooperating rather than competing with each other, both parties may reach their desired results, even in situations that seem competitive

- Learn the difference between positions and interests and show the possibility of reaching a win-win solution

- Identify the qualities of good and bad leadership, and think about how they would like to develop to become leaders

\section{SESSION TIME}

1 hour

Action item debrief: 5 minutes

Warm-up: Islands, 10 minutes

Activity 1: What is negotiation? 10 minutes

Activity 2: Positions and interests: Case of the lemon, 20 minutes

Activity 3: Good leader, bad leader, 10 minutes

Wrap-up: 2 minutes

Action item: 3 minutes

\section{REQUIRED MATERIALS}

Chalkboard and chalk

\section{PRE-SESSION PREPARATION}

Read through the entire session and practice presenting the activities Prepare all materials needed

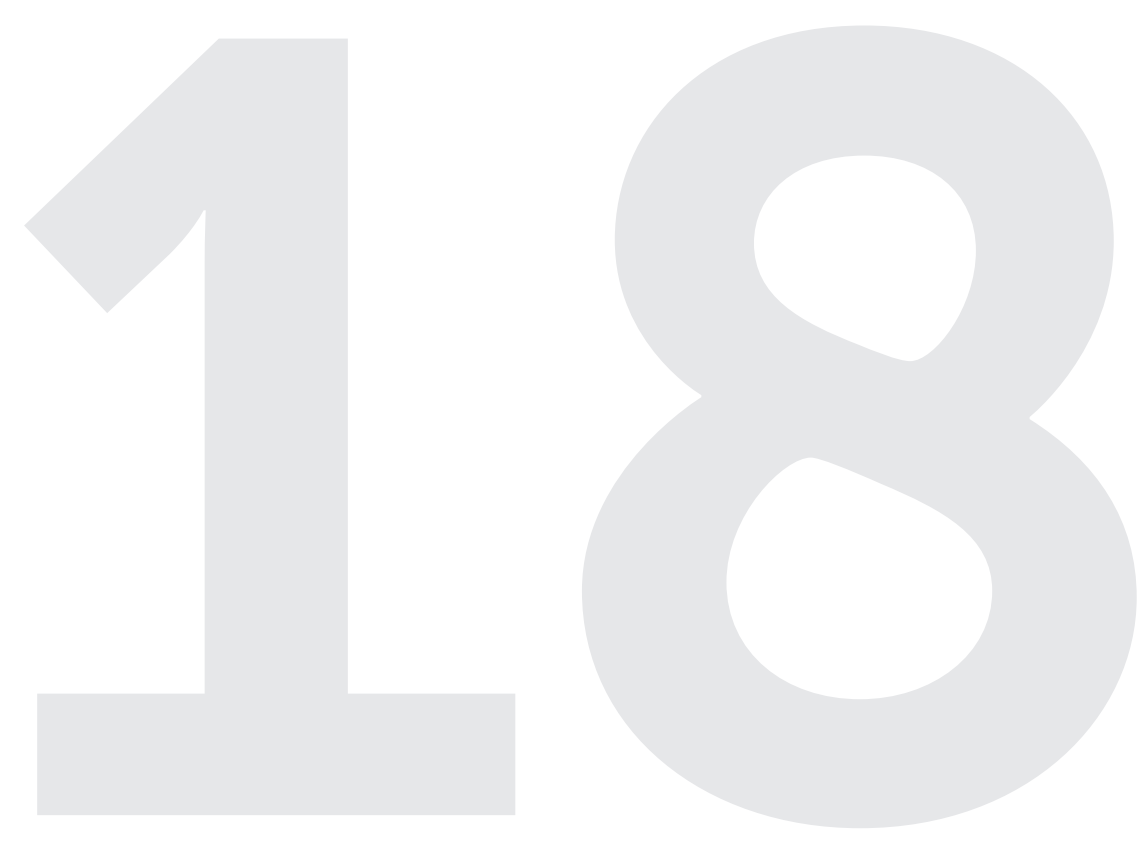




\section{session 18 / negotiation and leadership (cont.)}

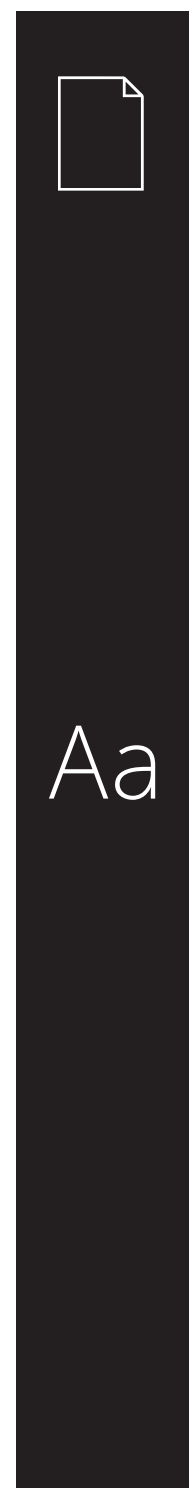

\section{FACILITATOR NOTES*}

This session will cover two skills: negotiation and leadership.

Negotiation can happen in many different situations and in ways that participants might not think of as negotiation. No matter how difficult the situation, negotiating parties almost always have a reason to work together despite some conflict in their objectives.

Negotiation is a way that you can get what you want by also helping the other person to get what they want. Working together can be better than working competitively.

\section{TERMS}

Interest: What you care about and why.

Leadership: The art of motivating a group of people to act towards achieving a common goal or a state of being in control of a group of people.

Negotiation: Talking and working with other people to find solutions to problems together.

Position: Your demand, or what you are asking for.

Win-win solution: When negotiation helps both people to win by meeting their interests.
Young women are change agents and their leadership can bring vitality, creativity, and courage for social change. Young women have the power to inspire and mobilize others for positive action. They can encourage the questioning of systems and beliefs that limit lives and choices. With courage they can confront even the injustices that have been in place long before our lives began. With their leadership young women can contribute to social change for peace, justice, health, human dignity, and care for the environment for everywhere, and for everyone. By supporting one another, young women ensure that their leadership remains strong in the face of unfair gender and age biases, and maximize our power to change.

As they continue to develop and define

leadership, the advice and example of older, more experienced women are invaluable. By working together, women of all ages can help each other grow, maximize their strengths, and fulfill their potential as change makers.

*Sources: McGinn, Kathleen, Corinne Low, and Nava Ashraf. 2014. GIRLS ARISE: Working Together for a Better Future. Zambia: Innovations for Poverty Action (IPA). Page 10. Population Council. 2013. Life Skills and Health Curriculum for the Adolescent Girls Empowerment Program (AGEP). Page 241. 


\section{warm-up}

\section{ACTION ITEM DEBRIEF [5 MINUTES]}

How did your tracking of spending go? Were you surprised at the amount of money you spent in a week? How many of you think you have some money you could save each

\section{ISLANDS*}

\section{[10 MINUTES]}

Designate two corners or parts of the room as 'agree' and 'disagree' with signs or by pointing out the two spots in the room to the group.

\section{Explain:}

I am going to read a statement, and you have to decide if you agree or disagree with it. After I read the statement, you have to race to stand in the designated corner or space in the room that describes how you feel. You must decide quickly as the last one to reach each corner or space will have to defend their reason.

Read the statement: Girls are just as smart as boys.

After everyone races to the sign, ask the last person under 'agree' to say why they agree and the last person under 'disagree' to say why they disagree. After they each state their week? Why is it important to pay attention to what we spend? [Answers include: money is power - taking control of our money is a way to empower ourselves.]

reasons, people may decide to change their positions and move to the other sign, which is fine.

Repeat the exercise with other statements

When a girl says no, she really means yes

- Boys should not have to cook and clean; it is girls' work

If all my friends are doing something, I

must also do it

If a younger student is doing something

wrong, it is okay for me to hit them

If I see a student bullying another student, should stop them

\section{Ask}

Where do we get our assumptions (meaning something that you accept as true without question of proof) and beliefs?
Is everyone open to changing their beliefs if they receive new information (think about how many people moved from the 'agree' corner to the 'disagree' corner and vice versa)? If not, why?

How can we become more open? Are there ways we can help others to become more open? 


\section{activity 1}

\section{WHAT IS NEGOTIATION* [10 MINUTES]}

1. Explain: One way to reach solutions to our problems is by talking and working with other people to find a solution together. We call this a negotiation.

Negotiation can happen when two people seem to want different things, and yet they want to work together.

Negotiation is not about arguing with or convincing the other person. Instead, negotiation is a method of working together with the other person to solve a problem, and to get both people what they need

Now let's go through an example where two people are trying to work together, but seem to want different things.

2. Read: Your best friend wants to meet up for a walk after dark, but you do not like going out in the compound at night.
Ask:

Who are the people involved in this negotiation?

[My best friend and me.]

What do you seem to want that is different?

[She wants to go for a walk at night, and would rather meet in the daytime.]

- Why do you want to work together with your best friend?

[I like my best friend, and I want her to be happy; my best friend likes me and wants my company.]

\section{Explain}

When two people seem to want different things, and yet they also want to work together, they can use negotiation to solve problems together. 


\section{activity 2}

\section{POSITIONS AND INTERESTS: CASE OF THE LEMON* [20 MINUTES]}

1. Let's talk about why negotiation can help both people get what they want by working together.

Have you ever tried to bargain with a seller at the market?

[Get a few quick responses from participants.]

When we bargain at the market, it seems that if one of us is happy, the other one will be less happy. If I get the price I want and pay less, the seller will be less happy because he gets less money. If I pay his first price, though, I am less happy because I have to spend so much money.

But negotiation is not always like that. Sometimes it is possible to find solutions that help both people.

I am going to tell you a story that shows this idea:

- Was anything wasted? What would have
Story: The Case of the Lemon

Two sisters are arguing over a lemon from their neighbor's tree. One says, "I should get the lemon because I'm older and bigger." The other says, "I should get the lemon because I saw it first."

They argue back and forth, each one trying to get the lemon. Finally, they decide to split the lemon in half. They get out a knife and cut the lemon in half.

The younger sister takes her half of the lemon peels it, throws away the peel, and eats the inside with salt. The older sister takes her half of the lemon, peels it, throws away the inside, and boils the peel to make cough syrup.

\section{Ask:}

-What did you think about the story? been a better solution?

[Each sister wasted part of the lemon. One sister should have taken the peel and one should have taken the inside.]

Did they talk about what they wanted to do with the lemon? What did they say instead? [They didn't talk about what they wanted/why they wanted the lemon; they just argued.
Explain: What this story shows us is that when we only state our demands - what we are asking for - it is hard to come up with a good solution. But when you talk about WHY you are asking for something - the things you care about beneath the demands - sometimes you can see solutions you did not see before.

In a negotiation, your position is what you are demanding and your interest is what you care about and why.

\section{Continued on next page}

*Source: McGinn, Kathleen, Corinne Low, and Nava Ashraf. 2014. 


\section{activity 2 (cont.)}

3. Ask: When people are arguing and demanding things, are they usually asking for the same things or opposite things?

[Answer: When we're arguing we want different things, or opposite things.]

Positions are usually opposite each other, like two fists going against each other.

[Make the gesture of two fists against one another.]

Ask: Can we make a good agreement like this?

[Answer: No.]

Explain: But the things people deeply care about and their reasons for wanting them are not always opposite. Interests go in all different directions, like two open hands.

[Open the fists and pull hands apart slowly to show fingers pointing in different

directions. This motion shows both people opening to think about their interests.]

Behind someone's position, you can always find many interests. If you talk about positions only, it is very hard to have a good negotiation, because you will just end up arguing over opposite demands. But, if you open up the positions to find the interests behind, you can start to negotiate. [lllustrate this by starting with the fists hitting against each other, then pulling apart and opening up, and slowly coming back together with the finger tips all touching.]

4. Let's talk about interest and position in the case of the lemon.

Explain: Let me remind you that the position is the demand-what you are asking for-and the interest is what you care about and why.

When the sisters were arguing, they were only talking about their position which is, " want the lemon." Since there was only one lemon, it seemed that there was no way for both to get what they wanted.

However, if they had talked about their interests - what they really cared about and why - they would have realized there was a way for them both to be happy. One could have taken the inside of the lemon and the other could have taken the outside of the lemon. This is called a "win-win solution."

5. Ask: What do you think "win-win" means? [Answer: That both sisters get their way: win and you win.]

Explain: Negotiation can help both people to win. If the sisters had talked about their interests - why they wanted the lemon in the first place - they could have both won. One would have the full peel, and one the full inside.

Ask: When the sisters split the lemon in half, they were compromising. Was that a win-win solution?

[Allow the participants to answer. Some might point out that a compromise was still good because both sisters got some of the lemon. But prompt them with questions like: Did any lemon get wasted?

Or, what solution would give each sister the most lemon?]

Explain: Often when people are trying to settle a conflict, they look for a compromise, like each sister gets half the lemon. But you just explained that the compromise was not as good as a win-win solution.

Continued on next page 


\section{activity 2 (cont.)}

Compromises are what you get if you only talk about positions, not interests - and because positions are often opposing,

both people have to give something

up and are a bit unhappy as a result.

Sometimes this might be the best solution.

Win-win solutions come from talking about interests instead of positions. Win-win solutions are the reason that negotiation can work for you, even if you feel like you do not have power over people in your life. You might think, I am just a girl, why would anyone negotiate with me? But actually, if you learn how to create win-win solutions, the people you negotiate with in your life will be made better off, because they will also "win."

If you can show the other person that negotiation is about helping both people get what they want, you can get others to negotiate with you. 


\section{activity 3}

\section{GOOD LEADER, BAD LEADER* [10 MINUTES]}

1. Arrange seats in a circle with the chalkboard visible to the circle of participants. Draw two columns on the chalkboard. Write 'Good Leader' at the top of one column and 'Bad Leader' at the top of the other.

2. Explain: Next we are going to talk about leadership.

Ask: What do you think leadership means?

[Answer: The action of leading a group of people or an organization.]

Why is it important for everyone to have some good leadership skills?

[Answer: Advancement of your own goals, use your resources to reach your vision, they strengthen communication and decision-making, increase productivity etc.]

3. Say: Think of a leader you admire (for example, mother, community leader, celebrity, politician), and think of three qualities you believe makes that person an effective leader.
Next think of a leader you dislike (for example a dictator, a celebrity or politician, or a

character from a well-known story), and think of three qualities that make that person a bad leader.

Allow a couple minutes for participants to think of these responses. Ask for volunteers to share what qualities they have come up with.

Record the qualities on the chalkboard under the columns 'Good Leader' or 'Bad Leader.

4. Discuss the similarities and differences in the qualities that were suggested:

- Was anything surprising?

- Are there any similarities with the qualities for a good leader and for a bad leader?

Do the leaders we don't admire have similar qualities to ones we do admire?

How can we avoid becoming bad leaders? What can we do to be effective leaders?

5. Explain: Now answer the following questions in your head:

[Pause after each question and read each

one twice to allow the participants to identify their answer.]
A positive quality that you believe you already have

A positive quality that you would like to develop

A negative quality that you would like to

manage or eliminate

Ask if anyone would like to share any of their answers briefly.

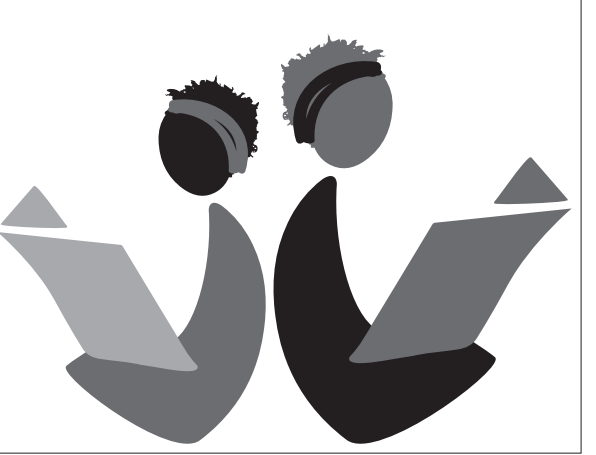




\section{wrap-up}

\section{WRAP-UP \\ [2 MINUTES]}

Ask participants to summarize what they have learned. Fill in any key points they miss.

Key Messages: One of the best ways to solve a problem is to talk or discuss with others to

find a solution together through negotiation.

Leaders in our communities, families, and

countries possess qualities causing different

types of leadership. You can be a leader too!

\section{Action item: 3 minutes}

Think about something in your school that you would like to see changed. It can be about bullying, or about teachers beating students as punishment, boys harassing girls or one of the other topics we have talked about that are an issue. We'll decide now together as a group, what the issue will be. Then, before our next meeting, I want you all to meet as a group, and come up with a plan for trying to change this inequality and prepare a role play showing what you will do. So next week, you'll act out your plan, with some of you acting out the roles of other participants or adults, and some of you will act out the role of being this group. Your role play should convey who you will speak with, what you will say to different actors, how they might react, and how you will negotiate. Remember, you may want to plan to speak with some allies who will support your effort as well. So next week, l just want to see you act out your plan - don't implement it yet! Any questions?

Ask for any final questions or comments.

Remind participants where and when the next meeting will take place, and what topics will be discussed.

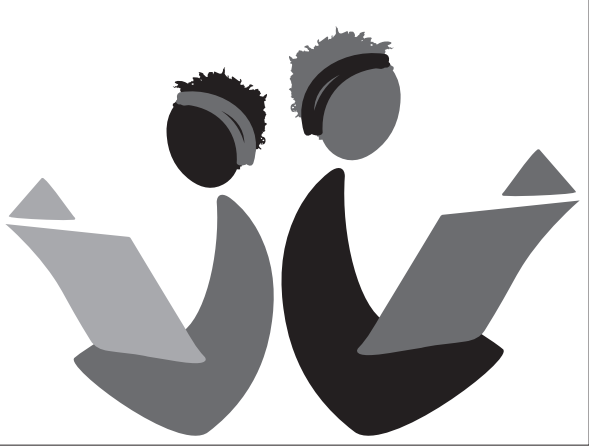




\section{SESSION 19 MAKING THE WORLD A BETTER PLACE}




\section{session 19 / making the world a better place}

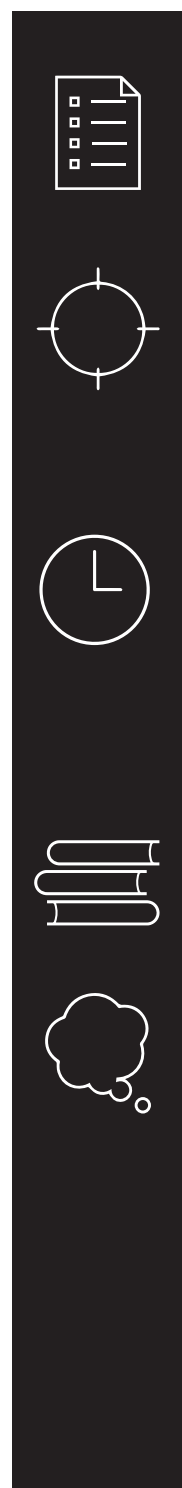

SESSION DESCRIPTION

Participants explore what they can do in their own lives to make the world a better place.

OBJECTIVES

By the end of the session, participants will:

Feel supported by their peers

- Have increased motivation and confidence to change the world in which they live

\section{SESSION TIME}

1 hour

Warm-up: Giving compliments, 10 minutes

Action item debrief: 10 minutes

Activity 1: Get inspired! Creating change, 30 minutes

Wrap-up: 10 minutes

\section{REQUIRED MATERIALS}

Chalkboard and chalk

\section{PRE-SESSION PREPARATION}

Read through the entire session and practice presenting the activities. Prepare all materials needed.

Write the four quotes from Activity 1 on the chalkboard.

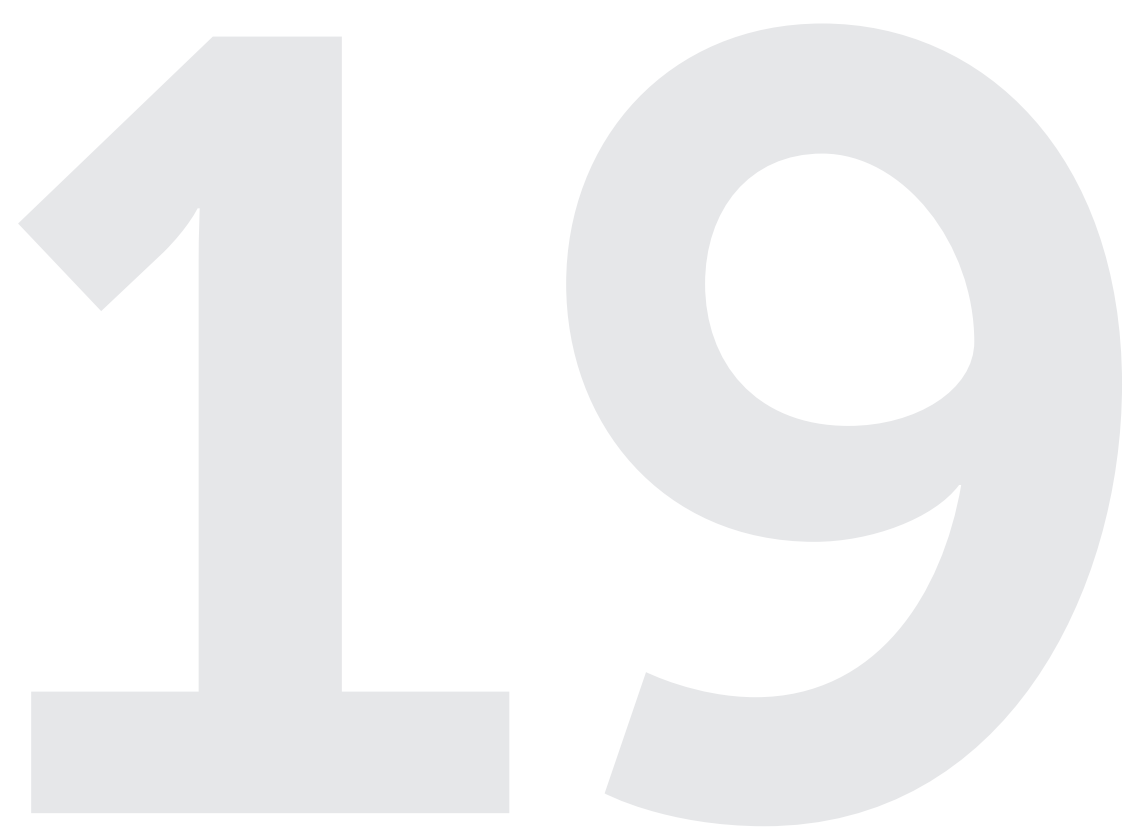




\section{session 19 / making the world a better place}

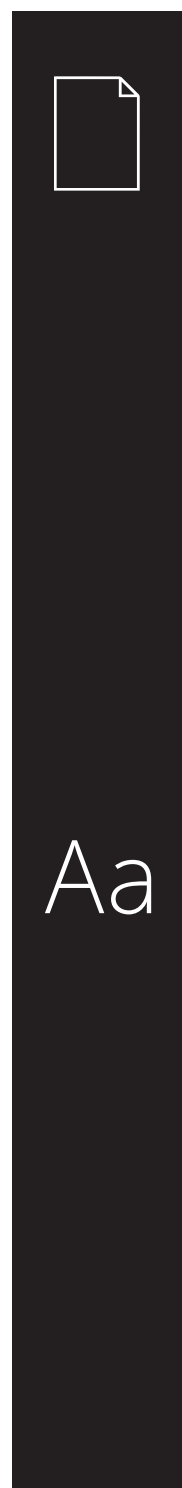

\section{FACILITATOR NOTES}

Over the course of this curriculum we have examined issues of sexual health (including HIV and AIDS), human rights, power, communication, and gender equality. As participants complete the program, encourage them to continue to reflect on their own behaviors, to continue to think critically about what is fair or unfair, and continue to build their skills for empathy and standing up for what is right. Remind them that they can take steps whether large or small - to make a difference in their own lives and in the lives of others. This kind of personal and civic engagement helps empower individuals as responsible citizens, helps promote democratic culture, and makes the world a better place.

\section{TERMS}

None
The five quotes in Activity 1 are attributed to the following individuals:

Mahatma Gandhi is considered by Indians as the father of their nation. He inspired nonviolent civil disobedience, which led to India's independence from Britain and inspired movements for civil rights and freedom around the world.

Martin Luther King, Jr., a minister, was the most famous leader of the American civil rights movement. A promoter of nonviolence and activist for the equal treatment of all races, he was awarded the Nobel Peace Prize.
- His Holiness the 14th Dalai Lama, the spiritual leader of Tibetan Buddhists and an activist for Tibetan autonomy.

- Margaret Mead, an American cultural anthropologist.

Nelson Mandela was a South African antiapartheid revolutionary, political leader and philanthropist who served as the first black president of South Africa from 1994 to 1999 . He helped bring an end to apartheid and was a global advocate for human rights. 


\section{warm-up}

\section{GIVING COMPLIMENTS* [10 MINUTES]}

1. Divide participants into two groups and ask each group to form a circle. Ask one student to stand in the center.

2. Go around the circle and ask each person to say something nice about the person in the middle or thank them for something they have done. Be sure to supervise the activity and to remind participants to say only positive things.

\section{ACTION ITEM DEBRIEF [10 MINUTES]}

Ask participants to perform their role play about what they would like to see changed at their school. Praise them for their hard work and good ideas. Ask them if they think this is something they could undertake in real life. What kind of support would they need to do so? Did performing their role play give them ideas about how to improve their plan? Brainstorm possible ways to strengthen their plan and who could help. Encourage them to implement their plan, provided it is something that does not endanger their safety in any way.
3. Repeat with each student in the middle.

4. After the exercise, have a brief discussion about how it felt to be in the middle of the circle and how it felt to say nice things about others.

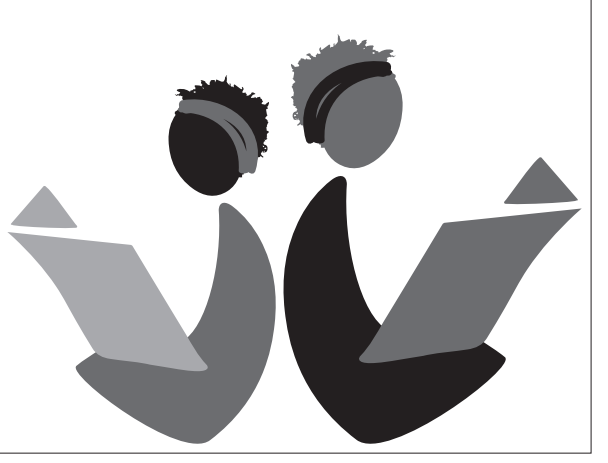




\section{activity 1}

\section{GET INSPIRED! CREATING CHANGE* [30 MINUTES]}

\section{Explain:}

Today we will explore what it means to work for social justice (meaning that everyone deserves equal economic, political, and social rights and opportunities) or to change the world we live in, even in a very small way. We will review a series of quotations, written on the board, from people who have made a difference through their own efforts.

"Be the change that you want to see in the world."

- Mahatma Gandh

"Injustice anywhere is a threat to justice everywhere...Whatever affects one directly, affects all indirectly."

- Martin Luther King, Jr.

"Responsibility does not only lie with the leaders of our countries...It lies with each of us individually.

- His Holiness the 14th Dalai Lama
"Never doubt that a small group of thoughtful, committed citizens can change the world. Indeed, it is the only thing that ever has."

- Margaret Mead

"We can change the world to make it a better place. It is in your hands to make a difference."

- Nelson Mandela

2. Read each of the quotes aloud.

3. Explain: Select the quotation that most inspires you. [Pause for a moment to let participants choose their quote.

4. Ask: Has everyone decided which quote they are going to focus on?

Now think about what your quote means. I'm going to ask three questions and I want you to answer the questions in your head. Ready?

-What do you think is the message of the quote? [Write "1. What does it mean?" on the board. Give participants a minute to think before asking the next question.]
Why is this quote meaningful to you, and why did you select it? [Write " 2 . Why is it meaningful to you?" on the board. Give participants a minute or two to think before asking the next question.]

How can you apply the message of this quote in your own life? Or if you already apply it, think about that. [Write "3. How will I apply this message in my life?" on the board. Give participants a few minutes to think, repeating the question after the first minute to remind them.]

\section{Continued on next page}

Source: International Sexuality and HIV Curriculum Working Group. 2009, updated 2011. It's All One Curriculum: Guidelines and Activities 


\section{activity 1 (cont.)}

5. Ask: Is everyone ready? Did anyone select the first quote on the list? If so, who would like to share their thoughts on what the

quote means and how you can apply it in your own life?

6. Go through all four quotes on the board in this manner.

7. After going through each quote, lead a discussion asking the following questions:

What are some of the key messages that you draw from these quotes?

What are some of the positive personal benefits that people who work for social justice enjoy?

- What are some of the challenges and risks?

Is it important for ordinary citizens to take action on issues that they care about? 


\section{wrap-up}

\section{WRAP-UP \\ [10 MINUTES]}

Key message: Individuals can challenge injustices (including gender inequality,

bullying, and stigma) that they see in their own

relationships and lives. For example, we can

all stop using degrading language or telling

demeaning jokes and we can speak up when

others do. We can pressure a friend who is

teasing or bullying someone to stop doing so.

We can convince our parents or aunts and

uncles to let their daughters stay in school.

People can also help end injustice that they

observe in their communities. For example, we

can educate people one-on-one to raise their

awareness about injustice, including violence

and harmful gender norms. We can work with

a trusted teacher on a campaign to make our

school a safe place - a school free of violence

and harassment - for all students.

Invite participants to share their feelings about their experience in GirlsRead!

Closing: Remind participants that they are smart, beautiful, and powerful. That you are super proud of them and know that they

will take what they learned to continue to secondary school, support each other, and

be role models for fairness, compassion, and

equality. Each one of them matters, and what

each one of them does and says matters.

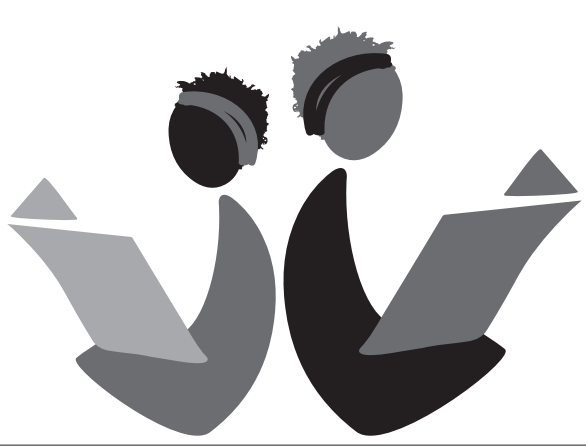


APPENDIK 


\section{glossary of terms}

Accountability: The ability to account for the decisions and actions we take; the ability to accept the results of our decisions and not

blame others for the consequences they lead to.

Adolescence: The period of time when people transition from childhood to adulthood, usually between ages 10 and 19 .

AIDS: Acquired Immune Deficiency Syndrome; the final stage of HIV disease, which causes severe damage to the immune system.

ART: Antiretroviral therapy; medication that treats HIV. The drugs do not kill or cure the virus. However, they can suppress (meaning restrain or keep down) replication of the virus. ART keeps the level of HIV in your blood low and reduces the likelihood of transmitting the virus to uninfected sexual partners. However, this is only true if a person can get and stay virally suppressed. One thing that can increase viral load is not taking HIV medicines the right way, every day.

Bladder: The sac where urine is collected before excretion.

Budget: A written plan that estimates future income, expenses, and savings.

Bullying: Unwanted, aggressive behavior that involves a real or perceived power imbalance.
The behavior is repeated, or has the potential to be repeated, over time. Both people who are bullied and people who bully others may have serious, lasting problems.

Cervix: The neck-like passage from the uterus to the vagina.

Clitoris: A sensitive area near the top of the opening of the vagina that helps a woman have sexual pleasure.

Communication: Process of sending and receiving information or thoughts, or

expressing ideas, desires, or feelings, through words, actions, or signs.

Consent: Permission for something to happen or agreement to do something.

Date Rape: Rape between individuals who are dating or know each other; also called Acquaintance Rape.

Decisions: A conclusion or resolution reached after consideration.

Deficit: When there is not enough money to cover all costs at the end of a budget period.

Discrimination: When a person is treated less favorably than another person in a similar situation because of a particular personal characteristic such as their age, sex, race, nationality, or beliefs.
Economic abuse: When a person tries to use their money to control their partner. For example, not allowing access to the family finances, preventing the person from having or keeping a job, taking the person's money, demanding an account of everything that the person buys. In this way, the exertion of power through the control of money can also be a form of violence.

Effective communication: Communication

that is clear and direct, avoids

misunderstandings and improves relationships.

Ejaculation: Release of semen from the penis during orgasm.

Emotional or psychological violence: Often the most difficult form of violence to identify. It may include humiliating, threatening, insulting, pressuring, and expressions of jealousy or possessiveness such as controlling decisions and activities

Empathy: Understanding and sharing the feelings of another person; putting ourselves in their place.

Equality: The quality of being equal. Equality is an important value in human rights and is the central idea behind universal human rights - i.e., every single person has these rights.

Continued on the next page 


\section{glossary of terms (cont.)}

Erection: The stiffened and swollen state of erectile tissue, especially that of the penis, usually as a result of sexual arousal.

Expenses: Money out-this can be money spent for any purpose.

Fairness: To ensure that everyone is treated with the same importance, and has the same rights and opportunities.

Fallopian Tubes: Tubes that connect a woman's ovaries to her uterus.

Fertilization: The fusion of a male sperm cell and a female egg; necessary before an egg can begin to grow into an embryo.

Freedom: The power or right to act, speak, or think as one wants. Or, the state of being free rather than in confinement or under physical restraint.

Friendship: A particularly fulfilling relationship involving intimacy, trust, and honesty.

Gender: The way society defines the roles, behaviors, activities, and attributes of males and females. These definitions are not fixed but change over time and from society to society.

Gender-Based Violence (GBV): Any act that results in, or is likely to result in, physical, sexual or psychological harm or suffering that targets individuals or groups on the basis of their gender.

Gender equality: Men and women are equal. They have the same rights, opportunities, and responsibilities. They should be treated with equal concern and respect, and should be entitled to develop to their full human potential.

Gender stereotype: An oversimplified or biased description of the abilities of men and women or how men and women think, feel, or act.

Goal: Something that you hope to achieve, especially when much time and effort will be needed.

HIV: Human Immunodeficiency Virus; the virus that causes AIDS and is transmitted through blood, semen, vaginal fluid, and breast milk.

Hormones: A chemical substance produced in the body that controls and regulates the activity of certain cells or organs.

Human rights: The fundamental freedoms that every person in the world is entitled to just because they are human. Nobody can take away these rights, and you have them forever.

Immune system: The body's natural defense system for fighting off disease.

Implantation: An event that occurs early in human pregnancy when a fertilized egg adheres to the uterus wal.

Incest: An act of two members of the same family having sexual intercourse, for example a father and daughter, or a brother and sister.

Income: Money in-this could be regular or irregular, from a job, or even a gift.

Interest: What you care about and why.

Labia: The two folds of skin, or lips, at the opening of the vagina.

Leadership: The art of motivating a group of people to act towards achieving a common goal or a state of being in control of a group of people.

Loan: A sum of money that is borrowed and that must be paid back.

Love: A strong feeling of affection towards something or someone.

Masturbation: Touching or stroking oneself (especially one's own genitals) for sexual pleasure.

Menstrual cycle: The period of time beginning on the first day of a woman's period until the day before she begins her next period.

Continued on the next page 


\section{glossary of terms (cont.)}

Menstrual hygiene: Taking care of oneself in a clean, safe, and healthy way during menstruation.

Menstruation: When blood leaves a woman's body through the vagina, because the egg that was released into her uterus was not fertilized. Menstruation signifies that a woman or girl can become pregnant if she has sexual intercourse. It occurs around once a month for most women, and is commonly called "menses" or "p's" in Zambia. It usually lasts between three and seven days.

Needs: A basic necessity that you cannot live without-like food, water, and a place to live.

Negotiation: Talking and working with other people to find solutions to problems together.

Non-verbal communication: Facial

expressions, eye movements and contact, body position, touch, and actions that transmit meaning.

Ovaries: A pair of organs that contain a female's eggs or ova.

Ovulation: The periodic release of a mature egg from the ovary, which happens around the middle of a woman's menstrual cycle.

Ovum: The mature female reproductive cell, which can produce an embryo after fertilization by sperm.
Penis: The male sex organ. It provides passage for both urine and semen; it places sperm in the woman's vagina during sexual intercourse.

Phenomenal: Remarkable, extraordinary, amazing.

Physical violence: Using physical force such as hitting, slapping, or pushing.

Position: Your demand, or what you are asking for.

Puberty: The physical and emotional changes that people go through during adolescence: results in sexual maturity and capability for reproduction.

Rape: Forced sexual activity, usually involving sexual intercourse, which is initiated by one or more people without the other person's consent.

Responsibility: The ability to respond to the demands of a situation that one finds oneself in

Right: A right is a moral or legal entitlement to have or do something.

Risky income: When getting money that is not in exchange for work, especially if it comes from boyfriends or other men, there may be an expectation that eventually you will have sex, or some kind of sexual activity, with them.
Saving: Putting money aside for future needs, wants, emergencies, education, or larger investments such as school or a house.

Savings Plan: A written guide for how to manage and save money to achieve a savings goal.

Self-employment: A self-employed person operates his or her own business or job, and makes all of the necessary decisions related to the business-such as working hours, investment, products and services, etc

Scrotum: The pouch of skin containing the testicles.

Sex: The biological and physiological characteristics of males and females. For example, only females can become pregnant. Sex is not the same as gender.

Continued on the next page 


\section{glossary of terms (cont.)}

Sexuality: How people experience and express themselves as sexual beings. Many factors contribute to people's sexual behaviors, relationships, feelings, identity, desires, and attitudes. One of these factors is biology, especially sex hormones. Another factor is individual personality and experience. Yet another factor is culture, which influences people's attitudes, expectations, and experiences related to sexuality. Cultural norms also affect laws and policies about sexuality. All of these factors interact throughout life.

Sexual coercion: The use of status and/or powe to coerce (meaning to persuade an unwilling person) or attempt to coerce a person into having sex. A person might use emotional manipulation, deception, physical force or threats, verbal insistence, or economic inducements.

Sexual harassment: Sexual harassment is unwanted attention of a sexual nature from someone in school or the workplace; it includes unwelcome sexual jokes, glances, or comments.

Sexual norms: Social standards that shape our understanding, attitudes, and experiences related to sexuality.

Sexual violence: Pressuring or forcing someone to perform sexual acts (from kissing to sex) against their will or making sexua comments that make someone feel humiliated or uncomfortable. It does not matter if there has been prior consenting sexual behavior.

Sperm: Male reproductive cells, which fuse with eggs during fertilization.

Statutory rape: Sex with a person who the law defines as too young to legally consent regardless of whether or not they consented.

Stereotype: Widely held generalizations and assumptions about a particular type of person or thing. For example, the stereotype of the woman as caregiver, or the stereotype of the city as polluted.

STIs: Sexually Transmitted Infections; infections passed from person to person through sexual intercourse or genital contact. These serious diseases infect the sexual and reproductive organs and can cause infertility, miscarriages, and stillbirths.

Surplus: Money remaining or left over (at the end of a budget period - like a week or month).

Testicles: These are two egg-shaped organs in front of and between a man's thighs; each testicle produces and stores sperm, which can fertilize a woman's egg during sexual intercourse.

United Nations: An international organization that was founded in 1945 by the governments of the world with the aim of promoting global peace, security, and human rights.

Universal Declaration of Human Rights: The key United Nations document establishing the standards of basic human rights for everyone. The Universal Declaration of Human Rights was adopted by the United Nations General Assembly on December 10, 1948.

Urethra: The duct which conveys urine (in males and females) and sperm (in males) outside the body.

Uterus: Where a fertilized egg grows and develops when a woman becomes pregnant; also called the womb.

Vagina: An elastic canal, leading from the vulva to the cervix and uterus. Menstrual blood leaves the body through the vagina, as does the baby when it is born. In vaginal intercourse, the penis penetrates the vagina.

Values: The beliefs that govern what people view as right and wrong. The things that are important to us (that we value), which we use to guide and direct our lives, and which are seen in the way we live and in our actions and behavior.

Vas Deferens: The duct that conveys sperm from the testicles to the urethra.

Continued on the next page 


\section{glossary of terms (cont.)}

Verbal communication: The use of language and sounds to express oneself.

Vulva: External female genital organs.

Wants: Something that is desired, but not

necessary for daily survival - such as sweets,

makeup, hair extensions, etc.

Win-win solution: When negotiation helps

both people to win by meeting their interests. 


\title{
fact sheets / table of contents
}

\author{
ANATOMY AND SEXUAL PLEASURE ........... 192 \\ CONTRACEPTIVE METHODS ....................... 194 \\ HIV (HUMAN IMMUNODEFICIENCY VIRUS) \\ AND AIDS (ACQUIRED IMMUNE DEFICIENCY \\ SYNDROME) …………………………........ 199 \\ MENSTRUAL CYCLE \\ (also called the ovulatory cycle) .................. 201 \\ PUBERTY AND BOYS .................................. 203 \\ PUBERTY AND GIRLS .................................. 204 \\ REPRODUCTION AND PREGNANCY ........ 206 \\ SEXUAL AND REPRODUCTIVE SYSTEMS \\ - FEMALE ………..................................... 208

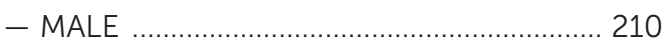 \\ SEXUALLY TRANSMITTED \\ INFECTIONS (STIS) ........................................ 211 \\ UNIVERSAL DECLARATION OF HUMAN \\ RIGHTS \\ VIOLENCE AGAINST WOMEN AND \\ GIRLS, INCLUDING SEXUAL VIOLENCE ..... 216
}

All the fact sheets are presented in

alphabetical order.

All content in Fact Sheets from:

International Sexuality and HIV Curriculum Working Group. 2009, updated 2011. It's All One Curriculum: Guidelines and Activities for a Unified Approach to Sexuality, Gender, HIV and Human Rights Education. New York: Population

Council. (Volume and page numbers listed in footnotes.) 


\section{fact sheets (cont.)}

\section{ANATOMY AND SEXUAL PLEASURE*}

Sexual response is not the same in any two people. It is often affected by past experiences, cultural attitudes, and feelings about one's sexual partner and about the specific sexual situation. Age; physical state (including illness or fatigue); use of alcohol, drugs, or medication; and emotional state (including a sense of comfort or anxiety) may also affect sexual response. These factors are examples of why it is sometimes said that the brain may be the most important organ involved in sexual arousal.

\section{What happens during sexual arousal?}

Sexual arousal refers to the body's response to wanting, anticipating, and participating in sex. It begins with sexual stimulation from, for example, a touch, smell, sight, taste, sound thought, or fantasy that has erotic meaning to a person. Males are often particularly aroused if the penis or scrotum is touched or stroked. In females, the most sensitive organ is the clitoris. The clitoris is rich in nerve endings, and sexual pleasure is the sole function of the clitoris. Both the penis and the clitoris fill with blood and become more erect in response to arousal; this engorgement increases their size and sensitivity.
Sexual arousal also involves the responses of other organs. Heart rate increases, muscles become tense, blood pressure is elevated skin may flush, and nipples may become erect. In women, the vagina becomes moister and expands. In men, the scrotum is pulled closer to the body, a gland releases a fluid that cleans the urethra, and the bladder closes so that urine and semen cannot mix. During a sexual experience, the level of arousal can go up and down. Arousal may last for just a few minutes or for several hours.

If sexual stimulation continues, arousal may intensify and lead to orgasm. Just before orgasm, breathing, blood pressure, and heart rate increase. Becoming aroused and reaching orgasm often take longer in women than in men. Although some women perceive sensitive areas in the vagina (sometimes called the "G-spot"), most women reach orgasm through direct stimulation of the clitoris rather than through intercourse.

Continued on next page
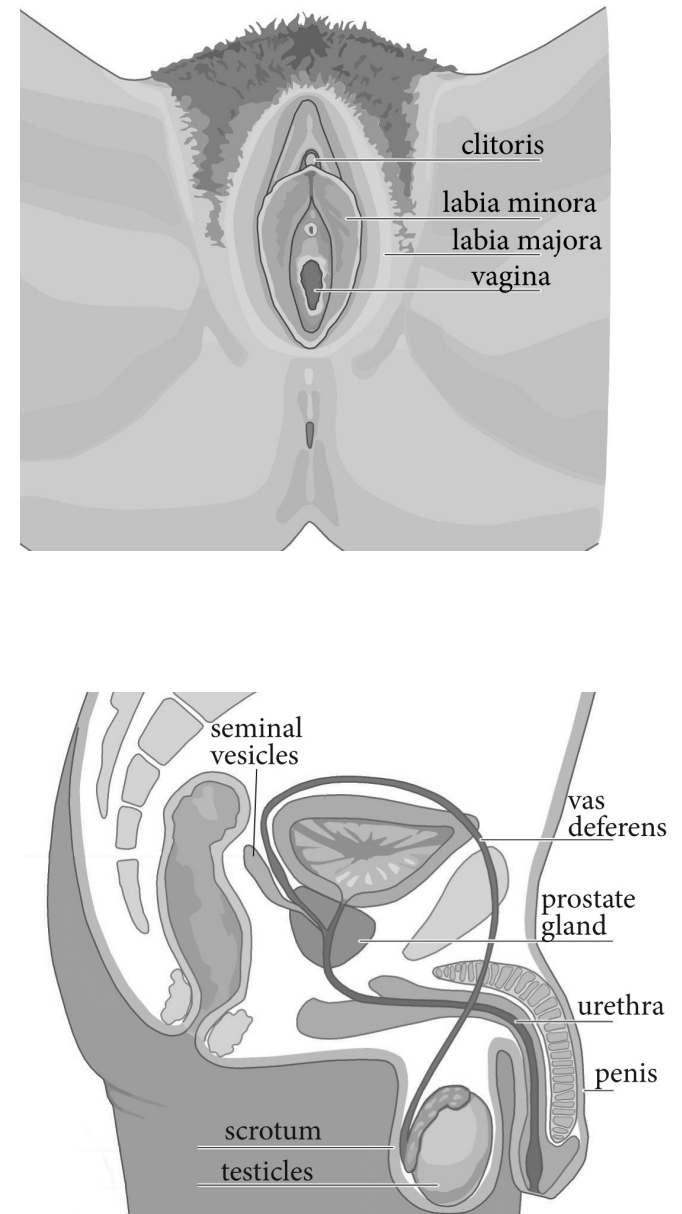


\section{fact sheets (cont.)}

\section{What happens during an orgasm?}

Orgasm is a peak of sexual pleasure. It

is accompanied by a series of rhythmic

contractions in the pelvic area, contractions

and sensations of pleasure throughout

the body, and a sudden release of sexual

tension. With orgasm, the body also releases

chemicals called endorphins, which produce

good feelings. The experience of orgasm

varies greatly among people and from one

orgasm to another in the same person. Some

women can have more than one orgasm

in a relatively short period of time; in fact

they may experience the urge to do so. The

vagina becomes more lubricated with fluid

secretions after orgasm.

In men, orgasm is usually, but not always, accompanied by ejaculation. During an

ejaculation, the prostate, seminal vesicles and vas deferens contract, releasing their

fluids, which mix with sperm produced by the testicles, to form semen. At this point, men sense that ejaculation is unstoppable. Then the pelvic muscles contract, pushing the

semen out of the penis through the urethra.

After ejaculation, men cannot become erect

again for a period of time, varying from

several minutes to 24 hours. The length of this

period increases with age.

\section{What happens when you become sexually}

excited but do not have an orgasm?

After orgasm, blood flows back out of the

congested organs. Blood pressure and heart

rate return to their resting state and muscular

tension is released. If a person does not

experience an orgasm, the blood congestion

may cause temporary discomfort. This feeling

goes away on its own, usually in less than an

hour, and has no lasting effect. 


\section{fact sheets (cont.)}

\section{CONTRACEPTIVE METHODS*}

\begin{tabular}{|c|c|c|c|}
\hline METHOD & $\begin{array}{l}\text { WHAT IT IS AND } \\
\text { HOW IT WORKS }\end{array}$ & $\begin{array}{l}\text { PROTECTION } \\
\text { AGAINST STIS/HIV? }\end{array}$ & OTHER CHARACTERISTICS \\
\hline Male condom & $\begin{array}{l}\text { A thin latex sheath rolled onto the erect } \\
\text { penis before intercourse that prevents } \\
\text { sperm from entering the vagina. }\end{array}$ & Yes & $\begin{array}{l}\text { - It is one of the two methods that offer double } \\
\text { protection, against pregnancy and infection, thus may } \\
\text { also protect against infertility and cervical cancer. } \\
\text { - It enables men and boys to protect themselves and their } \\
\text { partners. } \\
\text { - It is easily available. } \\
\text { - It must be put on during sexual activity prior to } \\
\text { intercourse. } \\
\text { - Some people find that it reduces sensation. } \\
\text { - It may break or leak, especially if used incorrectly. }\end{array}$ \\
\hline Female condom & $\begin{array}{l}\text { A lubricated plastic sheath with two } \\
\text { rings. One remains outside the vagina, } \\
\text { covering part of the labia, and the other } \\
\text { is placed in the vagina, covering the } \\
\text { cervix. It forms a pouch that collects } \\
\text { the semen. }\end{array}$ & Yes & $\begin{array}{l}\text { - It can be inserted hours before sexual activity } \\
\text { begins. } \\
\text { - It enables women and girls to protect themselves } \\
\text { and their partners. } \\
\text { - It is noticeable during sex, and insertion may } \\
\text { require practice. } \\
\text { - It is expensive in comparison with the male } \\
\text { condom. }\end{array}$ \\
\hline
\end{tabular}

Diaphragm or Cervical cap Diaphragm: A shallow, soft, rubber cup

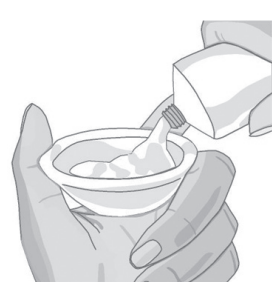
that is filled with spermicide and inserted whether the cap or into the vagina before intercourse. It covers the cervix to prevent sperm from entering, and the spermicide kills sperm. Cervical Cap: A thimble-shaped latex cup that is inserted into the vagina,

fitting snugly over the cervix and held

in place by suction to block sperm. It should be used with a spermicide.
- It can be inserted before sexual activity begins. - It is not widely available.

diaphragm offers - It may be dislodged during sex.

any protection - It must be fitted by a health care provider. 


\section{fact sheets (cont.)}

\begin{tabular}{|c|c|c|c|}
\hline Spermicides & $\begin{array}{l}\text { Chemical foams, creams, jellies, film, or } \\
\text { suppositories inserted into the vagina } \\
\text { before intercourse, creating a barrier and } \\
\text { killing sperm. A spermicide can be used } \\
\text { alone or with a barrier method, such as a } \\
\text { condom, to increase its effectiveness. }\end{array}$ & No & $\begin{array}{l}\text { - Repeated use of nonoxynol-9 }(\mathrm{N}-9) \text { spermicides } \\
\text { can lead to genital lesions, which can increase the } \\
\text { risk of HIV transmission. } \\
\text { - They should not be used by women at high risk for } \\
\text { HIV infection. Some are messy. }\end{array}$ \\
\hline \multicolumn{4}{|c|}{ Long-acting methods that work inside the body's system } \\
\hline METHOD & $\begin{array}{l}\text { WHAT IT IS AND } \\
\text { HOW IT WORKS }\end{array}$ & $\begin{array}{l}\text { PROTECTION } \\
\text { AGAINST STIS/HIV? }\end{array}$ & OTHER CHARACTERISTICS \\
\hline 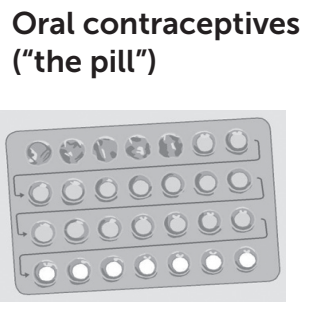 & $\begin{array}{l}\text { Small pills containing synthetic } \\
\text { hormones (estrogen and progestin, or } \\
\text { only progestin) that prevent ovulation } \\
\text { and interfere in sperm migration by } \\
\text { thickening the cervical mucus. They are } \\
\text { taken orally every day by the woman for } \\
21 \text { or } 28 \text { days, depending on the brand } \\
\text { and type. }\end{array}$ & No & $\begin{array}{l}\text { - It does not require the woman to insert or apply } \\
\text { anything at the time of sexual relations. } \\
\text { - It may reduce menstrual cramps and the risk of } \\
\text { certain kinds of cancer, anemia, breast problems, and } \\
\text { pelvic inflammatory disease. } \\
\text { - The woman must remember to take the pill regularly. } \\
\text { - Typically, fertility resumes quickly after the woman } \\
\text { stops taking the pill. }\end{array}$ \\
\hline Injectables & $\begin{array}{l}\text { An injection given at regular intervals, } \\
\text { usually every one or three months, } \\
\text { containing progestin, a synthetic } \\
\text { hormone that prevents ovulation and } \\
\text { thickens the cervical mucus. }\end{array}$ & No & $\begin{array}{l}\text { - The method can be used without the knowledge of } \\
\text { others. } \\
\text { - It does not require the woman to insert or apply } \\
\text { anything at the time of sexual relations. } \\
\text { - It may decrease the risk of certain kinds of cancer. } \\
\text { - Fertility resumes within a few months after stopping use. }\end{array}$ \\
\hline Vaginal ring & $\begin{array}{l}\text { A thin, soft, flexible ring inserted in the } \\
\text { vagina by the woman. It slowly releases } \\
\text { estrogen and progestin, stopping } \\
\text { ovulation and thickening the cervical } \\
\text { mucus. }\end{array}$ & No & $\begin{array}{l}\text { - It does not require the woman to insert or apply } \\
\text { anything at the time of sexual relations. } \\
\text { - After the woman stops using it, fertility returns } \\
\text { immediately. }\end{array}$ \\
\hline
\end{tabular}




\section{fact sheets (cont.)}

\begin{tabular}{|c|c|c|c|}
\hline Contraceptive patch & $\begin{array}{l}\text { A small adhesive patch applied to the } \\
\text { skin that slowly releases progestin and } \\
\text { estrogen through the skin to prevent } \\
\text { ovulation and thicken the cervical } \\
\text { mucus. }\end{array}$ & No & $\begin{array}{l}\text { - It does not require the woman to insert or apply } \\
\text { anything at the time of sexual relations. } \\
\text { - It is less effective for women weighing more than } \\
90 \text { kilos (198 lbs.) than for other women. } \\
\text { - After the woman stops using it, fertility quickly } \\
\text { returns. }\end{array}$ \\
\hline Implants & $\begin{array}{l}\text { One or two small, soft rods implanted } \\
\text { in the woman's upper arm that release } \\
\text { a steady low dose of progestin over a } \\
\text { period of three to five years. Thickens } \\
\text { the cervical mucus and inhibits } \\
\text { ovulation. }\end{array}$ & No & $\begin{array}{l}\text { - Implants can be removed at any time, but they must } \\
\text { be inserted and removed by a trained provider. } \\
\text { - It does not require the woman to insert or apply } \\
\text { anything at the time of sexual relations. } \\
\text { - Fertility resumes immediately upon removal. }\end{array}$ \\
\hline evices (IUDs) & $\begin{array}{l}\text { Small devices, commonly shaped like } \\
\text { a T, that are placed in the uterus by a } \\
\text { health care provider. Some IUDs release } \\
\text { progestin (a hormone), while others } \\
\text { contain copper, which has antifertility } \\
\text { effects. They keep the sperm from } \\
\text { reaching the egg. Some types of IUDs } \\
\text { can work for as long as ten years. }\end{array}$ & No & $\begin{array}{l}\text { - This method does not interrupt sex; it is not noticeable } \\
\text { during intercourse. } \\
\text { - If an infection is present during insertion, or if the } \\
\text { conditions for insertion are not sterile, insertion may } \\
\text { lead to pelvic infection and increased risk of infertility. } \\
\text { - The body sometimes expels the IUD. } \\
\text { - It must be inserted and removed by a trained provider. }\end{array}$ \\
\hline METHOD & $\begin{array}{l}\text { WHAT IT IS AND } \\
\text { HOW IT WORKS }\end{array}$ & $\begin{array}{l}\text { PROTECTION } \\
\text { AGAINST STIS/HIV? }\end{array}$ & OTHER CHARACTERISTICS \\
\hline $\begin{array}{l}\text { Lactational amenorrhea } \\
\text { method }\end{array}$ & $\begin{array}{l}\text { For breastfeeding women only. } \\
\text { Breastfeeding causes the body to produce } \\
\text { hormones that can prevent ovulation. As } \\
\text { contraception, this method is effective } \\
\text { only during the first six months of } \\
\text { breastfeeding or until the woman has } \\
\text { resumed menstruation (whichever comes } \\
\text { first), and only if the baby is fed only } \\
\text { breastmilk and on demand. }\end{array}$ & No & $\begin{array}{l}\text { - Breastfeeding is free and has positive health effects for } \\
\text { the mother and the baby. } \\
\text { - The lactational amenorrhea method (LAM) may be } \\
\text { difficult for women who need to be away from their } \\
\text { baby regularly. }\end{array}$ \\
\hline
\end{tabular}




\section{fact sheets (cont.)}

\begin{tabular}{|c|c|c|c|}
\hline Withdrawal & $\begin{array}{l}\text { Pulling the penis out of the vagina and } \\
\text { away before ejaculating prevents sperm } \\
\text { from entering the vagina. This method } \\
\text { can be effective if used correctly and } \\
\text { consistently. }\end{array}$ & No & $\begin{array}{l}\text { - Withdrawal is always available and free. } \\
\text { - It is considerably more effective than not } \\
\text { withdrawing. } \\
\text { - It depends on the man's self-control and ability to } \\
\text { predict ejaculation; women have no control with } \\
\text { this method. } \\
\text { - It interrupts sex and may lessen pleasure. }\end{array}$ \\
\hline $\begin{array}{l}\text { Cervical mucus method } \\
\text { of fertility awareness }\end{array}$ & $\begin{array}{l}\text { The cervix secretes mucus that can be } \\
\text { observed when wiping after urination or } \\
\text { on underwear. The type and amount of } \\
\text { this mucus changes during the woman's } \\
\text { cycle. A woman can learn to tell which } \\
\text { type of mucus indicates that she might be } \\
\text { fertile and which type indicates that she } \\
\text { is not fertile. During fertile days, she can } \\
\text { use a barrier method of contraception or } \\
\text { she can abstain from intercourse. (See fact } \\
\text { sheet on Menstrual Cycle). }\end{array}$ & No & $\begin{array}{l}\text { - This method increases a woman's awareness and } \\
\text { understanding of her body. } \\
\text { - It allows a woman to predict when she will begin her } \\
\text { next menstrual cycle. } \\
\text { - It can also help couples who are trying to become } \\
\text { pregnant to identify the most fertile days of the cycle. } \\
\text { - It is acceptable to religious groups that oppose the } \\
\text { use of other methods. } \\
\text { - It requires time to learn the method, the discipline } \\
\text { to maintain daily observation of mucus, and the } \\
\text { cooperation of the woman's partner. }\end{array}$ \\
\hline $\begin{array}{l}\text { Temperature method } \\
\text { of fertility awareness }\end{array}$ & $\begin{array}{l}\text { A woman's body temperature rises slightly } \\
\text { with ovulation. By taking her temperature } \\
\text { every morning before getting out of } \\
\text { bed or moving around, she can identify } \\
\text { when ovulation has occurred. Ovulation } \\
\text { cannot be predicted, but a few days after } \\
\text { ovulation occurs, the woman knows she } \\
\text { is not fertile for the remainder of the cycle. } \\
\text { Until ovulation has occurred, she can use } \\
\text { a barrier method of contraception or she } \\
\text { can abstain from intercourse. }\end{array}$ & No & $\begin{array}{l}\text { - A special thermometer called a basal body } \\
\text { thermometer is needed that enables the user to } \\
\text { notice slight differences in temperature. } \\
\text { - Because the woman's temperature sometimes dips } \\
\text { just before ovulation, the method can help couples } \\
\text { who are trying to become pregnant to identify the } \\
\text { most fertile days of the cycle. } \\
\text { - This method requires the woman's partner's } \\
\text { cooperation. }\end{array}$ \\
\hline
\end{tabular}




\section{fact sheets (cont.)}

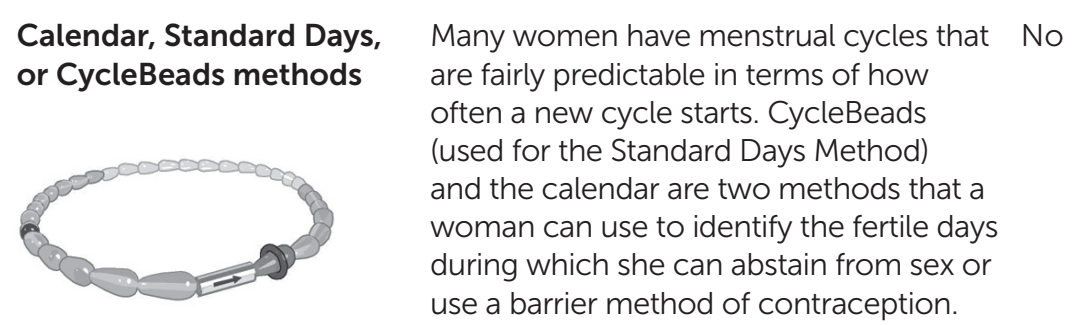

Calendar, Standard Days, Many women have menstrual cycles that No are fairly predictable in terms of how

and the calendar are two methods that

during which she can abstain from sex or
- This method is most practical for women with regular cycles.

It can also help couples who are trying to become pregnant to identify the most fertile days of the cycle.

- It requires the woman's partner's cooperation.

Permanent surgical methods

\begin{tabular}{|c|c|c|c|}
\hline METHOD & $\begin{array}{l}\text { WHAT IT IS AND } \\
\text { HOW IT WORKS }\end{array}$ & $\begin{array}{l}\text { PROTECTION } \\
\text { AGAINST STIS/HIV? }\end{array}$ & OTHER CHARACTERISTICS \\
\hline $\begin{array}{l}\text { Vasectomy, male } \\
\text { sterilization }\end{array}$ & $\begin{array}{l}\text { A simple, outpatient operation in which } \\
\text { the vas deferens is cut and tied. Sperm } \\
\text { then are harmlessly reabsorbed into } \\
\text { the man's body, rather than entering } \\
\text { the semen. It does not change a man's } \\
\text { ability to have sex, feel sexual pleasure, } \\
\text { or ejaculate. }\end{array}$ & No & $\begin{array}{l}\text { - Vasectomy is not effective until three months after } \\
\text { the surgery. } \\
\text { - This is a permanent method. }\end{array}$ \\
\hline $\begin{array}{l}\text { Female sterilization, tubal } \\
\text { sterilization }\end{array}$ & $\begin{array}{l}\text { A surgical procedure to cut and tie } \\
\text { (tubal ligation), or block, the fallopian } \\
\text { tubes, preventing the sperm and egg } \\
\text { from meeting. It does not change a } \\
\text { woman's ability to have sex or to feel } \\
\text { sexual pleasure. }\end{array}$ & No & - This is a permanent method. \\
\hline
\end{tabular}




\section{fact sheets (cont.)}

\section{HIV (HUMAN IMMUNODEFICIENCY VIRUS) AND AIDS (ACQUIRED IMMUNE DEFICIENCY SYNDROME)*}

What is the difference between HIV and AIDS? HIV (human immunodeficiency virus) is a virus that attacks and breaks down a person's immune system. When the immune system becomes weak from HIV, the body can no longer fight off illness and may develop serious, often life-threatening, infections and cancers. This condition is known as AIDS (acquired immune deficiency syndrome.) People with HIV may also be diagnosed with AIDS if their blood tests show that their cells that fight diseases have fallen below a certain number.

\section{How is HIV transmitted?}

HIV is present in the bodily fluids of persons infected with the virus. A person who is HIVpositive can pass the virus to others through their semen (including the pre-ejaculate), vaginal secretions, breastmilk, or blood. The virus is most commonly transmitted through the exchange of semen and vaginal secretions during sex. HIV is transmitted not only through vaginal or anal sex between a man and a woman; it can also be transmitted through anal sex between two men. Having a sexually transmitted infection can increase the risk of acquiring or passing HIV during sex. HIV can also be passed to others by transfusion of infected blood or by sharing needles with an infected individual for drug or steroid use, body piercing, or tattooing. HIV can also be passed from an HIV-positive mother to her baby during pregnancy, delivery, or breastfeeding. Oral sex also carries some risk for HIV transmission.

Although using contaminated instruments during manicures, pedicures, or shaving may carry a risk of infection, HIV transmission through these routes is highly unlikely. HIV cannot be transmitted by touching, kissing, sneezing, coughing, or by sharing food, drink or utensils, or through everyday contact at work, school, or home. It is not transmitted by using swimming pools, public toilets, or through insect bites. HIV cannot be transmitted by saliva tears or sweat Urine and feces do not transmit HIV if they do not contain blood.

\section{How can HIV be prevented?}

Currently no vaccine or cure for HIV has been developed, so prevention is essential.

Sexual transmission can be prevented by abstaining from unprotected sexual intercourse or by using male or female condoms for every instance of intercourse. Another approach to prevention is to confine oneself to a single sex partner, that is, to be "faithful" or monogamous. This approach works only if both partners are truly monogamous and if both partners are HIV negative. Unfortunately, many people are unaware that they - or their partner - are already infected with HIV; the only way to be certain is to be tested for HIV. Moreover, no one can guarantee that his or her partner will never have another sex partner. For these reasons, the "be faithful" approach carries risks for many people. For men, circumcision offers some protection against HIV, but it does not eliminate the risk of infection. For women there are currently no known direct benefits of male circumcision. Therefore, circumcised males should still use condoms.

Needle transmission from sharing an infected needle can also be prevented by using only new or sterile needles for all injections or skin piercing.

\section{Continued on next page}




\section{fact sheets (cont.)}

Mother-to-child transmission - Pregnant women should always be tested for HIV. HIVpositive pregnant women can take preventive medicines to reduce the chance that their baby will be infected with HIV during pregnancy and birth. Transmission of the virus from mother to baby can also occur after delivery through breastfeeding. HIV-positive mothers must seek the advice of a health care provider in order to prevent transmission of the infection during pregnancy and delivery, and also to learn appropriate feeding options for their newborn. [See fact sheet on Childbirth and Breastfeeding.

\section{Can HIV infection be cured or treated?} HIV infection cannot be cured, but it can be treated. The current treatment for HIV is called antiretroviral therapy (ART). ART is a combination of drugs that reduces the level of HIV virus in the blood and slows down the destruction of the immune system. ART has improved the quality and length of life for many individuals with HIV. These drugs also reduce illness and death due to AIDS, the most advanced stage of HIV. Not all people respond equally to the drugs. Without treatment however, a person infected with HIV generally progresses to AIDS within one to ten years of becoming infected. Without treatment, a person with AIDS may live less than a year.

How can a person know if he or she - or his or her sex partner - has HIV?

The only way to know if you have been infected with HIV is to take an HIV test. The only way to know if your sex partner is HIVpositive is if he or she takes an HIV test and shares the result with you. Millions of people who are HIV-positive feel and look completely healthy, have no symptoms, and have no idea that they are passing the virus to others.

The HIV test detects special cells (called HIV antibodies) that are present if the person is infected. Tests can usually detect HIV antibodies within six to eight weeks of exposure. In rare cases, it may take as long as six months for the antibody level to be detected by a test.

A positive HIV test means that the person has HIV antibodies and is infected with the virus. If the first test is positive, a second, different test is conducted to confirm the results.

A negative HIV test means that the person is not infected with HIV. Or it may mean that he or she is infected but has not yet made enough HIV antibodies to test positive. Someone who tests HIV-negative but suspects that he or she was recently exposed to the virus should take the test again in a few months.

\section{Why should people be tested for HIV?}

Being tested for HIV is important for many reasons. Obtaining a negative test result can bring enormous relief to a person. It can also encourage that person to practice safer sexual behavior in the future. Those who test HIVpositive can begin to seek care and treatment. Treatment can improve the quality of life and significantly prolong the life of an HIV-positive person. Those who are tested can also inform and protect their sex partners. For a woman

who is - or would like to become - pregnant knowing her HIV status is important so that she can take action, if necessary, to reduce the risk of transmission to her baby. [See fact sheet on Childbirth and Breastfeeding.]

\section{What support do people living with HIV and} AIDS need?

When people find out that they are HIVpositive, they may feel frightened, confused, and depressed. Being infected with HIV is life-changing, and it takes time to adjust to the knowledge. People living with HIV need a strong emotional support system, which may include parents, their spouse or partners, other family members, friends, counselors, social workers, other people living with HIV and AIDS, or religious or spiritual leaders.

They need to find a doctor who is caring, respectful, and knowledgeable about HIV and AIDS, and to have access to medical treatment when they need it. They need to learn as much as possible about HIV and AIDS, and how to protect their own health and that of their sex partners. To stay as healthy as possible, they need to eat well, exercise regularly, rest adequately, avoid smoking and drinking too much alcohol, and avoid using recreational drugs. Most important, by always practicing safe sex, they can protect themselves from other sexually transmitted infections and avoid infecting others with HIV. 


\section{fact sheets (cont.)}

\section{MENSTRUAL CYCLE (ALSO CALLED THE OVULATORY CYCLE)*}

\begin{abstract}
What is the menstrual or ovulatory cycle?
At puberty, girls begin to experience cycles

of fertility. Unlike males, who are fertile

continuously from puberty onward, females

can become pregnant only during certain days

of the cycle. The length of the cycle varies from person to person but is generally about one month. During each cycle, the female body goes through many changes. The most obvious part of the cycle is menstrual bleeding,
\end{abstract} also called menstruation or the "period.

We often think of menstruation as the climax of the cycle, but menstruation is just one part of an amazing array of changes that take place during the cycle. These changes are the body's way of preparing for a potential pregnancy. They include producing mucus at the cervix, growing and releasing an egg, and changes in the lining of the uterus. These changes are controlled by hormones (natural chemicals produced by glands in the body and carried in the bloodstream.)

These hormonal changes affect many parts of the female body, and also how women fee and function. Knowing about these changes can give a girl or woman a sense of greater comfort and control regarding her own body.

A woman can learn simple techniques for identifying when she is ovulating and when her menstrual period is due.

\section{What changes does the body go through during the cycle?}

\section{Before ovulation}

Menstrual bleeding - Menstruation, or menstrual bleeding, signals the beginning of a new cycle. During menstruation, blood and tissue are shed by the uterus and flow out of the vagina. The first day of bleeding is designated as "day one" of the cycle. Bleeding usually lasts between four and six days.

Dryness - After menstrual bleeding ends, the vagina may feel dry because hormone levels are low and the cervix is producing little or no mucus.

Thick mucus discharge/thickening of the uterine lining - After a few days, as her body releases more hormones, the woman (or girl) may notice a vaginal discharge of mucus. At first, this mucus is cloudy-white or yellowish and may feel sticky. At the same time although she cannot detect it, the lining of her uterus begins to thicken and an egg (also called the ovum) "ripens."
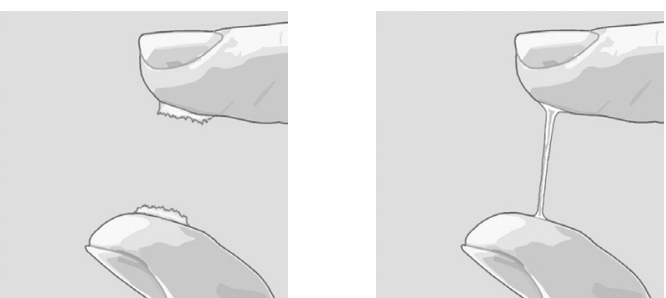

Ovulation

Clear mucus/ovulation - As the egg ripens, the mucus becomes clearer and slippery, often similar to raw egg white. Often it can be stretched between the fingers. This clear mucus nourishes sperm and helps them to move toward the egg. At this time, a woman's sexual desire may also increase. The release of the egg from the ovary is called ovulation. The days just before and around the time of ovulation are the time when a girl or woman can become pregnant. These are sometimes called her "fertile days."

The female body goes through other changes around this time as well. For example, some women experience an increase in sexual desire and in their sense of well-being for a few days. And some feel a twinge or slight discomfort on one side of their abdomen at about the time the egg pushes out of the ovary.

Continued on next page 


\section{fact sheets (cont.)}

\section{After ovulation}

Postovulation - After ovulation, the egg can live for one day. The mucus again becomes thicker and creamy or sticky. For the next 14 days (more or less), hormones keep the thickened lining of the uterus in place. The body temperature also rises slightly.

Menstrual Bleeding - If no pregnancy has occurred at the end of the 14 days, the hormone levels fall. The lining of the uterus sheds, and the body temperature falls back down. This shedding is menstruation, and a new cycle begins. (If a pregnancy occurs, the body continues to produce hormones to keep the thickened lining of the uterus in place for nine months.)

How long is the ovulation-menstrual cycle? During the first year or two after menarche (the first menstrual period), the length of time from one period to the next may vary. Several months may pass between periods. Even for adult women, the length of the cycle may vary from one woman to the next. It may also vary from cycle to cycle for any one woman. It can be affected by things like travel, stress, depression, malnutrition, and illness. Most commonly, however, women begin a new cycle every $24-36$ days.

The part of the cycle from the beginning of menstrual bleeding until ovulation may vary a great deal. It can be as short as a couple o days or as long as several months or more.
Most commonly, it lasts between one and three weeks. In contrast, the part of the cycle from ovulation to the next menstrual period does not vary; it is always close to 14 days. In other words, once ovulation occurs, a girl or woman knows that - unless she has become pregnant - her menstrual period is due in 14 days

Which are the fertile days of the cycle? The fertile period includes the day of

ovulation and the five previous days. Sperm can survive in the female genital tract for as long as five or six days, and the egg (if it is

not fertilized) survives for as long as 24 hours. Predicting the fertile days is difficult, however, because the first phase of the cycle (from menstruation to ovulation) is the part that may vary widely in duration. Some women learn how to observe the changes in their mucus (and in their body temperature) so that they can tell when they are likely to be ovulating. Some women also feel a slight pain when they ovulate. Many women and girls use such "fertility awareness" techniques to have a better sense of when their menstrual period is due. Knowing which days are the fertile ones can be useful for women who are trying to become pregnant and for those who want to avoid pregnancy. Using fertility awareness techniques correctly, however, requires thorough instruction, follow-up, and careful ongoing observation. [Also see fact sheet on Contraception for more information about fertility awareness techniques.]
For how long do women have menstrual or ovulatory cycles?

As women enter mid-life, their hormone levels change. Eventually they stop releasing eggs and menstruation also ceases. This phase, called menopause, also signals the end of fertility. The age of menopause varies by woman and differs in different settings, but typically it begins in the mid-40s in developing countries and in the early 50 s in developed countries.

[Also see fact sheet on Puberty and Girls.] 


\section{fact sheets (cont.)}

\section{PUBERTY AND BOYS*}

For boys, puberty usually begins between the ages of 10 and 13, a couple of years later than it begins for girls. Boys typically finish puberty in their late teens or early twenties, when

skeletal growth is complete.

\section{What changes do boys experience during puberty?}

Like girls, boys may find that their feelings and interests change during puberty. Physical changes also occur. These changes are

different for every person but typically occur in this order:

The testes and penis grow larger

Pubic hair begins to grow; it gradually

increases in amount and becomes coarser and curly.

- The voice begins to change and deepen, usually gradually but sometimes suddenly. - About a year after the testes begin to grow a boy may begin to experience ejaculation (release of a white milky fluid called semen from the penis.)

Underarm hair grows and sweat changes

scent to adult body odor.

Facial hair develops.

Boys also experience a growth spurt and muscle growth. Skin becomes oilier, increasing the likelihood of acne, a skin condition. About half of boys experience slight temporary breast growth, which disappears in a year or two.

\section{What causes erections?}

Erections occur throughout life. An erection is caused by blood filling the spongy tissue in the penis as a result of sexual stimulation lifting or straining; dreaming; being cold wearing tight clothing; feeling fear or excitement; or having a full bladder on waking. An erection may have no apparent cause, especially during puberty. Boys often get sudden or spontaneous erections, sometimes many times a day. These are the result of high or changing levels of the hormone testosterone.

Having an erection without ejaculating may cause a temporary feeling of "heaviness" but is not harmful in any way. If an erect penis is not touched, the erection will subside by itself.

\section{What happens during ejaculation?}

Prior to ejaculation, the Cowper's glands release a drop or two of fluid through the tip of the penis. This is called pre-ejaculate, and it cleans the urethra. The pre-ejaculate alone does not contain a sufficient number of sperm that are strong enough to cause pregnancy (unless sperm from a recent ejaculation are still present.) HIV may be present in the preejaculate, however
Full ejaculation involves the release of semen, which typically contains hundreds of millions of sperm in a teaspoon of fluid. Usually, but not always, ejaculation comes with a wave of pleasurable release known as orgasm. Once a boy can ejaculate, he can cause a pregnancy.

\section{What are wet dreams?}

Men regularly have erections during sleep, and about 80 percent of males occasionally ejaculate. This kind of ejaculation is called a nocturnal emission or "wet dream." Wet dreams are common during puberty, but adult men may also have them. A boy or man who masturbates or has regular sex is less likely to have wet dreams.

Wet dreams (and masturbation) are not harmful in any way. They may release tension and be a source of pleasure. Nor do wet dreams (or masturbation) "waste" sperm. The testes are continuously making new sperm, and wet dreams are one way the body rids itself of stored sperm.

Also see Fact Sheet on Sexual and Reproductive Systems - Male.] 


\section{fact sheets (cont.)}

\section{PUBERTY AND GIRLS*}

For girls, puberty begins between the ages of 8 and 13, about two years earlier than for boys. Girls typically finish puberty between the ages of 16 and 17 or around the time that their skeletal growth is complete.

\section{What changes do girls experience during puberty?}

Changes at puberty differ from person to person. Although they may vary in timing. sequence, and speed, girls' bodies typically develop in this order:

- Breast growth begins, often on only one side at first. Full development takes about two years.

- Pubic hair begins to grow, gradually increasing and becoming coarser and curly

- Inside a girl's body, the surface of the vagina thickens and the uterus and ovaries increase in size. [See fact sheet on Sexual and Reproductive Systems - Female.]

The first menstrual bleeding, menarche, usually occurs two to three years after breast development begins. Many girls have irregular periods for the first couple of years. Once a girl ovulates, she can become pregnant. [See fact sheet on the Menstrual Cycle.]

Underarm hair grows and sweat changes, resulting in adult body odor.

The cervix starts producing mucus that is discharged from the vagina. This mucus is normal and is a sign of natural changes related to fertility and menstruation.

Girls also experience a growth spurt, their pelvis and hips widen, fat tissue increases, and the skin becomes oilier, increasing the likelihood of acne.

As with boys, girls' interests and feelings may also change with puberty. In the days before menstruation, girls commonly experience strong feelings of different kinds, for example, joy, sadness, sensitivity, and anger.

\section{Managing menstruation}

Menstruation is natural and part of being a healthy female. Having one's first menstrual period can be an exciting event, especially if the girl knows what to expect. Unfortunately, many girls worry or are afraid when their first period comes because no one has explained to them what it means and requires. Some parents may feel embarrassed to talk about it. Or the girl may have absorbed messages from her culture or religion suggesting that menstruation is somehow unclean. Menstruation, however, is part of the body's means of renewing itself and maintaining fertility.

During menstruation a girl can generally engage in all of her regular activities. Bathing during menstruation is important. The vulva should be washed with water and mild soap to remove any blood that is left.

How women take care of their menstrual flow varies in different settings. Many women use pads to absorb the blood. In some places, women buy pads that can be thrown away after use. In other places, they employ reusable pads made from folded cloth; these must be washed thoroughly after each use with soap and water. Having a private place to change or wash pads (both at home and at school) is important.

Many women and girls use tampons instead of - or in addition to - pads. A tampon is a small mass, made of cotton (or other absorbent material), and often shaped like a finger to fit comfortably into the vaginal canal. Tampons are inserted into the vagina to absorb the menstrual blood. Tampons must be changed at least twice a day. Leaving a tampon in for more than a day can cause a serious, even deadly, infection. (Inserting any unclean object into the vagina can also cause a serious infection.)

Continued on next page 


\section{fact sheets (cont.)}

The amount of menstrual bleeding - the menstrual flow - varies from day to day and by person. Bleeding may be heaviest during the first days of the period. Some girls and women also experience pain - abdominal cramping - during these days. In some cases, these cramps are strong and include nausea.

A mild painkiller such as ibuprofen helps.

Taking a bath, or placing a plastic bottle or hot water bottle filled with warm water on the

lower belly or lower back, may also help.

A few days before their menstrual period begins, some girls and women may

experience one or more kinds of discomfort. These include sore breasts, constipation, tiredness, pimples, and strong feelings that are harder than usual to control. Other months they may experience, some, other, or none of these. Many girls and women find that their premenstrual discomfort and their menstrual cramps tend to decrease if they exercise regularly throughout the month.

Girls commonly have questions or difficulties with menstruation. They may find that

speaking with a health care worker, female relative, or friend is helpful.

[Also see fact sheet on the Menstrual Cycle and fact sheet on Sexual and Reproductive Systems - Female.] 


\section{fact sheets (cont.)}

\section{REPRODUCTION AND PREGNANCY*}

\section{How does pregnancy occur?}

Before a pregnancy can occur, an egg and a sperm must join. This event is called fertilization. Fertilization can occur only during the fertile phase of a woman's menstrual cycle. [See fact sheet on the Menstrual Cycle.]

During the woman's fertile phase, one of her two ovaries releases an egg. This event is called ovulation. Within minutes, fingerlike projections (called fimbria) at the ends of the fallopian tube begin moving to surround the egg and draw it into the tube. Also during the fertile phase, the woman's cervix moves into a position that eases the sperm's entry from the vagina. The cervix secretes a large amount of clear cervical mucus. This mucus provides nourishment to enable sperm to survive for several days. The mucus also provides an environment that helps sperm swim upward toward the fallopian tube, to reach the egg.

During sexual intercourse, the sperm are ejaculated near the cervix. They enter the cervix within seconds. If the woman is fertile, some sperm may reach the egg in the fallopian tube within five minutes, while other sperm can survive in the clear ("fertile-type") mucus in the cervix. In this way, for up to five days after ejaculation, sperm continue to exit the cervix and are available to fertilize an egg. Hence, a woman who ovulates several days after she has unprotected sex is likely to have sperm remaining in her cervix, and these sperm may still be able to reach the fallopian tube and fertilize the egg.

Once ovulation occurs, however, fertilization must occur within 24 hours because the egg can survive for only that long. Fertilization takes place in the fallopian tube. Once a sperm has fused with the egg, it creates a barrier to other sperm. The fertilized egg continues down toward the uterus, propelled by tubal contractions and by the cilia (little hairlike projections within the tube.)

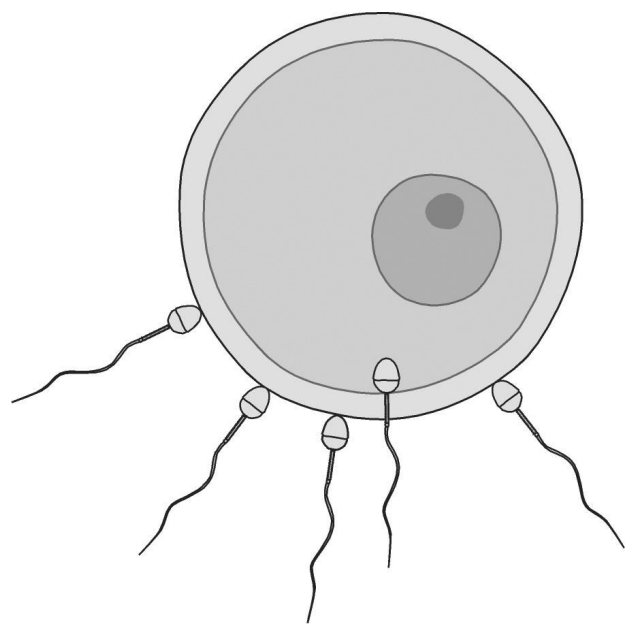

\section{What happens after fertilization?}

In the fallopian tube, the fertilized egg, or zygote, begins to divide and grow, as it moves toward the uterus. This journey takes about five days. After it has divided once, it is called an embryo. Within two days of reaching the uterus, the embryo attaches or implants itself in the lining of the uterus. Implantation is the beginning of pregnancy.

\section{How can a woman tell if she is pregnant?}

Early signs of pregnancy differ from woman to woman and between pregnancies. They include:

- A missed period:

Tender or swollen breasts:

Sensitive nipples;

- Frequent urination;

Unusual fatigue;

Nausea and vomiting:

- Cramps;

- Feeling bloated

Changes in appetite; and

- Feeling unusually emotional.

Continued on next page 


\section{fact sheets (cont.)}

Pregnancy can be confirmed with a pregnancy test, which may be performed by a health care provider or purchased from a pharmacy. Some women who have learned how to detect when their body is ovulating can predict fairly well which day menstruation is due; therefore, they may be aware of a pregnancy as soon as their period is late.

\section{What happens during pregnancy?}

After implantation, the embryo (at this stage called a blastocyst) also gives rise to an amniotic sac and a placenta. The sac provides a protective fluid environment for the growing fetus. The placenta provides the fetus with nutrients and oxygen from the mother, and carries out waste products. An umbilical cord connects the placenta to the fetus.

Human pregnancy lasts 38 weeks after fertilization (about 40 weeks from the last menstrual period.) Pregnancy is divided into three periods of about three months each called trimesters.

During the first trimester, until the twelfth week, all of the major organs and structures of the body are formed: the brain, heart lungs, eyes, ears, arms and legs. After the eighth week, the embryo is called a fetus. Women commonly feel nauseous during the first trimester the nausea is sometimes called "morning sickness."
During the second trimester, from the 13th to approximately the 27 th or 28 th week the fetus grows rapidly, and usually around the 19th week, the woman can feel fetal movement. Most women begin to put on weight during the second trimester.

In the third trimester, the fetus continues to gain weight, and its movements become stronger and more frequent.

\section{What can women do to promote a healthy} pregnancy?

If a woman or girl chooses to keep her pregnancy, it is particularly important for her to avoid taking unnecessary medications, drugs, and alcohol. Taking the recommended vitamins and mineral supplements (especially iron and folic acid) is very important (including before pregnancy, if possible.) She should also visit an antenatal-care provider, from whom she can get medical checkups and can learn about her pregnancy, potential danger signs, and childbirth. Women infected with HIV should take anti-HIV medication to prevent the fetus from becoming infected and to maintain their own health. Treatment with anti-HIV medicines during labor and delivery is critical for reducing the risk of transmitting HIV to the baby. 


\section{fact sheets (cont.)}

\section{SEXUAL AND REPRODUCTIVE SYSTEMS - FEMALE*}

What are the sexual and reproductive systems?

The sexual and reproductive systems share some but not all organs. The sexual system consists of those organs involved in sexual activity and pleasure, whereas the female reproductive system consists of those involved in pregnancy and birth

What are the parts of the female sexual and reproductive systems and their functions?

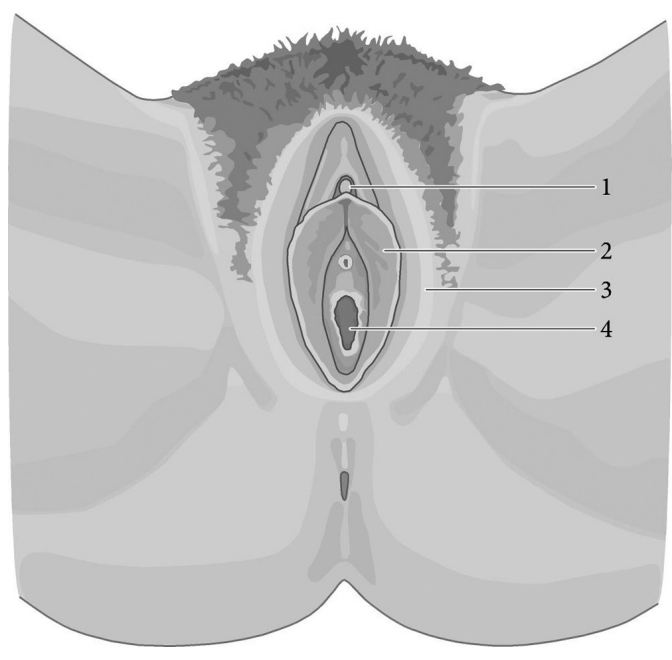

The vulva consists of all the visible externa genital organs of a woman (see illustration below.)

The clitoris (\#1 in the diagram) is a small organ, shaped like a flower bud with a bit of tissue forming a small "hood." The only function of the clitoris is to give girls and women sexual pleasure; it contains a rich network of nerve endings for sensation. During sexual arousal and during orgasm, the clitoris (and the genitalia in general) engorge and fill with blood, causing the clitoris to become erect. Women may feel vaginal contractions during orgasm.

The labia majora or outer lips (\#3) cover and protect the vaginal opening. The labia minora or inner lips (\#2) also swell during sexual arousal.

The vagina (\#4) is an elastic canal, leading from the vulva to the cervix and uterus. When a woman is sexually aroused, the vagina produces lubrication. It has few nerve endings and is therefore not highly sensitive. In vaginal intercourse, the penis penetrates the vagina. If the man ejaculates, semen enters the vagina and travels through the cervix into the uterus and fallopian tubes, where fertilization can occur if an egg is present. Menstrual blood leaves the body through the vagina, as does the baby when it is born. The vagina cleans itself and does not need to be washed out. Women should not insert substances to dry or tighten the vagina; such substances can be harmful.

The hymen (not shown) is a thin membrane that may stretch across part of the vaginal opening. The hymen can be easily torn during sports or other physical activity and can be stretched open if a girl uses tampons. Therefore, a torn or stretched hymen does not indicate that a girl or woman has engaged in sexual intercourse.

Continued on next page 


\section{fact sheets (cont.)}

The cervix (\#5) is the lower part of the uterus that extends into the top of the vagina. An opening in the cervix, called the os, connects the vagina and uterus. Menstrual blood passes out of the uterus through the os; and semen passes through it to the uterus. The cervix produces a secretion (cervical mucus) that aids sperm in entering the uterus. The cervical mucus changes during the menstrual cycle; women can learn to identify the fertile period according to the characteristics of the mucus. During childbirth, the cervix stretches, allowing the baby to pass through.

The uterus (\#6) is a hollow, muscular organ that rests above the bladder. It is shaped like an upside-down pear. Its lining (called the endometrium) thickens with blood and tissue during the first part of the ovulationmenstrual cycle. If no embryo implants itself, the lining breaks down, becoming the menstrual flow. If an embryo implants itself, a fetus develops in the uterus.

The fallopian tubes (\#7) are two narrow, 4-to-5-inch-long tubes through which the egg travels from the ovary to the uterus and in which the egg may be fertilized.

The ovaries (\#8), two organs, each the size of an almond or a grape, store the immature eggs in follicles, produce and secrete female hormones (estrogen and progesterone), and produce and release mature eggs.
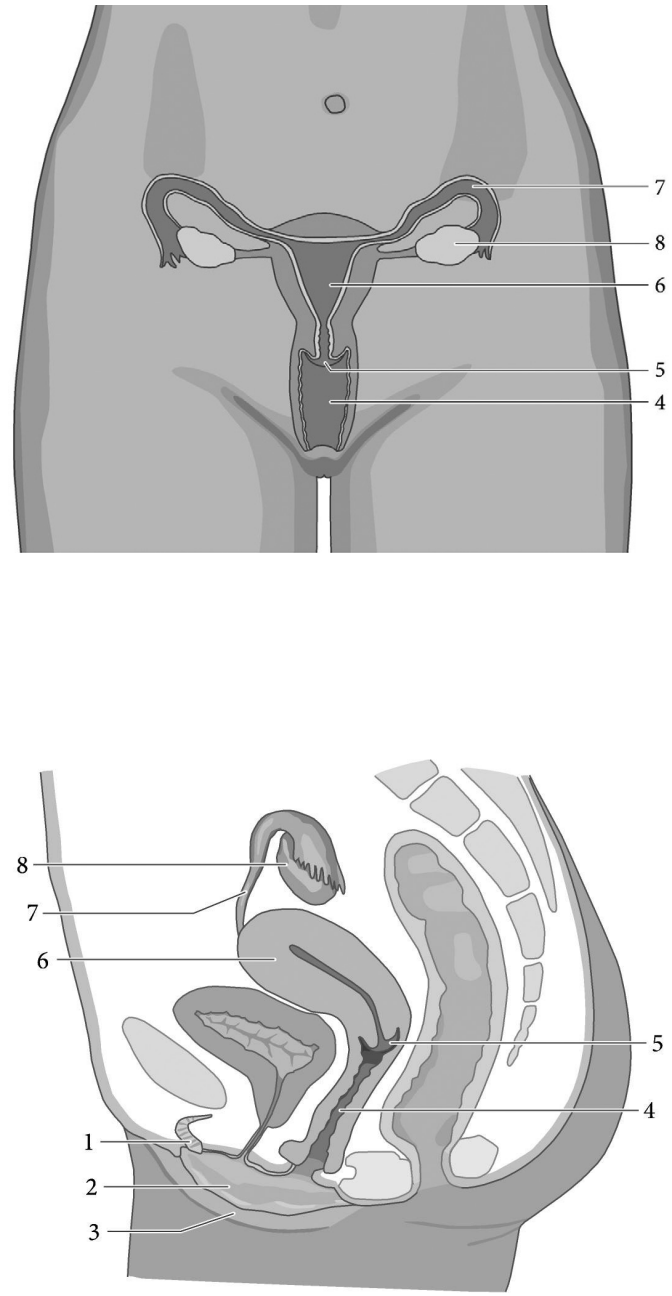


\section{fact sheets (cont.)}

\section{SEXUAL AND REPRODUCTIVE SYSTEMS - MALE*}

\section{What are the sexual and reproductive systems?} The sexual and reproductive systems share some, but not all organs. The sexual system consists of those organs involved in sexual activity and pleasure. In males the reproductive system includes those organs that produce, store, or transport sperm for reproduction.

\section{What are the parts of the male sexual and} reproductive systems and their functions? The penis (\#1) has several functions. It is involved in sexual feeling: in this function it corresponds to the clitoris in the female. The penis may fill with blood and become hard and erect in response to sexual stimulation. The reproductive function of the penis is to deliver semen into the vagina. The third function is the excretion of urine (see urethra below.) The end of the penis is covered by a layer of skin called the foreskin. In many populations, the foreskin is removed through a procedure called male circumcision.

The testicles (or testes) (\#2), two ball-shaped glands inside the scrotum, produce sperm and the male hormone testosterone. The scrotum and testes are sensitive to touch and can be a source of pleasure.

The scrotum (\#3), a loose bag of skin, holds and protects the testicles. When cold, it is pulled up tight toward the body to keep the testicles at the right temperature to produce sperm.
The urethra (\#4) is a tube that runs from the bladder through the penis. The urethra is the passageway through which semen (a mixture of seminal fluid, prostatic fluid, and sperm) travels out of the body during ejaculation; urine also passes out of the body through the urethra. A valve at the bottom of the bladder closes when the penis is erect to prevent urination during ejaculation.

The epididymis (not numbered, but visible) is a highly coiled tube that sits on top of each testis and stores sperm as they mature until they are ejaculated.

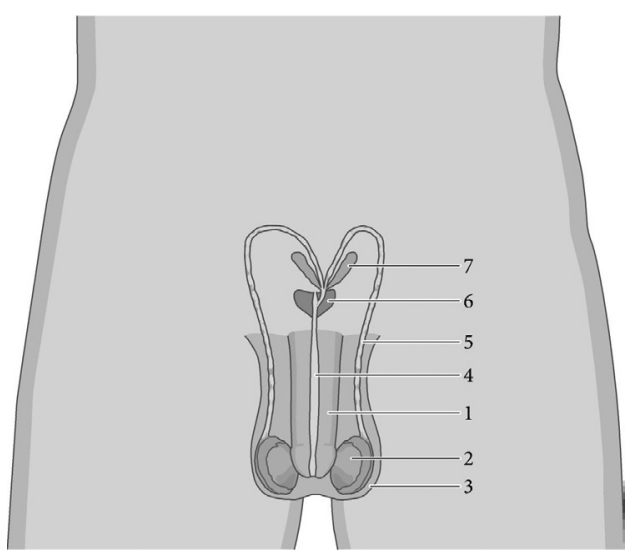

The vas deferens (\#5) are two long thin tubes that carry the sperm toward the urethra. They contract during ejaculation.

The prostate gland (\#6) produces a fluid that makes up part of semen and helps sperm to move. Many men find stimulation of the prostate to be sexually pleasurable.

The seminal vesicles (\#7) produce much of the fluid that ultimately becomes semen. This fluid nourishes the sperm.

The Cowper's glands (not shown) produce a thick alkaline fluid, called pre-ejaculate, that neutralizes the acid in the urethra before ejaculation

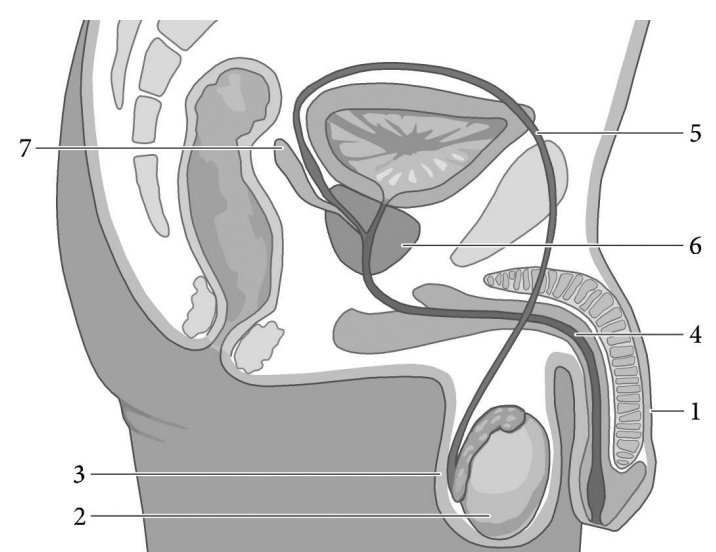




\section{fact sheets (cont.)}

\section{SEXUALLY TRANSMITTED INFECTIONS (STIS)*}

\author{
What are sexually transmitted infections? \\ Sexually transmitted infections (STIs) are \\ infections passed primarily by sexual contact, \\ including vaginal, oral, and anal intercourse. \\ A variety of different organisms may cause \\ an STI (see following chart.) Certain parasites \\ such as pubic lice and scabies also may be \\ transmitted by sexual contact. STIs are part \\ of a broader group of infections known as \\ reproductive tract infections, or RTIs. [See fact
} sheet on RTIs.

\section{Are these infections transmitted only} through sex?

Some STIs can be transmitted by skin-toskin contact. Some are transmitted through the exchange of bodily fluids. Some can be passed to a baby before it is born, during childbirth, or via breastfeeding.

\section{What are the consequences of STIs?}

STIs can have serious health consequences for men and women (see following chart) Many common STIs are difficult to detect among women, however, and some have more serious consequences for women than for men. For example, the spread of chlamydia or gonorrhea to the upper reproductive organs is a common cause of infertility among women. Infection with certain STIs increases the likelihood of acquiring or transmitting HIV infection. Some, but not all, STIs are curable. Others, such as HIV, are not. Early treatment eliminates or reduces the consequences of most STIS.

\section{How can people prevent acquiring or}

\section{transmitting STIs?}

Find out if you have an STI by being tested by a health care provider.

If you have an STI, obtain treatment, and notify all of your recent sex partners so that they can also be tested.

Find out whether your partner has an STI and if so, make sure that he or she is tested and treated.

Talk with your partner about ways to be sexually intimate that do not involve the risk of transmitting an infection.

Use male or female condoms and avoid sexual contact that allows transmission of an infection. Condoms protect against most STIs (including HIV.) They do not protect against all STIs.

Obtain a vaccination for those STIs that can be prevented. At the present time, a vaccine exists for hepatitis $B$ and human papilloma virus (HPV).

\section{When should a person obtain an STI test?} A person is at risk of acquiring an STI and should be tested if he or she has one or more of the following:
Symptoms of an STI

A sex partner who has an STI, or who has signs of an STI

More than one sexual partner

- A new partner in the past three months

- A partner who has or may have other sex partners

A partner who lives elsewhere or travels often.

Early testing is important. A person diagnosed with an STI can obtain treatment and can

help their recent partners to be tested as well. A couple should not resume sexual activity until both partners have been tested and have completed any necessary treatment. Because some STIs do not show up in test results right away, a repeat test may be necessary. 


\section{fact sheets (cont.)}

\begin{tabular}{|c|c|c|c|c|}
\hline STI & $\begin{array}{l}\text { SYMPTOMS } \\
\text { FOR WOMEN }\end{array}$ & $\begin{array}{l}\text { SYMPTOMS } \\
\text { FOR MEN }\end{array}$ & CAN IT BE CURED? & $\begin{array}{l}\text { IS THERE } \\
\text { A VACCINE? }\end{array}$ \\
\hline Chancroid & \multicolumn{2}{|c|}{$\begin{array}{l}\text { Painful sores on the genitalia; swollen lymph nodes on the groin. } \\
\text { Women are often asymptomatic. }\end{array}$} & Yes & No \\
\hline Chlamydia & $\begin{array}{l}\text { Most women are asymptomatic. } \\
\text { Women who do have symptoms } \\
\text { might have abnormal vaginal } \\
\text { discharge or a burning sensation } \\
\text { when urinating. }\end{array}$ & $\begin{array}{l}\text { Often asymptomatic. Men with } \\
\text { symptoms may have a pus-like } \\
\text { discharge from their penis or } \\
\text { burning sensation when urinating. }\end{array}$ & $\begin{array}{l}\text { Yes. Left untreated, it can lead to } \\
\text { pelvic inflammatory disease (PID) } \\
\text { among women, which may lead } \\
\text { to infertility. Complications among } \\
\text { men are rare. }\end{array}$ & No \\
\hline Gonorrhea & $\begin{array}{l}\text { Most women are asymptomatic; } \\
\text { abnormal vaginal discharge or } \\
\text { burning sensation when urinating. }\end{array}$ & $\begin{array}{l}\text { Men often experience discharge } \\
\text { or burning when urinating. Some } \\
\text { men have no symptoms. }\end{array}$ & $\begin{array}{l}\text { Yes. Left untreated, it can lead to } \\
\text { PID among women, and may lead } \\
\text { to infertility among both women } \\
\text { and men. }\end{array}$ & No \\
\hline Hepatitis B & \multicolumn{2}{|c|}{$\begin{array}{l}\text { Some people experience flu-like symptoms, jaundice, and dark- } \\
\text { colored urine; others experience no symptoms. }\end{array}$} & $\begin{array}{l}\text { Although no medicine has been } \\
\text { found that cures hepatitis B, in } \\
\text { many cases the body clears the } \\
\text { infection by itself. Occasionally } \\
\text { it develops into a chronic liver } \\
\text { illness. Small children and infants } \\
\text { are at a much greater risk of } \\
\text { becoming chronically infected. }\end{array}$ & Yes \\
\hline $\begin{array}{l}\text { Herpes (herpes } \\
\text { simplex virus) }\end{array}$ & \multicolumn{2}{|c|}{ Recurrent episodes of painful sores on genitals or anus. } & $\begin{array}{l}\text { No, but symptoms can be } \\
\text { controlled through treatment. }\end{array}$ & No \\
\hline $\begin{array}{l}\text { HIV (human } \\
\text { immunodeficiency } \\
\text { virus) }\end{array}$ & \multicolumn{2}{|c|}{$\begin{array}{l}\text { HIV generally has no symptoms in its early stages. HIV usually leads } \\
\text { to AIDS. People with AIDS may suffer various infections, cancers, and } \\
\text { other life-threatening ailments. }\end{array}$} & $\begin{array}{l}\text { No, AIDS is a chronic, ultimately } \\
\text { fatal disease, but treatment } \\
\text { (antiretroviral therapy) dramatically } \\
\text { slows the progress of the disease. }\end{array}$ & No \\
\hline
\end{tabular}




\section{fact sheets (cont.)}

\begin{tabular}{|c|c|c|c|c|}
\hline $\begin{array}{l}\text { Human papilloma } \\
\text { virus (HPV) }\end{array}$ & \multicolumn{2}{|c|}{$\begin{array}{l}\text { HPV can be asymptomatic. Some strains cause genital warts. Others } \\
\text { cause cancer. This includes head, neck, and anal cancer; penile cancer } \\
\text { in men; and - most commonly - cervical cancer in women. }\end{array}$} & $\begin{array}{l}\text { No, but symptoms can be } \\
\text { controlled through treatment. } \\
\text { Some cancers secondary to HPV } \\
\text { are treatable. }\end{array}$ & $\begin{array}{l}\text { Yes. HPV } \\
\text { vaccines can } \\
\text { protect both } \\
\text { males and } \\
\text { females against } \\
\text { many strains of } \\
\text { the virus. }\end{array}$ \\
\hline Syphilis & \multicolumn{2}{|c|}{$\begin{array}{l}\text { Begins with one or more painless sores on the genitals, rectum, or } \\
\text { mouth. The second stage may produce skin rashes, lesions on mucus } \\
\text { membranes, fever, and malaise. The latent stage begins when these } \\
\text { symptoms go away. }\end{array}$} & $\begin{array}{l}\text { Yes, if treated in its early stages. } \\
\text { Without treatment, infection } \\
\text { remains in the body. The late } \\
\text { stage of syphilis includes damage } \\
\text { to internal organs and can be fatal. }\end{array}$ & No \\
\hline $\begin{array}{l}\text { Trichomoniasis } \\
\text { (trichomonas or } \\
\text { trich) }\end{array}$ & $\begin{array}{l}\text { Women may experience frothy, } \\
\text { yellow-green vaginal discharge } \\
\text { with a strong odor. May also } \\
\text { cause itching or discomfort during } \\
\text { intercourse and urination. }\end{array}$ & $\begin{array}{l}\text { Men are usually asymptomatic; } \\
\text { sometimes mild discharge or } \\
\text { slight burning with urination or } \\
\text { ejaculation. }\end{array}$ & Yes & No \\
\hline
\end{tabular}




\section{fact sheets (cont.)}

\section{UNIVERSAL DECLARATION OF HUMAN RIGHTS*}

The following list explains each human right in simple language:

Article 1: When children are born, they are free and each should be treated in the same way. They have reason and conscience and should act toward one another in a friendly manner.

Article 2: Everyone can claim the following rights, regardless of his or her:

- Gender

- Skin color

- Language

- Political beliefs

- Religion

- Wealth or poverty

Social group

- Country of birth

- Country's status as independent or not

Article 3: You have the right to live and to live in freedom and safety.

Article 4: Nobody has the right to treat you as his or her slave, and you should not make anyone your slave.

Article 5: Nobody has the right to torture you.

Article 6: You should be legally protected in the same way everywhere and in the same way everyone else is protected.
Article 7: The law is the same for everyone; it should be applied in the same way to all.

Article 8: You should be able to ask for legal help when the rights your country grants you are not respected.

Article 9: Nobody has the right to put you in prison to keep you there, or to send you away from your country unjustly or without a good reason.

Article 10: If you must go on trial, the trial should be conducted in public. The people who try you should not let themselves be influenced by others.

Article 11: You should be considered innocent until you are proved guilty. If you are accused of a crime, you should always have the right to defend yourself. Nobody has the right to condemn you or punish you for something you have not done.

Article 12: You have the right to ask to be protected if someone tries to harm your good name, enter your house, open your mail, or bother you or your family without a good reason.

Article 13: You have the right to come and go as you wish within your country. You have the right to leave your country to go to another one; and you should be able to return to your country if you want.
Article 14: If someone hurts you, you have the right to seek asylum (safe haven) in another country. You may lose this right if you have committed a serious violation of human rights.

Article 15: You have the right to belong to a country, and nobody can prevent you, without a good reason, from belonging to another country if you wish

Article 16: As soon as a person is legally entitled to do so, he or she has the right to marry and have a family. Neither the color of your skin, nor the country you come from, nor your religion should be impediments to doing this. Men and women have the same rights when they are married and also when they are separated. Nobody should force a person to marry. The government of your country should protect your family and its members.

Article 17: You have the right to own things, and nobody has the right to take these from you without a good reason.

Article 18: You have the right to profess your religion freely, to change it, and to practice it on your own or with others.

Continued on next page 


\section{fact sheets (cont.)}

Article 19: You have the right to think what you want and to say what you like, and nobody should forbid you from doing so. You have a right to share your ideas with anyone - including people from any other country.

Article 20: You have the right to organize peaceful meetings or to take part in meetings in a peaceful way. No one has the right to force you to belong to a group.

Article 21: You have the same right as anyone else to take part in your country's political affairs. You may do this by belonging to the government yourself or by choosing politicians who have the same ideas as you do. Governments should be elected regularly, and voting should be secret. You should be allowed to vote, and all votes should be counted equally.

Article 22: The society in which you live should help you to develop and to make the most of all the advantages (culture, work social welfare) that are offered to you and to everyone in your country.

Article 23: You have the right to work, to be free to choose your work, and to receive a salary that allows you to live and support your family. If a man and a woman do the same work, they should get the same pay. All people who work have the right to join together to protect and defend their interests.
Article 24: Workdays should not be very long, because everyone has the right to rest and should be able to take regular paid holidays.

\section{Article 25: You have the right to have} whatever you need so that you and your family do not become ill; do not go hungry: have clothes and a house; and receive help if you are out of work, if you are ill, if you are old, if your wife or husband is dead, or if you are unable to earn a living for any other reason that you cannot help. Both a mother who is going to have a baby and her baby should get special help. Every child has the same rights as every other child, whether or not its mother is married.

Article 26: You have the right to go to school; everyone should be able to go to school. Primary schooling should be free. You should be able to learn a profession or skill or continue your studies as far as you wish. At school, you should be able to develop all your talents. You should be taught to get along with others, whatever their race, religion, or background. Your parents have the right to choose how and what you are taught at school.

Article 27: You have the right to share in your community's arts and sciences, and in any good they do. Your works as an artist, a writer or a scientist should be protected, and you should be able to benefit from them.
Article 28: To ensure that your rights are respected, an "order" must be established that can protect them. This "order" should be local and worldwide.

Article 29: You have duties toward your community. The law should guarantee your human rights. It should allow everyone to respect others and to be respected.

Article 30: No society and no human being in any part of the world should act in such a way as to destroy the rights that are listed here. 


\section{fact sheets (cont.)}

\section{VIOLENCE AGAINST WOMEN AND GIRLS, INCLUDING SEXUAL VIOLENCE*}

\section{How widespread is violence against women} and girls?

Sadly, violence against women and girls

(sometimes called gender-based violence) is very widespread. It is a major public health and human rights issue. Worldwide, rates of such abuse vary widely. In most settings, however, between one-third and two-thirds of women are beaten, coerced into sexual activity, or otherwise abused by an intimate partner during their lifetime. Hundreds of thousands of women and girls are trafficked across borders annually. Roughly 140 million women and girls have undergone female genital mutilation and another 3 million are at risk annually in Africa. In the next decade, more than 100 million girls in developing countries will marry as children. In every war zone, violence against women, including systematic rape, has been reported during or after armed conflicts.

\section{What are the consequences of violence} against women?

The health consequences include:

- Serious pain and injuries, such as broken bones, burns, black eyes, cuts, bruises, headaches, and abdominal and muscle pain, sometimes enduring for years. - Mental health problems such as depression, anxiety, and eating disorders.

- Sexual dysfunctions, including painful sex lack of desire, and fear of sex. - Reproductive health problems, including miscarriage, STIs and HIV infection, unplanned pregnancy, and increased sexual risk-taking among adolescents.

Severe injuries, intentional homicide, and suicide related to violence all contribute to female mortality rates. In a community, violence against women can perpetuate the false belief that men are better than women. Gender-based violence creates a climate of fear and insecurity in families, schools, communities, and workplaces.

\section{What are some effective strategies for} addressing violence against women?

Changing attitudes and conducting other prevention efforts, including:

Engaging men in efforts to change cultural attitudes about masculinity and violent behavior.

Integrating gender education, including information about gender-based violence, into formal and informal education.

Introducing campaigns, such as the annual 16 Days of Activism to End Violence Against Women.

Educating women and girls about their legal rights.

Other activities to empower women and girls.

Ending child marriage, which puts many girls in relationships in which they are at risk of violence.
Providing services: Women who experience violence and their children need access to various services, ideally in one place. They may need hotlines, counseling, support networks, shelters that meet safety standards, legal services, and health care, including emergency contraception for rape victims.

Providing training: Trained health care providers can help detect abuse and assist victims by offering medical, psychological, and legal support and referrals.

Changing laws, including:

Demonstrating political commitment

through statements from high-level government officials, backed by action and the commitment of resources.

Enacting and implementing laws that address violence against women, and evaluating the application of these laws.

Developing guidelines and protocols and providing systematic, mandatory training for police, prosecutors, and judges. Establishing specialized courts and police units.

Enacting vigorous arrest and prosecution policies and appropriate sentencing. Expanding knowledge: Research and documentation of violence against women and girls increase recognition of the problem and the commitment to address it. 
Australian Human Rights Commission. 2016. Introduction to Human Rights and Responsibilities. www.humanrights.gov.au/ introhumanrights/resources/lesson_1.html

Centre for Development and Population Activities (CEDPA). 2009. Choose a Future! Issues and Options for Adolescent Girls in Southern Africa.

www.k4health.org/sites/default/files/CAF\%20

manual\%20final\%205-20-098.pdf

Carrizales-Engelmann, Dianna, Laura L. Feuerborn, Barbara A. Gueldner, and Oanh K. Tran. 2016. Merrell's Strong Kids - Grades 3-5: A Social and Emotional Learning Curriculum. Brookes Publishing.

http://products.brookespublishing.com/

Merrells-Strong-KidsGrades-3-5-P944.aspx

Courtney, Elaine A. 2006. Money Starts: Ice Breakers for Financial Programs. University of Florida/IFAS Extension in Okaloosa County. www.moneycrunch.org/planning/iceBreakers. pdf

Danforth, Jessica and the Native Youth Sexual Health Network. 2011. Step into the circle. www.teentalk.ca/wp-content/

uploads/2014/05/Ice-Breakers-Energizersand-Other-Activities-Web-2012.pdf

Global Children's Fund, Child Safety and Abuse Prevention Programs, www.keepyourchildsafe.org
HORIZONS. 2009 Investigators: Ralph J. DiClemente, Gina M. Wingood, Eve S. Rose, Jessica M Sales, Delia L. Lang, Angela M. Calienda, James W. Hardin \& Richard A. Crosby. www.socio.com/passt29.php

International HIV/AIDS Alliance. 2002. 100 ways to energize groups: Games to use in workshops, meetings and the community. www.icaso.org/vaccines_toolkit/subpages/ files/English/ energiser_guide_eng.pdf

International Sexuality and HIV Curriculum Working Group. 2009, updated 2011. It's All One Curriculum: Guidelines and Activities for a Unified Approach to Sexuality, Gender, HIV and Human Rights Education. New York: Population Council.

www.popcouncil.org/publications/

books/2010_ItsAllOne.asp

Johns Hopkins Bloomberg School of Public Health/Center for Communication Programs. 2011. Go Girls! Community-based Life Skills for Girls: A Training Manual. Baltimore Maryland. Developed under the terms of USAID Contract No. GHH-1-00-07-0003200, Project SEARCH, Task Order 01

www.archive.k4health.org/toolkits/go-girls/ go-girls

McGinn, Kathleen, Corinne Low, and Nava Ashraf. 2014. GIRLS ARISE: Working Together for a Better Future. Zambia: Innovations for Poverty Action (IPA).
Naker, Dipak. 2012. The Good School Toolkit Raising Voices. Kampala.

www.raisingvoices.org/wp-content/

uploads/2013/03/downloads/GoodSchool/

Good_School_Toolkit/STEP_5.pdf

PACERS: National Bullying Prevention Center, Elementary School, Educational Lesson Plan. www.pacer.org/bullying/classroom/ elementary/ele-lesson-plan.asp

Peace Corps. 2001. Information Collection and Exchange Publication: Life Skills Manual. www. peacecorps.gov/multimedia/pdf/library/ M0063_lifeskillscomplete.pdf

Population Council. 2013. Dream Big! Kwacha for Our Future - Financial Education Curriculum.

www.popcouncil.org/uploads/pdfs/2013PGY_ FinancialEducation_AGEP.pdf

Population Council. 2013. Life Skills and Health Curriculum for the Adolescent Girls Empowerment Program (AGEP).

www.popcouncil.org/uploads/pdfs/2013PGY HealthLifeSkills_AGEP.pdf

Continued on next page 


\section{references (cont.)}

Promundo, Salud y Género, ECOS,

Instituto PAPAl and World Education. 2006.

Program M: Working with Young Women:

Empowerment, Rights and Health.

www.promundoglobal.org/wp-content/

uploads/2014/12/Program-M-Working-With-

Young-Women.pdf

Sonke Gender Justice. 2008. One Man Can: Workshop Activities: Talking to men about gender, domestic and sexual violence and HIVIAIDS.

http://genderjustice.org.za/publication/workshopactivities-talking-to-men-about-gender-

domestic-and-sexual-violence-and-hivaids/

Sonke Gender Justice. 2016. One Youth Can: Facilitator's Guide.

www.genderjustice.org.za/publication/oneyouth-can-facilitators-guide/

The Inclusion Lab: Tips and Takeaways for Teaching All Kids, Brookes Publishing http://blog.brookespublishing.com/5 activities-for-building-empathy-in-yourstudents/

Wilson, Pamela M. 1999. Our Whole Lives: Sexuality Education for Grades 7-9. Boston: Unitarian Universalist Association. 


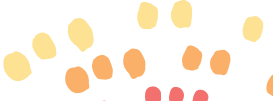

$0.000 \cdot 0$

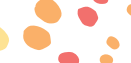

$\because \because \because \because 0$

DREAMS

WORKING TOGETHER FOR

AN AIDS-FREE FUTURE

FOR GIRLS \& WOMEN

O O O

\section{Determined

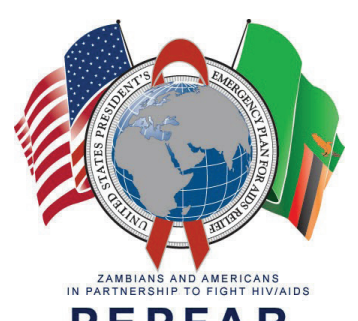 \\ Resilient \\ Empowered \\ POPULATION
COUNCIL}

PEPFAR

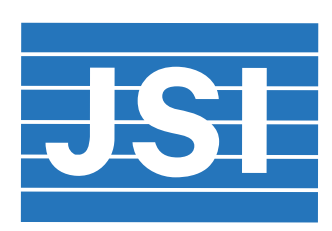

Ideas. Evidence. Impact.
AlDS-Free

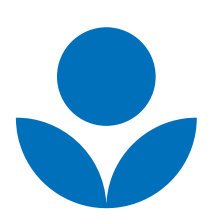

Worldreade
Mentored

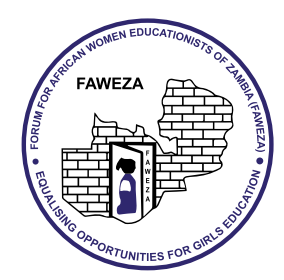

Safe

$$
\text { girlsread! }
$$

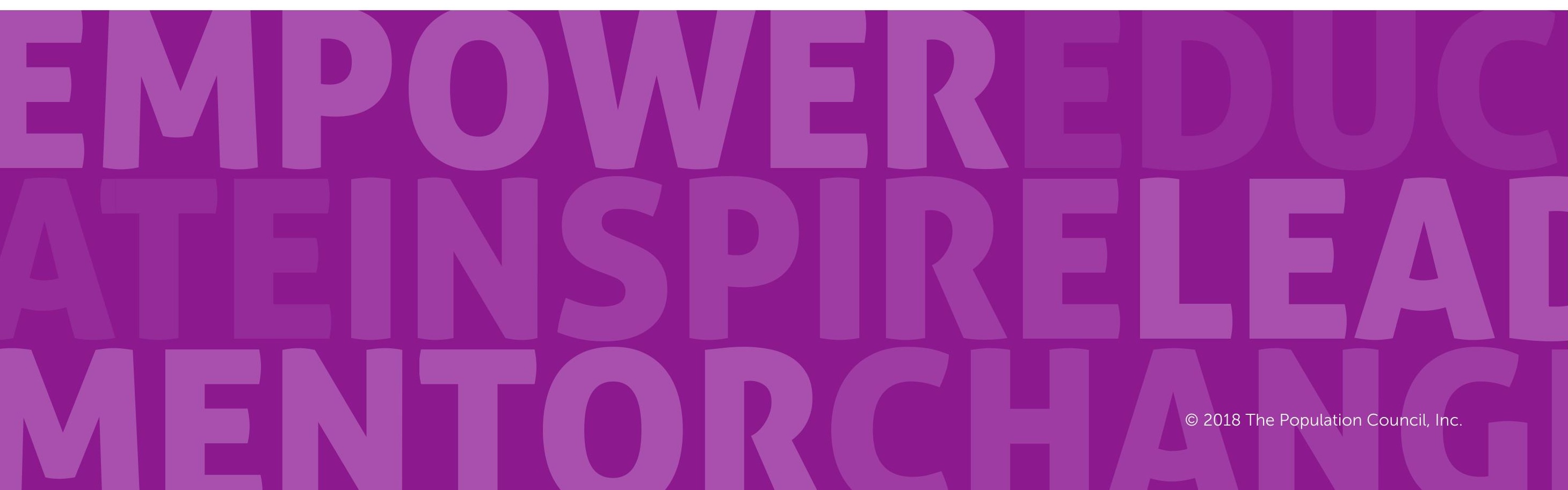

